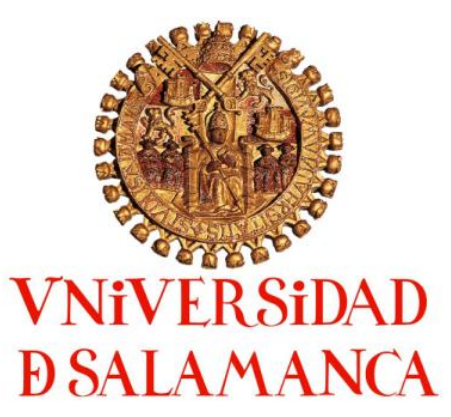

Departamento de Anatomía e Histología Humanas

Departamento de Cirugía

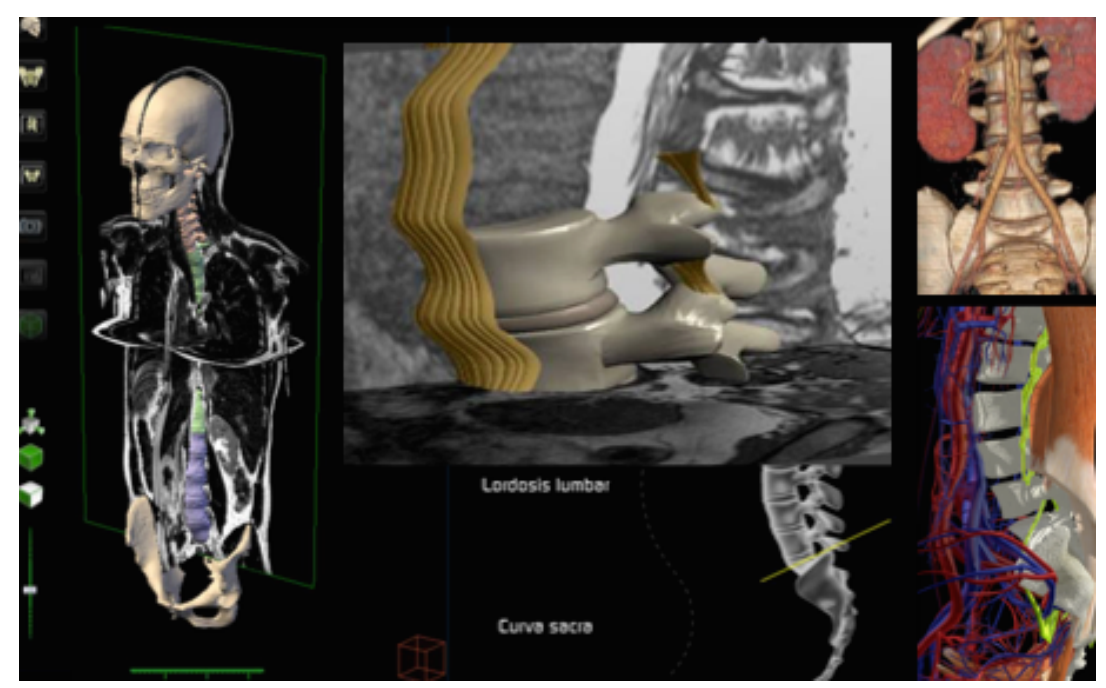

\title{
MODELO TECNOLÓGICO VIRTUAL DE VISUALIZACIÓN TRIDIMENSIONAL DEL ABORDAJE A LA COLUMNA: CORRELACIÓN ANATOMO-RADIOLÓGICA Y NEUROQUIRÚRGICA
}

Carlos Manuel Bautista Jiménez

Tesis Doctoral

2015 


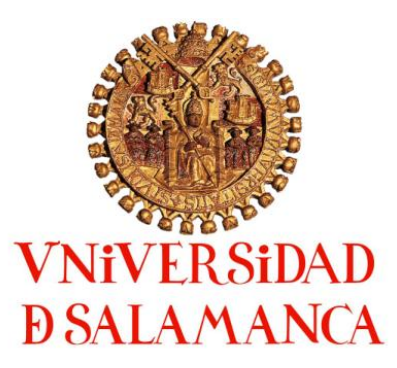

Departamento de Anatomía e Histología Humanas

Departamento de Cirugía

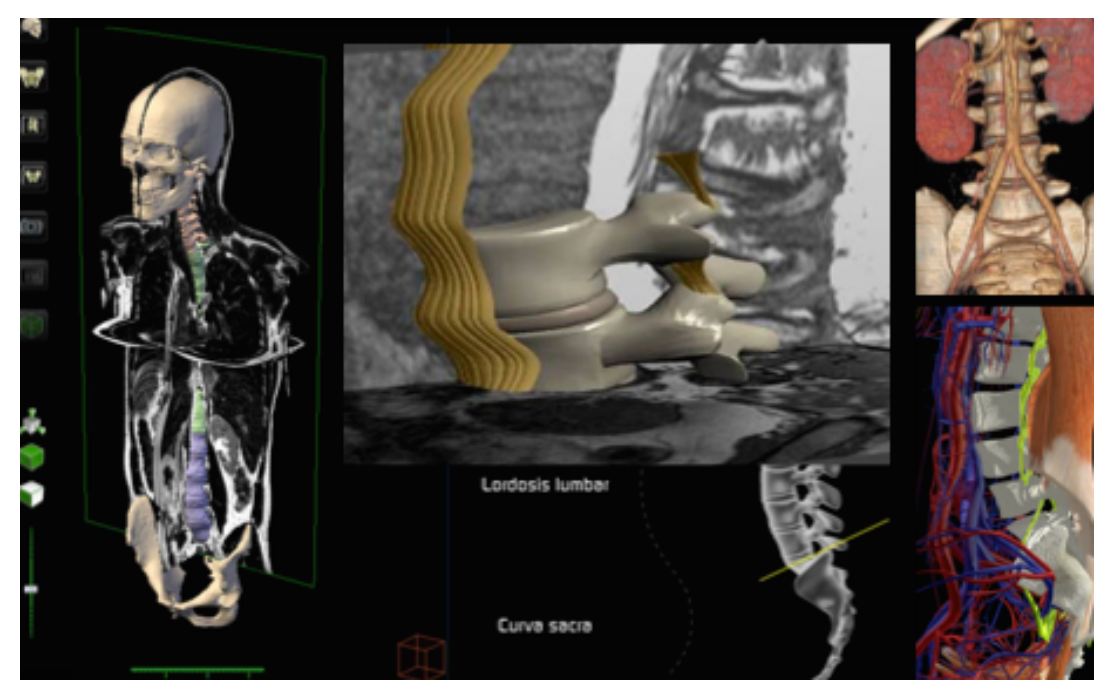

\section{MODELO TECNOLÓGICO VIRTUAL DE VISUALIZACIÓN TRIDIMENSIONAL DEL ABORDAJE A LA COLUMNA: CORRELACIÓN ANATOMO-RADIOLÓGICA Y NEUROQUIRÚRGICA}

Presentada por

Carlos Manuel Bautista Jiménez

Licenciado en medicina

Dirigida por

Prof. Dr. Juan Antonio Juanes Méndez Profa. Dra. María José Sánchez Ledesma Prof. Dr. Jesús María Gonçalves Estella

Tesis Doctoral

2015 


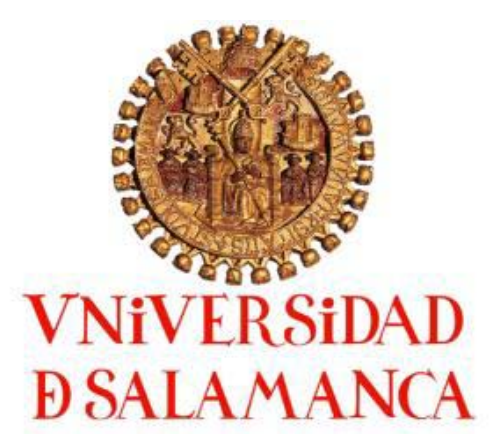

Profesor Dr. D. Francisco Santiago Lozano Sánchez, Director del Departamento de Cirugía de la Universidad de Salamanca.

\section{CERTIFICA QUE:}

La presente Tesis Doctoral, realizada por Don Carlos Manuel Bautista Jiménez con el título "Modelo tecnológico virtual de visualización tridimensional del abordaje a la columna: correlación anatomo-radiológica y neuroquirúrgica.” reúne los requisitos necesarios para su presentación y defensa ante el Tribunal Calificador para poder optar al Grado de Doctor por la Universidad de Salamanca.

Y para que así conste, se firma la presente certificación en Salamanca a 17 de febrero de 2015.

Fdo. Dr. Francisco Santiago Lozano Sánchez 


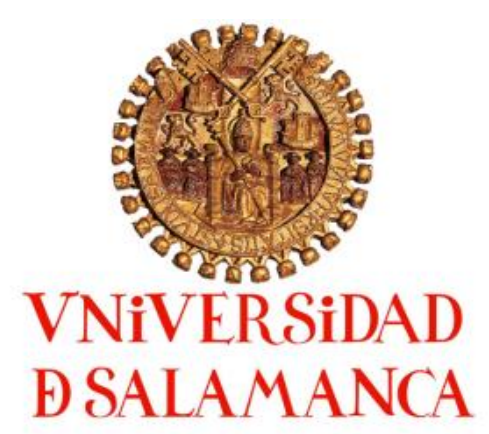

Juan Antonio Juanes Méndez, Profesor Titular del Departamento de Anatomía e Histología de la Universidad de Salamanca.

María José Sánchez Ledesma, Profesora Contratado Doctor, del Departamento de Cirugía de la Universidad de Salamanca.

Jesús María Gonçalves Estella, Profesor Asociado del Departamento de Cirugía de la Universidad de Salamanca.

\section{CERTIFICAN QUE:}

Que la Tesis Doctoral realizada bajo su dirección por Don Carlos Manuel Bautista Jiménez con el título "Modelo tecnológico virtual de visualización tridimensional del abordaje a la columna: correlación anatomo-radiológica y neuroquirúrgica." reúne los requisitos necesarios para su presentación y defensa ante el Tribunal Calificador para poder optar al Grado de Doctor por la Universidad de Salamanca.

Y para que así conste, se firma la presente certificación en Salamanca a 16 de febrero de 2015.

Fdo. J.A. Juanes Méndez Fdo. M.J. Sánchez Ledesma Fdo. J.M. Gonçalves Estella 
A mi familia 
Felicidad no es hacer lo que uno quiere, sino querer lo que uno hace Jean Paul Sartre 
Quiero expresar mi más sincero reconocimiento a mis directores de tesis, al Prof. Dr. D. Juan Antonio Juanes Méndez por abrirme la puerta de su despacho, por su apoyo continuo, por su constante predisposición y su mentalidad positiva, sin cuya ayuda no hubiera podido realizar este trabajo. A la Profa. Dra. María José Sánchez Ledesma, por su apoyo constante, por su entusiasmo, orientación y aliento permanente. Y, por último, al Prof. Dr. Jesús María Gonçalves Estella Jefe del Servicio de Neurocirugía del Complejo Asistencial Universitario de Salamanca, por estar disponible para ayudarme siempre que lo he necesitado. Gracias, por la magnífica dirección de este trabajo de Tesis Doctoral.

Igualmente, quiero agradecer al Prof. Dr. D. Alberto Prats Galino, de la Universidad de Barcelona, por su gran aportación y ayuda en la ejecución del trabajo informático para el estudio tridimensional de las estructuras anatómicas de la columna vertebral. Agradecimiento que hago extensivo al Profesor José Ramón Mérida Velasco, del departamento de Ciencias Morfológicas de la Universidad Complutense de Madrid, por sus contribuciones a este trabajo. Así mismo quiero agradecer la colaboración del los Dres.: Collante, de la Cruz Blanco, Rodríguez Vázquez, Aylon y Sanz Casado.

Al Departamentos de Anatomía e Histología Humanas, y al Departamento de Cirugía de la Facultad de Medicina de la Universidad de Salamanca, junto con los Servicios de Neurocirugía y Radiodiagnóstico del Complejo Universitario Asistencial de Salamanca, por las facilidades prestadas y por su aportación en la adquisición de las imágenes quirúrgicas y radiológicas.

El mayor agradecimiento, es a mis familiares, por el apoyo desde la distancia, a mi abuela, a mi madre, a mi tía Ramona y a Leonardo, que han sido un apoyo en todos los aspectos de mi vida, sin ellos no habría sido posible lograr todos los éxitos que he conseguido. 
Al personal técnico del Centro de Imagen y Tecnología del Conocimiento Biomédico de Madrid (CITEC-B), por la implementación de la aplicación informática.

Me gustaría dar las gracias a mis compañeros del Servicio de Neurocirugía de Salamanca, a los Dres.: Pascual, Otero, Miranda, Ruiz, Sousa, Onzain, Jaramillo, Gleeson y Roa, por todos los momentos que hemos pasado juntos, dentro y fuera del Hospital.

Al Servicio de Neurocirugía del Hospital de Sevilla, en especial a los Dres.: Julio Valencia, Javier Márquez y Mónica Garvia, por las facilidades prestadas y el apoyo brindado cuando lo he necesitado.

A mis amigos, por todos los momentos vividos juntos, por estar siempre a mi lado y animarme en todo lo que hago.

A todos los demás, que comparten o han compartido conmigo momentos de mi vida, a todos ellos, gracias.

Deseo hacer extensiva mi gratitud a todos aquellos que de una forma u otra han colaborado en el desarrollo de esta Tesis Doctoral. por lo que muy probablemente me olvide agradecer la colaboración de alguna de ellas. Por ello, le o les pido disculpas.

Mi más sincero agradecimiento a todos. 


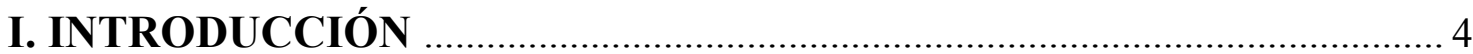

1.1. Definición: planificación preoperatoria y modelo 3D …...................... 6

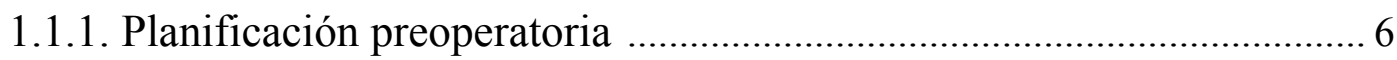

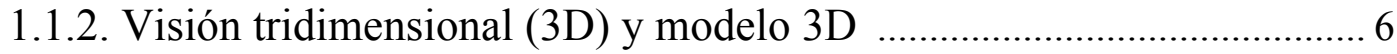

1.2. Sinopsis histórica sobre la utilización de modelos $3 D$ para la

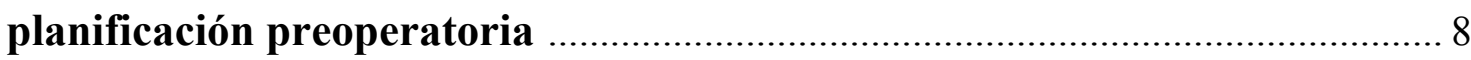

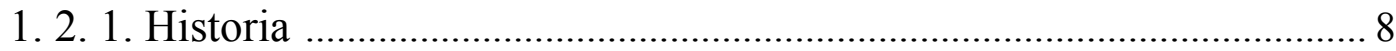

1. 2. 2. Avances de la tecnología 3D en diferentes áreas de la medicina ...... 9

1.3. Planificación preoperatoria en neurocirugía ….................................... 10

1.3.1. Imágenes DICOM y principales aplicaciones para su visualización . 12

1.3.2. Planificación prequirúrgica en un entorno digital con modelos $3 \mathrm{D}$.. 13

1.3.3. Ventajas de la planificación asistida con modelos 3D ....................... 14

1.3.4. Limitaciones de la planificación asistida por ordenador .................. 15

1.3.5. Desarrollo de modelos 3D a partir de imágenes DICOM ................... 15

1.3.5.1. Reconstrucción 3D a partir de imágenes DICOM......................... 16

1.3.5.2. La tomografía computarizada ó tomografía por rayos $\mathrm{X}$............. 16

1.3.5.3. Imágenes por resonancia magnética ............................................ 18

1.3.5.4. Parámetros y almacenamiento de imágenes médicas ................... 19

1.4. Procesamiento de imágenes para la obtención de modelos 3D ............20

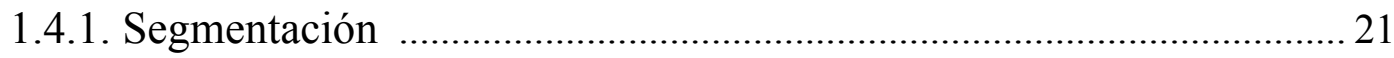

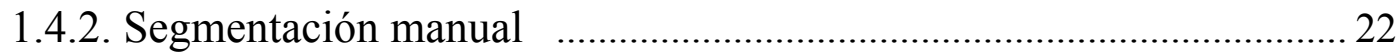

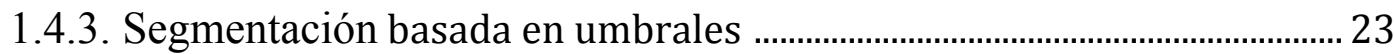

1.4.4. Segmentación basada en regiones de crecimientos ............................ 23

1.5. Desarrollo y anatomía de la columna vertebral .................................. 24

1.5.1. Embriogénesis de la columna vertebral ............................................. 25

1.5.2. Anatomía de la columna vertebral ......................................................... 29

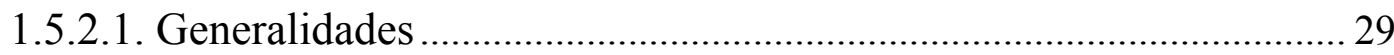


1.5.2.2. Movimientos de la columna vertebral ................................................. 31

1.5.2.3 Canal espinal ................................................................................ 33

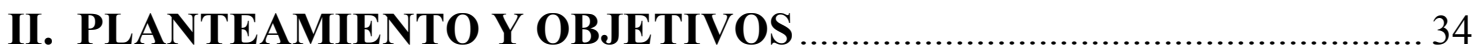

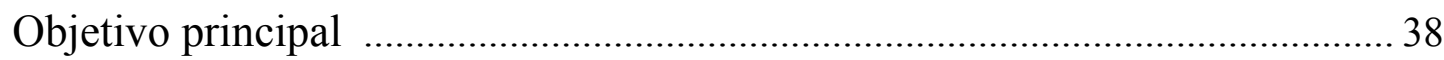

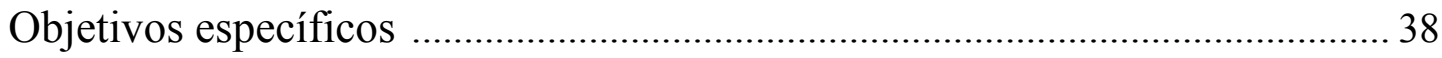

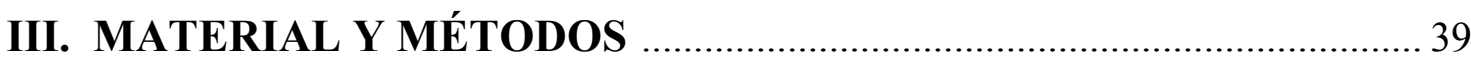

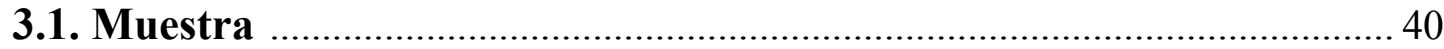

3.2. Material iconográfico (TC, RM y fotos) ……………………………….... 41

3.2.1. Descripción de las principales fases empleadas para la adquisición del

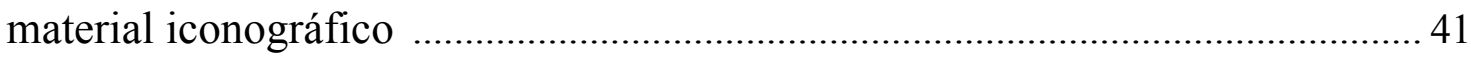

3.2.1.1. Adquisición de las imágenes del TC ............................................... 41

3.2.1.2. Adquisición de las imágenes de RM …………………………....... 43

3.2.1.3. Adquisición de imágenes de los abordajes más comunes ............. 44

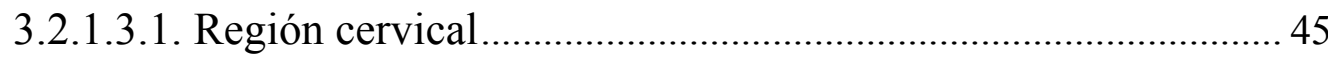

3.2.1.3.2. Laminectomia, laminoplastia y unión cráneo-cervical............. 47

3.2.1.3.3. Columna dorsal y lumbo-sacra ……………………………...... 53

3.2.1.4. Fotografías de los elementos óseos de la CV ...................................... 60

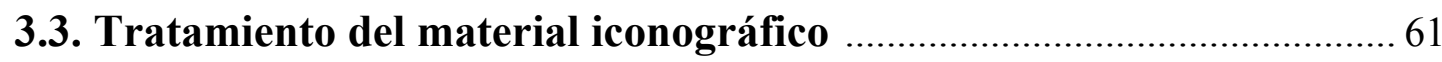

3.3.1. Reconstrucciones 3D a partir de imágenes DICOM ............................. 62

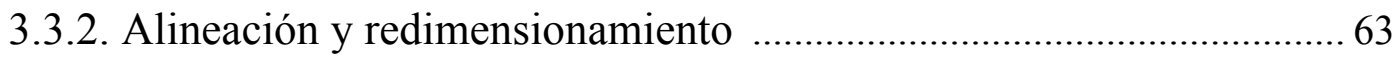

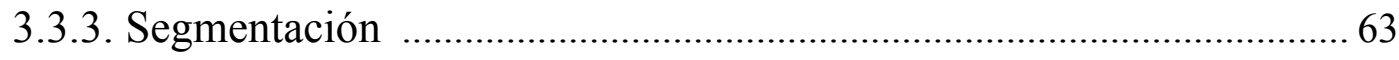

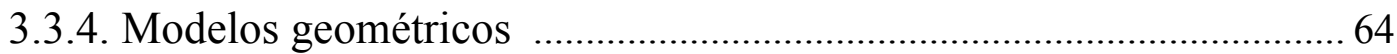

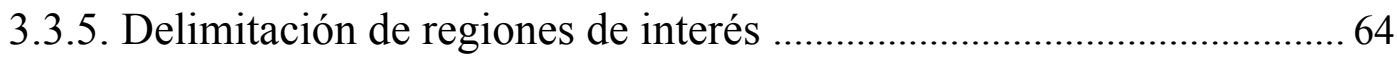

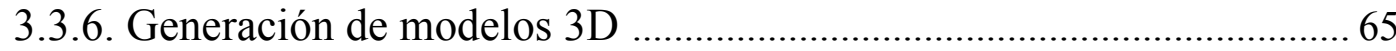

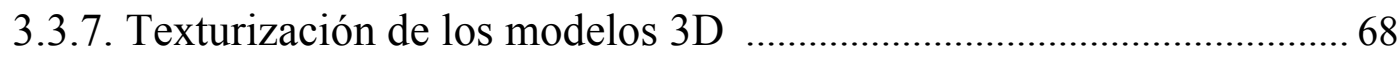

3.4. Visor anatómico funcional para la visualización de los modelos 3D .72

3.4.1. Interface Gráfico de usuario ................................................................ 72 
3.4.2. Fichero de definición de imágenes del visor anatómico funcional ....73

3.4.3. Fichero de definición de modelos ............................................................ 73

3.4.4. Programación en Visual C++ ............................................................. 74

3.4.5. Requerimientos del sistema ................................................................. 77

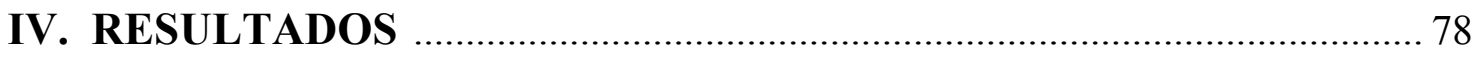

4.1. Enfoque general de la columna vertebral ………………………………....... 79

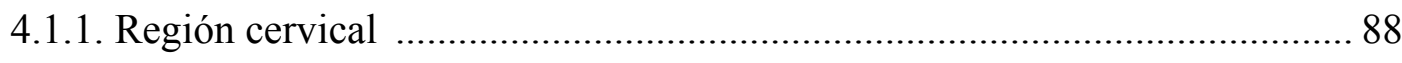

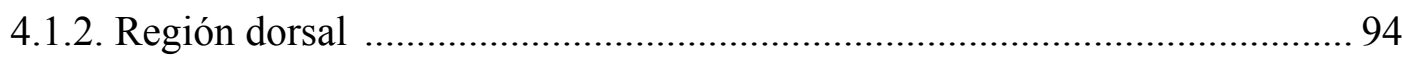

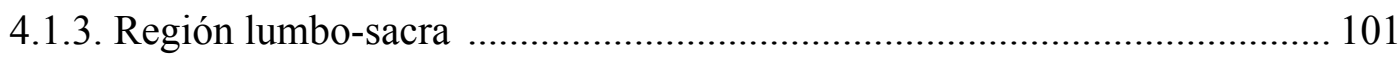

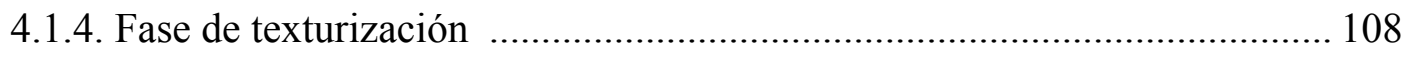

4.1.5. Partes blandas: estructuras neurovasculares y músculos ............................ 118

4.1.6. Visor anatómico funcional ....................................................................... 123

4.1.6.1. Características del visor anatómico funcional ................................ 124

4.1.6. 1. Características del visor anatómico funcional ................................ 124

4.1.6. 2. Detalle de la barra de herramientas ............................................. 125

4.1.6.3. Visor en detalle ............................................................................. 127

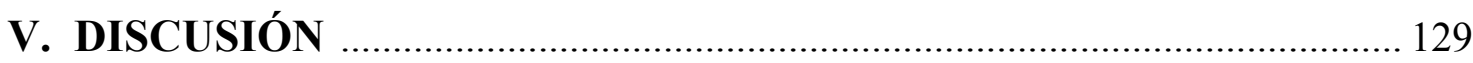

5.1. Planificación preoperatoria con modelos 3D ……………………….... 137

5.2. Utilización de modelos 3D para el entrenamiento de vías de abordajes

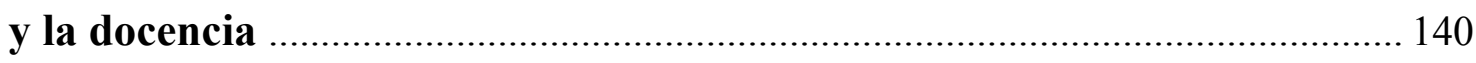

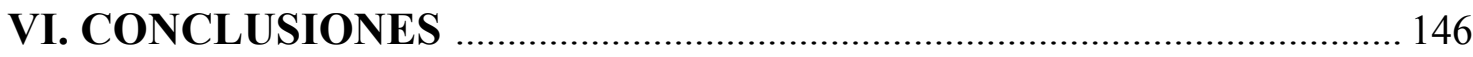

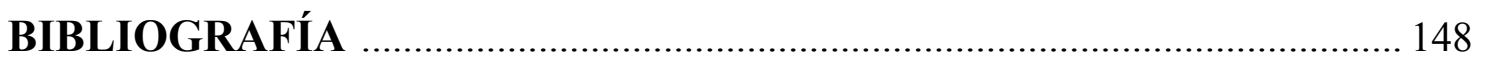


ÍNDICE DE FIGURAS 
Tabla 1. Principales aplicaciones de código abierto (freeware), utilizadas para el modelado 3D 7

Figura 1. A y B. Transición del entorno analógico al digital, en la visualización de imágenes médicas 11

Figura 2. Clasificación de las principales técnicas de segmentación 23

Figura 3. Embrión: formación de la columna vertebral 25

Figura 4. Somita típico con las tres porciones 26

Figura 5. Formación de la CV en diversas etapas del desarrollo 26

Figura 6. Centros de osificación de la columna vertebral 28

Figura 7. Telerradiografía de la columna vertebral 31

Figura 8. A, B y C. Radiografías simple de columna completa (Bending) ..... 32

Figura 9. Radiografías de columna cervical dinámicas 33

Figura 10. Tomógrafo, modelo Aquilion TSX 42

Figura 11. Equipo de resonancia magnética de 1,5 Teslas 43

Figura 12. Equipo fotográfico utilizado en el trabajo 44

Figura 13. Abordaje cervical anterior. Se observa el espacio intervertebral entre la quinta (C-5) y la sexta (C-6) vértebra cervical 46

Figura 14. Imagen intraquirófano, que muestra un abordaje a la columna cervical por vía anterior, con exposición del nivel C4-C5 46

Figura 15. Abordaje cervical anterior multinivel 47 
Figura 16. Abordaje cervical posterior, se observan los elementos posteriores de la columna cervical de los niveles $\mathrm{C} 2-\mathrm{C} 7$ 48

Figura 17. Laminoplastia expansiva de puerta abierta $\mathrm{C} 3, \mathrm{C} 4, \mathrm{C} 5, \mathrm{C} 6$ y $\mathrm{C} 7$ en un paciente con estenosis de canal cervical degenerativa multinivel 49

Figura 18. Reparación osteo-plástica dorsal D5, D6 y D7 49

Figura 19. Abordaje a la unión cráneo-cervical por vía posterior 51

Figura 20. A y B. Fijación posterior de C1-C2 con tornillos y barras de titanio, en un paciente con inestabilidad $\mathrm{C} 1-\mathrm{C} 2$ 52

Figura 21 A y B. Atornillado anterior de la odontoides 52

Figura 22. Abordaje a la columna dorso-lumbar por vía posterior 53

Figura 23A, B, C y D. Abordaje amplio a la columna dorsal y lumbo-sacra por vía posterior, para la corrección de una escoliosis del adolescente 54

Figura 24. Abordaje dorso-lumbar posterior (charnela dorso-lumbar), en un paciente con carcinoma de Ewing 55

Figura 25. Abordaje lumbo-sacro para tratar una estenosis de canal congénita severa a nivel de L5-S1 55

Figura 26. Abordaje a la columna lumbar vía posterior, con exposición de los niveles L2, L3 y L4 56

Figura 27. Abordaje dorso-lumbar para realización de vertebrectomía radical por vía posterior más instrumentación transpedicular 56

Figura 28. Abordaje transtorácico anterior 57

Figura 29. Vertebrectomía fragmentaria posterior de la sexta vértebra dorsal, mediante abordaje posterolateral o costotransversectomía 58 
Figura 30. Discectomía mínimamente invasiva D10-D11 59

Figura 31. Fotografías de vértebra típica cervical y lumbar 60

Figura 32. Fotografía de vértebras lumbares en diferentes proyecciones 6

Figura 33. Interface de usuario del software MRIcro (Nottingham, UK), para la manipulación y tratamiento de las imágenes DICOM 62

Figura 34. Interface del editor 3-D Maya, para la delimitación de las regiones de interés (ROIs) 65

Figura 35. Interface del software Autodesk Maya, que muestra la generación de modelos de superficie del esqueleto de la columna vertebral, a partir de las ROIs, aplicando algoritmos de 'marching cubes'. Modelado geométrico de malla triangular 66

Figura 36. Simplificación y suavizado del modelado geométrico de malla triangular 66

Figura 37. Interface del editor 3D Maya, en el que se visualiza la columna cervical modelada, a partir de la simplificación y suavizado del modelo geométrico 67

Figura 38. Representación de la reconstrucción ósea tridimensional de la columna dorsal 68

Figura 39. A y B. Modelado geométrico de malla triangular y estructura anatómica de la región lumbar tras la fase de texturizado 70

Figura 40. Proyección superior y lateral de una vertebra lumbar tras su texturización 71 
Figura 41. Visualización del interface de usuario del visor anatómico funcional estructurado en dos partes 72

Figura 42. Visualización del interface de usuario para la manipulación de los modelos anatómicos tridimensionales 76

Figura 43. Captura de pantalla del interface de usuario del visor anatómico funcional 80

Figura 44. Modelado 3D de la columna vertebral a partir de ventana ósea de $\mathrm{TC}$, muestra una visión panorámica lateral de la columna lumbar. 81

Figura 45. A y B. Visión panorámica de la columna vertebral normal, con algunos de los detalles anatómicos generales 82

Figura 46. A y B. Correlación de un modelo 3D de la Columna vertebral, con estudio de RM potenciada en T2 eco spin de la columna vertebral 84

Figura 47. A y B. Modelo 3D de la Columna vertebral completa incluyendo cráneo y pelvis, embebidas en cortes medio sagitales del tronco de RM potenciada en $\mathrm{T} 2$ 85

Figura 48. CV completa, cráneo y pelvis, vista anterior oblicua 86

Figura 49. Correlación anatómica y radiológica entre el modelo 3D y los órganos y estructuras del tronco 87

Figura 50 A, B, C y D. Modelo 3D de la columna cervical en las diferentes posiciones del espacio 88

Figura 51 A y B. Corte sagital de RM de columna cervical y Modelo 3D en proyección cráneo-caudal mostrando el primer segmento de la columna cervical (segmento C1-C2) 89

Figura 52. Vista anterior de la columna cervical y correlación con abordaje 
anterior amplio a la columna cervical 90

Figura 53. Reconstrucción 3D de la Columna cervical y fusión con estudios de $\mathrm{RM}$ 91

Figura 54. Modelo 3D que muestra en detalle la unión cráneo cervical 92

Figura 55. Modelo 3D de la columna cervical y RM en diferentes proyecciones del espacio 93

Figura 56. Correlación anatómica de modelo $3 \mathrm{D}$ con abordaje de la unión cráneo-cervical 94

Figura 57. A, B, C y D. Correlación de la charnela dorso-lumbar (vértebras D12-L1) con modelo 3D en diferentes proyecciones 96

Figura 58. A y B. Modelo 3D de la columna dorsal. A: vista posterior oblicua de la columna 96

Figura 59. A y B. Correlación de la anatomía quirúrgica de un abordaje por vía posterior a la columna dorsal con los elementos posteriores del modelo 3D de Columna dorsal 97

Figura 60. A y B. Modelo 3D de la columna dorsal y correlación con las partes blandas paramedial de la caja torácica 98

Figura 61. Modelo 3D para valoración global de la columna dorsal 99

Figura 62. Modelo 3D de la columna dorsal en proyección anterior embebido en cortes coronal y axial de RM. 100

Figura 63. A, B, C Y D. Correlación radiológica de modelo 3D de la columna lumbo-sacra en proyección lateral 102

Figura 64. Correlación de modelo 3D de la región lumbo-sacra con la imagen de un abordaje lumbar posterior amplio 
Figura 65. Visualización de interface de usuario desde donde es posible manipular el modelo 3D, mediante pequeños íconos dispuestos verticalmente en la parte izquierda del visor 104

Figura 66. A y B. Modelado de vértebras lumbares, ligamento longitudinal anterior y ligamento capsular facetario 105

Figura 67. A, B, C y D. Modelo 3D de la columna lumbo-sacra y correlación radiológica en diferentes proyecciones espaciales 106

Figura 68. A , B C y D. modelos 3D de vértebras lumbares en diferentes proyecciones espaciales 107

Figura 69. Texturizado de vértebras lumbares, mostrando los cuerpos vertebrales y su unión con los elementos posteriores 108

Figura 70. Columna vertebral completa tras la fase de texturizado 109

Figura 71. Correlación de tercera vértebra lumbar texturizada con vértebra lumbar dividida en dos partes: cuerpo y elementos posteriores, tras una vertebrectomía en bloque

Figura 72. Vertebra texturizada en la posición lateral 110

Figura 73. A: modelo 3D en posición lateral de D10 y D11 111

Figura 74. Superposición de modelo 3D sobre vértebra y defecto óseo 111

Figura 75. Proyección posterior oblicua de modelo 3D para valorar elementos posteriores. 112

Figura 76. Correlación de modelo 3D de la columna lumbar con huesos de la misma zona anatómica de espécimen 113 
Figura 77. Correlación de modelo 3D con huesos de las vértebras D10-D11 de espécimen

Figura 78. Modelo 3D de la columna lumbar en proyección anterior... 115

Figura 79. Correlación de modelo 3D con el abordaje lumbar posterior...... 116

Figura 80. Texturización de las tres primeras vértebras lumbares y charnela dorso-lumbar en la posición espacial lateral derecha

Figura 81. A y B. Representación $3 \mathrm{D}$ de la columna lumbo-sacra, con identificación en color de estructuras nerviosas 118

Figura 82. Representación tridimensional de nervios raquídeos, en su salida por los agujeros de conjunción y abordaje lumbar posterior mostrando el saco tecal y las raíces de $\mathrm{L} 5$ bilateral.

Figura 83. Reconstrucción $3 \mathrm{D}$ de la columna lumbo-sacra a partir de tomografía computarizada multicorte y modelo 3D de la columna lumbo-sacra, con identificación en color de las diferentes estructuras vasculares 120

Figura 84. Reconstrucción 3D de la columna lumbo-sacra a partir de tomografía computarizada multicorte y modelo 3D de la columna lumbo-sacra mostrando las estructuras vásculo-nerviosas y musculatura paravertebral..... 121

Figura 85. Modelado 3D de la columna lumbo-sacra, estructuras neurovasculares, musculatura paravertebral y piel en transparencia 122

Figura 86. Visor anatómico funcional: a la izquierda el visor anatómico para la observación de los modelos anatómicos tridimensionales generados a partir de las imágenes en formato DICOM; y a la derecha el visor dinámico 123

Figura 87. Características del visor anatómico funcional 
Figura 88. El visor anatómico funcional en detalle

Figura 89. Visor en detalle mostrando ventana secundaria 128 
El desarrollo tecnológico en el campo de la adquisición y visualización de imágenes médicas ha revolucionado la medicina convencional. La visualización y el análisis de imágenes médicas por ordenador se han convertido en una de las herramientas mas utilizadas e indispensables para el diagnostico y la planificación preoperatoria.

Gracias al desarrollo de los ordenadores de nueva generación y de las nuevas aplicaciones informáticas, es posible sacar el máximo provecho a un estudio radiológico mediante la utilización de los métodos numéricos que aproximen una solución a problemas reales y permitan la obtención de modelos anatómicos en tres dimensiones (3D) con una gran precisión. Así uno de los métodos más empleados para el modelado de las estructuras anatómicas es el análisis por elementos finitos, donde la definición de los elementos se hace en base a ecuaciones diferenciales. Sin embargo, las estructuras anatómicas conformadas por tejidos duros y tejidos blandos, constituyen geometrías complejas, generalmente asimétricas, en cuyo análisis es difícil realizar simplificaciones. En los últimos años, esta dificultad ha sido resuelta, al obtener modelos anatómicos complejos que reproducen con precisión los detalles geométricos, a partir de técnicas radiológicas como la tomografía computarizada (TC), o la resonancia magnética (RM), entre otras. No obstante los programas informáticos y equipos diseñados para tales fines, no se encuentran al alcance del neurocirujano, debido entre otras razones al alto costo de estos equipos y a la necesidad de ser manejados por personal cualificado.

El trabajo que presentamos para optar al Grado de Doctor por la Universidad de Salamanca, tiene por objetivo el estudio de la columna vertebral mediante el desarrollo de modelos en tres dimensiones a partir de los estudios radiológicos de tomografía computarizada y resonancia magnética, con la asistencia de aplicaciones distribuidas de manera libre o de código abierto, sin 
incrementar el costo del estudio y sin la necesidad de someter al paciente a pruebas adicionales.

Gracias al estándar DICOM (digital imaging and communication in medicine), es posible obtener la información necesaria contenida en los estudios de imágenes del paciente para su posterior tratamiento en un ordenador mediante aplicaciones de visualización y modelado en 3D, las cuales permiten mejorar considerablemente la calidad del estudio. Con la utilización de la metodología que proponemos en este trabajo mediante el modelado geométrico de la columna vertebral se puede eliminar en cierta medida el ruido proveniente del equipo médico utilizado para la adquisición de la imagen, además es posible resaltar zonas de interés y segmentar la imagen en diferentes partes o reconstruir estructuras anatómicas complejas.

Este modelo tiene un gran potencial como soporte para el diagnostico y la planificación preoperatoria, con la ventaja de que es compatible con la mayoría de ordenadores personales. Si bien son muchas las ventajas que ofrece la tecnología del modelado 3D, y a pesar de que en este trabajo hemos conseguido modelos 3D con una alta precisión y muy próximos a la realidad, aún no existen soluciones definitivas ni algoritmos generalmente aplicables, por lo que la segmentación y el modelado 3D de imágenes medicas constituyen un campo de continua investigación.

Así esperamos y es nuestro deseo que las aportaciones científicas realizadas en el presente trabajo de Tesis Doctoral puedan servir para el desarrollo de futuras líneas de investigaciones con modelos tridimensionales. 
I. INTRODUCCIÓN 
El constante progreso tecnológico, favorece el acceso a los ordenadores, no solo desde el punto de vista de los costes, sino también en cuanto a la mayor facilidad de su utilización. Así en los últimos años se han llevado a cabo estudios que permiten automatizar el análisis de imágenes médicas y la reconstrucción tridimensional con gran valor para el diagnóstico clínico y para el desarrollo de sistemas quirúrgicos de navegación. Por otro lado, las técnicas de imagen aportan valores numéricos que en la actualidad comienzan a tenerse en cuenta y a comprender su significado y aplicación (CLARKE et al, 1995; DUERSTOCK et al., 2000; DUMOULIN et al., 2003; LIEW \& YAN, 2005; PARK et al., 2005; VERHEY \& NATHAN, 2006; JAMALI, 2009; MAO, et al., 2010; KLAPAN 2011; FERROLI et al., 2013; CERROLAZA, 2014; HAQ, et al., 2014; ABREU et al., 2014; HANKEN et al., 2014; ONEN et al., 2014; XIANG et al., 2014).

Todo esto conduce a una nueva manera de presentar las imágenes médicas que sirven para el diagnóstico y la planificación preoperatoria; así nuestro trabajo de tesis doctoral se centrará en la utilización de imágenes médicas en formato DICOM (digital imaging and communication in medicine) para el desarrollo de reconstrucciones en tres dimensiones (3D), con el fin de servir de soporte a la realización de la planificación preoperatoria en la práctica neuroquirúrgica, la cual puede ser personalizada a la anatomía individual del paciente (DUMOULIN, 2003; HANDLER \& ADAMS, 2004; RUNGE, 2004; CHAUDHRY et al., 2006; VERHEY \& NATHAN, 2006; AMALI, 2009; MAO, et al., 2010; HANKEN; RAMÍREZ et al., 2011; FERROLI et al., 2013; ABREU et al., 2014; HANKEN et al., 2014; ONEN et al., 2014; XIANG et al., 2014). 


\subsection{DEFINICIÓN: PLAN PREOPERATORIO Y MODELO 3D}

\subsubsection{Planificación preoperatoria}

La planificación prequirúrgica o preoperatoria consiste en el establecimiento de una serie de pautas previas a una intervención quirúrgica con el objetivo de enumerar todos los pasos, procedimientos y herramientas a utilizar en el quirófano durante una intervención quirúrgica, con la finalidad de obtener un resultado satisfactorio.

Así, la planificación permite identificar y analizar la zona a intervenir de manera más precisa, con el fin de decidir las diversas acciones a realizar; estableciendo la vía de abordaje y la técnica quirúrgica más adecuada (BÄTHIS et al., 2004; RANCO, et al., 2010; RAMÍREZ \& COTO, 2011; FERROLI et al., 2013; ABREU et al., 2014; HANKEN et al., 2014; ONEN et al., 2014; XIANG et al., 2014).

\subsubsection{Visión tridimensional (3D) y modelo 3D}

El espacio físico a nuestro alrededor es tridimensional a simple vista. "Tridimensional" es un término proveniente de la geometría y el análisis matemático, que denomina a un objeto que posee tres dimensiones. Esto es, cada uno de sus puntos puede ser localizado dentro de un espacio, especificando tres números dentro de un mismo rango. Así un modelo tridimensional corresponde a una serie de fórmulas matemáticas que describen una interpretación virtual de una realidad volumétrica. Desde una perspectiva gráfica, el diseño tridimensional es una representación esquemática visible, a través de un conjunto de objetos, elementos y propiedades que, una vez procesados, o renderizados, se convertirán en una imagen o animación tridimensional (MOTOHASHI, 1999; LIEW \& YAN, 2005; IVICA et al, 2008; GAVIDIA \& SOUDAH, 2011). 
De esta forma, se puede decir que un modelo en 3D se diseña a partir de la organización y complementación de objetos geométricos que cuentan con volumen, como son los polígonos y la adhesión de elementos que colaboran con el realismo de un modelo y la calidad de éste (JAIN, 1989; RICHARD et al., 2000; BENEDETTI, et al., 2003; UMBAUGH, 2005; JAMALI, 2009; MAO, et al., 2010; HANKEN et al., 2014).

Hoy en día, existen numerosas aplicaciones que facilitan la modelación de diversos objetos en tres dimensiones; entre estas, destacan aplicaciones de distribución gratuita o Freeware, con gran cantidad de recursos mostradas en la tabla 1.

\begin{tabular}{ll}
\hline \multicolumn{1}{c}{ Principales aplicaciones de modelado 3D de libre distribución } \\
\hline Aplicación & Desarrollador \\
\hline Autodesk 3ds Max & Autodesk, Inc. San Rafael, California. \\
\hline Lihgtwave & NewTek, Inc. San Antonio, Texas. \\
\hline Autodesk Maya & Autodesk California, EEUU. \\
\hline XSI Softimage & Autodesk Media \& Entertainment. Montreal, Canadá \\
\hline Blender & Fundación Blender, Países Bajos, Ámsterdam. \\
\hline Cinema 4D & Maxon, Berlín. \\
\hline Rhinoceros & Robert McNeel \& Associates, Seattle, EEUU. \\
\hline
\end{tabular}

Tabla 1. Principales aplicaciones de código abierto (freeware), que pueden ser utilizadas para el modelado 3D. En este trabajo de tesis doctoral se ha utilizado Autodesk Maya (Autodesk California, EEUU). 


\subsection{SINOPSIS HISTÓRICA SOBRE LA UTILIZACIÓN DE MODELOS 3D PARA LA PLANIFICACIÓN PREOPERATORIA}

\section{2. 1. Historia}

Desde el inicio de la década de los ochenta han ido apareciendo diversas publicaciones de autores tales como, D. SMET que en 1980 publicó un novedoso método radiográfico para determinar con mayor precisión la ubicación tridimensional y la rotación de cada vértebra, utilizando radiografías simple postero-anterior y oblicuas de la columna vertebral, con el paciente de pie dentro de un marco que era utilizado como referencia. Así otros autores como GIORGI et al., que en 1983 propusieron diferentes métodos para el análisis y valoración de deformidades óseas, basados en imágenes radiográficas, que aportaban información gráfica en 3D de la columna vertebral (JEFFRIES et al., 1980; SMET et al., 1984; STOKES, 1987; BLADEN et al., 1993; MEROLLI et al., 1995; SOTO et al., 1996; KOCKRO et al., 2007).

En 1992, el profesor de informática H. FUCHS y 2 estudiantes de postgrado superponen las imágenes de ultrasonido de un feto a una imagen de vídeo del abdomen de una mujer embarazada proporcionando una perspectiva de la imagen más precisa, con el objetivo de servir de ayuda, para introducir y manipular guías en el cuerpo. Al año siguiente (1993), el gastroenterólogo J. BLADEN y su equipo de cirujanos desarrollaron una técnica de imagen que permitía al médico usar las imágenes de los tejidos del paciente generadas por un ordenador, para guiar la actuación de una colonoscopia (JEFFRIES et al., 1980; SMET et al., 1984; STOKES, 1987; BAJURA \& FUCHS, 1992; BLADEN et al., 1993; KOCKRO et al., 2007; HOARAU et al., 2014). 
Estos informes representan la aparición de las primeras aplicaciones de planificación con imágenes generadas en 3D por un ordenador en la medicina. Desde entonces, los avances en las capacidades de procesamiento de los ordenadores y la fabricación de hardware han llevado al uso generalizado de múltiples herramientas destinadas al tratamiento de imágenes médicas, de la realidad virtual y sus implementaciones, tales como sistemas de realidad aumentada y reconstrucciones en 3D.

\section{2. 2. Avances de la tecnología $3 D$ en diferentes áreas de la medicina}

En los últimos años se han realizado esfuerzos y grandes avances en esta tecnología, como es el caso de las investigaciones sobre la ecografía 3D, con resultados prometedores. Estos trabajos se orientan al desarrollo de técnicas de adquisición automática así como de procesamiento. Por otra parte, se realizan esfuerzos para obtener imágenes 3D de partes blandas, así como intraesofágicas e intravasculares. La adquisición de imágenes intravasculares consiste en introducir un catéter en una arteria en cuyo extremo se fija una sonda ecográfica miniaturizada. En cada posición del transductor se obtiene una capa ecográfica. El transductor se desplaza progresivamente y en cada posición se adquiere una capa de la arteria. El apilamiento y procesamiento posterior de todas las capas permite obtener la forma 3D de la arteria estudiada (BLADEN 1993; UNSGAARD 2006; KLAPAN 2011; FERROLI et al., 2013).

En la actualidad se están desarrollando y perfeccionando nuevas técnicas y disciplinas como es el caso de la cirugía asistida por ordenador, avances en la calidad de las imágenes y el tiempo de adquisición de los equipos de tomografía y resonancia magnética, cirugía asistida con neuroendoscopio, telecirugía, cirugía guiada por imágenes, robótica y la neuronavegación. Esta revolución digital obliga al neurocirujano a desarrollar nuevas habilidades y modalidades de 
planificación preoperatoria para los diferentes abordajes neuroquirúrgicos (KOCKRO et al., 2000; VICECONTI et al., 2008; TANG \& YAMADA, 2010; ALARAJ \& LEMOLE, 2011; PUIGDELLÍVOL et al., 2011; FERROLI et al., 2013).

\subsection{PLANIFICACIÓN PREOPERATORIA EN NEUROCIRUGÍA}

Para que el neurocirujano realice una planificación preoperatoria convencional requiere de al menos imágenes en dos dimensiones (2D) de tomografía computarizada (TC), resonancia magnética (RM) o radiografías simples de la región a intervenir, con sus diferentes vistas o cortes (anteroposterior, lateral, axial, sagital o coronal), marcadores, regla y las plantillas de los implantes para las artrodesis. El proceso de planificación se debe llevar a cabo sobre un negatoscopio para garantizar el contraste de la placa, o en una estación de trabajo digital, en el caso de los Centros que cuentan con equipos con salida de imágenes en formato digital (Figura 1).

Los equipos radiológicos modernos permiten grabar la información en medios extraíbles (discos compactos, tarjetas de memoria) en diversos formatos, de los cuales el DICOM (digital imaging and communication in medicine) es el más común y el estándar reconocido para el intercambio de imágenes médicas (LAMADE et al., 2000; BENEDETTI et al., 2003; BEYER \& HADWIGER, 2007; RASMUSSEN et al., 2007; KOCKRO et al., 2007; RANCO, et al., 2010; GARCÍA SÁNCHEZ et al., 2011; RAMÍREZ \& COTO, 2011; HANKEN et al., 2014; ZENG et al., 2014). 

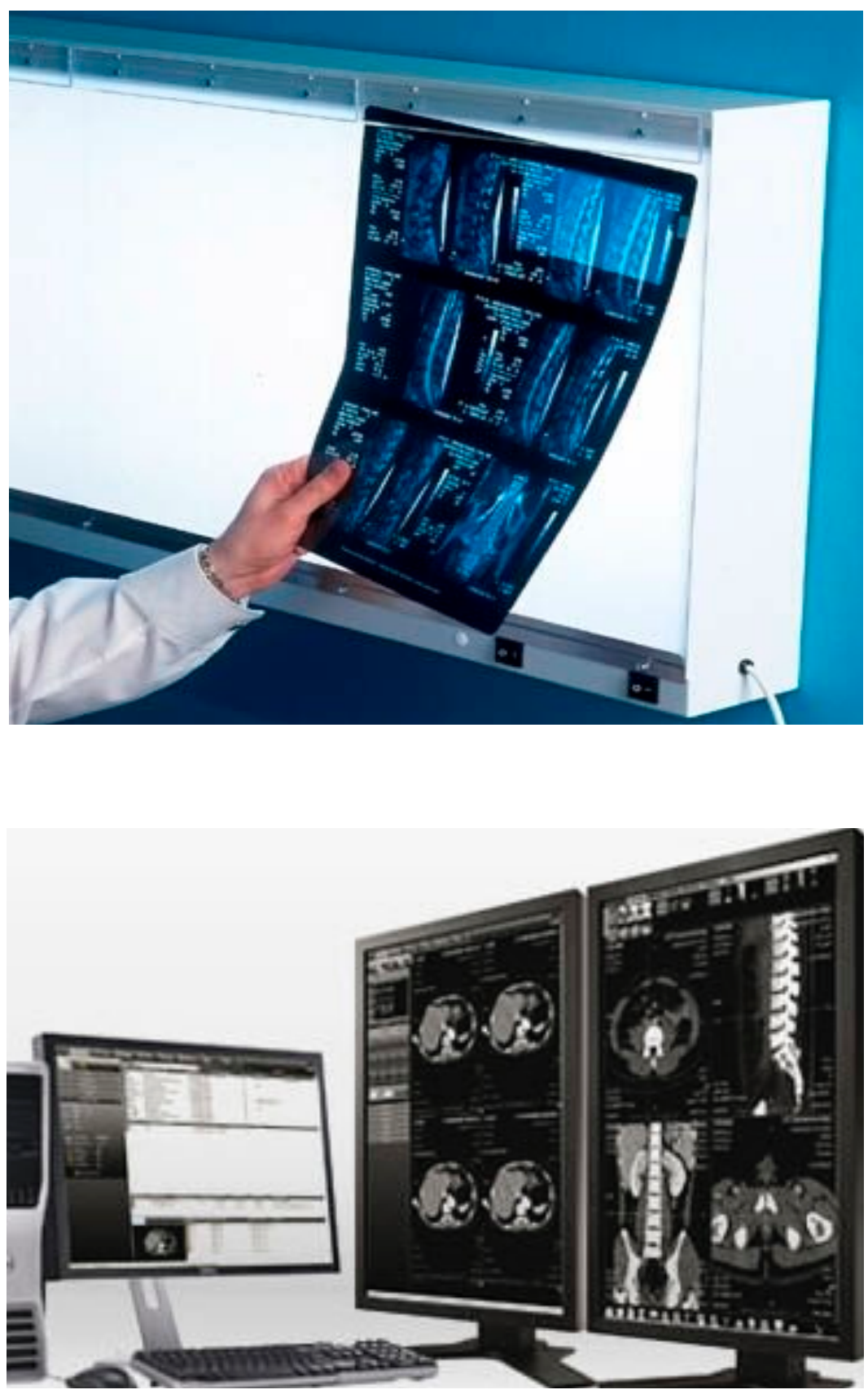

Figura 1. A y B. En la figura se muestra la transición de un entorno analógico a uno digital, en la utilización de equipos para la visualización de imágenes médicas. A: muestra un negatoscopio, que es un dispositivo que permite ver las radiografías a través de un sistema de iluminación por transparencia del negativo colocado ante un vidrio esmerilado. B: Estación de trabajo (workstation) asociada a un sistema PACS (Picture Archiving and Communications System), también denominados sistemas de gestión de imágenes médicas, el cual mejora el flujo de trabajo al ofrecer una plataforma centralizada de revisión de imágenes. 


\subsubsection{Imágenes DICOM y principales aplicaciones para su visualización}

El estándar de transmisión y almacenamiento para las imágenes médicas es el formato DICOM (digital imaging and communication in medicine). Su formato de almacenamiento (.dcm), contempla la integración de imágenes, datos de adquisición, protocolos utilizados para el estudio, equipo utilizado e informe adjunto del radiólogo. El formato DICOM es también el protocolo utilizado para las comunicaciones entre los diferentes equipos que componen una red DICOM (SCP, SCU, PACS, DICOM printers, DICOM routers, Workstations). A pesar del rápido avance y desarrollo de sistemas de visualización de imágenes DICOM, hasta hace poco tiempo, estas imágenes médicas solo era posible visualizarlas y manipularlas en las estaciones de trabajo de radiología, y por personal entrenado, o mediante costosos programas para ordenadores personales (BIDGOOD et al., 1997; GRAHAM \& SCARSBROOK, 2005; KAHN JR et al., 2007; GRAUER et al., 2009).

En la actualidad existen aplicaciones informáticas libres, que están permitiendo que este estándar (DICOM), pueda visualizarse en cualquier parte del mundo, realizando una mínima inversión, y sin necesidad de un complejo entrenamiento. La desventaja de estas aplicaciones libres es que, en la mayoría de los casos, solo permiten la visualización, no siendo posible reconstruir o editar las imágenes (RATIB \& ROSSET, 2006; NAGY, 2007).

Existen otras aplicaciones como OsiriX ${ }^{\circledR}$, desarrollado en el año 2004 por los doctores Antoin Rosset y Osman Ratib y MRIcro ${ }^{\circledR}$, desarrollado por Chris Rorden. Son programas de código abierto que transforman un ordenador Macintosh ${ }^{\circledR}$ o Windows ${ }^{\circledR}$ respetivamente en una estación de trabajo DICOM para procesar y visualizar imágenes médicas. Con estas herramientas, aunque se encuentran limitadas en su versión libre, es posible visualizar las imágenes en forma multimodal y multidimensional: bidimensionales, tridimensionales, series 
tridimensionales con dimensión temporal, reconstrucción multiplanar, simulación de superficie y volumen. Así, basta con grabar el estudio tomográfico en algún medio extraíble e introducirlo en un ordenador personal, para que el neurocirujano pueda visualizar todos los cortes y realizar las reconstrucciones que crea más convenientes, lo que elimina la pérdida de información que se genera en el proceso de impresión radiológica (BIDGOOD JR et al., 1997; MILDENBERGER et al., 2002; GRAHAM et al., 2005; ROSSET \& RATIB, 2005; RATIB \& ROSSET, 2006; NAGY, 2007; SIERRA et al., 2009; SIERRA \& FERNÁNDEZ, 2009; BOCANEGRA, 2010; RATIB et al., 2011; HAEBERLEN, 2012; WAUGH, 2012; MÁRQUEZ \& GARCÍA, 2014).

\subsubsection{Planificación prequirúrgica en un entorno digital con modelos $3 D$}

El concepto de cirugía asistida por ordenador fue introducido por $\mathrm{M}$. DIGIOIA (1998), al crear un programa informático para la planificación de abordajes en traumatología, y quien coincide en definir el uso de esta tecnología como la unión entre hombre y máquina, de forma que el trabajo en diferentes procedimientos sea superior al realizado por el hombre o la máquina de forma aislada (DIGIOIA \& JARAMAZ, 1998; DIGIOIA \& SIMON, 2001).

La planificación prequirúrgica asistida por ordenador y generación de modelos 3D, ayudan al cirujano, dotándole de información adicional mediante realidad aumentada, mejorando su orientación, precisión y la seguridad del paciente. Con estos sistemas los médicos pueden realizar las planificaciones preoperatorias y tener un proceso más preciso y repetible que los métodos convencionales (LAMADE et al., 2000; JUERGENS et al., 2008; RAMÍREZ \& COTO, 2011). 
Estos sistemas pueden emplear las imágenes reales de cualquier zona del cuerpo humano proveniente de los distintos equipos médicos utilizados en radiología, tales como ultrasonido, rayos $\mathrm{X}$, tomografía computarizada (TC) o imágenes de resonancia magnética $(\mathrm{RM})$; además pueden crear imágenes virtuales de las estructuras óseas o de partes blandas afectadas. Esta característica constituye una enorme ventaja respecto a otros sistemas, pues estas imágenes están en formato DICOM (Digital Imaging and Communication in Medicine) y el proceso de adquisición, transmisión y procesamiento de las mismas está controlado por un sistema PACS (Picture Archiving and Communications System). Así se asegura que dicho proceso además de seguro sea de cierta forma más sencillo (KIKINIS et al., 1996; DIGIOIA \& JARAMAZ, 1998; WILLIAMSON, 1998; DIGIOIA \& SIMON, 2001; ROGERS, 2001; KANG et al., 2005; FERROLI et al., 2013; XIANG et al., 2014; ZENG et al., 2014).

\subsubsection{Ventajas de la planificación asistida con modelos $3 D$}

Además de las ventajas expuestas anteriormente, en la actualidad existe una amplia evidencia científica, que justifican el uso de esta nueva modalidad de visualización y planificación preoperatoria. Hoy sabemos que las intervenciones quirúrgicas, planificadas y asistidas por ordenadores, incluyendo los modelos $3 \mathrm{D}$, suponen no sólo más seguridad para los pacientes y neurocirujanos, sino también una disminución en los costes al reducir el margen de error (TAYLOR et al., 1995; MOTOHASHI, 1999; UNSGAARD et al., 2006; HANKEN et al., 2014).

En el caso de la columna vertebral, estas nuevas tecnologías pueden ayudar a reducir el margen de error en los diferentes tipos de abordajes, además con una buena planificación es posible reducir el uso del fluoroscopio intraoperatorio, 
con lo cual disminuyen los riesgos potenciales asociados a la radiación para los pacientes y el personal de quirófano (SMET et al., 1984; UNSGAARD et al., 2006; STADIE et al., 2008; RANCO et al., 2010; HAQ et al., 2014).

\subsubsection{Limitaciones de la planificación asistida por ordenador}

Aún cuando existen equipos, sistemas y programas informáticos que permiten asistir al neurocirujano en la delicada tarea de la planificación preoperatoria, su elevado costo ha frenado la difusión rápida de tales técnicas, por lo cual muchos autores consideran que su elevado costo, es el factor limitante mas importante. Otras limitaciones, se encuentran relacionadas a la manipulación de imágenes y la generación de reconstrucciones $3 \mathrm{D}$, que en la mayoría de las ocasiones únicamente pueden efectuarse en la estación de trabajo del radiólogo con equipos y programas complejos, a los cuales no siempre se tiene acceso por razones de tiempo o capacitación. (KLAPAN ET AL, 2011; FERROLI et al., 2013; ABREU et al., 2014; ONEN et al., 2014).

\subsubsection{Desarrollo de modelos 3D a partir de imágenes DICOM}

El desarrollo de modelos 3D requiere el conocimiento de las propiedades anatómicas y respuesta biomecánicas de los tejidos o estructuras que se desean modelar. A continuación haremos una breve descripción de los aspectos teóricos fundamentales de la adquisición de imágenes DICOM a partir de equipos de resonancia magnética y tomografía computarizada, para el modelado 3D, así mismo más adelante realizaremos una breve descripción sobre el desarrollo y la anatomía de la columna vertebral (WANG et al., 2005; RATIB \& ROSSET, 2006; KAHN JR et al., 2007; KUMAR, 2007; VICECONTI et al., 2008; GRAUER et al., 2009; WANG \& SUN, 2013). 


\subsubsection{Reconstrucción 3D a partir de imágenes DICOM}

La reconstrucción 3D de estructuras anatómicas a partir de imágenes médicas como resonancia magnética (RM) y tomografía computarizada (TC), se ha convertido en una técnica útil, que facilita la visualización optima de los segmentos corporales que necesitan ser evaluados, además están siendo utilizadas como una herramienta importante en el diagnóstico médico y la planificación de terapias y procedimientos quirúrgicos, permitiendo el desarrollo de aplicaciones en diversas áreas de la medicina. Así mismo, el perfeccionamiento de los sistemas informáticos y nuevos ordenadores, reflejados en las mejoras de la velocidad y capacidad de almacenamiento, han permitido un gran avance en el área de procesamiento de imágenes médicas, que ha hecho posible el estudio biomecánico de estructuras óseas por el método de elementos finitos como herramienta para el análisis de geometrías complicadas y materiales no lineales (DEFRISE, 2001; GRAHAM et al., 2005; KANG et al., 2005; WANG et al., 2005; WATANABE et al., 2005; HAQ et al., 2014).

\subsubsection{La tomografía computarizada ó tomografía por rayos $X$}

Una importante modalidad de imágenes médica es la tomografía asistida por ordenador o tomografía computarizada en donde las imágenes del interior del cuerpo se reconstruyen a partir de un conjunto de medidas de proyección. Tales proyecciones son obtenidas mediante la exposición de un objeto a un tipo de radiación, según diversos ángulos y midiendo, para cada posición angular, la intensidad del haz de radiación que atraviesa el objeto. En el caso de la TC, las proyecciones se obtienen mediante la exposición a los rayos X (HOUNSFIELD, 1973; BRENNER \& HALL, 2007). 
La medición de la intensidad de rayos X que atraviesa un plano o capa del cuerpo humano según un ángulo dado da lugar a un perfil de proyección. La reconstrucción tomográfica de una capa del cuerpo humano se obtiene a partir de los diferentes perfiles de proyección obtenidos, utilizando técnicas de reconstrucción de tipo analíticas o algebraicas. La calidad de la imagen depende del número de perfiles considerados (HOUNSFIELD, 1973; VERHELST et al., 1996; MURAI et al., 1999).

Para obtener imágenes útiles desde el punto de vista del diagnóstico médico, es necesario considerar un número importante de perfiles de proyección. En la actualidad la investigación en esta área se orienta hacia el mejoramiento del tiempo de adquisición y hacia el desarrollo de equipos y algoritmos de reconstrucción basados en detectores bidimensionales (VERHELST et al., 1996; MURAI et al., 1999; GRAUER et al., 2009).

Para la reconstrucción 3D a partir de TC, se consideran los siguientes parámetros: (a): Resolución espacial compuesta por el número de cortes y el número de píxeles de cada corte. Este parámetro es representado por una matriz 3D de la imagen, cuyas medidas $\mathrm{X}, \mathrm{Y}$ dependen del tamaño en píxeles de cada corte y $\mathrm{Z}$ depende del número de cortes obtenidos. Por ejemplo, en un conjunto de datos de TC con una matriz de imagen de $512 \times 512$ pixels y 300 cortes, obtendremos un volumen de datos con la resolución $512 \times 512 \times 300$. (b): Las distancias entre voxels (voxel spacing) es calculada a partir de la distancia en $\mathrm{x}$, y de los pixeles dentro de cada corte (en el plano) y la distancia $\mathrm{z}$ de los píxeles entre dos cortes, llamado grosor del corte (fuera del plano). Si x,y,z tienen el mismo valor, se tendrían voxels isotrópicos, caso contrario se denominan anisotrópicos (HOUNSFIELD, 1973; WEINSTEIN, 1998; MURAI et al., 1999; GRAUER et al., 2009). 


\subsubsection{Imágenes por resonancia magnética (RM)}

La resonancia magnética, consiste en medir la concentración y el tiempo de relajación de ciertos núcleos atómicos (generalmente núcleos de hidrógeno) excitados bajo la acción de un campo magnético fijo y de un pulso de radiofrecuencia. Cuando se ubica un objeto en un gradiente de campo magnético, la frecuencia de las señales de resonancia magnética producidas por los núcleos atómicos es dependiente del campo magnético local aplicado y de la interacción a nivel molecular. Un núcleo sometido a un campo magnético $\mathrm{H}_{0}$ se comporta como vector dipolo magnético, el cual gira con un movimiento de precesión alrededor de la dirección de $\mathrm{H}_{0}$ a una frecuencia conocida como frecuencia de Larmor, la cual es característica del elemento químico considerado y de la intensidad del campo $\mathrm{H}_{0}$. En presencia de un campo magnético $\mathrm{H}_{1}$ capaz de orientar al dipolo magnético total en sentido perpendicular a $\mathrm{H}_{0}$ corresponde a un estado excitado de los núcleos atómicos. Al apagar el campo de radiofrecuencia $\mathrm{H}_{1}$ el estado de excitación va decayendo progresivamente en función de la densidad de los tejidos. El retorno al equilibrio está caracterizado por dos constantes de tiempo denominadas $\mathrm{T} 1$ y $\mathrm{T} 2$, para cada punto de la imagen en función de la posición en el espacio tridimensional, de la concentración $\mathrm{p}$ de núcleos atómicos y de las constantes de tiempo de relajación (MORRIS, 1986; ERNST ET AL, 1991; EDELMAN \& WARACH, 1993).

El interés en el campo de la radiología por la resonancia magnética se debe al hecho de que el equipo utiliza una radiación no ionizante que permite una buena discriminación de los tejidos y la adquisición tridimensional de una zona del cuerpo. El contraste de los tejidos, puede mejorarse adicionalmente mediante la utilización de materiales de contraste paramagnéticos inyectados en el cuerpo. El campo de aplicación de esta modalidad es muy amplio y la limitación principal es el alto costo de los equipos (ERNST et al., 1991; HAACKE \& BROWN, 1999; MORI et al., 1999; PUIGDELLÍVOL et al., 2011). 


\subsubsection{Parámetros y almacenamiento de imágenes médicas}

Las imágenes digitales representan información visual asociada con una escena ambiental real que correspondería a lo que observamos con el sentido de la vista o bien información no visible pero que puede ser medida utilizando sensores apropiados tales como radiación infrarroja, ultravioleta, rayos $\mathrm{X}$ y ultrasonidos.

El proceso de adquisición de la imagen involucra un sensor apropiado para detectar el tipo de fuente de información visual o emisión y convertirla en una señal eléctrica. Posteriormente esta señal eléctrica se convierte en un arreglo de cantidades binarias las cuales se pueden almacenar o procesar utilizando un ordenador. Esta imagen digital obtenida de un equipo radiológico corresponde a un arreglo de dos dimensiones (2D) que se podría denotar como $\mathrm{f}(\mathrm{x}, \mathrm{y})$ en donde cada punto se denomina pixel y tiene asociadas las coordenadas espaciales definidas por $\mathrm{x} \& \mathrm{y}$. La imagen tiene un tamaño de NxM píxeles en donde $\mathrm{N}$ corresponde al ancho de la imagen y $\mathrm{M}$ corresponde al largo de la imagen. Tal valor binario requiere un determinado numero de bits para representar la información y lo más usual es 8 bits que corresponde a un byte o bien, 16 bits o 32 bits que corresponden a 2 bytes y 4 bytes respectivamente.

En cambio las imágenes tridimensionales (3D) se denotan como $\mathrm{f}(\mathrm{x}, \mathrm{y}, \mathrm{z})$ en donde cada punto se denomina voxel y tiene asociadas tres coordenadas espaciales definidas por $\mathrm{x}, \mathrm{y} \& \mathrm{z}$. En este caso el tamaño total sería NxMxP voxels y es equivalente a manejar $\mathrm{P}$ imágenes bidimensionales cada una de tamaño NxM pixels. Una vez adquirida la imagen se puede procesar y/o almacenar en disco duro, cintas magnéticas, discos compactos (CD), y otros. (THOMAS, 1995; NERI et al., 1998; ESCOTT \& RUBINSTEIN, 2003; JANG \& KIM, 2004; VOSSBERG, 2008; SIERRA et al., 2009). 


\subsection{Procesamiento de imágenes para la obtención de modelos 3D}

La visualización tridimensional se refiere a la representación visual obtenida a partir de un conjunto de imágenes, cortes ó slices de la misma resolución alineados paralelamente con respecto a una posición adyacente (por lo general la coordenada $\mathrm{z}$ ), de esta manera se obtiene un volumen constituido por voxels. Esta nueva forma de visualizar las estructuras anatómicas representa una ventaja para el médico, al agregar una tercera dimensión en las vistas desplegadas en el ordenador y proporcionar una información más completa. Sin embargo, unos de los principales problemas de la representación 3D, es la forma en que los usuarios pueden interpretar y manipular la información de manera rápida. Por este motivo, resulta más ventajoso utilizar rutinas específicas de visualización que se centren en las zonas de interés, que pueden representar rápidamente los resultados de una manera más intuitiva (LANDINI et al., 2008; GAVIDIA et al., 2011; ZENG et al., 2014).

En la medicina, existen disciplinas relacionadas al desarrollo y procesamiento de imágenes médicas que trabajan en conjunto y se orientan al desarrollo y aplicación de técnicas para extraer con ayuda del ordenador, información clínica cualitativa y cuantitativa de las estructuras del cuerpo humano. Para ello, se opta por la utilización de los métodos numéricos que aproximen una solución a problemas reales y permitan la obtención de modelos anatómicos de tejidos. Sin embargo, esta aproximación se ve afectada por la complejidad de las estructuras anatómicas de los tejidos duros y blandos, generalmente asimétricos, en cuyo análisis es difícil realizar simplificaciones debido a errores en la resolución de las ecuaciones diferenciales del problema ocasionado por geometrías complejas e imposición inadecuada de las condiciones de contorno y cargas externas (LIESSI et al., 1990; CHAO et al., 1993; KAUS et al., 2001; PARK et al., 2005; GOLDENBERG et al., 2005; BANKMAN, 2008; CERROLAZA et al., 2014). 
En los últimos años, esta dificultad ha sido resuelta, al obtener los modelos anatómicos complejos que reproducen con precisión los detalles geométricos a partir de la reconstrucción tridimensional de estructuras biológicas empleando técnicas de procesamiento, segmentación y visualización de las imágenes médicas como la Tomografía Computarizada (TC), Resonancia Magnética (TC), Medicina Nuclear (MN), entre otras. El nacimiento de las técnicas radiológicas modernas han marcado el inicio de diversas investigaciones orientadas a la reconstrucción tridimensional de las imágenes radiológicas para obtener la vista volumétrica de los tejidos blandos y duros ( CLARKE et al., 1995; SATO et al., 1998; DUNCAN et al., 2000; FITZPATRICK et al., 2000; PHAM et al., 2000; ROGOWSKA, 2000; BAILLARD et al., 2001; KAUS et al., 2001; BEUTEL et al., 2002; BOSKAMP et al., 2005; PARK, et al., 2005; BANKMAN, 2008)

\subsubsection{Segmentación}

Tras seleccionar la región de interés (ROI), mejorar los niveles de intensidad y corregir los posibles artefactos en las imágenes médicas, la siguiente etapa es la segmentación, la cual consiste en dividir las imágenes en regiones contiguas (subregiones ó sub-volúmenes) cuyos elementos miembros (pixels ó voxels) tienen propiedades de cohesión comunes.

Las técnicas de segmentación se han aplicado en diversas ramas de la medicina, como la delimitación de tumores cerebrales (CHUANG \& CHEN, 2007), extracción y localización de la zona afectada por tuberculosis extra pulmonar, visualización de patologías del corazón (CIOFOLO \& FRANDKIN, 2008), la detección de contornos coronarios en angiografía coronaria, cuantificación de lesiones cerebrales de esclerosis múltiple, simulación y planificación de cirugías, medición del volumen de tumores y su respuesta a terapias, clasificación automatizada de células sanguíneas, estudio del desarrollo 
del cerebro, detección de micro calcificaciones en mamografías, entre otras aplicaciones. En cada uno de estos trabajos, se han empleado diferentes técnicas de segmentación, y su elección ha dependido de las características de las imágenes médicas y el tipo de tejido a segmentar (CLARKE et al., 1995; SATO et al., 1998; DUNCAN et al., 2000; CHUANG \& CHEN, 2007; CIOFOLO \& FRADKIN，2008; BANKMAN，2008; AVAZPOUR \& SARIPAN，2009; GAVIDIA et al., 2010; GAVIDIA \& SOUDAH, 2011; LEI et al., 2013; CERROLAZA et al., 2014).

BANKMAN (2008) describe los diferentes tipos y técnicas de segmentación (figura 2), que son: segmentación manual, semiautomática y automática. Asimismo, el autor describe que las técnicas más comunes de segmentación pueden ser clasificadas en dos categorías: (a) Técnicas de segmentación basadas en regiones y (b) Técnicas de segmentación basada en bordes (CHUANG \& CHEN, 2007; CIOFOLO \& FRADKIN, 2008; BANKMAN, 2008; AVAZPOUR \& SARIPAN, 2009; GAVIDIA et al., 2010; GAVIDIA \& SOUDAH, 2011; LEI et al., 2013; CERROLAZA et al., 2014).

\subsubsection{Segmentación manual}

La segmentación manual, es muy usada para segmentar estructuras anatómicas. Consiste en dibujar manualmente sobre un slice las regiones de interés. Para modificar los contornos trazados, se le permite al usuario redibujar un fragmento particular que reemplaza al inicial. Esta técnica siempre es aplicable, sin embargo, tiene la desventaja de ocupar mayor tiempo. 


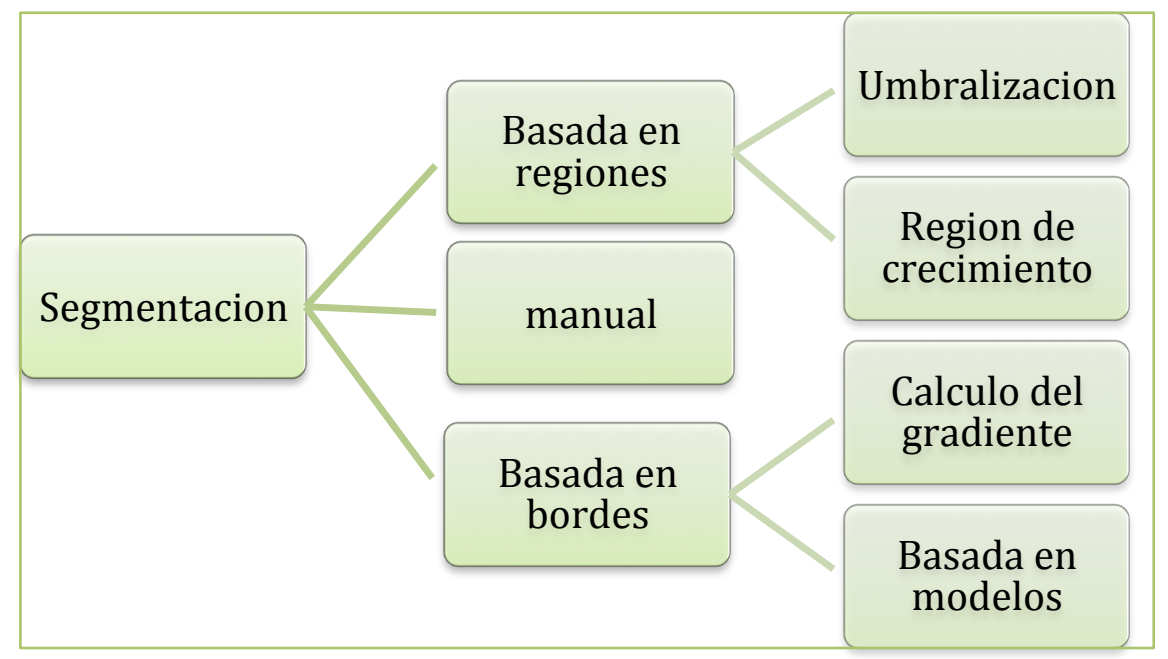

Figura 2. Esquema con la clasificación de las principales técnicas de segmentación

\subsubsection{Segmentación basada en umbrales}

La umbralización es una técnica efectiva para obtener la segmentación de imágenes donde las estructuras tienen diferentes intensidades $\mathrm{u}$ otras características diferenciables. Algunas de las técnicas de umbralización están basadas en el histograma de la imagen y otras están basadas en propiedades locales como el valor promedio local, la desviación estándar ó el gradiente local. En su forma más simple, esta técnica se denomina umbralización global ó umbralización bimodal, en la cual, a partir de un histograma bimodal para una imagen $f(x, y, z)$, el objeto puede ser extraído del fondo con una simple operación que compara los valores de $\mathrm{f}(\mathrm{x}, \mathrm{y}, \mathrm{z})$ con un umbral $\mathrm{T}$ que puede separar las dos modas del histograma generando como resultado una imagen binaria (BANKMAN, 2008).

\subsubsection{Segmentación basada en regiones de crecimientos (Región Growing) \\ Comúnmente, esta técnica se emplea para extraer regiones de la imagen que están conectadas según cierto criterio predefinido (los objetos a segmentar son regiones con características similares). En su forma más sencilla, se inicia}


con el establecimiento de una semilla que puede ser un pixel, voxel ó conjunto de ellos, los cuales son seleccionados manualmente por el usuario. En el siguiente paso los elementos vecinos son examinados y adicionados a la región sí, son suficientemente similares, basados en un test de uniformidad (criterio de homogeneidad como intensidad de gris, promedio, desviación estándar). El procedimiento continúa hasta que no puedan ser adicionados más voxels. Finalmente, el objeto segmentado es representado por todos los elementos que han sido aceptados durante el procedimiento de búsqueda.

La técnica growing es muy utilizada en aplicaciones médicas para extraer estructuras del cuerpo y sus patologías. LIU et al. (2009) emplearon este algoritmo para segmentar los ventrículos cerebrales. AVAZPOUR y cols., 2009 segmentaron la infección por tuberculosis extrapulmonar, modificando el algoritmo de Región Growing. MÜHLENBRUCH et al. (2005) consiguieron extraer el ventrículo izquierdo de un TC cráneo-cerebral para su posterior análisis numérico. Asimismo, esta técnica se emplea habitualmente para segmentar estructuras vasculares (PRASTAWA et al., 2004; MÜHLENBRUCH et al., 2006; JUERGENS et al., 2008; AVAZPOUR \& SARIPAN, 2009; LIU et al., 2009; LIU et al., 2010).

\subsection{DESARROLLO Y ANATOMÍA DE LA COLUMNA VERTEBRAL}

Es muy importante el conocimiento del desarrollo y la anatomía de la columna vertebral, que es fundamental para la interpretación de las imágenes médicas, así como para una buena planificación preoperatoria y una correcta correlación radiológica-neuroquirúrgica. Por lo cual realizaremos una breve descripción sobre el desarrollo de la columna vertebral, así mismo sobre los aspectos anatómicos más relevantes. 


\subsubsection{Embriogénesis de la columna vertebral}

En la literatura existe suficiente evidencia sobre el desarrollo de la columna vertebral $(\mathrm{CV})$. La CV es una estructura segmentada cuyos precursores pueden apreciarse hacia el vigesimoprimer día del desarrollo. En este periodo el mesodermo para-axial se organiza en somitas que presentan una de las primeras manifestaciones de segmentación (ver figura 3) (MOORE, 2007; SADLER, 2011).

En las regiones de la cabeza y la cola, los somitas se desarrollan atípicamente o degeneran. En el cuerpo del embrión cada somita típico se diferencia en tres porciones:

1.- Una placa epitelial lateral y superficial, el dermatomo;

2.- Una masa lateral pero más profunda, el miotomo;

3.- Una masa mediana y ventral, el esclerotomo;

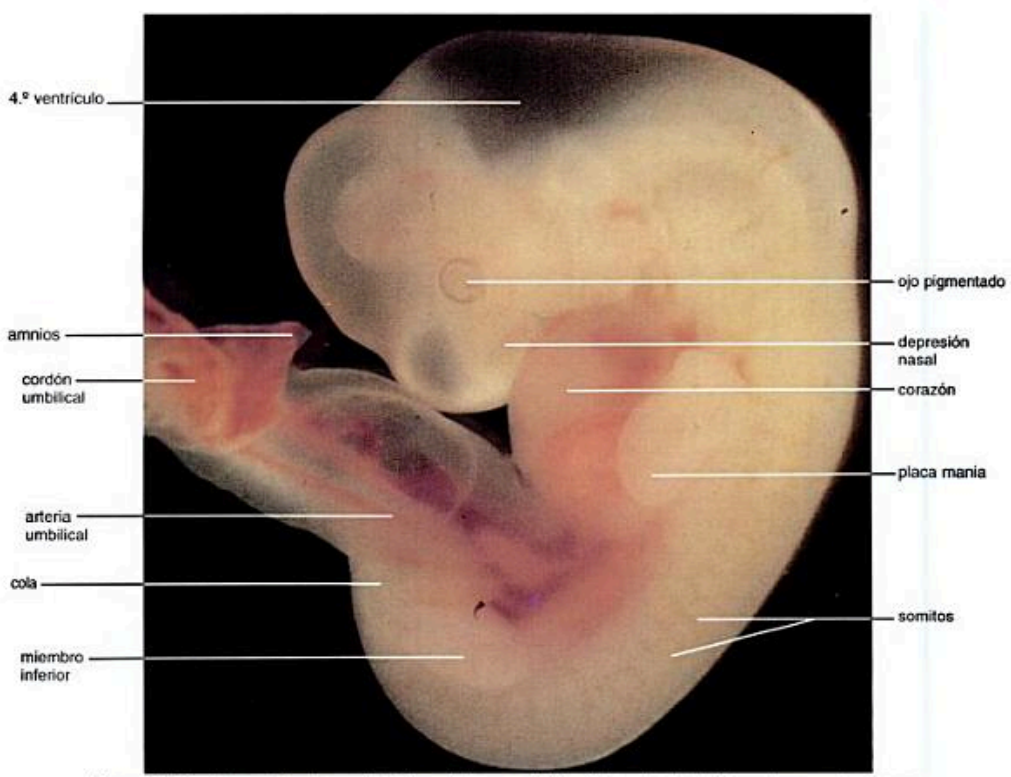

Figura 3. Vista lateral de un embrión de aproximadamente 36 días, donde se observa el inicio de la formación de las extremidades y la columna vertebral (imagen tomada de T.W. Sadler; Langman Embriología Médica. 11a edición (2010). 


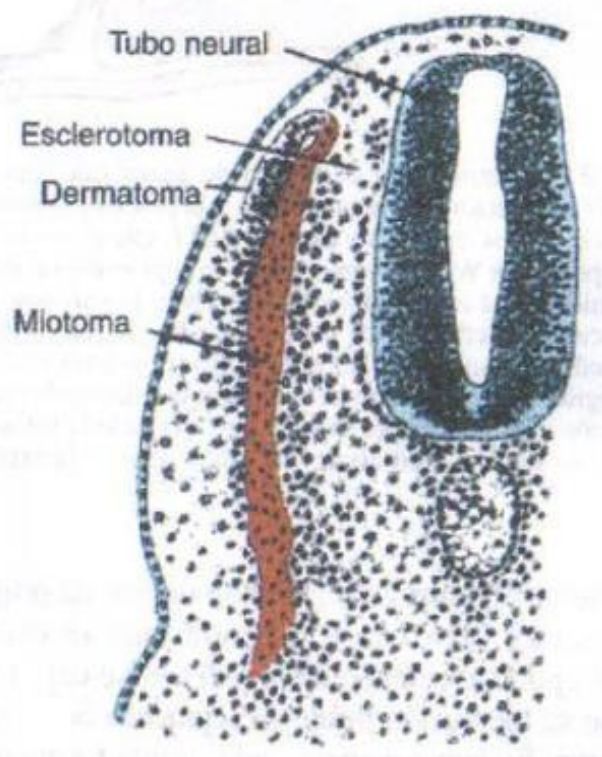

Figura 4. Se muestra un somita típico con las tres porciones: dermatomo, miotomo y esclerotomo (Esquemas tomados de T.W. Sadler; Langman Embriología Médica. 11a edición (2010).

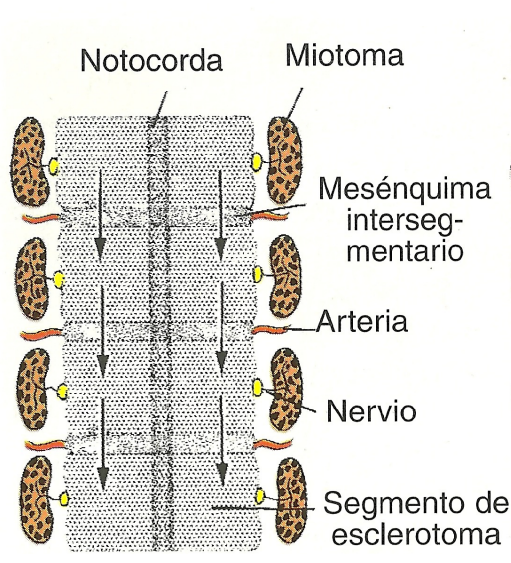

A

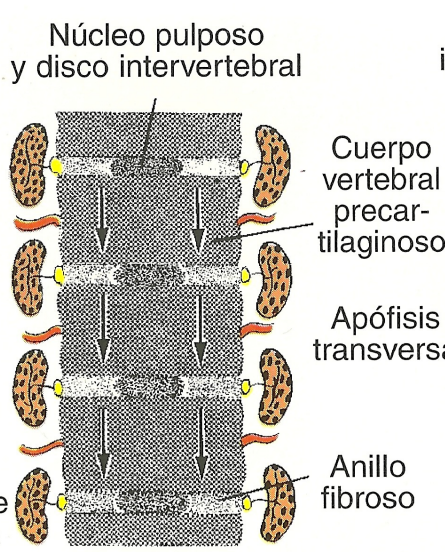

B

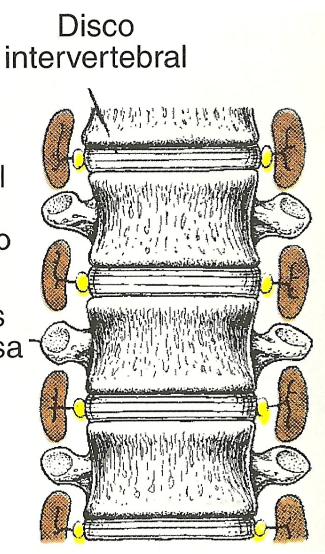

C

Figura 5. Se muestra la formación de la CV en diversas etapas del desarrollo. A: En la cuarta semana de desarrollo. B: Aparición del núcleo pulposo y disco intervertebral. C: Los cuerpos vertebrales son formados por las mitades superior e inferior de dos esclerotomas sucesivos y por el tejido intersegmentario. Los miotomos se disponen a manera de puente sobre los discos intervertebrales y, por tanto, pueden mover la columna vertebral (Esquemas tomados de T.W. Sadler; Langman Embriología Médica. 11a edición (2010). 
Las células escleróticas de cada par de somitas emigran hacia la línea media (Figuras 4 y 5). Estas células salen del conjunto epitelial y se transforman en elementos estrellados ramificados, que mediante sus múltiples prolongaciones forman una especie de red. En la línea media encuentran estas células la notocorda, alrededor de la cual se disponen así como a los lados del tubo neural. Estas células estrelladas, conjuntivas, son las que en definitiva constituyen el mesénquima (HAMILTON, 1962; MOORE, 1996; SADLER \& LANGMAN, 2007; SCHOENWOLF, 2009; SADLER, 2011)

El mesénquima axial es el origen del tejido que forma el esqueleto vertebral. El notocordio persiste a través de los estadios mesenquimatosos y cartilaginoso del desarrollo vertebral, pero tarde o temprano desaparece, entre tanto ocurre la osificación de las vértebras como se muestra en la figuras 5 y 6 . El derivado adulto del notocordio es el núcleo pulposo, el cual forma la parte central del disco intervertebral (HAMILTON, 1962; MOORE, 1996; SADLER \& LANGMAN, 2007; SCHOENWOLF, 2009; SADLER, 2011).

Mientras continúa el desarrollo, aparecen apófisis espinosas, arco vertebral, dos apófisis transversas, y dos costales. La apófisis que forman el arco vertebral (arco neural), crecen en dirección dorsomedial y se funden una con otra en el plano medial para encerrar la médula espinal en desarrollo (FRENCH, 1982; THEILER, 1988; JINKINS, 2002; KAPLAN, 2005; TORTORI-DONATI et al., 2000; SADLER \& LANGMAN, 2007; MOORE, 2007; CARLSON, 2009). 


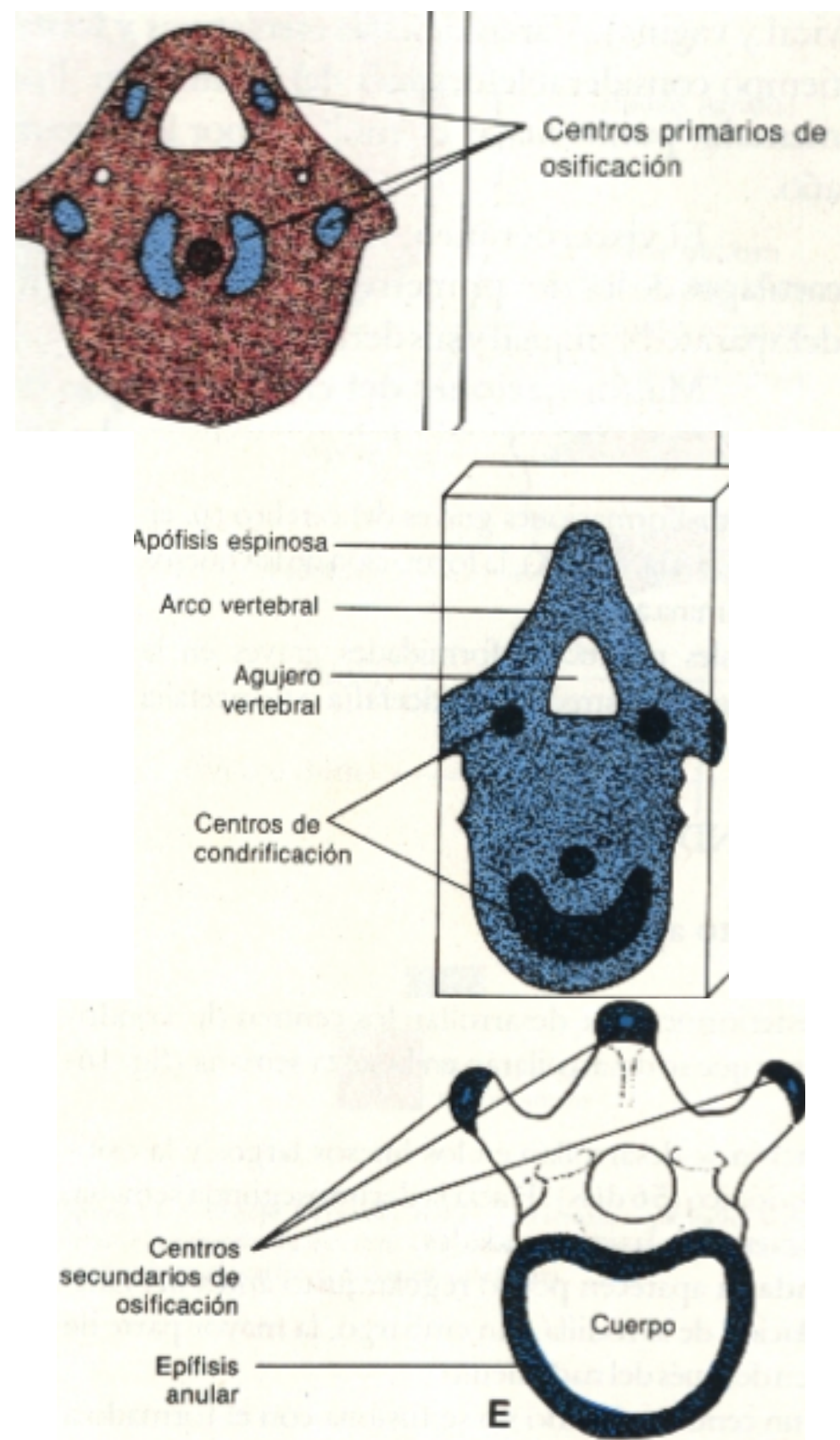

Figura 6. En esta figura se puede observar los centros primarios y secundarios de osificación. (esquema tomado de T.W. Sadler; Langman Embriología Médica. 11a edición (2010). 
Durante o un poco después de la pubertad (de 12 a 16 años), aparecen cinco centros secundarios de osificación en las vértebras (Fig. 6). Todos los centros secundarios se unen con el resto de las vértebras alrededor de los 25 años.

\subsubsection{Anatomía de la columna vertebral}

Es suficientemente conocida la estructura anatómica de la columna vertebral; por este motivo, no vamos pues a insistir en la misma. Haremos únicamente una breve descripción de las generalidades anatómicas más importantes, centrando la atención sobre los puntos que juzgamos de fundamental interés desde el punto de vista radiológico y neuroquirúrgico para el tema que nos ocupa.

\subsubsection{Generalidades}

La columna vertebral (CV) es una compleja estructura osteofibrocartilaginosa, articulada, fuerte y flexible. compuesta por 33 a 34 vértebras sus respectivos discos intervertebrales, además de ligamentos y masas musculotendinosas que conectan y sostienen éstas estructuras. Se extiende desde la base del cráneo hasta el cóccix y su longitud es variable según el grado de sus curvaturas y la estatura de la persona $(70 \mathrm{~cm}$. en hombres y $60 \mathrm{~cm}$. en mujeres, aproximadamente). La estructura de la columna vertebral está conformada de tal manera que goza de flexibilidad, estabilidad y amortiguación de impactos durante el movimiento normal del organismo. Su forma de articulación y sus fijaciones músculo-ligamentarias la convierten en un eje flexible que sustenta el tronco y su función global, es mantener el equilibrio estático y dinámico de los 3 planos en el espacio, en la figura 7, se muestra una radiografía de la $\mathrm{CV}$ completa donde se puede observar algunos de los detalles anatómicos más relevantes (LATARJET \& LIARD, 2004; MOORE, 2007). 
Así el plano frontal mantiene el equilibrio de las desviaciones laterales. El plano sagital hace su equilibrio en el sentido anteroposterior. Las secciones transversas nos dicen de la rotación axial. La posición del raquis en el plano coronal debe ser totalmente medial. En el plano sagital una línea desde el pabellón de la oreja debe pasar por el trocánter mayor y el maléolo externo.

De perfil puede observarse las cuatro curvas fisiológicas: lordosis cervical y lumbar; cifosis dorsal y sacro-coxígea. Este último compuesto, por su ubicación en la cintura pélvica-sacra sometido con menor frecuencia a traumas. La unión de las vértebras con la cintura escapular se hace, actuando la columna como un mástil central.

En la región dorsal, la columna vertebral ocupa el cuarto posterior. En la región cervical el tercio posterior que corresponde al centro de gravedad del cráneo, a quien soporta. El peso del cuerpo es soportado por la región lumbar, de allí su avance a la parte media y el mayor desarrollo de las vertebras. A nivel del sacro, se ubica en el plano posterior.

La vértebra típica esta compuesta por una parte anterior, el cuerpo, quien soporta la mayor parte del peso y el arco posterior quien protege la médula espinal. Las apófisis transversas y las apófisis espinosas en continuidad con el arco posterior, permiten las inserciones musculo-ligamentosas. Las apófisis articulares, dos superiores y dos inferiores, limitan los movimientos espinales según las orientaciones de las carillas articulares (LOUIS \& GOLDSTEIN, 1983; PANJABI et al., 1993; ROHEN et al., 1996; PANJABI, et al., 1997; LUND et al., 1998; LATARJET \& LIARD, 2004; GRIEVE, 2005; ROUVIÈRE \& DELMAS, 2005). 


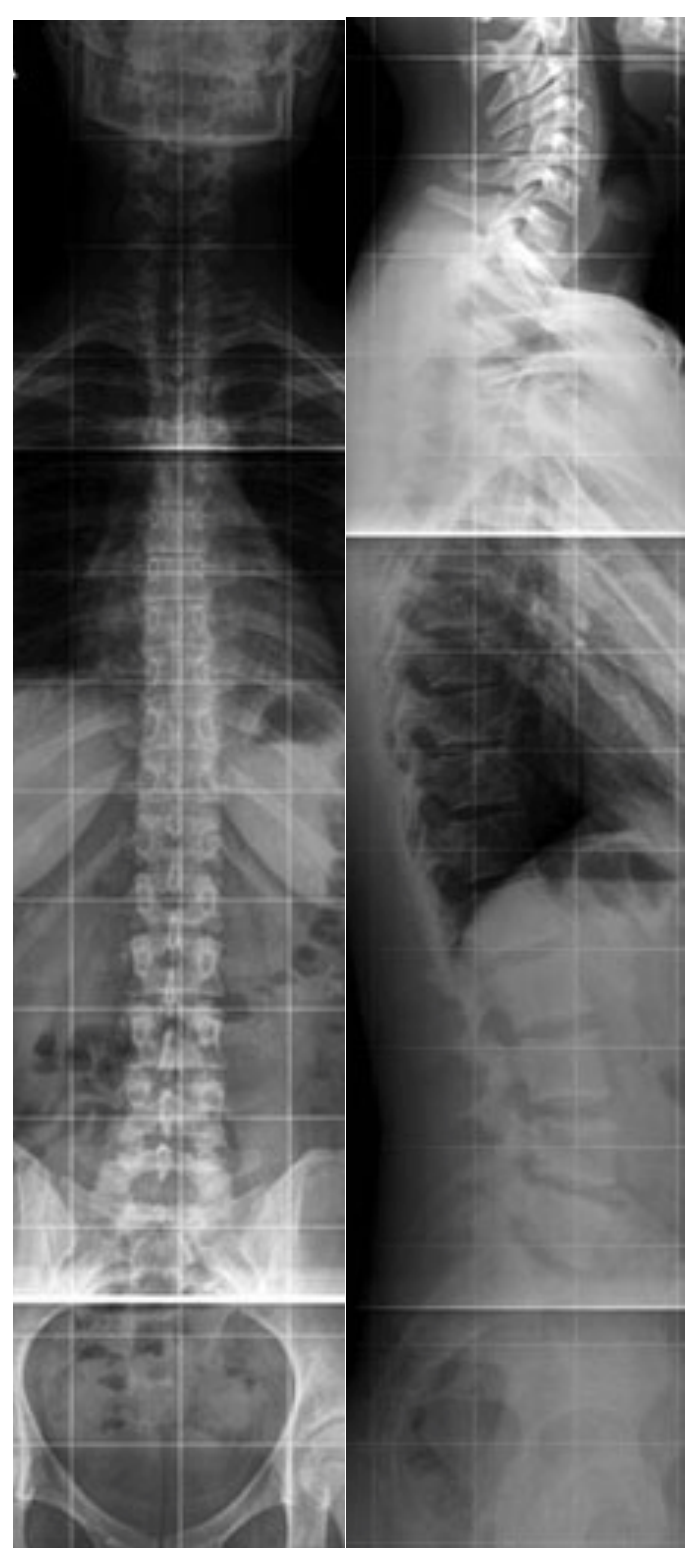

Figura 7. Muestra una telerradiografía de la columna vertebral completa, donde se pueden observar sus principales características. A: vista antero-posterior. B: vista lateral.

\subsubsection{Movimientos de la columna vertebral}

La suma de los movimientos limitados entre vértebras adyacentes permite un importante grado de movilidad a la columna vertebral en conjunto, como se muestra en las figuras 8 y 9 (DOLAN et al., 1994; ROHEN et al., 1996; LATARJET \& LIARD, 2004; LUND et al., 1998; NETTER, 2010). 
Son posibles los siguientes movimientos: flexión, extensión, flexión lateral y rotación. Estos movimientos se dan con mayor facilidad en la columna cervical y lumbar debido a las siguientes razones:

(a) En estas regiones los discos intervertebrales son más gruesos.

(b) Las apófisis espinosas de estas regiones son más cortos y están más separados entre sí.

(c) No existe sujeción a la caja torácica.

(d) Existe una disposición favorable de las articulaciones facetarias.

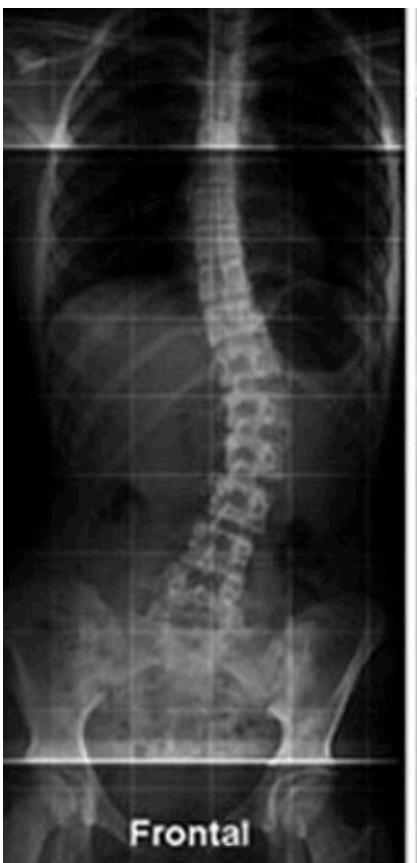

A

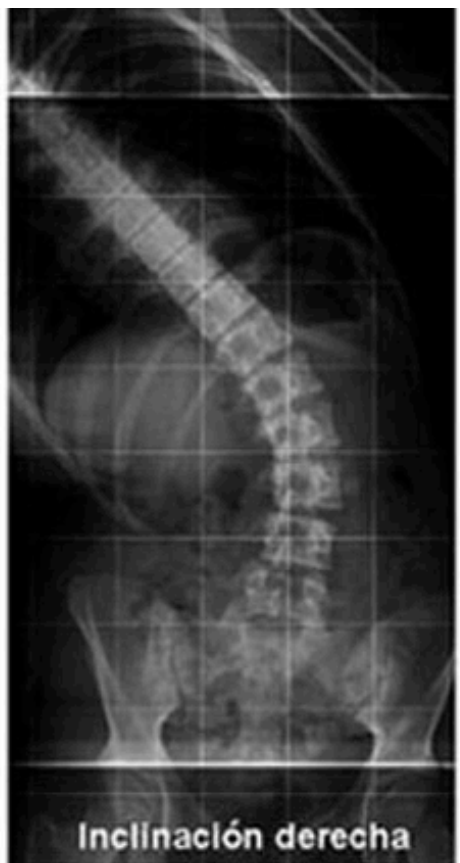

B

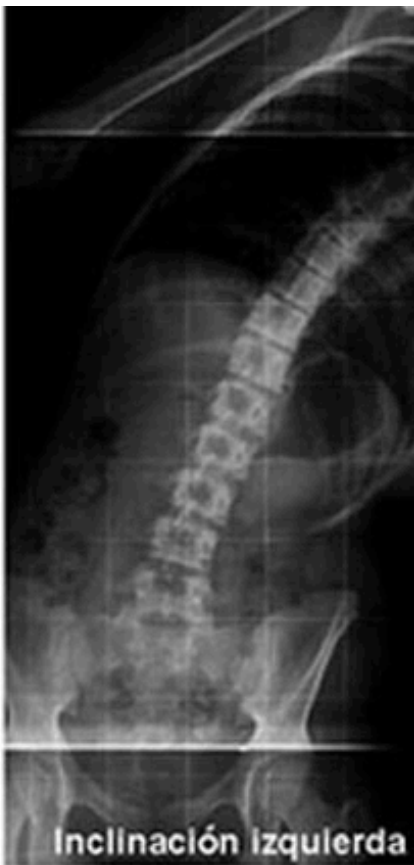

C

Figura 8. A, B y C. Radiografía simple de columna completa (Bending) de un paciente con escoliosis, en la imagen se observa los movimientos laterales de la columna vertebral. A: posición neutra. B: inclinación derecha. C: inclinación izquierda. 


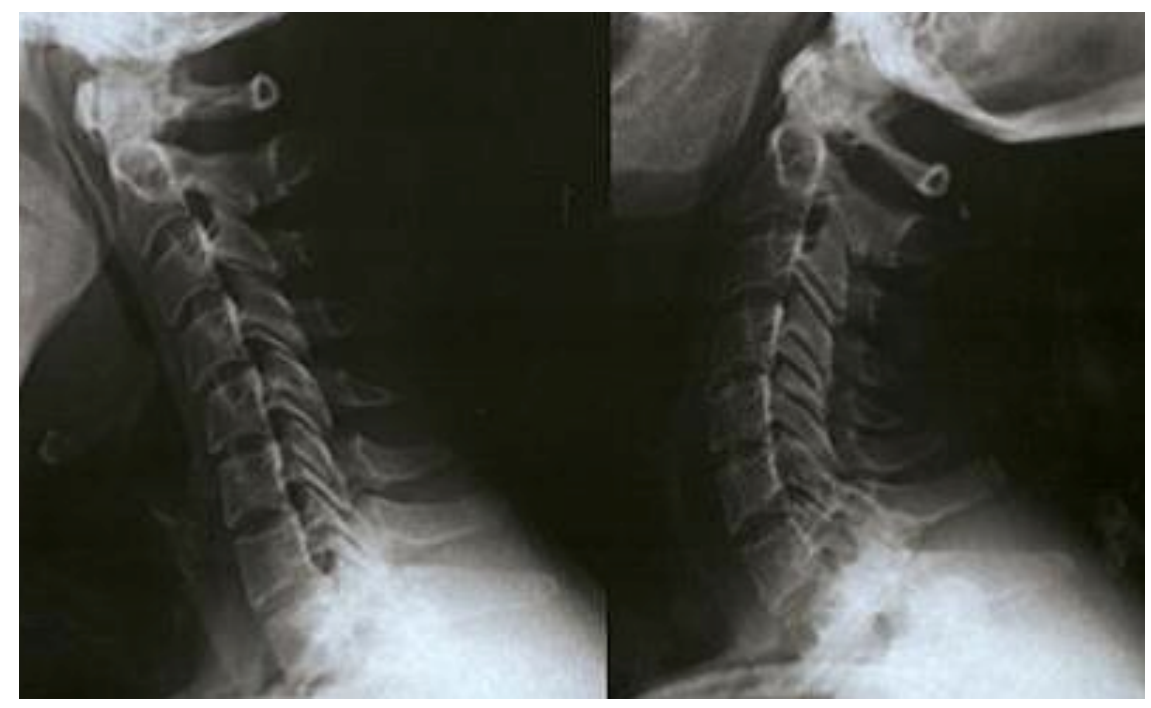

Figura 9. Radiografía lateral de columna cervical, donde se muestran los movimientos de flexión y extensión de la columna cervical.

\subsubsection{Canal espinal}

Es el que se encuentra constituido por todo aquel espacio cilíndrico, irregular, variable en su forma y el diámetro de arriba abajo, limitado por la cara posterior de todos los cuerpos vertebrales junto con sus correspondientes discos y su ligamento vertebral común posterior que va desde el occipital hasta el sacro y que se adhiere adecuadamente a los discos. pero no a los cuerpos vertebrales; limita por detrás y lateralmente, por el llamado arco posterior o elementos posteriores de las vértebras, de arriba hacia abajo y de los ligamentos que los une, el ligamento amarillo (PANJABI et al., 1993; ROHEN et al., 1996; PANJABI, et al., 1997; LUND et al., 1998; GRIEVE, 2005; ROUVIÈRE \& DELMAS, 2005). 


\section{PLANTEAMIENTO DEL TRABAJO Y OBJETIVOS}


La columna vertebral (CV) es una de las estructuras anatómicas fundamentales del organismo, interviene en funciones tan variadas como desplazamientos, sostén de órganos, y protección a la médula espinal. Las enfermedades de la columna vertebral son muy comunes, con una alta incidencia y prevalencia; afectando hasta un $80 \%$ de la población mundial, causando dolor e incapacidad. El dolor a nivel de la columna vertebral o derivado de esta, es generalmente una condición autolimitada. En más del 50\% de los pacientes, los síntomas generalmente se resuelven espontáneamente dentro de cuatro a ocho semanas, pero hay una tasa de recurrencia muy alta, estimada en alrededor del $85 \%$ de los casos. El dolor de espalda ocupa el séptimo lugar entre los principales problemas de salud y sólo precedido por las enfermedades del corazón, diabetes, hipertensión, afecciones relacionadas con el accidente cerebrovascular, y la osteoartritis (KELSEY \& WHITE, 1980; MODIC et al., 1983; STOVER \& FINE, 1987; WEISHAUPT et al., 1998; DEMETRIADES et al., 2000; RUBIN, 2007; BANASZKIEWICZ \& KADER, 2014).

Las patologías que afectan a la $\mathrm{CV}$, representan un importante volumen en la consulta de la especialidad de Neurocirugía. La prescripción de imágenes radiológicas de la $\mathrm{CV}$ es una de las pruebas más solicitadas por parte del neurocirujano, con el objetivo del diagnostico, planificación prequirúrgica y seguimiento (PANJABI et al., 1985; POPE \& PANJABI, 1985; HAMILL et al., 1989; THOMPSON \& FLOYD, 1996; KOCKRO et al., 2000; LAMADE et al., 2000; FERROLI et al., 2013; HAQ et al., 2014; XIANG et al., 2014).

Sin embargo a pesar de la revolución tecnológica y del desarrollado de sistemas informatizados para la planificación prequirúrgica, aún existen retos relacionados con la percepción espacial anatómica, variabilidad anatómica interindividual o distorsión anatómica por el propio proceso patológico. Además en el caso de la cirugía de la columna vertebral en la actualidad la mayoría de las intervenciones quirúrgicas a la columna vertebral, se continúan planificando 
totalmente con la ayuda de las clásicas imágenes en 2D en escala de grises (ANDERSSON, 1999; SHIN et al., 2000; ROSAHL et al., 2002; AUROUER et al., 2009; YAMAUCHI et al., 2010).

La evaluación radiológica de la región del raquis a intervenir precisa definir la lesión o las lesiones tomando en consideración las estructuras blandas y óseas en tres dimensiones, por lo cual, nos encontramos con las limitaciones inherentes en la utilización de información bidimensional (2D), en escala de grises, tal y como se plantea al utilizar las clásicas imágenes radiológicas en 2D, así en ocasiones se limita la precisión del estudio, debido a que la información puede estar incompleta (RATIB \& ROSSET, 2006; SIERRA et al., 2009; ALARAJ et al., 2013).

Al intentar valorar una estructura tridimensional representando esa estructura en imágenes en dos dimensiones, las estructuras se desplazan vertical y horizontalmente de una manera proporcional a la distancia a la que se encuentra la película. Por otro lado es importante destacar que las imágenes en 2D son imágenes estáticas en un plano (LAMADE \& GLOMBITZA, 2000; ROSSET et al., 2004; KIM et al., 2008; JAMALI, 2009)

Puesto que el plan preoperatorio puede disminuir la duración de la intervención, permitir establecer la técnica quirúrgica a seguir, así como las posibles incidencias relacionadas al paciente o a la intervención, siendo además una guía fidedigna para determinar o pronosticar el resultado final de la cirugía; sin embargo este procedimiento puede ser realizado de manera imprecisa y poco efectiva, si no se emplean las herramientas adecuadas. Por esta razón, se han buscado alternativas, que eleven tanto la calidad como la eficacia a la hora de interpretar la imagen para planificar una intervención (APUZZO, \& MICHAEL, 2003; BENEDETTI et al., 2003; WANG et al., 2005; LEARDINI et al., 2006; SPICER et al., 2008; YAMAUCHI et al., 2010; HOARAU et al., 2014). 
Es necesario que se implementen sistemas de planificación asequibles que faciliten el análisis tridimensional del raquis. Con las nuevas tecnologías de visualización y tratamiento de imágenes basadas en la utilización del ordenador, actualmente es posible obtener información espacial que sea plasmada en representaciones graficas tridimensionales (3D) de la columna vertebral, sin necesidad de otras técnicas invasivas, ni costosos equipos, ni la necesidad de seguir procedimientos complejos de adquisición e interpretación de los datos (REINER et al., 2003; FERROLI et al., 2013; HOARAU et al., 2014).

Por otro lado los equipos radiológicos de nueva generación permiten grabar la información en medios extraíbles (discos compactos, tarjetas de memoria) en formato DICOM, con lo cual es posible que el cirujano obtenga toda la información necesaria a la hora de planificar una intervención quirúrgica (NAGY, 2007; SIERRA et al., 2009; RATIB, et al., 2011).

Así con los programas y aplicaciones informáticas de libre distribución o de fácil acceso, se puede obtener de manera personalizada a la anatomía individual de cada paciente, un modelo en tres dimensiones o imagen 3D, siendo esta imagen una forma simple de realidad virtual, la cual puede ser explorada de forma interactiva con un ordenador personal. Generalmente mediante la manipulación del teclado o el ratón, es posible mover el contenido de la imagen en alguna dirección.

De esta forma, nuestro trabajo se centra en el desarrollo de modelos tridimensionales de la columna utilizando las imágenes DICOM del paciente, obtenidas a partir de equipos de resonancia magnética (RM) y tomografía computarizada (TC). Estos modelos 3D además de elevar la calidad y la eficacia a la hora de interpretar la imagen, pueden ser útiles al neurocirujano en la tarea de la planificación prequirúrgica, para los diferentes abordajes a la columna vertebral. 
Teniendo en cuenta lo anteriormente expuesto, los objetivos marcados en este trabajo son los siguientes:

\section{Objetivo principal}

Desarrollar modelos 3D de las estructuras que forman la columna vertebral, a partir de datos de resonancia magnética y tomografía computarizada, con el objetivo principal de servir de ayuda a la planificación preoperatoria, mejorando la visualización del objetivo quirúrgico en los estudios radiológicos de una manera más precisa e intuitiva, aumentando la seguridad tanto del paciente como del cirujano.

\section{Objetivos específicos}

1. Favorecer la orientación espacial sobre la anatomía del raquis, en la práctica neuroquirúrgica.

2. Ayudar a disminuir el margen de error, mediante una mejora en la planificación preoperatoria.

3. Reducir la dependencia del fluoroscopio en las intervenciones a la columna vertebral, al identificar el objetivo quirúrgico de manera más precisa.

4. Apoyar al diagnóstico mediante imágenes de alta calidad en 3D, embebidas en secciones de RM y TC.

5. Contribuir a la enseñanza y/o aprendizaje de la anatomía y técnicas quirúrgicas, al permitir observar y estudiar repetidamente el modelo $3 \mathrm{D}$ y las imágenes del paciente. 
III. MATERIAL Y MÉTODOS 
Todo el estudio se realizó conforme a la Declaración de Helsinki en su versión modificada de la $64^{\mathrm{a}}$ Asamblea General, en Brasil, octubre 2013, que regula la investigación médica con normas éticas que sirven para promover, proteger la vida, la salud, la dignidad, la integridad, el derecho a la autodeterminación, la intimidad y la confidencialidad de la información personal de las personas que participan en la investigación.

\section{1. MUESTRA}

La selección de los casos y la recogida de datos se efectuaron, tras una revisión de la base de datos del Servicio de Neurocirugía, del Complejo Asistencial de Salamanca, durante el periodo comprendido desde febrero 2013 hasta abril de 2014; se recogió una muestra inicial de 200 estudios de TC y 160 estudios de RM. Se incluyeron todos los casos, de los cuales seleccionamos los estudios radiológicos sin alteraciones anatómicas significativas.

Durante el transcurso de la realización de nuestro trabajo de Tesis Doctoral, se adquirieron imágenes para correlacionar con los modelos 3D tanto radiológicas (imágenes de resonancia magnética, tomografía computarizada y radiografías simples), como fotografías intraquirófano de los diferentes abordajes neuroquirúrgicos a la CV practicados en el Servicio de Neurocirugía durante el periodo comprendido entre enero del 2013 hasta febrero del 2014, para obtener 350 intervenciones a la $\mathrm{CV}$ de las cuales obtuvimos imágenes de los abordajes más representativos. Además se obtuvieron imágenes de los elementos óseos de la columna vertebral existentes en el Departamento de Anatomía Humana de la Universidad de Salamanca. Los parámetros que se tomaron en cuenta para la selección de las imágenes adquiridas consistieron en una correcta visualización de las estructuras a estudiar, tanto óseas como de partes blandas. 


\subsection{MATERIAL ICONOGRÁFICO}

El material iconográfico ha incluido diferentes tipos de objetos gráficos:

-- Imágenes óseas y de partes blandas de la columna vertebral y estructuras adyacentes generadas con tomografía computarizada multidetector (TC) e imágenes de resonancia magnética $(\mathrm{RM})$;

-- Imágenes intraoperatorias de los diferentes abordajes a la columna vertebral;

.- Fotografías de los elementos óseos de la columna vertebral del Departamento de Anatomía Humana de la Universidad de Salamanca, utilizados como referencias anatómicas para la reconstrucción de los modelos 3D;

-- Reconstrucción de modelos tridimensionales (3D) de las diferentes vértebras y regiones que constituyen la columna vertebral, desde secciones de RM y TC;

A continuación describiremos cómo se adquirió el material gráfico y documental, para su posterior tratamiento y reconstrucción en modelos tridimensionales (3D).

\subsubsection{DESCRIPCIÓN DE LAS PRINCIPALES FASES EMPLEADAS} PARA LA ADQUISICIÓN DEL MATERIAL ICONOGRÁFICO

\subsubsection{Adquisición de las imágenes de TC}

El tomógrafo utilizado para la realización de nuestro estudio fue un Aquilion TSX 101a de 32 detectores (Fig. 10) del Hospital Universitario de Salamanca. Siguiendo el siguiente protocolo según cada región:

- Columna cervical, se realizó un escanograma lateral desde el agujero magno hasta D1, con el plano de referencia cráneo-caudal, y un grosor o intervalo de corte de $1 \mathrm{~mm}$ para $\mathrm{C} 1-\mathrm{C} 2$, y de $3 \mathrm{~mm}$ para $\mathrm{C} 3, \mathrm{C} 4, \mathrm{C} 5, \mathrm{C} 6$ y C7, seguidamente se adquirieron las imágenes helicoidales con reconstrucciones volumétricas del área de interés. 
- Columna dorsal, se adquirió un escanograma lateral desde D1 hasta L1, con un grosor de corte de $3 \mathrm{~mm}$.

- Columna lumbo-sacra, se adquirió un escanograma desde L1 hasta S1, con plano de reconstrucción axial, coronal y sagital y un grosor de corte de $3 \mathrm{~mm}$.

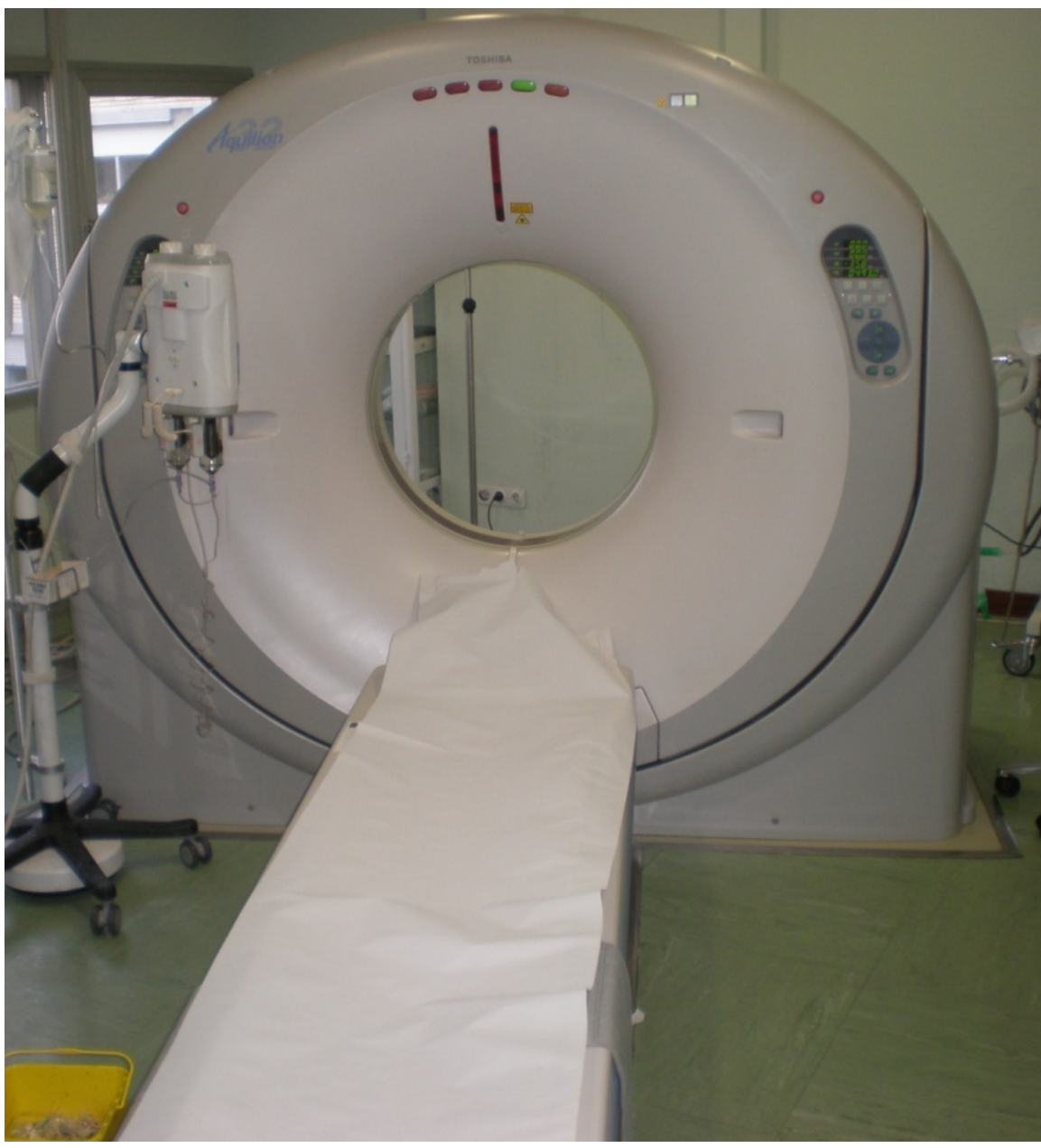

Figura 10. Tomógrafo, modelo Aquilion TSX 101a de 32 detectores de la casa comercial Toshiba Medical Systems del Hospital Universitario de Salamanca, utilizado para la adquisición de las diferentes imágenes anatómicas en formato DICOM. 


\subsubsection{Adquisición de las imágenes de RM}

Los estudios de resonancia magnética, se realizaron con un equipo marca General Electric, Signa Horizon de 1,5 Teslas (Fig. 11) con los protocolos siguientes: para el protocolo estándar de columna realizamos una secuencia sagital potenciada en T1 Spin Eco (SE), una secuencia sagital potenciada en T2 Spin Eco (TSE), T2 axial Fast Spin Eco (FSE), axial T2. El Eco Spin (SE) continua siendo la secuencia de pulso estándar. El SE T1 proporciona alto contraste entre la grasa epidural (hiperintensa) y la relativa hipointensidad del saco tecal adyacente y el disco intervertebral. Las Secuencias SE T2 muestran una alta relación Señal-Ruido y Contraste-Ruido.

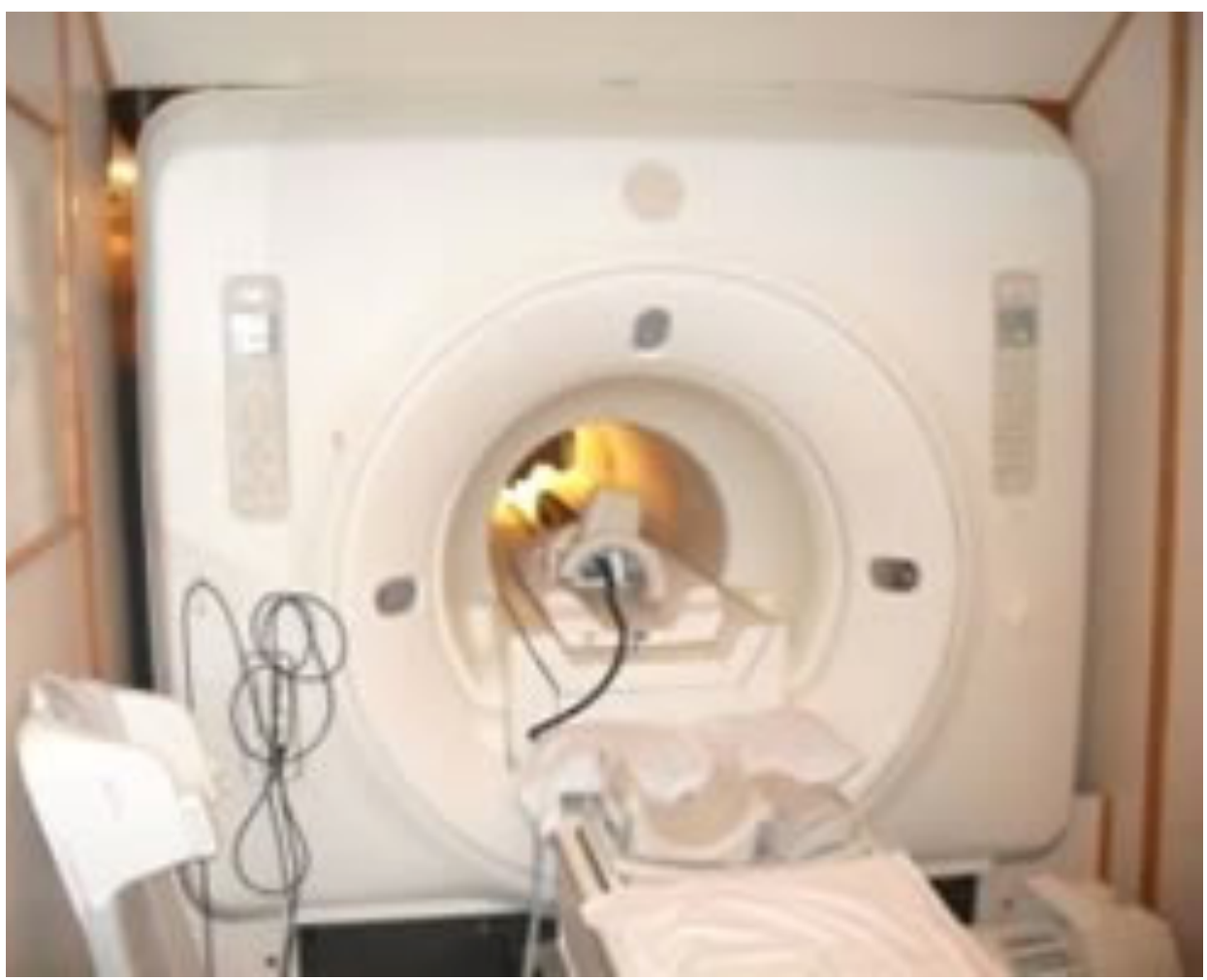

Figura 11. Equipo de resonancia (General Electric, Signa Horizon de 1,5 Teslas) del Hospital Universitario de Salamanca. 


\subsubsection{Imágenes intraquirófano de los abordajes más comunes}

En este apartado del trabajo el objetivo buscado es correlacionar los modelos 3D con los diferentes abordajes a la columna vertebral mediante imágenes intraquirófano. Excede al objetivo de esta Tesis Doctoral la descripción exhaustiva de los numerosos abordajes al conjunto del raquis, por lo que enumeraremos a continuación algunas de las técnicas más empleadas en nuestro Servicio de Neurocirugía, durante el tiempo de recogida de datos. Realizaremos breves descripciones de los aspectos más importantes, centrando la atención sobre los puntos que juzgamos de fundamental interés para el tema que nos ocupa. Las fotografías de los abordajes quirúrgicos se obtuvieron con una cámara Canon 650D (Canon Inc., Tokio, Japón) (figura 12).

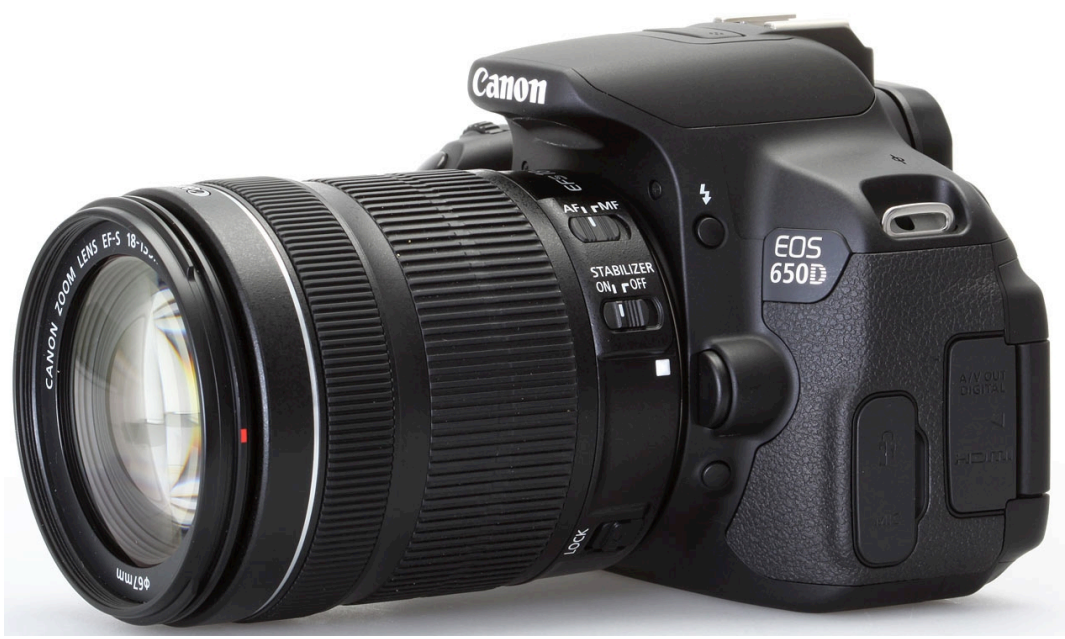

Figura 12. Cámara canon 650D (Canon Inc.) Equipo fotográfico utilizado para la adquisición de las fotografías de nuestra Tesis Doctoral. 


\subsection{Región cervical}

En esta zona anatómica, destacamos abordajes por vía anterior, donde los más representativos y más utilizados en la practica clínica en el Servicio de Neurocirugía se corresponden a los abordajes a la columna cervical subaxial para la descompresión anterior mediante la discectomía y fusión con artrodesis intersomática (figs. 13 y 14). Así la técnica habitualmente usada por el Servicio de Neurocirugía, es la descrita por CLOWARD (1958) y posteriormente por los doctores Smith y Robinson (1958), y avalada por muchas publicaciones que confirman su utilidad (CLOWARD, 1958; SMITH \& ROBINSON, 1958; BAILEY \& BADGLEY, 1960; FANG \& ONG, 1962; SCOVILLE，1966; HUKUDA et al, 1985; CASPAR et al., 1989; BÖHLER \& GAUDERNAK, 1990; HERKOWITZ et al., 1990; AEBI et al., 1991; WANG et al., 2000)

Los criterios quirúrgicos para seleccionar el paciente que será sometido a este procedimiento, además del dolor incluyen una adecuada correlación entre los hallazgos clínicos y radiológicos (CLOWARD, 1958; SMITH \& ROBINSON, 1958; CLEMENTS \& O'LEARY, 1990; CASPAR et al., 1998; THORELL et al., 1998; LANZINO et al., 1999; HELLER et al., 2009). Este abordaje permite una amplia descompresión del canal medular y radicular (CLOWARD, 1958; SMITH \& ROBINSON, 1958; HUKUDA et al, 1985; CASPAR et al., 1989; BÖHLER \& GAUDERNAK, 1990; HERKOWITZ et al., 1990; AEBI et al., 1991; WANG et al., 2000). 


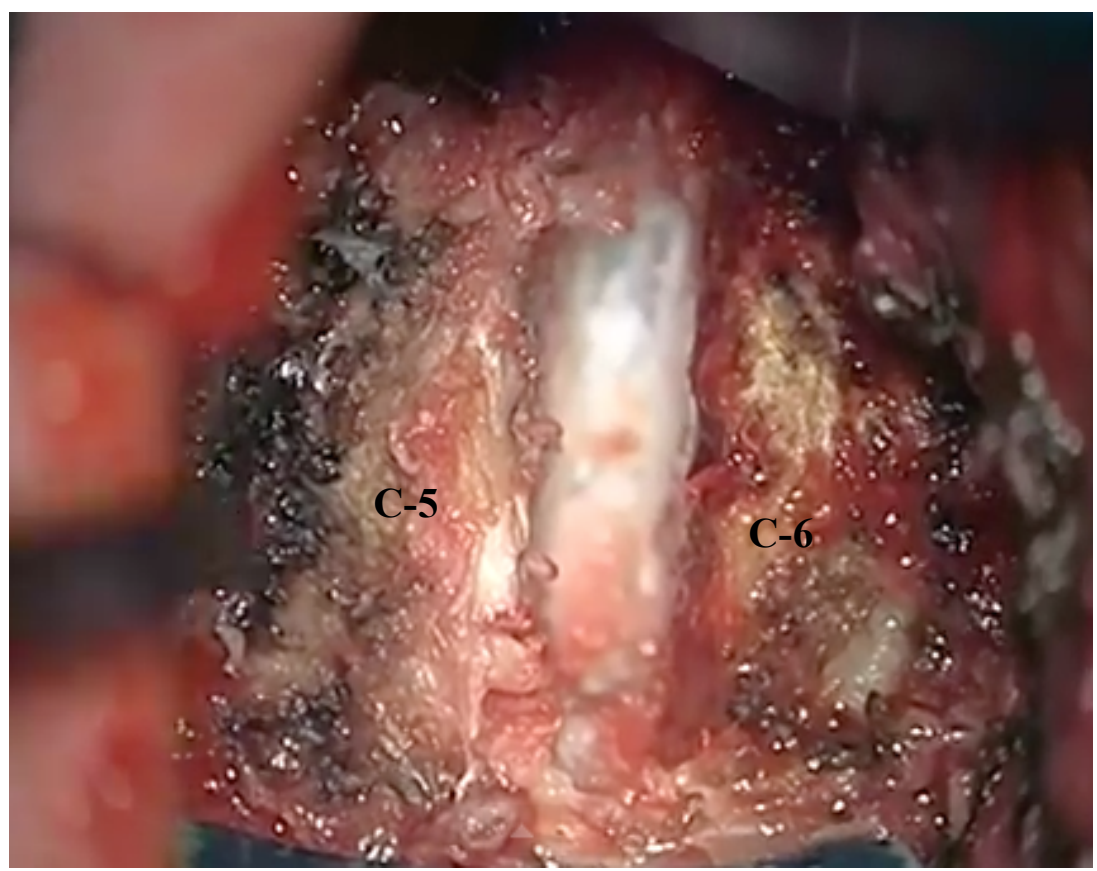

Figura 13. Abordaje cervical anterior. Se observa el espacio intervertebral entre la quinta (C-5) y la sexta (C-6) vértebra cervical, con resto de material discal al fondo tras incidir el disco y extirparlo mediante pinzas de disco y fresado.

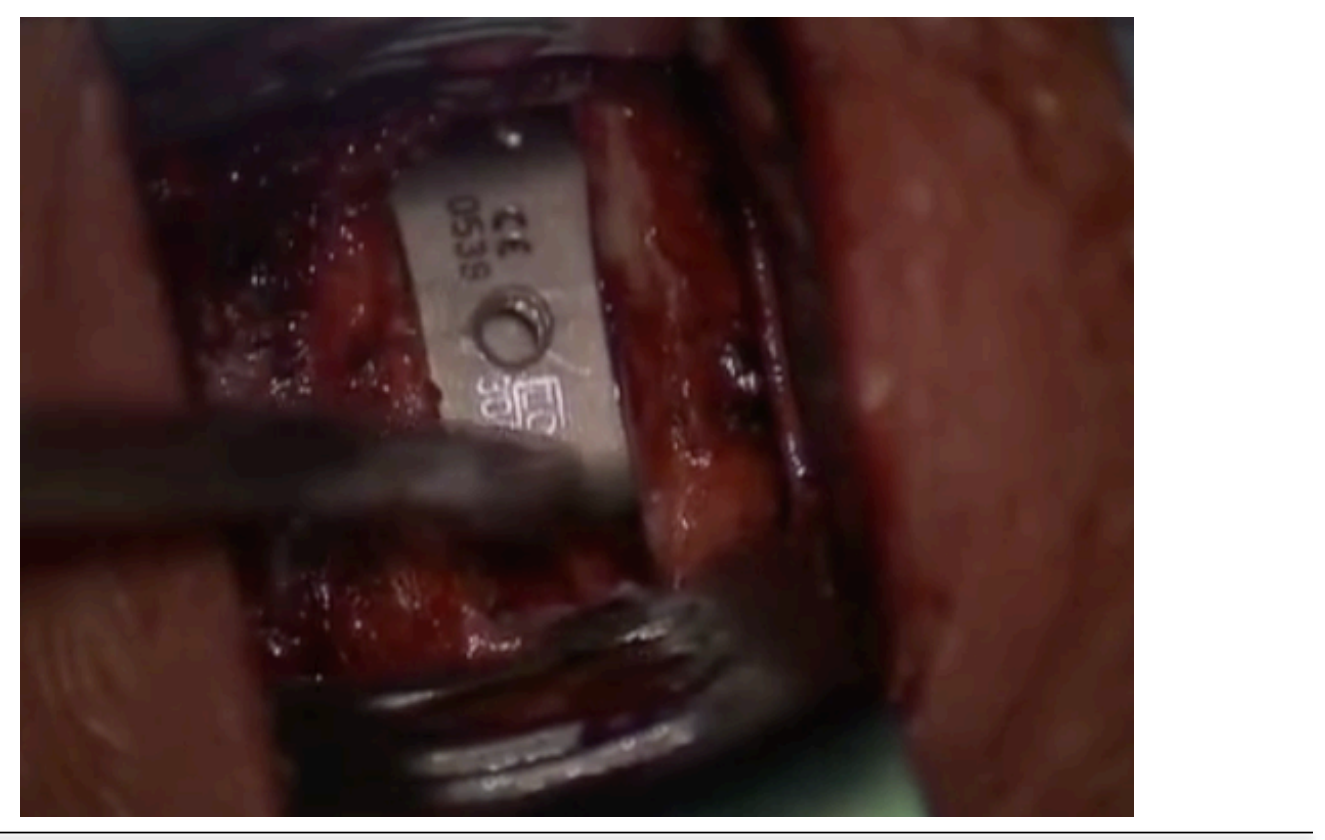

Figura 14. Imagen obtenida intraquirófano, que muestra un abordaje a la columna cervical por vía anterior, donde se observa exposición del nivel C4-C5 con una caja intersomática para la artrodesis. 
En algunos casos, es necesario realizar una o varias corpectomías o un abordaje multinivel para conseguir la descompresión neural, en estos casos se realiza un abordaje con una mayor exposición (figura 15) (ZDEBLICK \& BOHLMAN, 1989; KOJIMA et al., 1989; EMERY et al., 1994; SWANK et al., 1997; FESSLER et al., 1998; MEDOW et al., 2006).

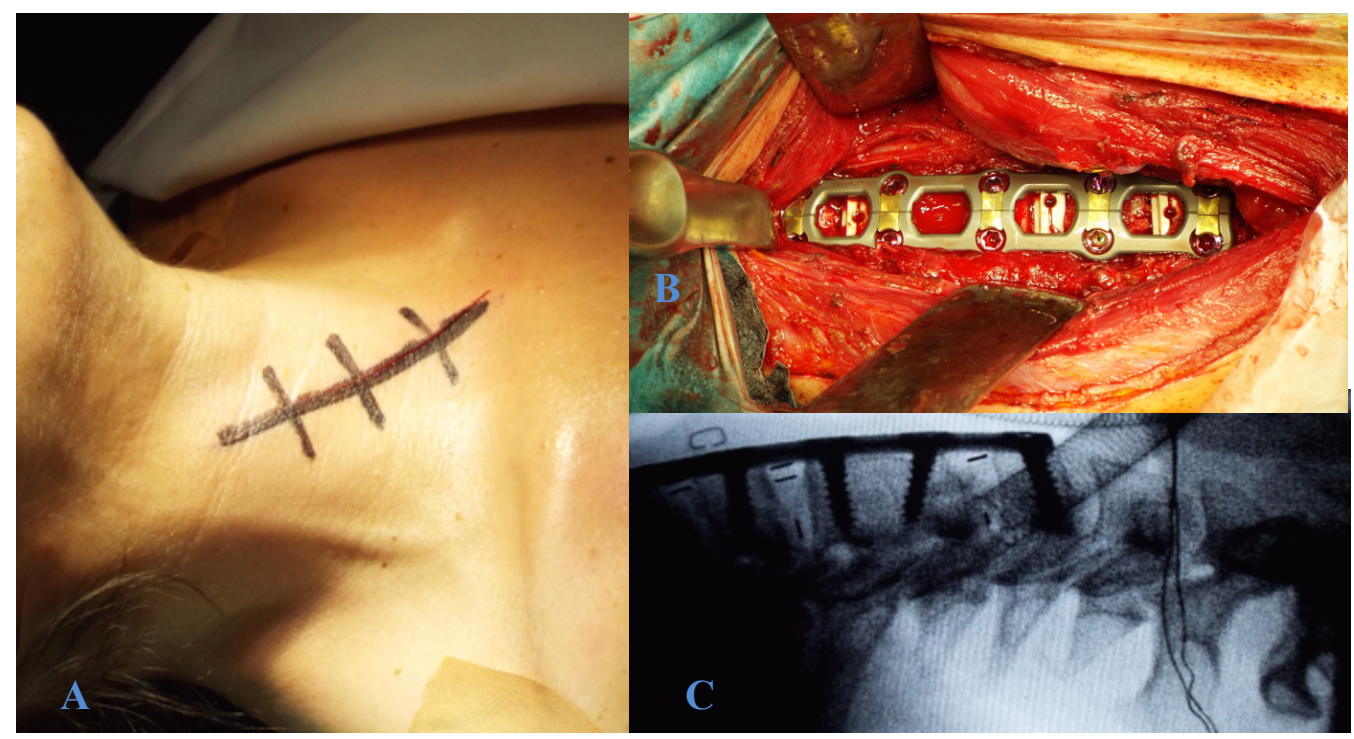

Figura 15. A, B y C. Abordaje cervical anterior multinivel, mediante incisión longitudinal. A: Marca longitudinal de referencia sobre la piel. B: tráquea y esófago rechazados hacia medial y el paquete vásculo-nervioso hacia lateral. Tras realizar las discectomía se procedió a la colocación de tres injertos (cajas) rellenos de sustituto óseo y placa de titanio para asegurar la estabilidad. C: Radiografía de control, donde se observa la correcta colocación de la placa anterior y de los injertos.

\subsection{Laminectomia, laminoplastia y unión cráneo-cervical}

Con frecuencia se practican abordajes por vía posterior, fundamentalmente la laminectomía descompresiva con o sin instrumentación (figura 16). Los pacientes apropiados para ésta intervención son aquellos con signos y síntomas de mielopatía cervical con evidencia radiológica de compresión medular degenerativa multinivel o la osificación del ligamento longitudinal posterior (YASUOKA et al., 1982; MIKAWA et al., 1987; HERKOWITZ \& HARRY N, 1988; MILLER et al., 1996; FESSLER et al., 1998). 


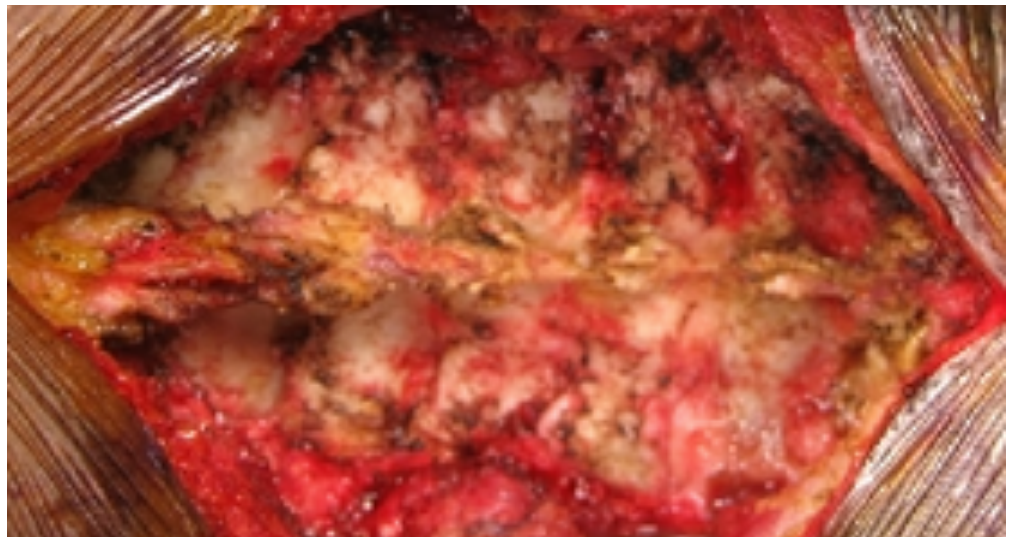

Figura 16. Abordaje cervical posterior, se observan los elementos posteriores de la columna cervical de los niveles $\mathrm{C} 2-\mathrm{C} 7$.

La laminoplastia expansiva, es una técnica alternativa a la laminectomía (MATSUNAGA, 1999). Su finalidad, es aumentar el área del canal cervical y su reconstrucción osteo-plástica, para evitar la cifosis postlaminectomía y la fibrosis postoperatoria (HIRABAYASHI, 1983; KAWAI, 1988; HIRABAYASHI et al., 1999). La laminoplastia expansiva de puerta abierta, se emplea en nuestro Servicio para tratar la calcificación del ligamento longitudinal común posterior con mielopatía y en las estenosis de canal cervical multinivel con mielopatía. La técnica quirúrgica es idéntica a la laminectomía en cuanto a la exposición de los elementos posteriores (ver figura 16), la diferencia entre ambas, es que la apertura de las láminas se realiza mediante fresado unilateral en los niveles afectados de la unión lamino-articular y disección del ligamento amarillo, mientras que en el lado opuesto se realizará un fresado superficial para adelgazar el hueso y permitir la fractura en tallo verde con apertura del canal en forma de bisagra. La interposición de miniplacas de titanio mantendrá el canal abierto (figuras 17 y 18) (HERKOWITZ, 1988; KOHNO et al., 1997; HIRABAYASHI et al., 1999; MATSUNAGA et al., 1999; HELLER et al., 2001; WADA et al., 2001; HOUTEN \& COOPER, 2003; RATLIFF \& COOPER, 2003; CHIBA et al., 2006 NURBOJA et al., 2012). 


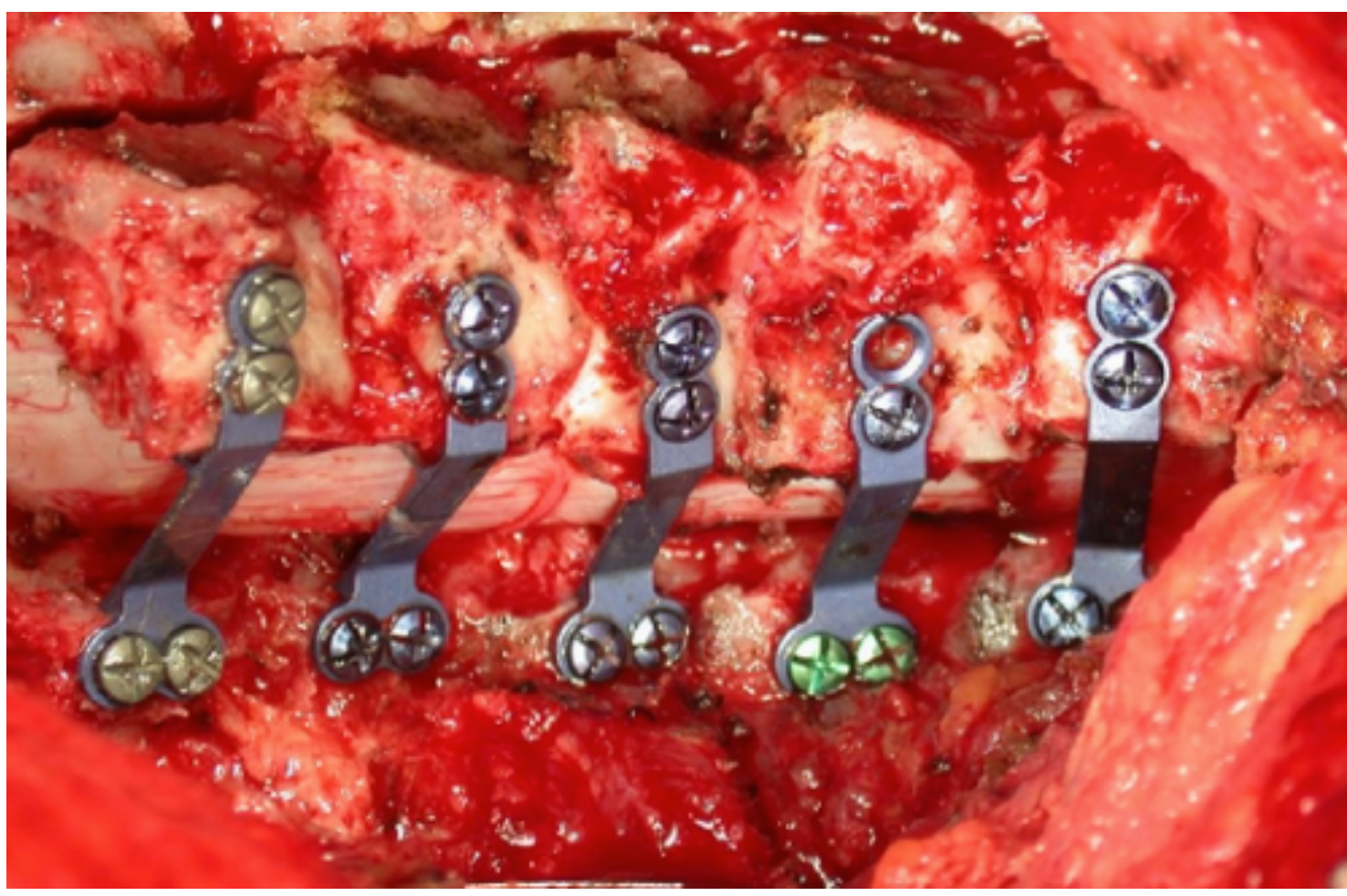

Figura 17. Laminoplastia expansiva de puerta abierta $\mathrm{C} 3, \mathrm{C} 4, \mathrm{C} 5, \mathrm{C} 6$ y $\mathrm{C} 7$ en un paciente con estenosis de canal cervical degenerativa multinivel.

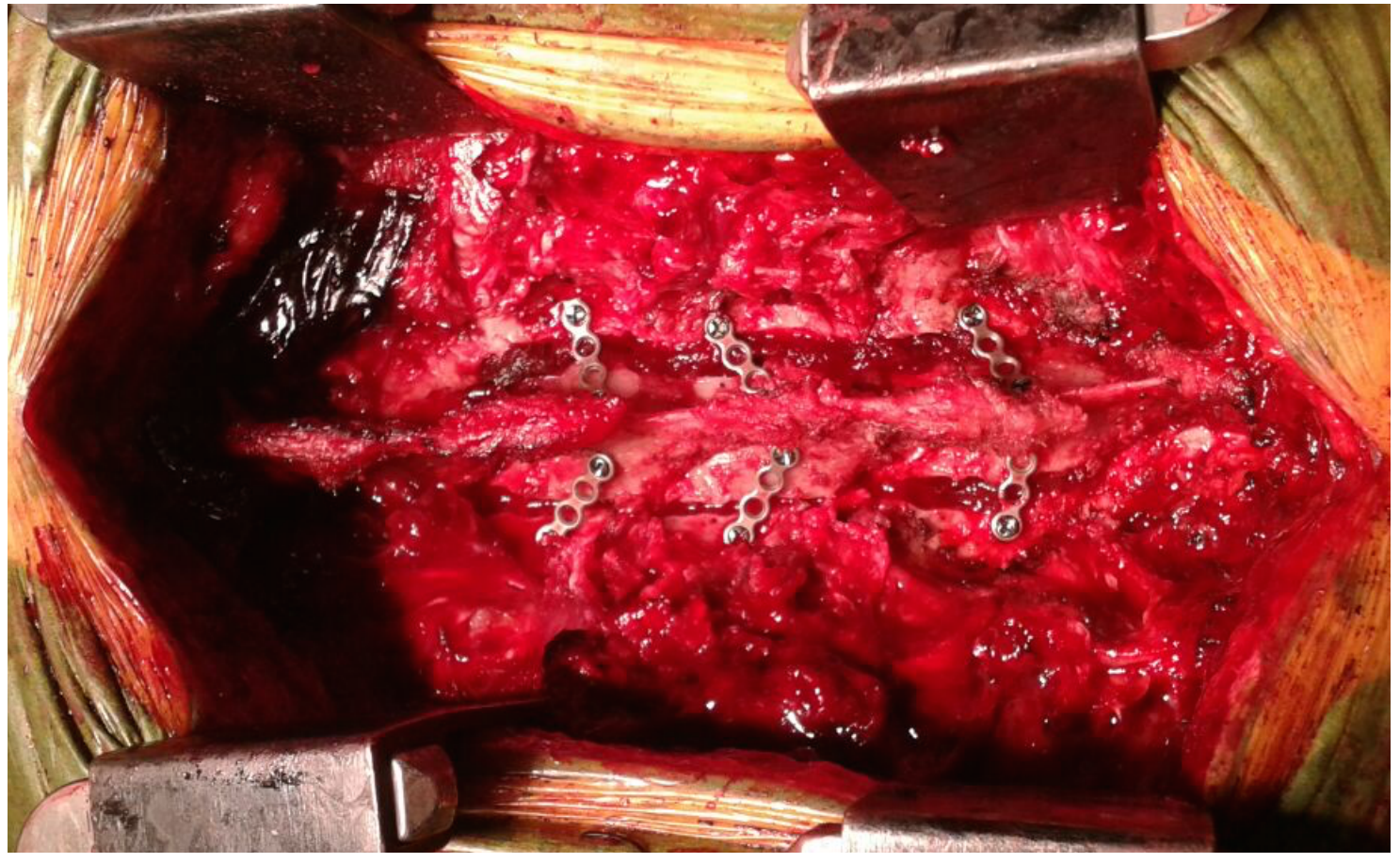

Figura 18. Reparación osteo-plástica dorsal. Este caso es un abordaje posterior a la columna dorsal, practicándose laminotomía D5, D6 y D7 con el objetivo de exéresis de un Schwannoma intradural. 
Otra patología neuroquirúrgica frecuente en nuestro Servicio, es la inestabilidad de la unión cráneo-cervical $(\mathrm{C} 0$, atlas y axis), que se caracteriza por una hipermovilidad más allá de los límites fisiológicos de una vértebra sobre la otra al menos en uno de los tres planos de los movimientos de la columna (PANJABI, 1991): el eje X (flexión-extensión), el eje Y (rotación) y el eje Z (movimiento lateral). La causa más común de inestabilidad de la columna vertebral superior (atlas, axis y C3), es de tipo traumático aunque también existen otras causas de tipo degenerativas, congénitas, metabólicas y neoplásicas (PANJABI et al., 1991; PAPADOPOULOS et al., 1991; SHIRASAKI et al., 1991; DICKMAN \& SONNTAG, 1998; FESSLER et al., 1998; HAID et al., 2001).

Así el objetivo quirúrgico va dirigido a restablecer la estabilidad de la unión cráneo-cervical (PAPADOPOULOS, 1991), en la figura 19, se muestra un abordaje a la unión cráneo-cervical por vía posterior. Los procedimientos más demandados en la practica neuroquirúrgica para las patologías de la unión cráneo-cervical incluyendo los abordajes por vía posterior, son: la fijación occipito-cervical, instrumentación con tornillo transarticular de C-1-C-2 (figura 20), la instrumentación anterior con tornillos de la odontoides (figura 21), fijación de las masas laterales de $\mathrm{C}$-1 y otros procedimientos actualmente menos utilizados como es el caso del abordaje transoral (ANDERSON \& D'ALONZO, 1974; APUZZO et al., 1978; ANDERSON \& MONTESANO, 1978; BÖHLER, 1982; BORNE et al., 1984; PANJABI et al., 1991; PAPADOPOULOS et al., 1991; SHIRASAKI et al., 1991; ADAMS, 1992; DICKMAN \& SONNTAG, 1998; FESSLER et al., 1998; HAID et al., 2001). 


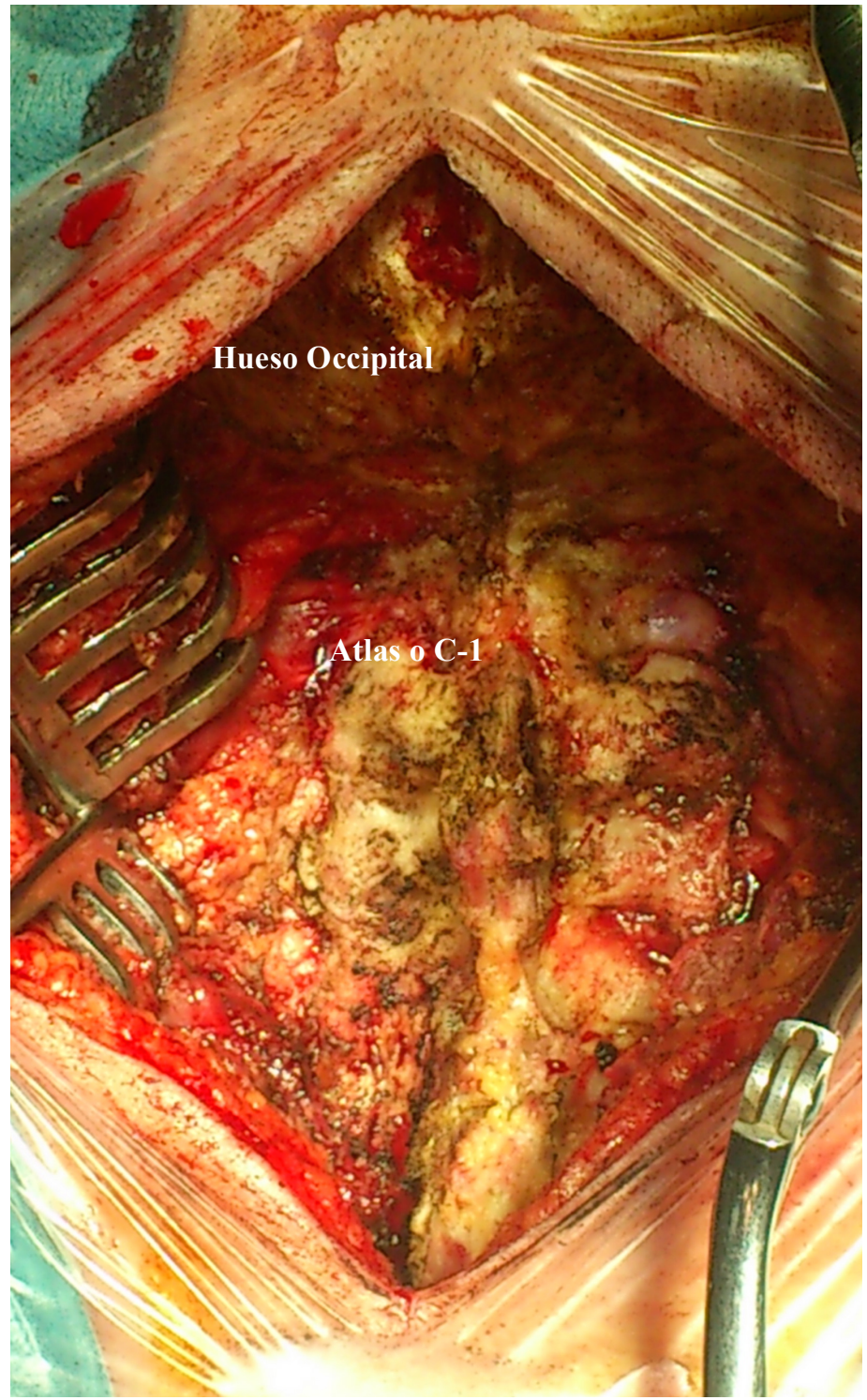

Figura 19. Abordaje a la unión cráneo-cervical por vía posterior. Este abordaje permite un acceso rápido y seguro a los elementos posteriores de la unión cráneo-cervical. Es necesario realizar una incisión recta sobre la línea media, y siguiendo el plano subcutáneo hasta el rafe medio o ligamento nucal. A continuación disección de la musculatura subperiosticamente, dependiendo de la exposición que se precise, llevando la exposición tan lateral como sea necesario para exponer hueso occipital, las láminas y resto de elementos posteriores. 


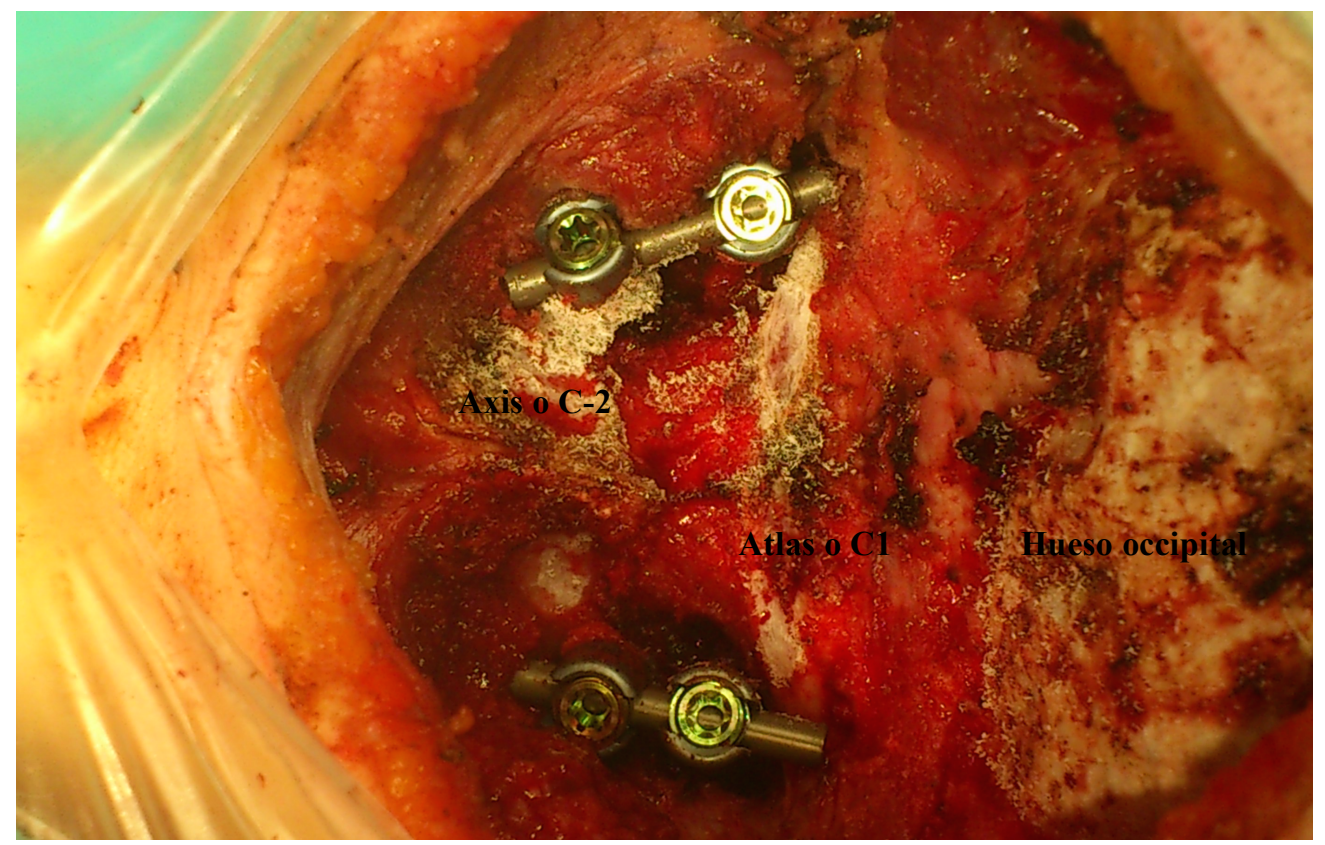

Figura 20. A y B. Fijación posterior de $\mathrm{C} 1-\mathrm{C} 2$ con tornillos y barras de titanio, en un paciente con inestabilidad C1-C2.

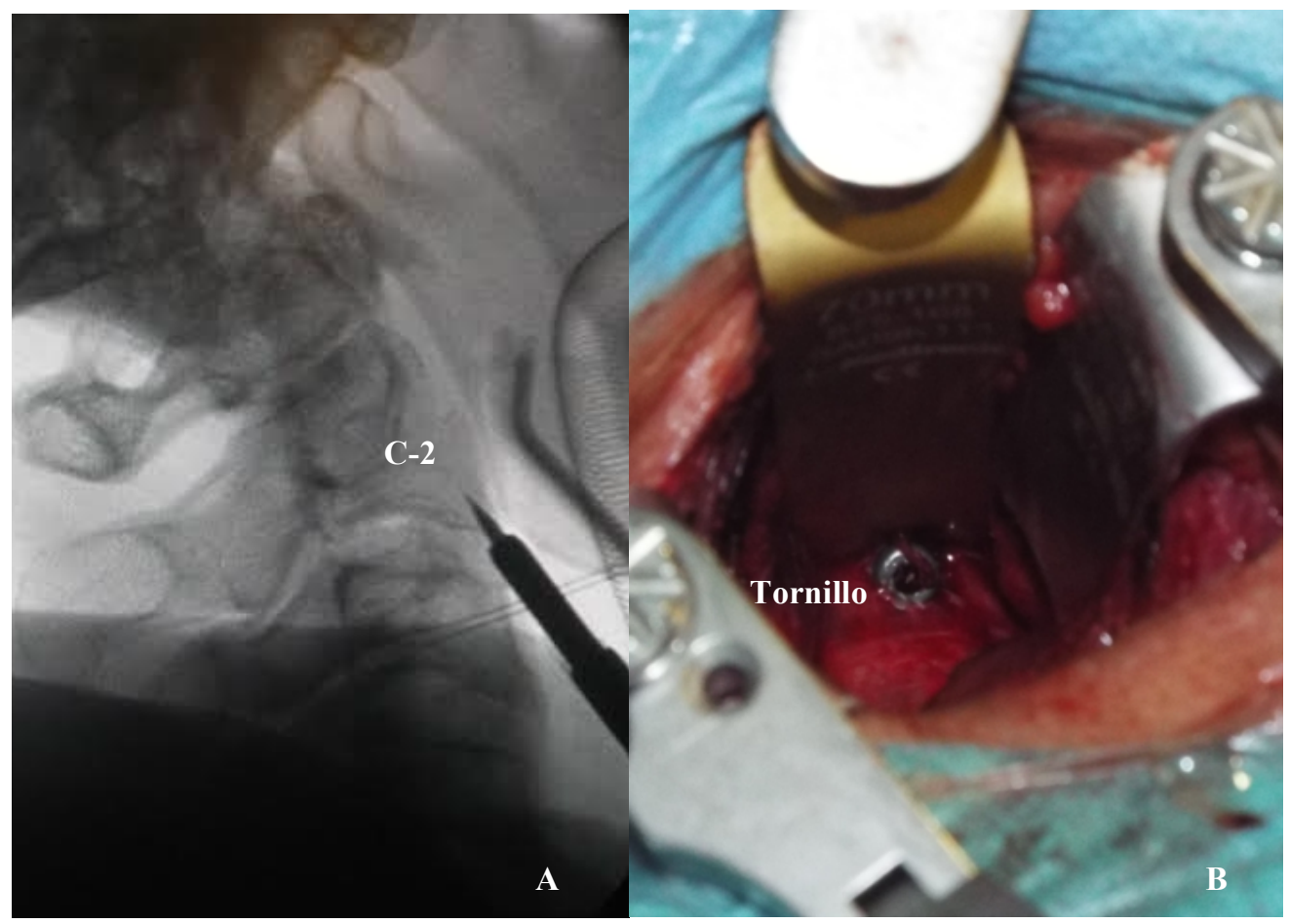

Figura 21. A y B. Atornillado anterior de la odontoides. A: imagen del fluoroscopio, muestra preparación del borde de C2 para facilitar la instrumentación. B: abordaje cervical anterior, muestra el tornillo sobre el cuerpo de $\mathrm{C} 2$. 
Otro procedimiento menos utilizado es la foraminotomía cervical posterior descrito por HENDERSON (1983). La foraminotomía cervical posterior es apropiada para pacientes con radiculopatía cervical causada por estenosis foraminal o hernia discal lateral. (HENDERSON et al., 1983; ZDEBLICK et al., 1992; RUETTEN et al, 2008).

\subsection{Abordajes a la columna dorsal y lumbo-sacra}

Entre los abordajes a la columna dorsal y lumbo-sacra, destaca el abordaje posterior, debido a que proporciona acceso a los elementos posteriores, al canal medular, la cauda equina, y a los discos intervertebrales para la descompresión radicular; en las figuras 22-27 se muestran diferentes exposiciones a la columna dorsal y lumbo-sacra (DICKMAN \& FESSLER, 1992; FERNYHOUGH et al., 1992; GÜVEN et al., 1994; AKEYSON \& MCCUTCHEON, 1996; WEBER et al., 1997; HUMPHREYS et al., 2001; KAWAHARA et al., 2001; RUF \& HARMS, 2002; SHIMODE et al., 2002; ISSACS et al., 2006; SPEARS et al., 2006).

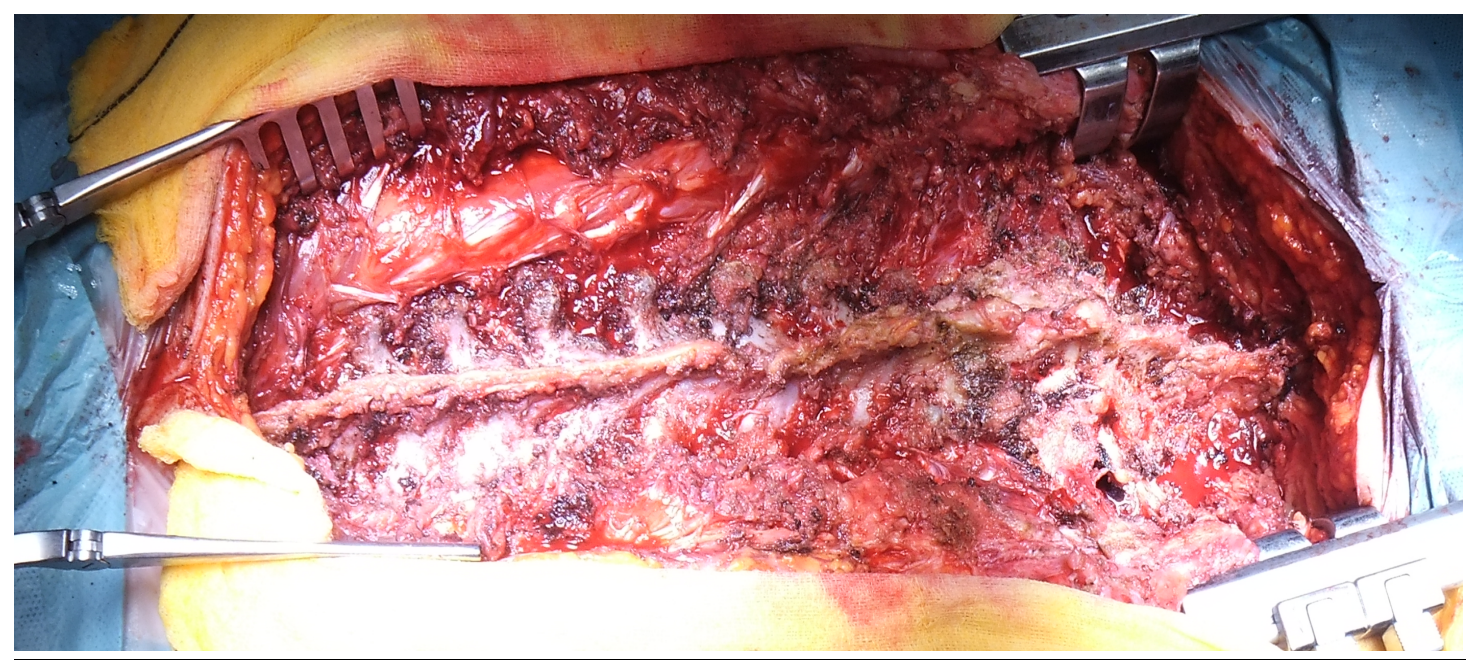

Figura 22. Se muestra un abordaje a la columna dorso-lumbar por vía posterior, donde se puede apreciar los principales puntos anatómicos de los elementos posteriores de la columna vertebral. 


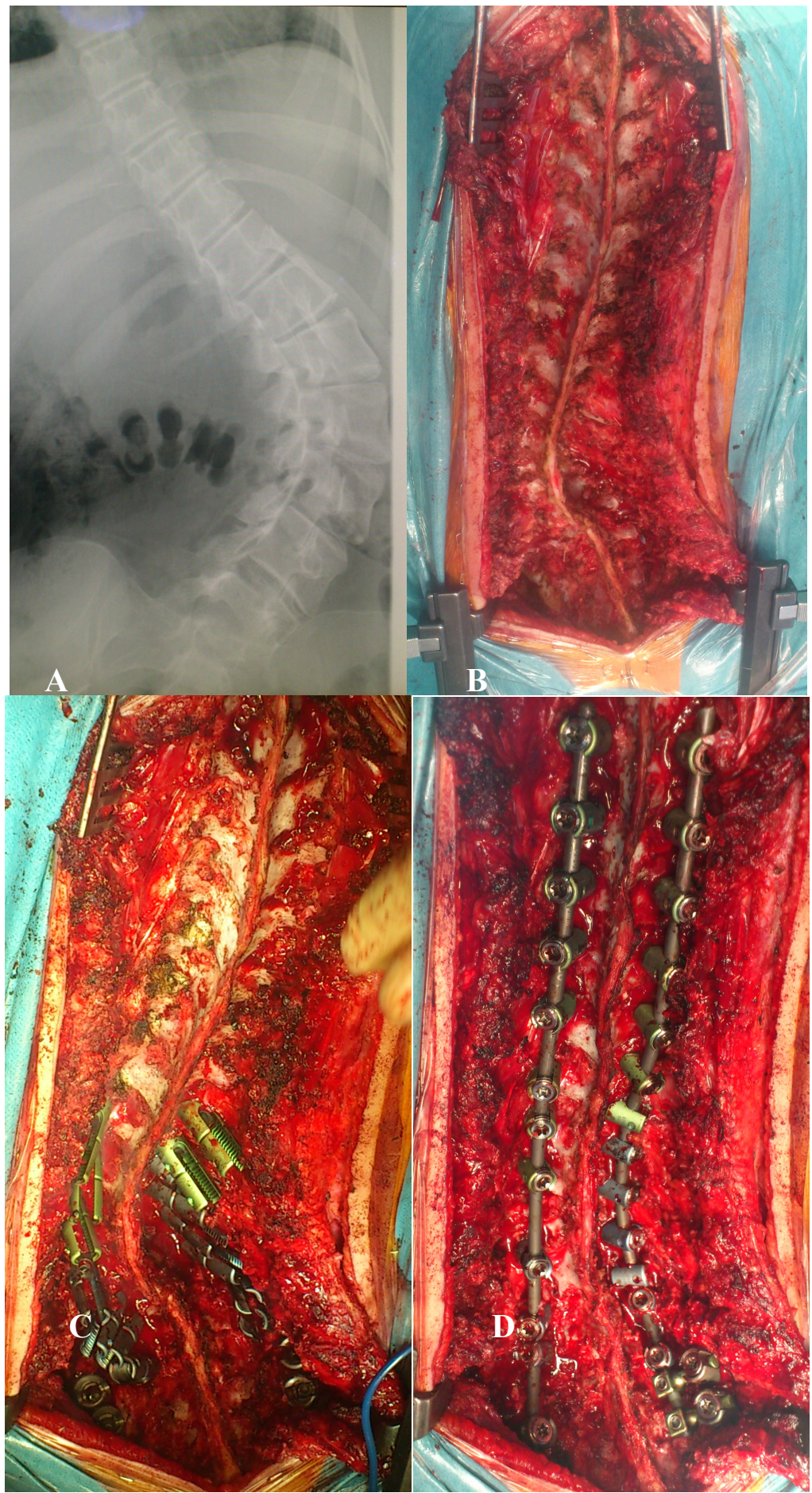

Figura 23. A, B, C y D. Abordaje amplio a la columna dorsal y lumbo-sacra por vía posterior, para la corrección de una escoliosis del adolescente. A: radiografía simple que muestra la escoliosis. B: Abordaje posterior amplio D3-S1. C: colocación de tornillos transpediculares. D: corrección de la deformidad mediante colocación de barras y tornillos. 


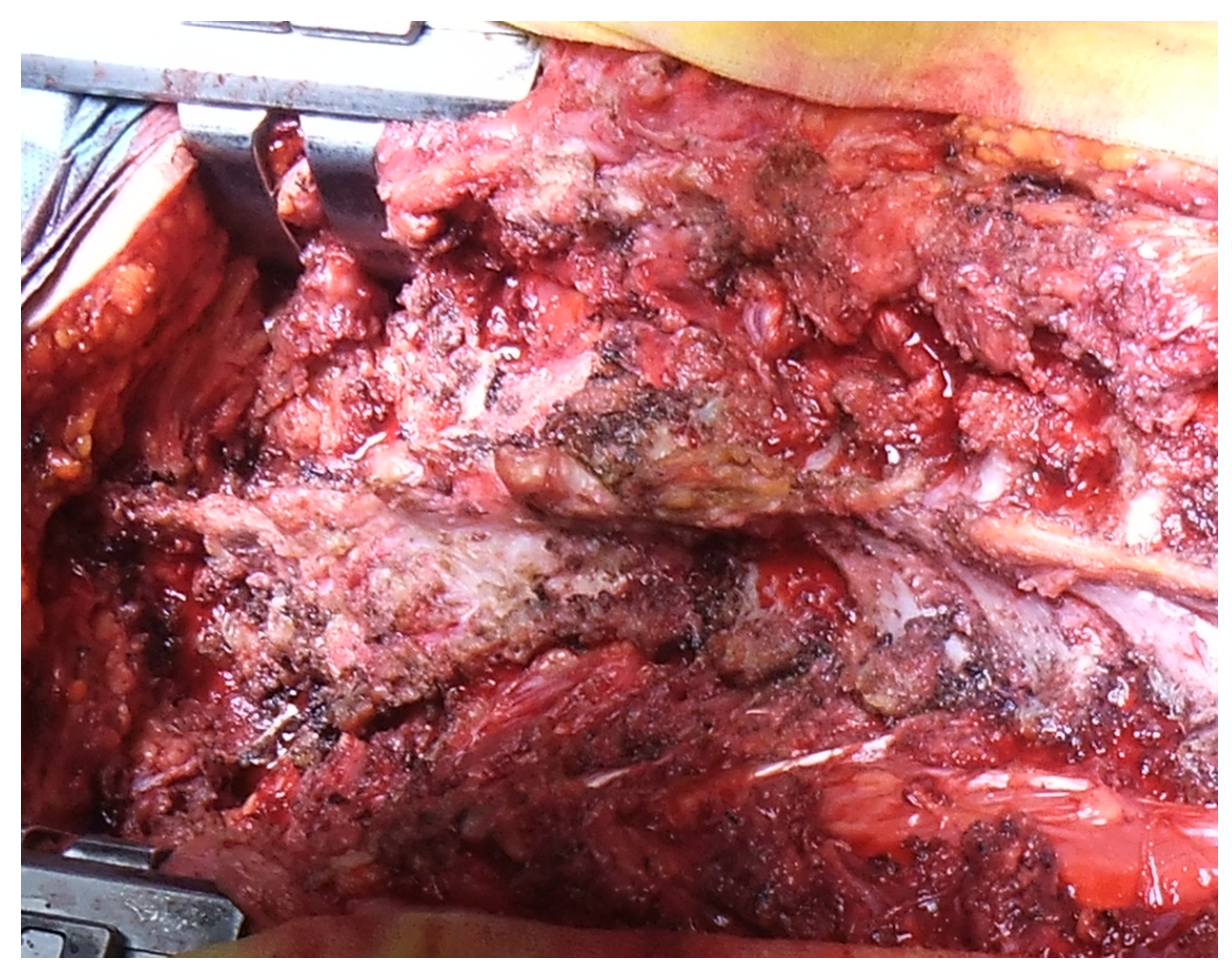

Figura 24. Abordaje dorso-lumbar posterior (charnela dorso-lumbar), en un paciente con afectación de la tercera vértebra lumbar por un carcinoma de Ewing.

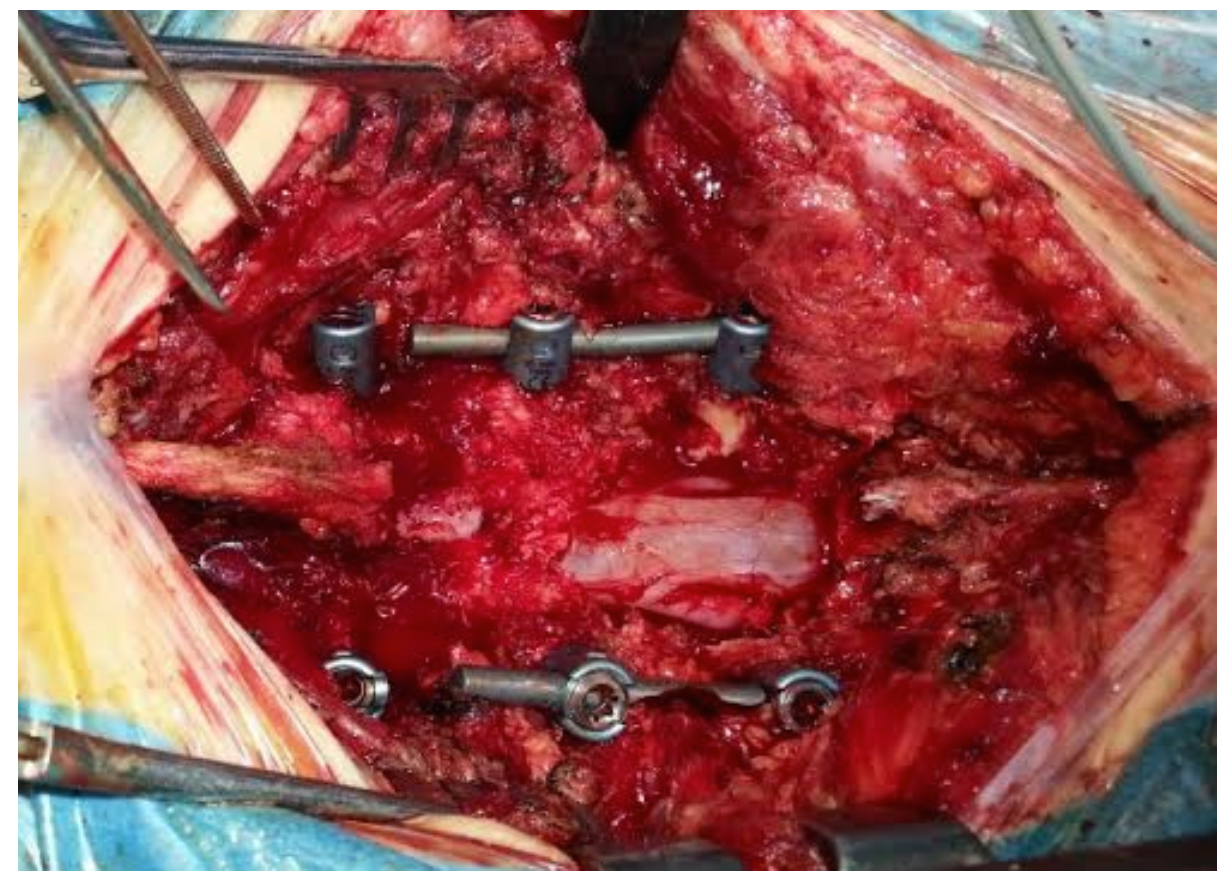

Figura 25. Abordaje lumbo-sacro para tratar una estenosis de canal congénita severa a nivel de L5-S1. Se observan el saco tecal y las raíces L5 bilateral en su salida por el foramen. 


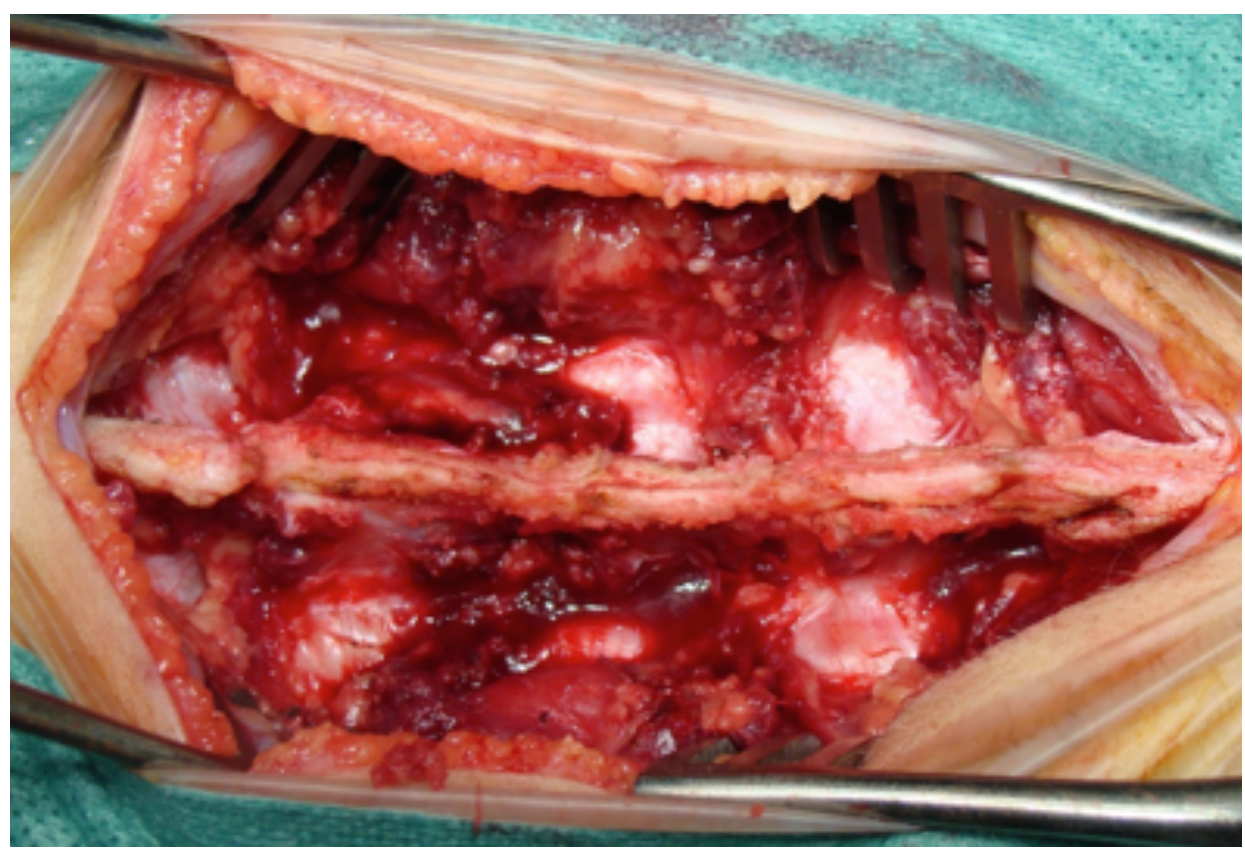

Figura 26. Abordaje a la columna lumbar vía posterior, con exposición de los niveles L2, L3 y L4.

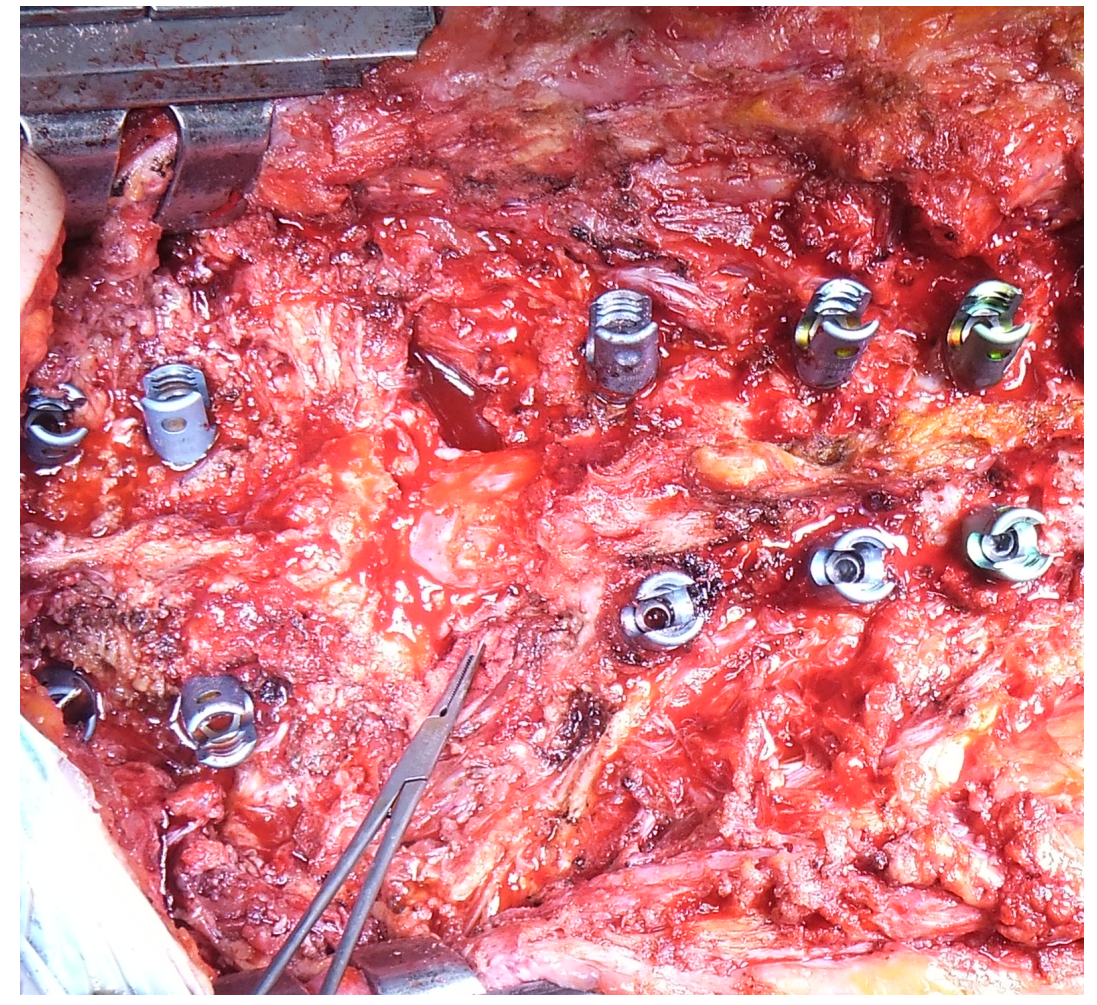

Figura 27. Abordaje dorso-lumbar para realización de vertebrectomía radical por vía posterior más instrumentación transpedicular para estabilización de la $\mathrm{CV}$. Cavidad quirúrgica de la vertebrectomía señalada por las pinzas de Kocher. 
Otra técnica para abordar hernias de la columna dorsal, es la vía transtorácica anterior (figura 28). Fue el Dr. CRAFFOORD (1958) quien reportó esta vía de abordaje transtorácica para las discopatías dorsales. Posteriormente, PEROT (1969) y RAHASOHOFF (1969), publicaron los primeros resultados en series acotadas. Así mismo, las técnicas para abordar la columna lumbar por vía anterior están descritas en la literatura (STAUFFER \& COVENTRY, 1972; CROCK, 1982; COOPER et al., 1993; MCAFEE et al., 1998; OXLAND et al., 2000; ZDEBLICK \& DAVID, 2000; BRAU, 2002; SARAPH et al., 2004; OZGUR et al., 2006).

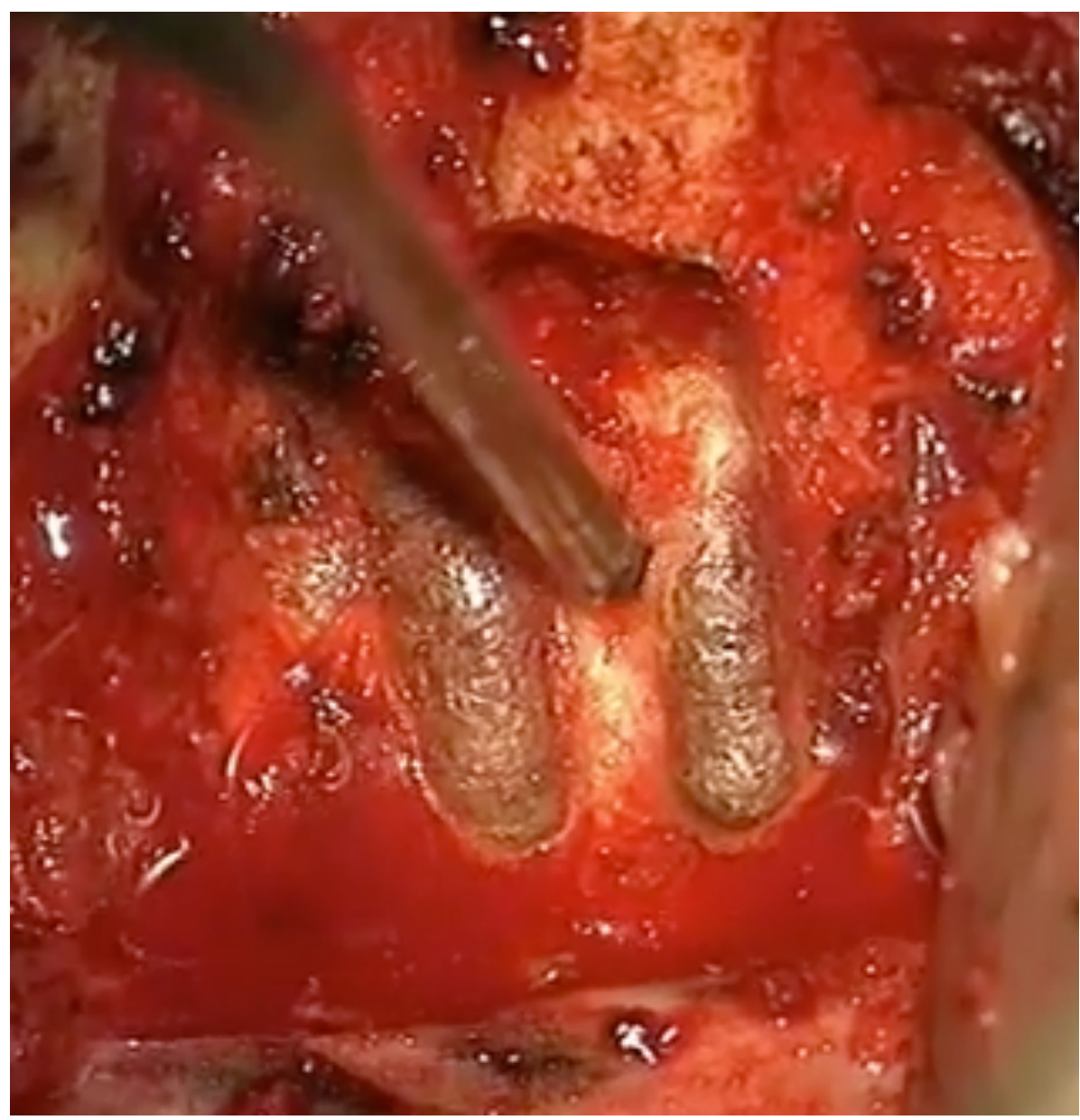

Figura 28. Se muestra un abordaje transtorácico anterior para tratar una hernia discal D7-D8. Disco intervertebral señalado por la punta del aspirador quirúrgico. 
La costotransversectomía o abordaje posterolateral (figura 29), es otro abordaje a la columna torácica ampliamente utilizado, originalmente descrito por MENARD y popularizado por CAPENER (YONENOBU et al, 1990; FESSLER et al., 1998). Este abordaje permite acceso a patologías localizadas anterior y lateralmente al cuerpo vertebral posterior, disco intervertebral, espacio epidural anterior y lateral y al foramen intervertebral.

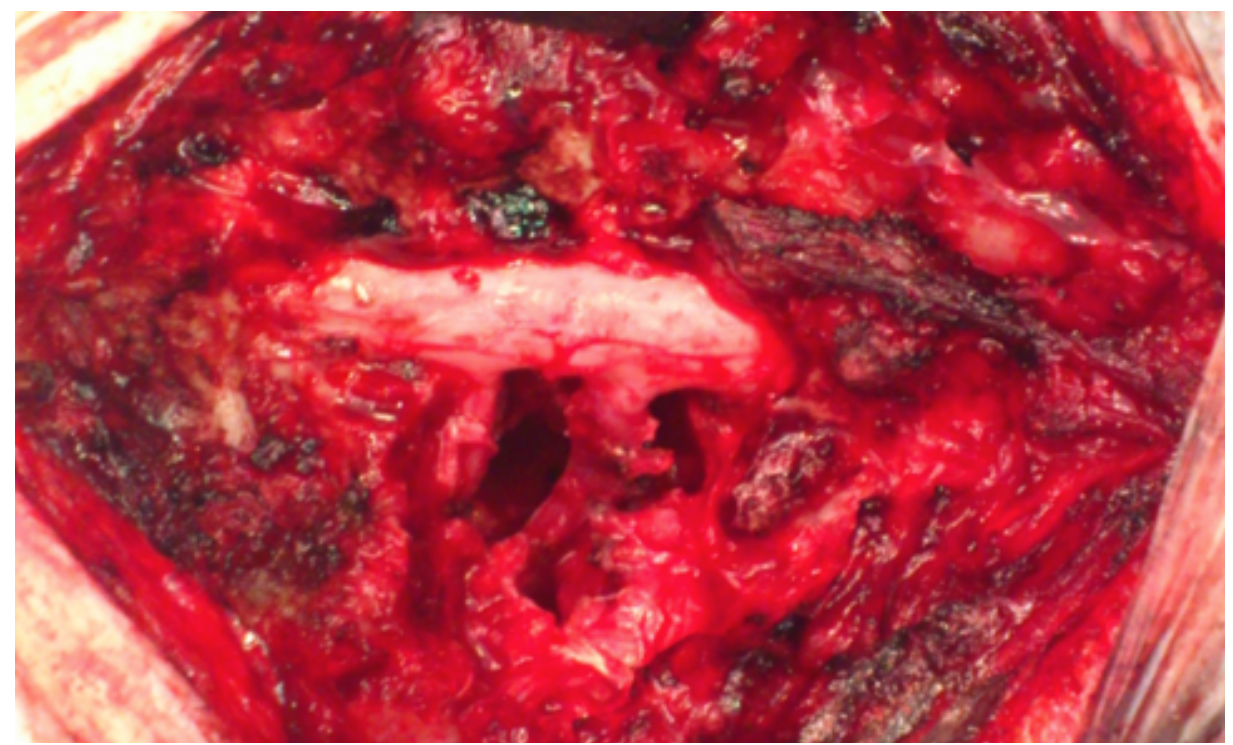

Figura 29. Saco tecal y raíces D5 y D6 bilaterales tras realizar vertebrectomía fragmentaria posterior de la sexta vértebra dorsal, mediante abordaje posterolateral o costotransversectomía.

Por otro lado las técnicas mínimamente invasivas para abordar la columna dorsal y lumbo-sacra han revolucionado el manejo de muchas patologías en la practica neuroquirúrgica. Son muchos los procedimientos que pueden ser realizados con esta técnica, aunque el procedimiento más realizado y del que existen mas publicaciones, es la discectomía mínimamente invasiva (MCAFEE et al., 1995; MCCULLOCH, 1996; MCAFEE, 1998; ROSENTHAL \& DICKMAN, 1998; MCCULLOCH, 1998; DICKMAN et al., 1999; BRAYDA \& CINNELLA, 2000; FOLEY et al., 2003; SCHWENDER et al., 2005; MAYER, 2006; PARK \& HA, 2007). 


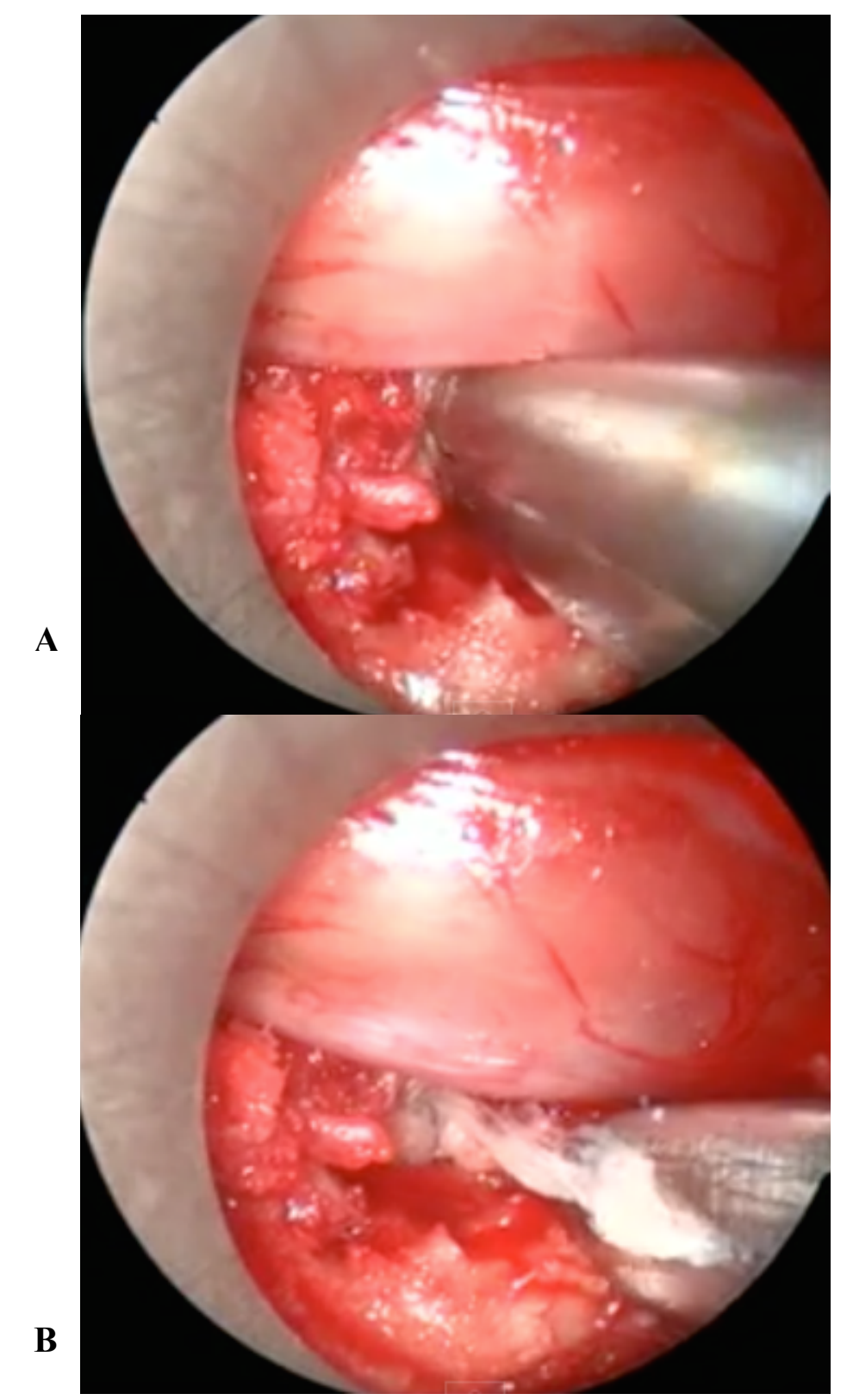

Figura 30. A y B. Discectomía mínimamente invasiva D10-D11, se observan la raíz y el espacio discal. A: introducción micropinzas en el espacio discal. B: se muestra la salida del material discal durante la discectomía.

En la mayoría de los casos con estas técnicas se pueden abordar la mayoría de las patologías de la columna vertebral; existen condiciones en la que es necesario el empleo de otras técnicas como por ejemplo, el abordaje lateral extracavitario de la columna toracolumbar (ALEC), para la descompresión anterolateral y estabilización posterior. La técnica quirúrgica y la evolución de este procedimiento ha sido discutida por LIFSHUTZ et al., (2004). 


\subsubsection{Fotografías de los elementos óseos de la CV de especímenes}

Se adquirieron fotografías de huesos de la columna vertebral pertenecientes al Departamento de Anatomía e Histología de la Universidad de Salamanca (USAL), para ser utilizados como referencia anatómica (figuras 31 y $32)$.

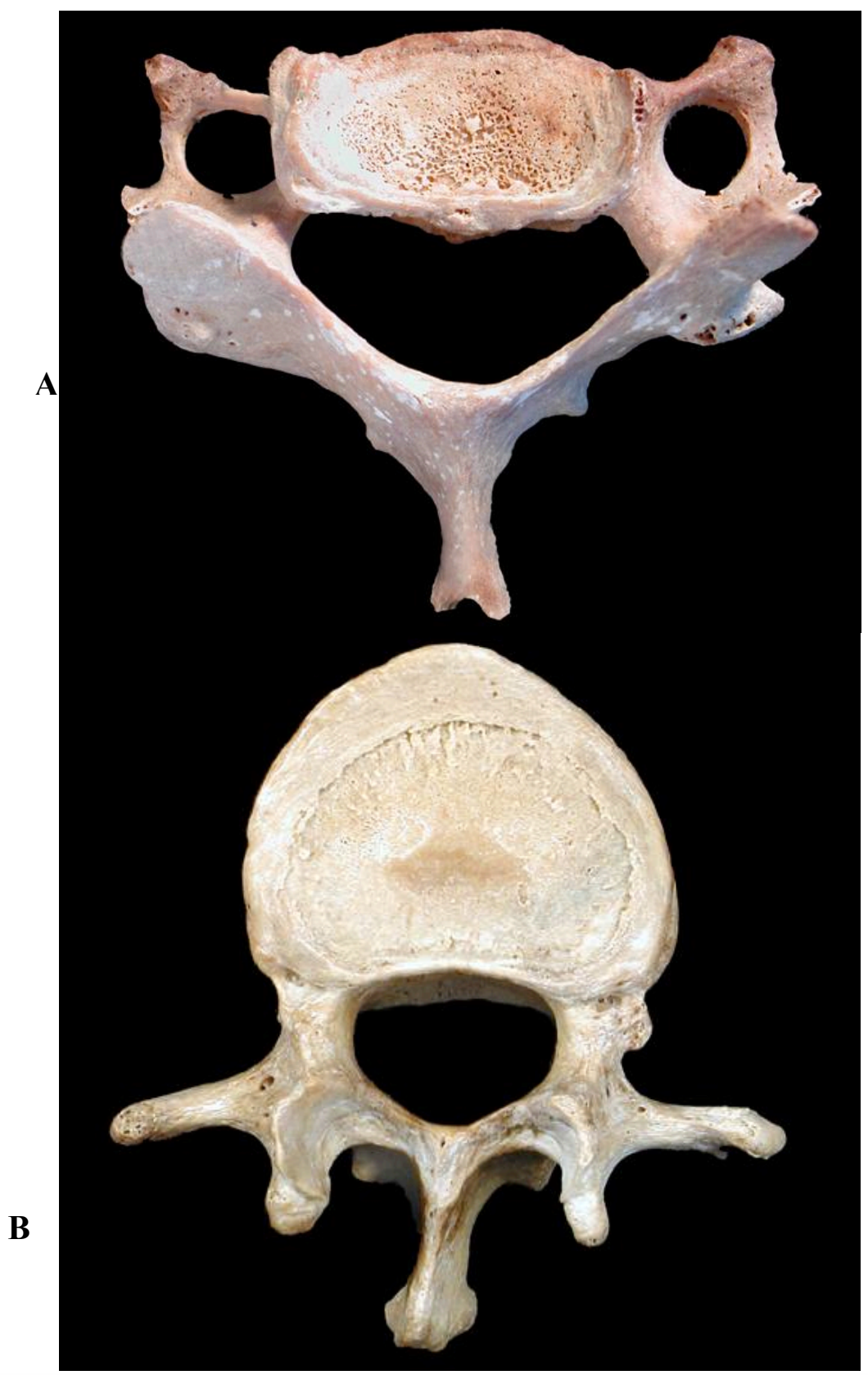

Figura 31. Fotografías perteneciente al Dpto. de Anatomía e Histología de la USAL. A: Fotografía de vértebra típica cervical. B: vertebra típica lumbar. 
A
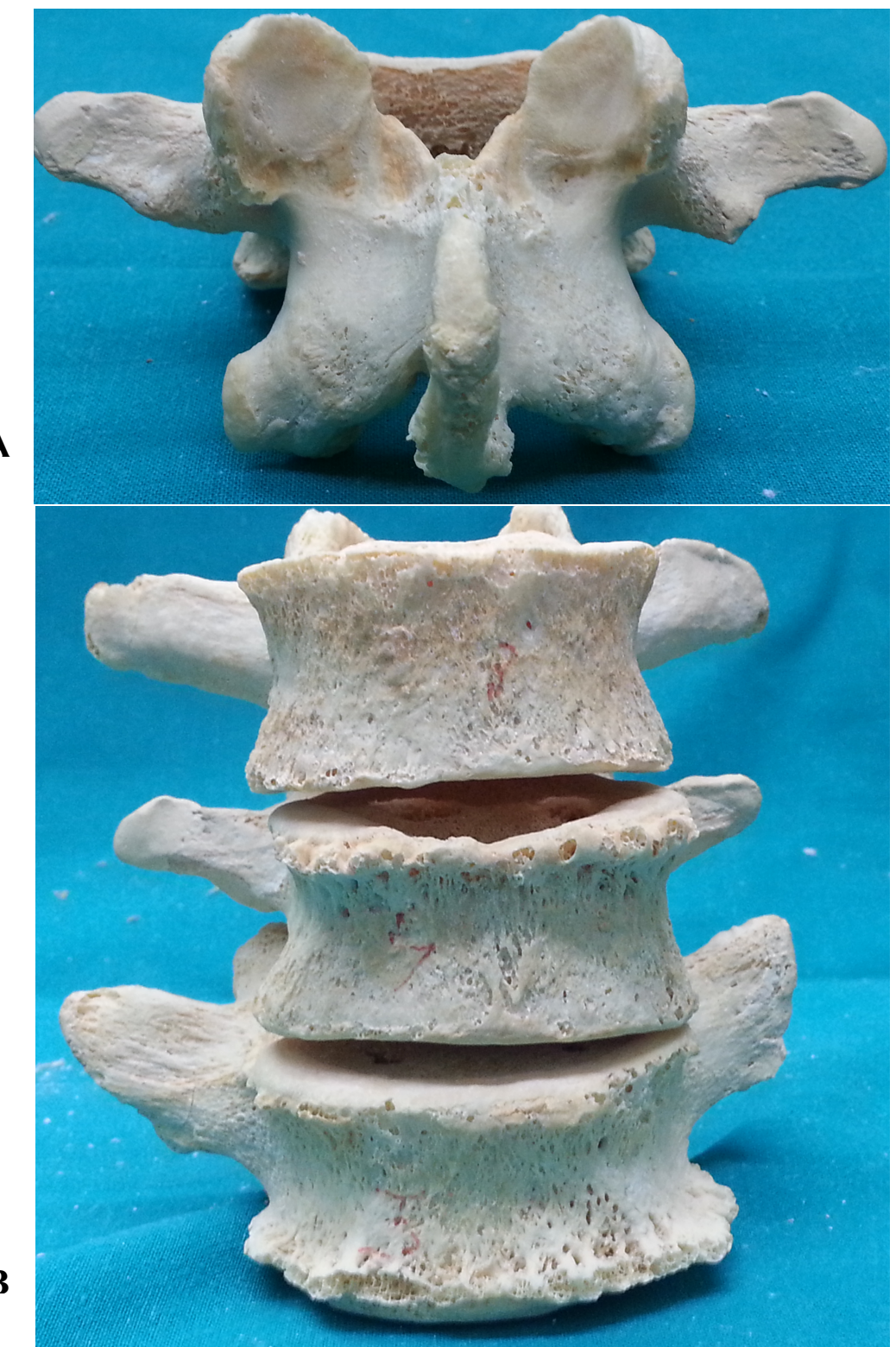

Figura 32. Fotografía de vértebra típica lumbares. A: vista posterior. B: vista anterior; perteneciente al Dpto. de Anatomía e Histología de la USAL.

\subsection{TRATAMIENTO DEL MATERIAL ICONOGRAFICO}

Las imágenes se interpretaron y reconstruyeron en un ordenador personal (PC) bajo sistema Windows, para su posterior procesamiento y almacenamiento, para luego ser incorporadas en un sistema de visualización de imágenes tridimensionales, mediante un visor de DirectX, bajo la denominación ViX. 


\subsubsection{Reconstrucciones 3D a partir de imágenes DICOM}

A partir de los ficheros raw data DICOM se reconstruyó, para cada orientación, un volumen que fue salvado en formato ANALYZE 7.5 mediante el software de libre distribución MRIcro (Nottingham, UK), figura 33.

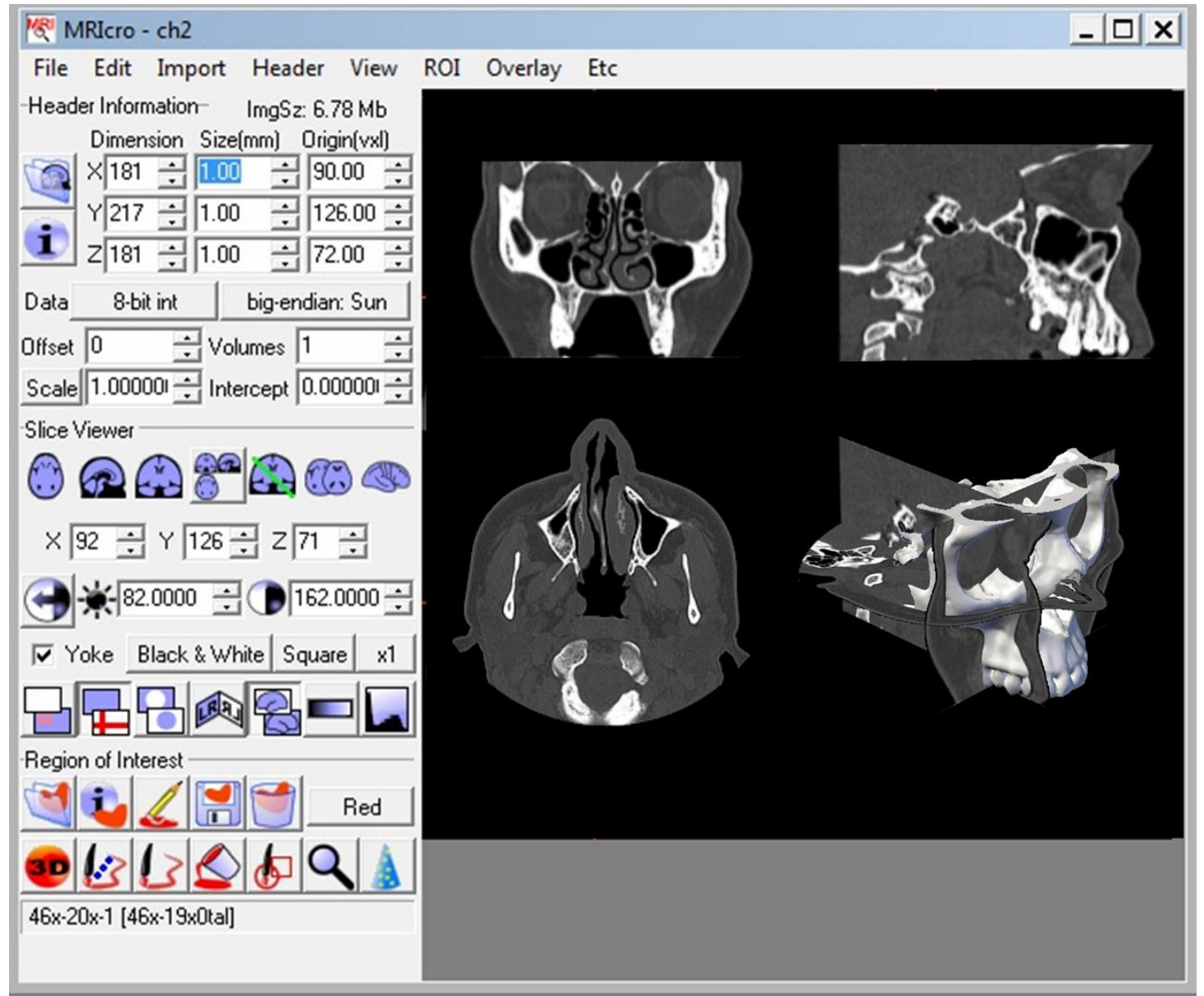

Figura 33. Interface de usuario del software MRIcro (Nottingham, UK), para la manipulación y tratamiento de las imágenes DICOM obtenidas tanto desde el tomógrafo computarizado como del equipo de resonancia magnética. 


\subsubsection{Alineación y redimensionamiento}

Con la finalidad de homogeneizar al máximo las dimensiones entre los tres volúmenes, éstos fueron alineados, tomando como referencia el adquirido en el plano axial. A continuación se redimensionaron, aplicando un filtro Lanczos, resultando en un volumen axial de 600x560x30 slices (voxelsize $=$ $0.5 \times 0.5 \times 3.5 \mathrm{~mm} 3$ ), un volumen sagital de 30x560x560 slices (voxelsize $3.5 \times 0.5 \times 0.5 \mathrm{~mm} 3$ ) y un volumen coronal de 600x28x560 slices (voxelsize 0.5x5.0x0.5 mm3). De cada uno de estos volúmenes se exportaron imágenes en formato PNG para su representación en un visor 3D (ver la sección visualización y renderización).

Así mismo, para facilitar la fase de modelización, los 3 volúmenes fueron redimensionados (reslicing), obteniéndose imágenes isotrópicas con vóxeles de $1 \mathrm{~mm}$, es decir, con vóxels que poseen el mismo tamaño en todas las dimensiones.

Para la reconstrucción de las estructuras óseas se emplearon imágenes de tomografía computarizada y de resonancia magnética, obteniéndose unos volúmenes finales de $512 \times 512 \times 117$ voxels, y tamaño de $0.23 \times 0.23 \times 0.5 \mathrm{~mm}$.

\subsubsection{Segmentación}

La segmentación se basó en la delimitación manual empleando Autodesk (Maya 6.0 Unlimited; Alias Systems Corp., Delaware, Maryland 2013). Se procedió a la detección de bordes relativos a las diferentes estructuras anatómicas en base a su forma, tamaño y localización. Estos métodos se basan en detección de bordes y reconstrucción de fronteras. 
En esta etapa un buen proceso de detección de bordes facilita la elaboración de las fronteras de las estructuras 3D a modelar, con lo que el reconocimiento de objetos se facilita. De esta forma se obtendrán superficies deformables, representadas en $3 \mathrm{D}$, por medio de mallas triangulares cerradas.

\subsubsection{Modelos geométricos}

Para la obtención de modelos 3D de superficie, consistentes en modelos geométricos delimitados por mallas poligonales (triangulares), se han seguido las siguientes fases:

\subsubsection{Delimitación de regiones de interés}

Mediante un editor 3D (Autodesk Maya 6.0 Unlimited; Alias Systems Corp., Delaware, Maryland 2013), se procedió a delimitar en los volúmenes isométricos las regiones de interés (ROIs), también denominados labels, de las estructuras anatómicas a reconstruir como se muestra en la figura 34 .

Precisamente, dado que el cambio de intensidad o borde entre muchas de las estructuras que nos ocupan es difícilmente perceptible, por la falta de nitidez en sus límites, empleamos estrategias de segmentación manuales, en vez de algoritmos de segmentación automáticos. El suavizado de bordes sí se realizó de forma automática, a través del módulo de Maya ${ }^{\circledR}$ correspondiente, basándose en el promediado de los píxeles de una región.

Uno de los requisitos a la hora de modelar, es no elevar los requerimientos de procesado de los modelos para que estos se rendericen de forma mas rápida. Se habla de baja poligonización cuando un modelo emplea los mínimos polígonos para crear una imagen (figuras 35 y 36). 


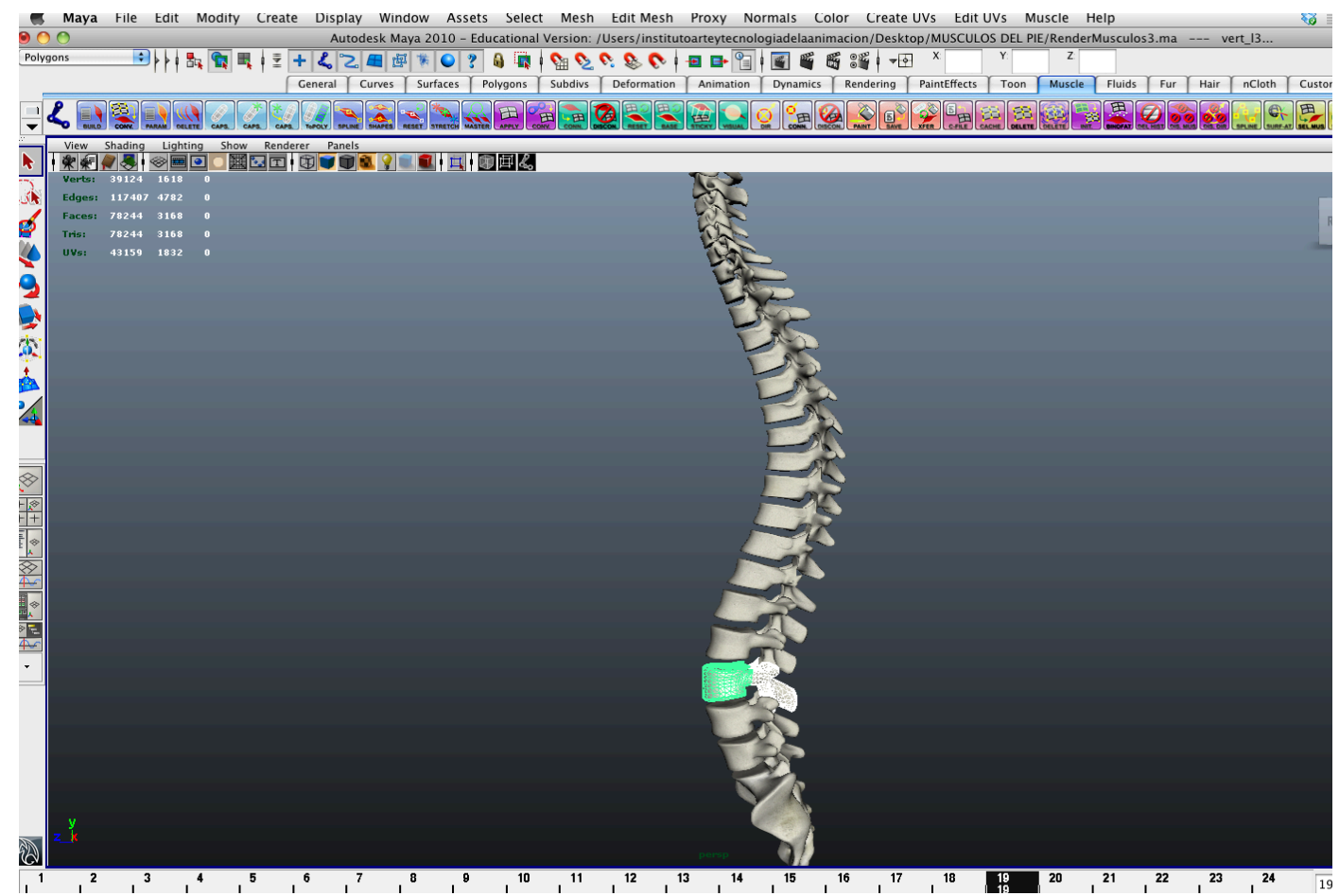

Figura 34. Interface del editor 3-D Maya, para la delimitación de las regiones de interés (ROIs) Estas regiones han incluido: vertebras de la regiones cervical, dorsal, lumbar y sacra.

\subsubsection{Generación de modelos 3D}

A partir de las ROIs, y aplicando un algoritmo conocido como marching cubes, se obtuvo un modelo de malla triangular de la superficie de cada una de estas estructuras identificadas, figura 35.

Dada la alta resolución de las imágenes, se procedió a la simplificación y suavizado de la malla, obteniendo modelos poligonales que podían posteriormente editarse con mayor facilidad, mediante programas específicos de modelado (Autodesk Maya), figuras 36 y 37. 


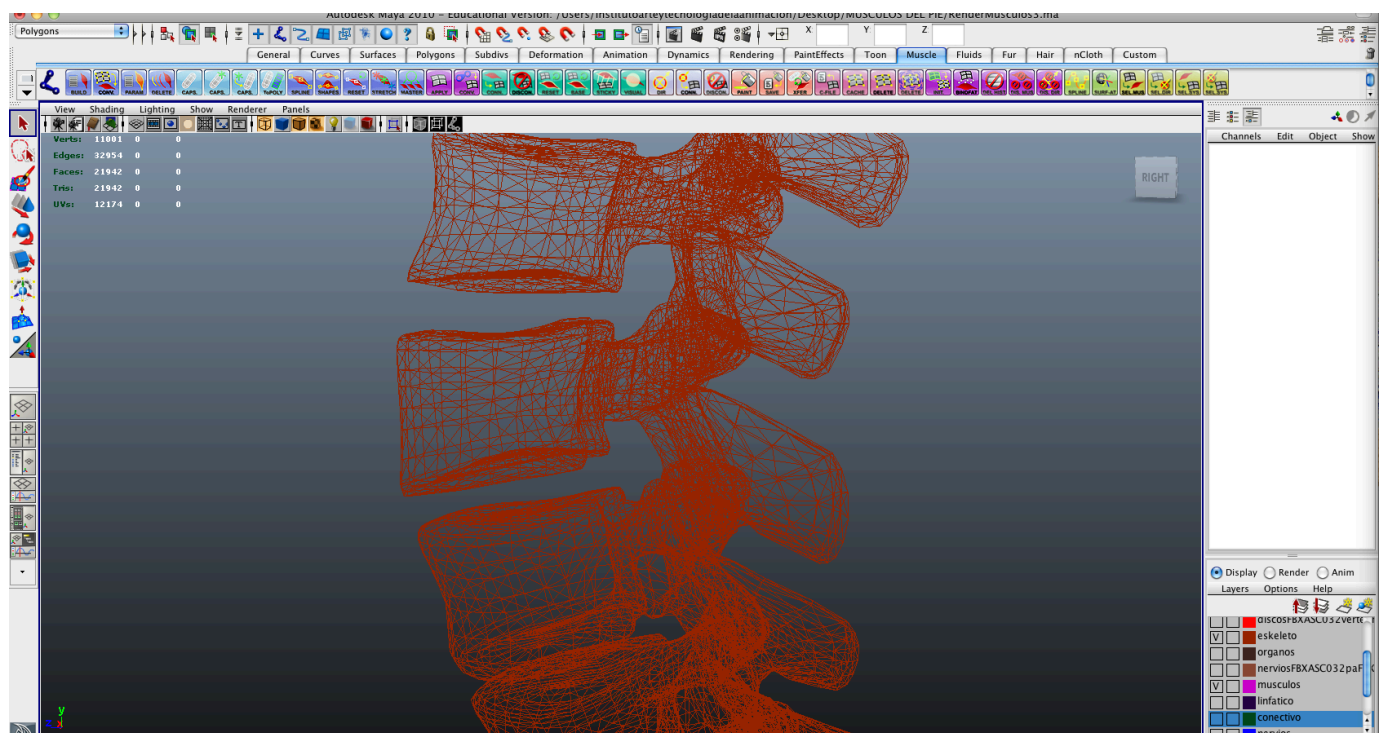

Figura 35. Interface del software Autodesk Maya, que muestra la generación de modelos de superficie del esqueleto de la columna vertebral, a partir de las ROIs, aplicando algoritmos de 'marching cubes'. Modelado geométrico de malla triangular.

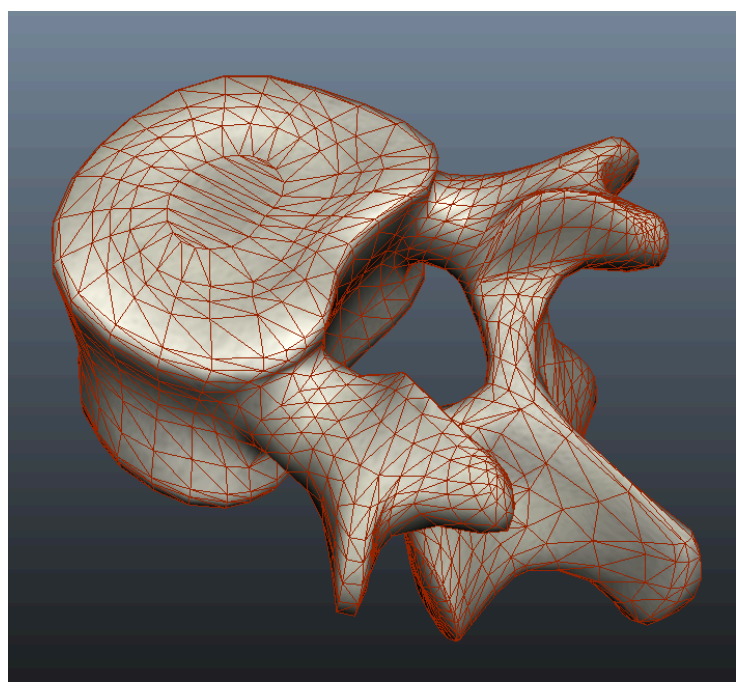

Figura 36. Simplificación y suavizado del modelado geométrico de malla triangular, que facilita un mejor manejo posterior en la aplicación informática final. Cada objeto que el programa proporciona por defecto (las primitivas) puede ser convertido en malla poligonal, lo que significa que el objeto se dividirá en subobjetos y sus diferentes elementos podrán ser modificados mediante herramientas como mover, rotar o escalar. Con ello se pueden conseguir formas más personalizadas u orgánicas, adecuadas para la creación de personajes, animales o vegetales. 


\section{Estas regiones han incluido:}

1.- Estructuras óseas y,

2.- Partes blandas.

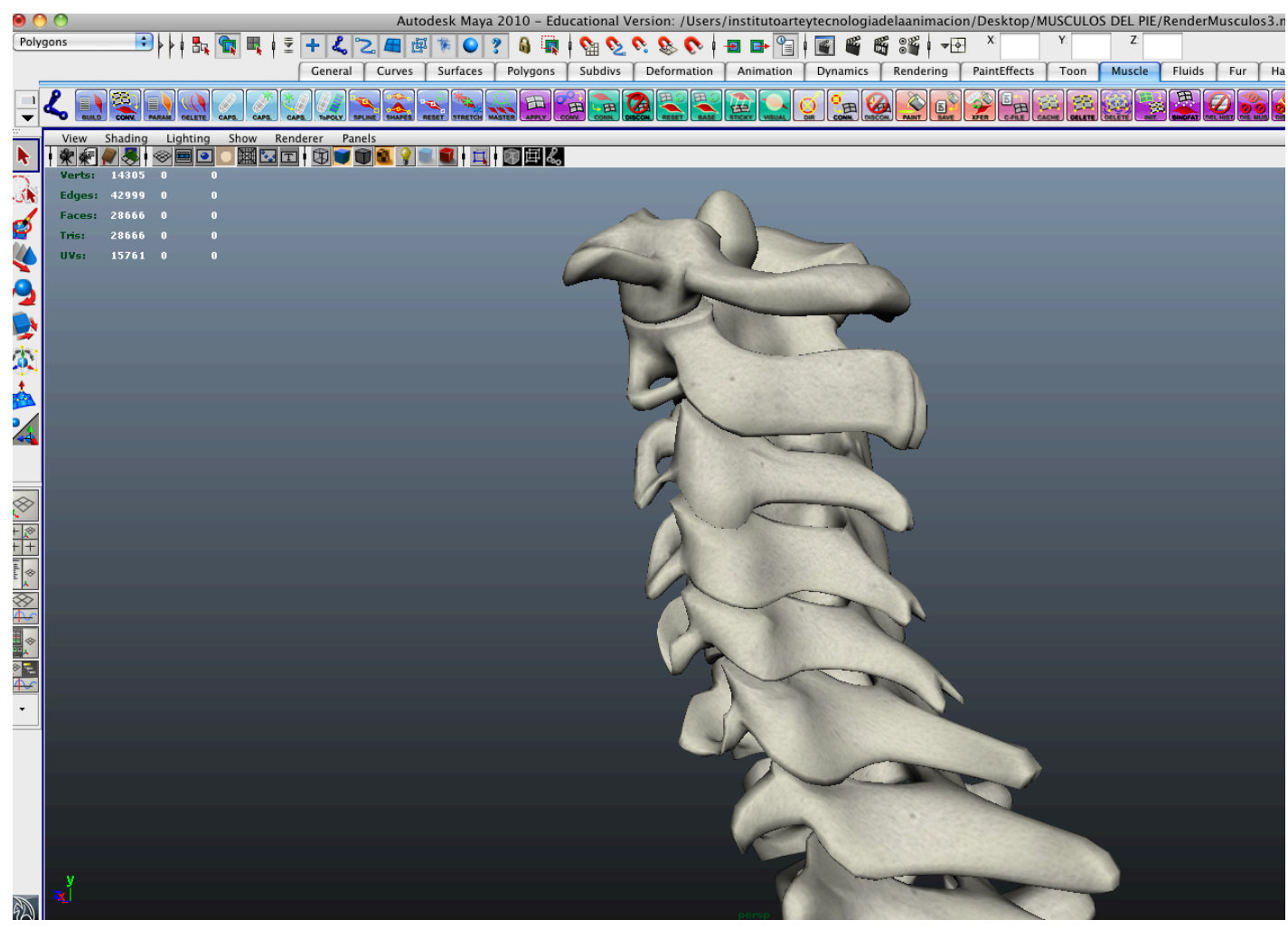

Figura 37. Muestra la interface del editor 3D Maya, en el que se visualiza la columna cervical modelada, obtenida a partir de la simplificación y suavizado del modelo geométrico de malla triangular.

Para dar más robustez al proyecto, se procedió a correlacionar los modelos 3D generados con los estudios radiológicos de las estructuras vecinas; embebiendo y superponiendo las imágenes 3D generadas sobre las secciones radiológicas de resonancia magnética y TC (figura 38). 


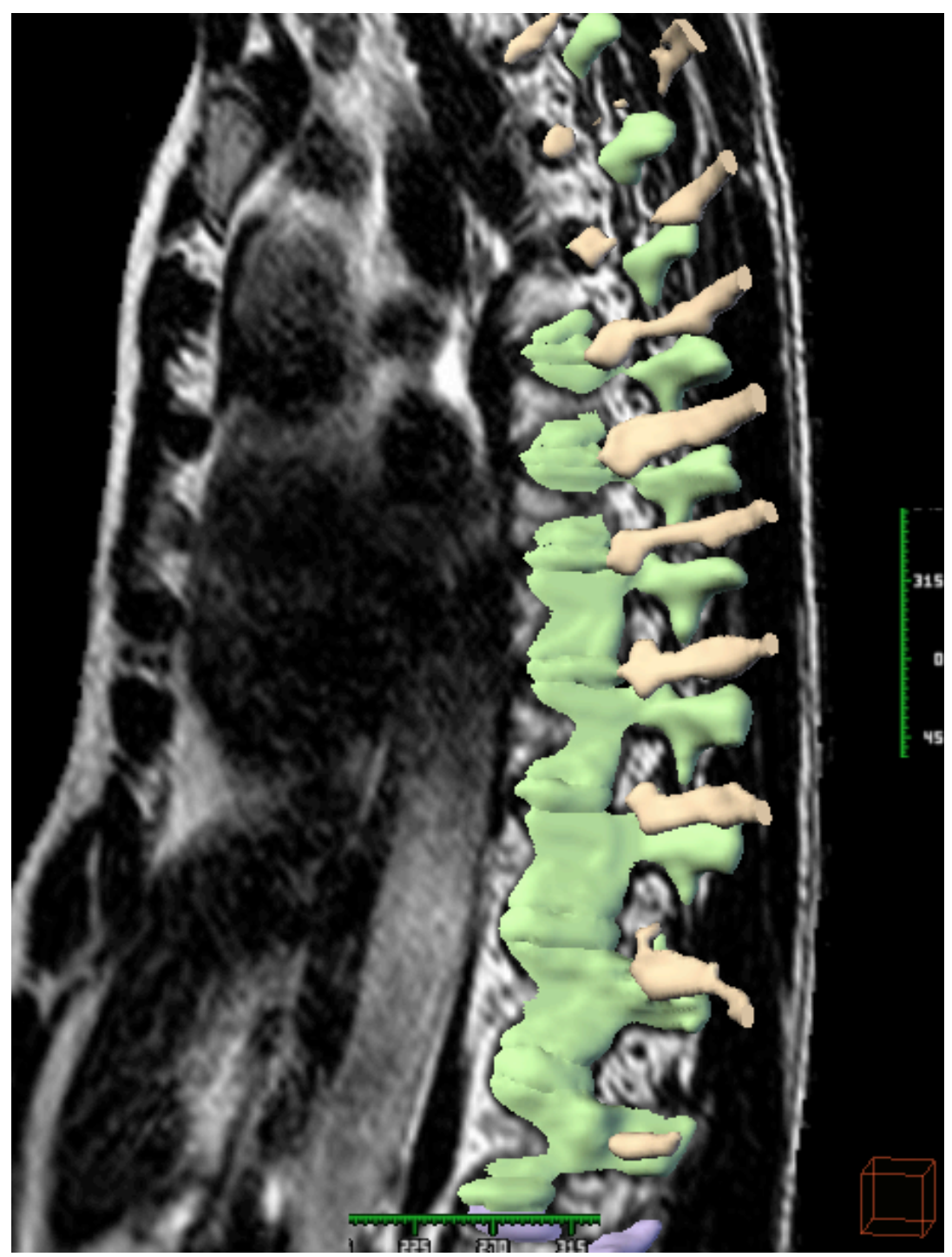

Figura 38. Representación de la reconstrucción ósea tridimensional de la columna dorsal, superpuesta a una imagen latero-sagital de resonancia magnética, potenciada en T2. Se aprecia la relación de la columna dorsal con las partes blandas: vísceras, músculos y estructuras vasculares.

\subsubsection{Texturización de los modelos 3D}

Para lograr aumentar el realismo y obtener un buen acabado anatómico de las estructuras anatómicas modeladas, la fase de texturizado es de las más importante. El primer paso para texturizar es el mapeo, que representa las coordenadas de la textura en el modelo. Para lograr una correcta texturización de 
los modelos anatómicos 3D de nuestra Tesis Doctoral, fue necesario desarrollar coordenadas de textura a través de proyecciones geométricas y desarrollos más complejos mediante la aplicación splines (curvas diferenciables definida en porciones mediante polinomios) y operaciones matemáticas. Los splines nos permitieron trabajar tanto en una como en varias dimensiones. Los volúmenes generados en la etapa de modelado de las diferentes vértebras que configuran la columna vertebral, se reorganizaron en base a las texturas aplicadas.

Este proceso de texturización puede variarse dependiendo si son texturas repetitivas, imágenes fotográficas, texturas de iluminación o de detalle, lo que cambiaría las características de un modelo anatómico, que en nuestro trabajo siempre se ha buscado obtener el menor número de archivos para su procesamiento en tiempo real, en ordenadores personales con características técnicas elementales; por ello optamos a la utilización de modelos de baja resolución poligonal, lo que solamente orienta sobre la morfología global de la estructura anatómica, siendo por tanto, menos realista que si se optara por elementos poligonales masivos de alta resolución, esto sin apenas afectar el efecto visual de realismo. Las figuras 39 y 40 muestran unos ejemplos evidentes de las posibilidades gráficas que podemos alcanzar con el proceso de texturizado de los modelos anatómicos vertebrales.

Este procedimiento se consigue mediante la reorganización de la información, aplicándose por cada una de las caras y los vértices de cada estructura anatómica (vértebras), lo que conlleva a que un mismo vértice y cara puede tener coordenadas separadas por polígonos, permitiendo un mayor aprovechamiento del espacio, y evitar no desperdiciar memoria en espacios vacíos en el modelo alámbrico o de malla. 
De este aprovechamiento del espacio depende la división o adición de determinadas mallas, manteniendo una escala uniforme entre elementos del mismo material y en los casos que no se logra, la malla tiene que subdividirse, reordenando el modelo anatómico. También se pueden aplicar otros elementos para aumentar el realismo del modelo anatómico, como son el falso relieve, que permite aparentar un mayor detalle mediante una técnica de iluminación en el renderizado en tiempo real, sin modificar la superficie de la malla y el proceso de renderizar la iluminación a la textura, que permite aplicar cálculos de iluminación complejos y ejecutarlos como una textura.

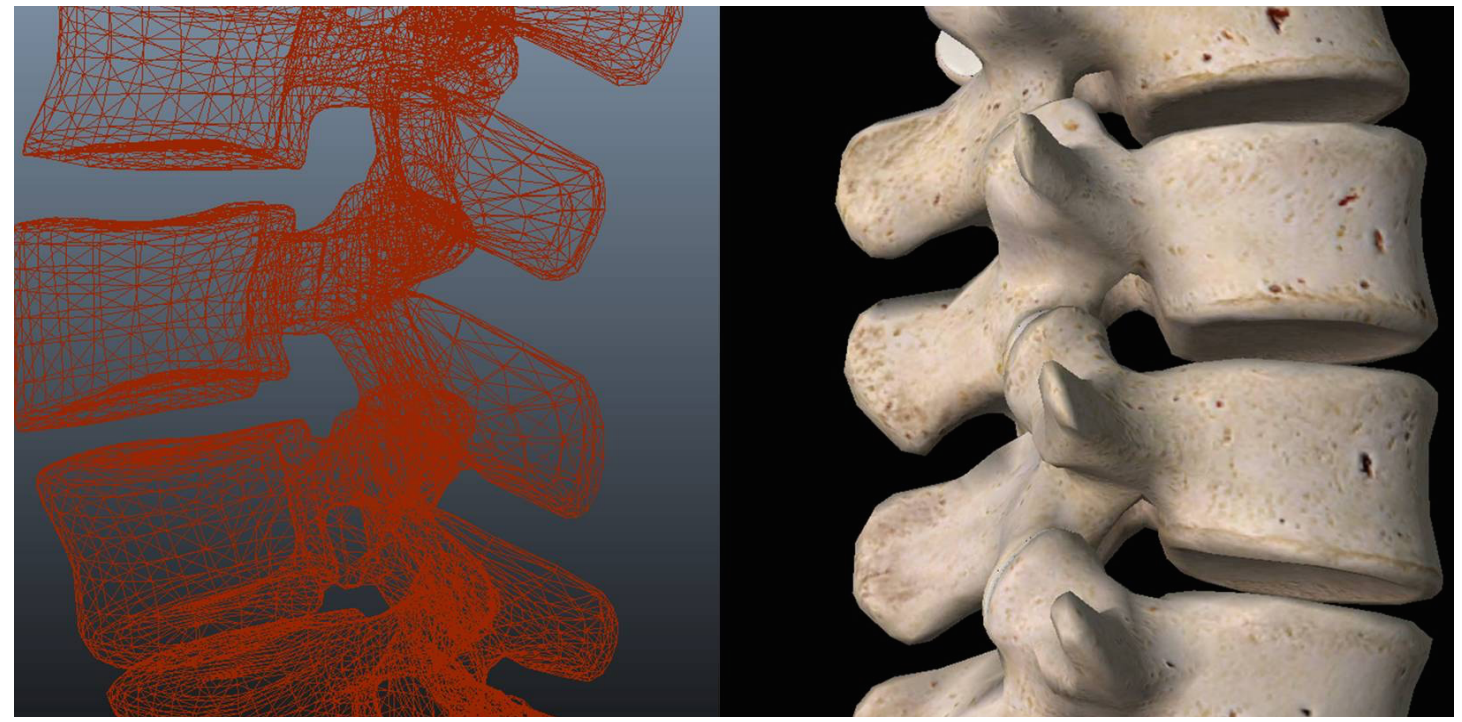

Figura 39. A y B. A: modelado geométrico de malla triangular. B: estructura anatómica de la región lumbar tras la fase de texturizado. En la fase de texturización modificar la geometría para añadir detalle al objeto implicaría aumentar el número de polígonos del modelo. Cuantos más polígonos tiene un modelo, mayor es la potencia de procesamiento necesaria para que éste quede representado en la pantalla, por lo que en términos de procesamiento, es más eficaz emplear texturas de alto detalle y de modelos de baja poligonización que a la inversa, como se observa en ésta figura . 

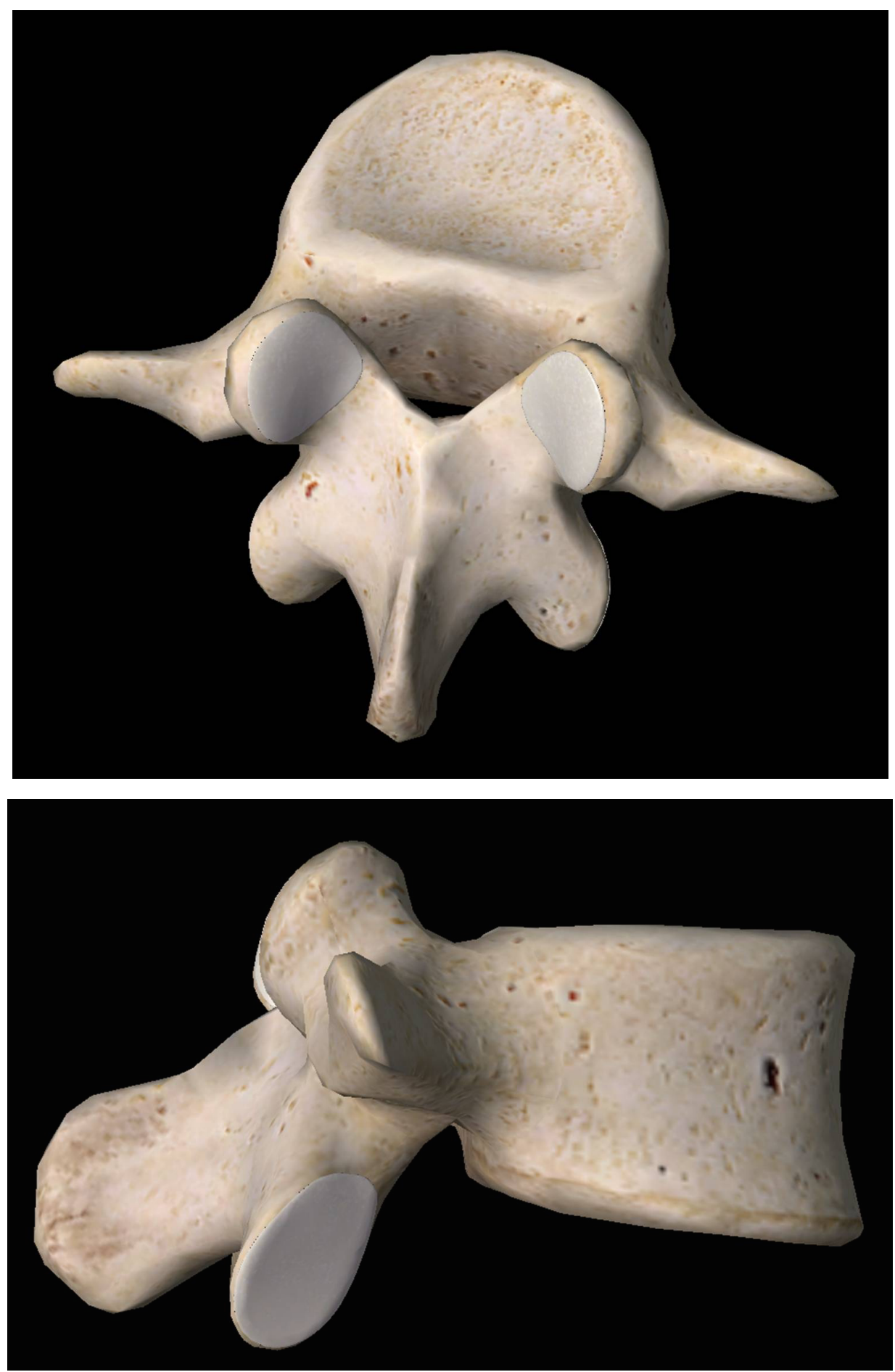

Figura 40. El texturizado no sólo nos permitió añadir los colores y relieves más próximos a la realidad a los modelos $3 \mathrm{D}$, sino que también nos permitió dar mayor detalle a determinadas formas anatómicas, alcanzando un alto grado de realismo. A: vista superior de una vertebra lumbar tras su texturización. B: La misma vertebra lumbar en la posición espacial lateral. 


\section{4. VISOR ANATÓMICO FUNCIONAL}

Finalmente todas las estructuras reconstruidas fueron implementadas en un visor de directX, un formato gráfico estándar compatible con ViX, utilizando un programa de conversión (3D Exploration v 1.831, Right Hemisphere, Inc.), (figura 25).

\subsubsection{Interface Gráfico de usuario}

El interface del visor anatómico funcional consta fundamentalmente de dos áreas, la primera, situada a la izquierda del visor anatómico, para la observación de los modelos anatómicos tridimensionales generados; y la segunda, a la derecha, corresponde al visor dinámico de los aspectos funcionales de la columna vertebral, como se muestra en las figuras 41 y 42 .

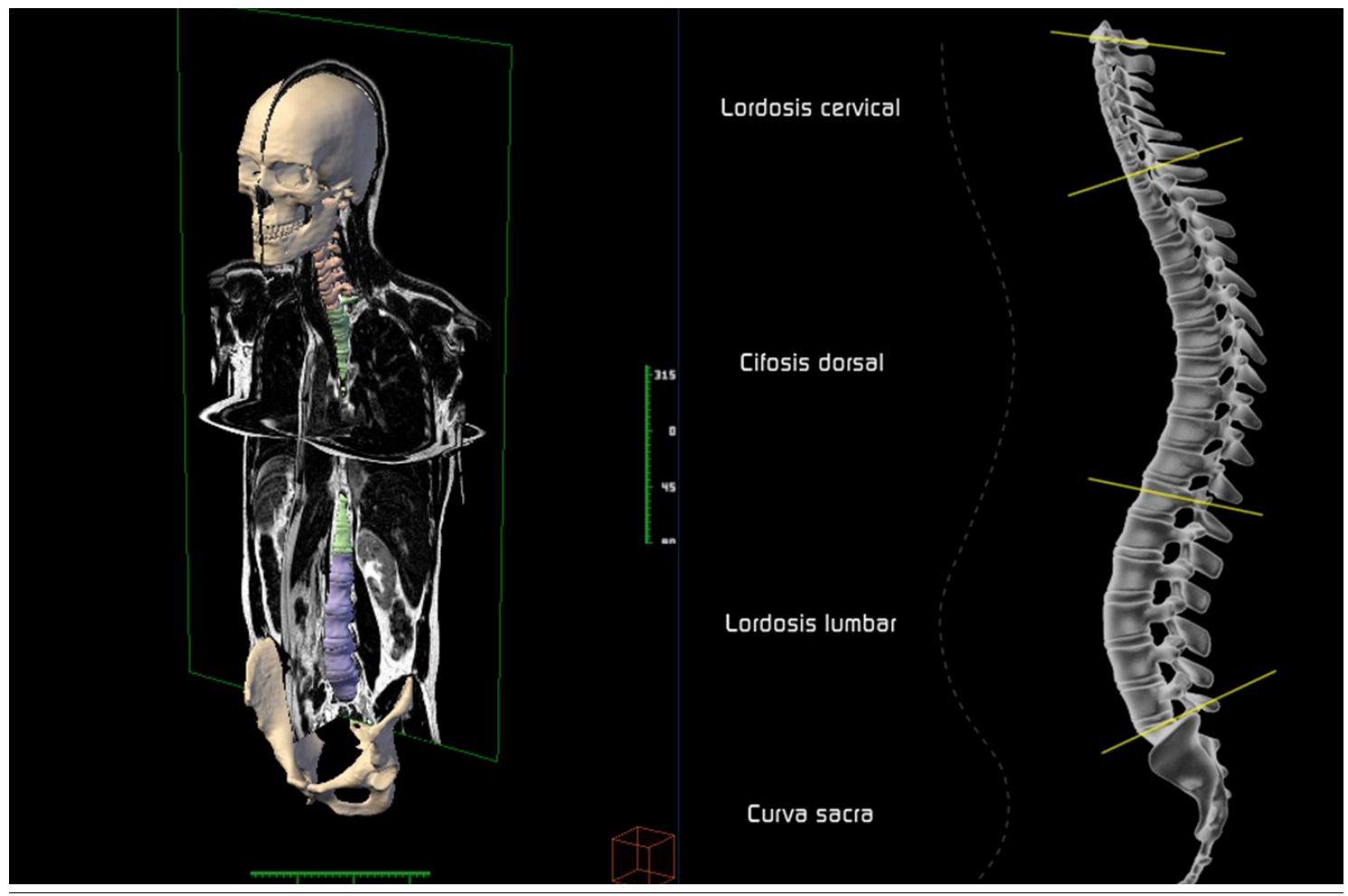

Figura 41. Visualización del interface de usuario estructurado en dos partes: a la izquierda el visor anatómico para la observación de los modelos anatómicos tridimensionales generados; y a la derecha el visor dinámico de los aspectos funcionales de la columna vertebral. 


\subsubsection{Fichero de definición de imágenes del visor anatómico funcional}

Este fichero contiene la información para disponer las imágenes en su orientación y posición espacial adecuada, que vienen determinadas por los siguientes parámetros:

a) dimension $(\mathrm{x}, \mathrm{y}, \mathrm{z})$ : indica la dimensión total del volumen del que se han obtenido las imágenes, es decir, el número total de slices (300x280x280)

b) pixelsize $(\mathrm{x}, \mathrm{y}, \mathrm{z})$ : tamaño del vóxel, en cada dirección espacial, expresado en milímetros $(1 \mathrm{~mm} \times 1 \mathrm{~mm} \times 1 \mathrm{~mm})$

c) origin $(\mathrm{x}, \mathrm{y}, \mathrm{z})$ : origen -centro de referencia- del volumen $(148,131,139)$

d) orientación: puede ser Sagital, Coronal o Axial.

e) nombre del fichero de imagen, seguido del slice al que corresponde

\subsubsection{Fichero de definición de modelos}

Se trata de un fichero de texto, que contiene las especificaciones de cada modelo 3D. Los principales nodos empleados en este tipo de fichero son los siguientes:

a) Model \{\} . Define la creación de un nuevo modelo, cuyas características se especifican entre llaves.

b) name. Nombre con el que se aparecerá el modelo en los menús desplegables de selección.

c) label. Identificador de modelo, para uso interno.

d) file. Fichero en formato DirectX con la geometría del modelo.

e) color. Color del modelo, en escala RGB, con valores de cada componente entre 0 y 1 . 
f) transparencyRange. Permite especificar el rango de variación del factor de transparencia. Generalmente 0 para objetos no transparentes y 1 para la máxima transparencia.

g) transparency. Factor de transparencia inicial del modelo.

h) drawStyle. Especifica el estilo con el que se representa la malla poligonal, que puede seleccionarse entre dibujo sombreado (shaded) o de líneas (lines).

i) visible. Nodo empleado para definir la visibilidad inicial del modelo. El valor 0 indica No visible y el valor 1, visible.

j) documentation. Fichero en formato $\mathrm{html}$ que contiene la documentación asociada al modelo.

\subsubsection{Programación en Visual C++}

La programación se llevó a cabo mediante el software Visual C++, el cual, como entorno integrado de desarrollo, nos permitió realizar una programación orientada a objetos (POO) bajo los lenguajes de programación $\mathrm{C}, \mathrm{C}++\mathrm{y}$ $\mathrm{C}++/ \mathrm{CLI}$, conjuntamente con el sistema de desarrollo SDK (también denominado API) de Windows.

Visual $\mathrm{C}++$ nos permitió el desarrollo y la depuración de código escrito para las API's de Microsoft Windows, DirectX y tecnología Microsoft .NET Framework.

Por otra parte, al tratarse de un entorno integrado, Visual $\mathrm{C}++$ nos permitió utilizar otras herramientas complementarias de desarrollo:

- Editor orientado a la codificación $\mathrm{C} / \mathrm{C}++$

- Compilador/Enlazador incremental, que aceleró el proceso de construcción de nuestro desarrollo informático. 
- Depurador visual, que permitió visualizar y modificar el contenido de variables y áreas de memoria.

- Visor de datos (browser) que permitió fácilmente controlar dependencias y referencias a funciones, datos, etc. Además permitió visualizar la jerarquía de las clases utilizadas en el programa.

- Herramientas adicionales como un analizador de ventanas (Spy ++) o un trazador de funciones MFC (Microsoft Foundation Classes).

Visual C++ incluye la librería de clases MFC que permite crear y gestionar de manera intuitiva componentes típicos de Windows. Esto es, la MFC es una implementación que utiliza el API encapsulando todas las estructuras y llamadas a funciones en objetos fáciles de utilizar. En este sentido y, basándose en la potencia de la MFC, Visual $\mathrm{C}++$ se convierte así en un generador de programas $\mathrm{C}++$ para Windows.

De esta manera, el lenguaje de programación que hemos utilizado para esta aplicación informática, es compatible en la mayor parte de su código con este lenguaje, a la vez que su sintaxis es exactamente igual. Para crear cualquier programa con Visual $\mathrm{C}++$ debemos comenzar creando un proyecto para él, codificando y añadiendo los módulos necesarios a dicho proyecto, y definiendo los recursos asociados.

En Visual $\mathrm{C}++$, la construcción de nuestro procedimiento informático se inscribe dentro del concepto de proyecto (workspace). Un proyecto define los pasos a seguir para alcanzar la construcción de un objetivo (un programa, una DLL, etc.), en realidad es un concepto análogo a lo que se conoce como "makefile" en otros entornos típicos de desarrollo en C. En realidad, Visual C++ genera para cada proyecto dos ficheros que lo definen, el fichero de workspace 
(con extensión wsp) y un makefile (con extensión mak) estándar que permitiría la utilización del mismo proyecto en otro entorno distinto.

Desde el punto de vista funcional, el proyecto contiene referencias a cada uno de los ficheros fuentes $(\mathrm{C} / \mathrm{C}++$, con extensiones c y cpp respectivamente), objetos, librerías o ficheros de recursos (extensión rc) que se deben utilizar para construir el objetivo final del proyecto.

Finalmente a los modelos 3D introducidos al visor multimedia, mediante un fichero en formato $\mathrm{html}$, procedimos a realizar breves descripciones anatómicas, con el objetivo de que estas descripciones puedan servir de ayuda para el estudio de la anatomía de la columna vertebral, o para ejercicios de abordajes (Fig. 26).

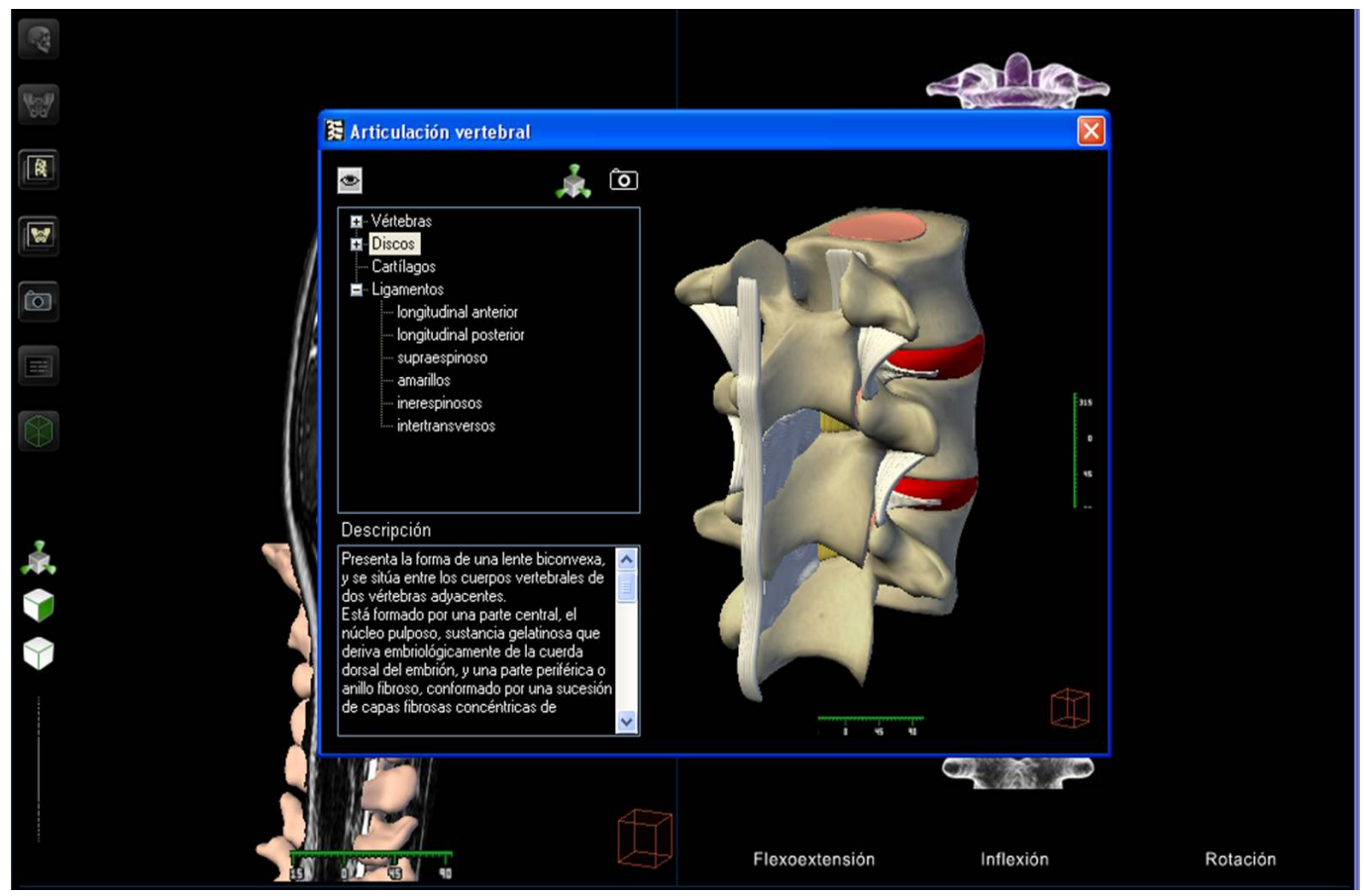

Figura 42. Visualización del interface de usuario para la manipulación de los modelos anatómicos tridimensionales generados. En la selección de cada modelo 3D se describen los aspectos morfológicos mas relevantes. 


\subsubsection{Requerimientos del sistema}

Todo el procedimiento informático finalmente fue empaquetado para su montaje en soporte CD-ROM o USB, para su instalación en ordenadores con sistemas operativos Windows. Los requerimientos técnicos, tanto de hardware como de software son los siguientes:

a) Tarjeta gráfica con al menos $32 \mathrm{Mb}$ de memoria (recomendado $64 \mathrm{Mb}$ ) que soporte DirectX 9.0 en modo ventana con transparencias.

b) Procesador Pentium III a $450 \mathrm{Mhz}$ (recomendado $600 \mathrm{Mhz}$ o superior)

c) $128 \mathrm{Mb}$ de memória RAM (recomendado $256 \mathrm{Mb}$ o superior)

d) $40 \mathrm{Mb}$ de memoria libre em disco duro.

e) Software necesario recomendado:

f) Sistema operativo Microsoft Windows 2000, XP, o superior

g) Software de DirectX 9.0 o superior

h) Microsoft NET Framework 2.0 o superior 
IV. RESULTADOS 
Para facilitar la interpretación de los resultados, primero realizaremos un enfoque general con los detalles anatómicos más relevantes de la columna vertebral (CV), representados con los modelos 3D generados. Posteriormente mostraremos los detalles anatómicos de cada región de la columna vertebral modelada: región cervical, región dorsal y región lumbo-sacra; así mismo para demostrar la correcta correlación existente entre los modelos 3D, con los órganos y estructuras adyacentes, haremos una correlación de los modelos 3D con imágenes radiológicas.

Para dar mayor robustez a los resultados, esta correlación se hará con los modelos 3D embebidos a imágenes de TC y RM con cortes axiales, coronales y sagitales. Tras describir la CV por regiones y dar más realismo a los modelos $3 \mathrm{D}$, continuaremos con la fase de texturización. Consecutivamente pasaremos a la parte de modelado 3D de partes blandas prestando mayor interés en la musculatura paravertebral y las estructuras neuro-vasculares. Para finalizar expondremos las características y detalles del visor anatómico funcional, desarrollado para la visualización de los modelos 3D, en la figura 43, se muestra una captura de pantalla con la interface de usuario del visor anatómico funcional.

\subsection{ENFOQUE GENERAL DE LA COLUMNA VERTEBRAL.}

El modelado 3D de la $\mathrm{CV}$, requiere como primer requisito conocer la anatomía de la $\mathrm{CV}$; así seguiremos la temática de mostrar los resultados describiendo los detalles anatómicos más relevantes de la columna vertebral, aunque la verdadera importancia, desde nuestro punto de vista, es mostrar la correcta correlación de los modelos 3D reconstruidos con las estructuras y órganos vecinos de la columna vertebral; así con la metodología propuesta en este trabajo de Tesis doctoral, el médico podrá reconstruir estructuras anatómicas personalizadas a la anatomía individual de cada paciente, sin la necesidad se seguir costosos y complicados protocolos de adquisición y reconstrucción de imágenes. A continuación expondremos los resultados. 


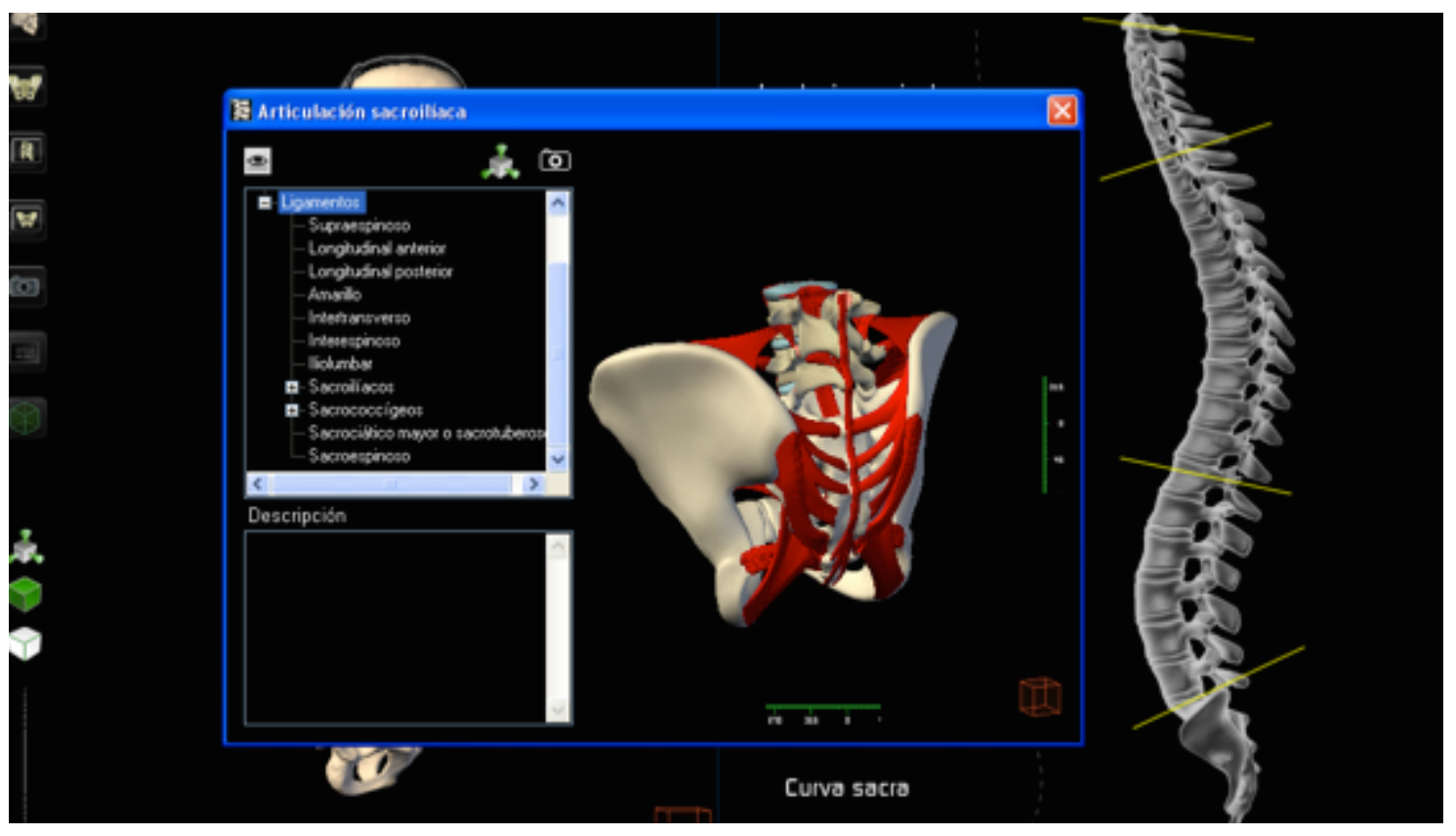

Figura 43. Captura de pantalla del interface de usuario del visor anatómico funcional, desarrollado para la manipulación de los modelos tridimensionales generados en este trabajo. El visor anatómico funcional permite observar un caso real de la columna reconstruida a partir de imágenes de RM y TC. Además con el visor anatómico, es posible analizar los movimientos de la misma sobre un modelo estándar.

El cuerpo vertebral ocupa la parte anterior de la vértebra. Tiene forma de cilindro, con dos caras, una superior y otra inferior. Sus caras laterales y anterior son algo cóncavas en sentido vertical, su cara posterior es cóncava en sentido transversal. El cuerpo forma la pared anterior del canal medular. El arco posterior protege la médula espinal lateral y dorsalmente. La parte dorsal del arco posterior se forma por las láminas cuya unión medial se conforma con la apófisis espinosa. Lateralmente las láminas se continúan con los pedículos que las unen al cuerpo vertebral. Los forámenes que forman el borde superior de un pedículo con el inferior del siguiente constituyen el agujero de conjunción a través del cual transcurren las raíces nerviosas particularmente ubicadas en el tercio superior del foramen intervertebral, posición que debe ser tomada muy en cuenta en la cirugía de instrumentación transpedicular. Ver detalles anatómicos de las vertebras en las figuras: 44, 57, 59 y 69-80. 
Las apófisis transversas se proyectan lateralmente entre la unión del pedículo con las láminas de cada lado (figura 44). Una línea horizontal que pasa por la mitad de las apófisis transversas, es una de las referencias anatómicas más importantes para localizar el pedículo; la otra la constituyen la línea vertical que pasa por el borde externo de las articulares. Las apófisis articulares se sitúan cerca de la unión del pedículo con la lámina. La cara articular del proceso superior tiene su cara hacia atrás, mientras que el proceso articular inferior tiene su superficie articular hacia adelante.

Los planos de las superficies articulares varían según el nivel de las vértebras. Así, la orientación de la carilla articular en relación con la horizontal que pasa por la superficie inferior del cuerpo vertebral produce un ángulo que va aumentando de las cervicales a las lumbares. En la región cervical el ángulo es menor de $45^{\circ}$ y en la región lumbar llega a los 90 grados. El hecho de ser diestro o zurdo crea una tracción desigual en los músculos retrosomáticos, por lo que suelen observarse pequeñas desviaciones laterales de la columna vertebral.

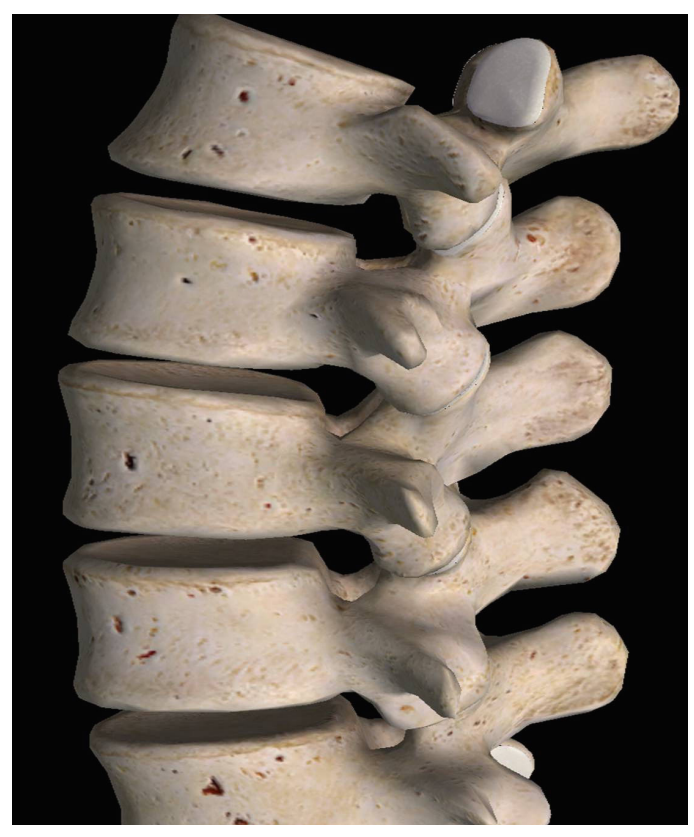

Figura 44. A y B. Modelado 3D de la columna vertebral a partir de ventana ósea de TC, muestra una visión panorámica lateral de la columna lumbar. 


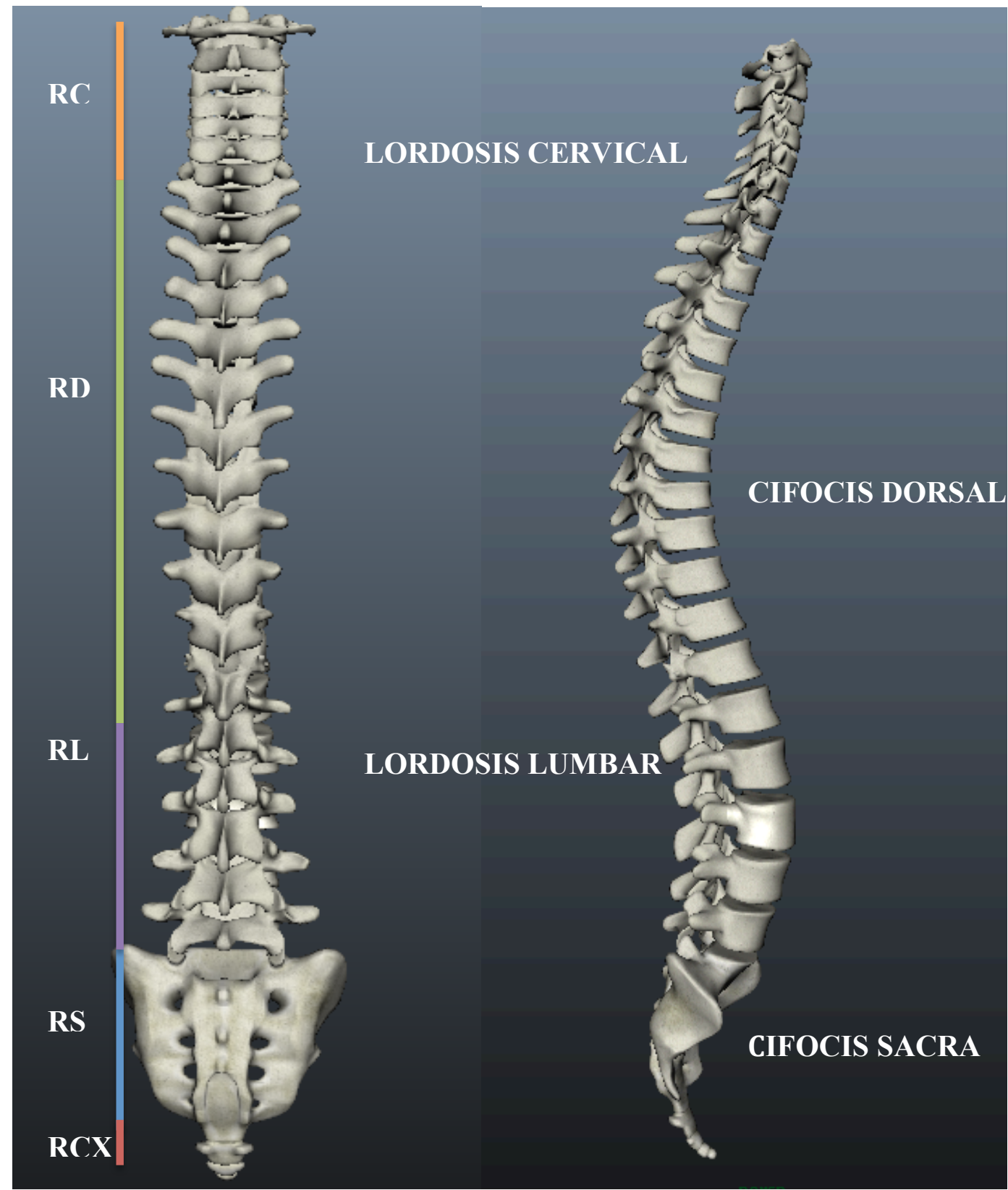

A

B

Figura 45. A y B. Modelado $3 \mathrm{D}$ de la columna vertebral a partir de ventana ósea de TC, muestra una visión panorámica de la columna vertebral normal, con algunos de los detalles anatómicos generales. A: proyección posterior B: proyección lateral derecha. RC: región cervical; RD: región dorsal; RL: región lumbar; RS: región sacra. RCX: región coccígea. 
En la imagen de la columna vertebral completa se puede observar que en el plano sagital, el raquis queda dividido en una serie de curvaturas de naturaleza fisiológica (figs.: 45 y 46), son: cervical, constituida por 7 vértebras (C1-C7) dispuestas con una curvatura de convexidad anterior; torácica o dorsal, constituida por 12 vértebras (D1-D12) de convexidad posterior; lumbar, constituida por 5 vértebras (L1-L5) de convexidad anterior; sacra, constituida por 5 vértebras (S1-S5) de convexidad posterior, habitualmente fusionadas formando un sólo hueso, el sacro. De éstas, las curvaturas cervical y lumbar son las más móviles (figs.: 45 a la 49).

En el plano frontal, el raquis presenta un alineamiento casi perfecto entre cada una de sus vértebras. Teniendo en cuenta los segmentos móviles, la resistencia del raquis con presencia de curvaturas será 10 veces superior que si fuese completamente rectilínea, además gracias a estas curvas sagitales móviles se genera mayor estabilidad y aumenta la resistencia a la compresión axial.

La estática del raquis está condicionada por la morfología de los cuerpos vertebrales, la funcionalidad de los discos intervertebrales, la estructura ligamentosa y la integridad anatomo-fisiológica de la musculatura existente a dicho nivel que, mediante ajustes reflejos por control nervioso, permite el mantenimiento del equilibrio postural. Por su estructura, los cuerpos vertebrales se hallan diseñados para soportar cargas de compresión, ofreciendo una geometría de mayores dimensiones a medida que aumenta la magnitud de las fuerzas a soportar, por lo que las vértebras caudales son más voluminosas que las craneales. Cuando se produce una alteración en cualquiera de estos elementos, las condiciones estáticas cambian, provocando que las acciones y movimientos efectuados en el raquis, comiencen a actuar de forma perjudicial, es por este motivo que resulta de utilidad la valoración de imágenes de la $\mathrm{CV}$ completa. 


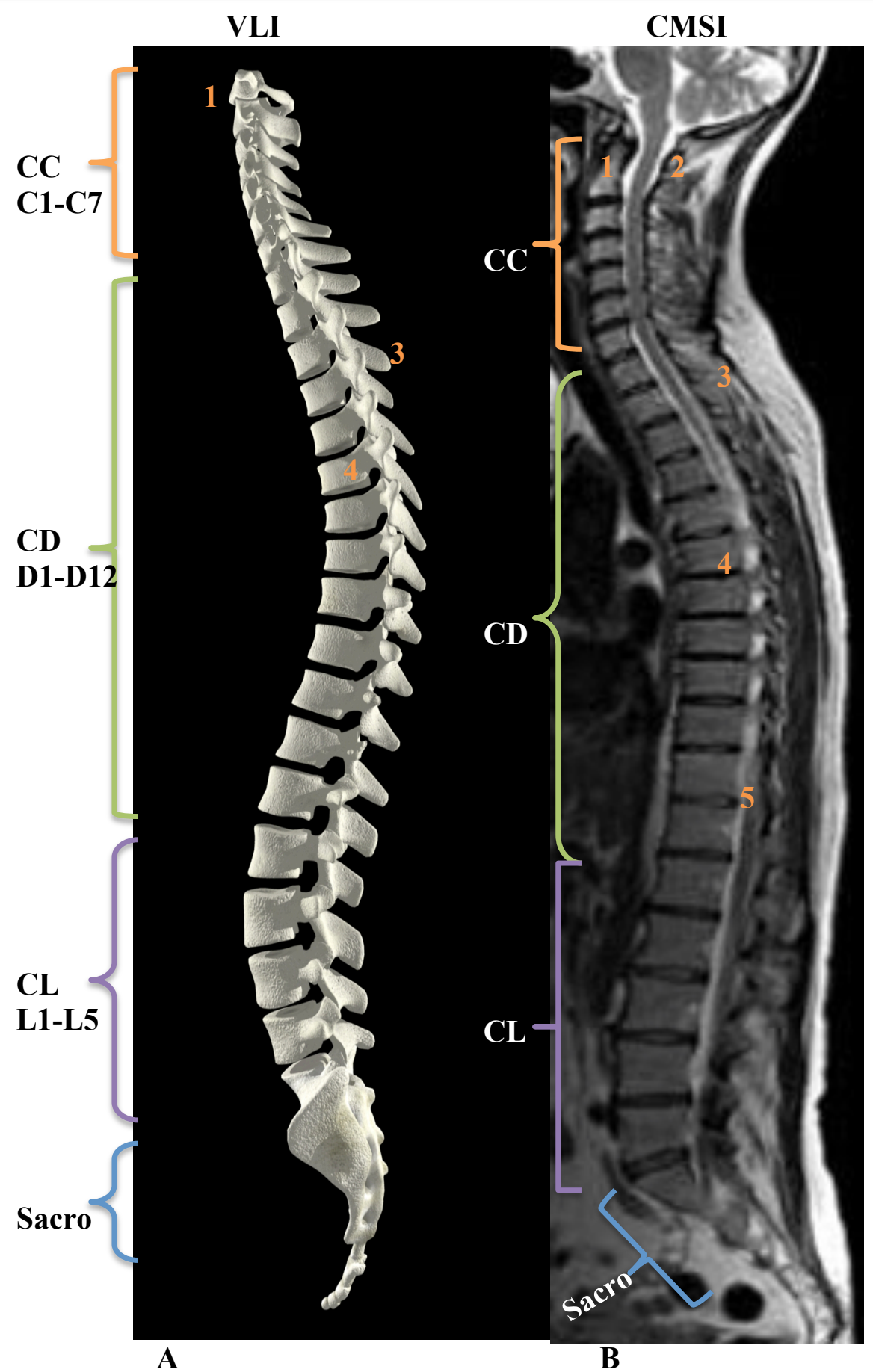

Figura 46. A y B. Correlación de un modelo 3D de la Columna vertebral, con estudio de RM potenciada en T2 eco spin de la columna vertebral. A: modelo $3 \mathrm{D}$ en posición de vista lateral izquierda (VLI). B: corte medio sagital de RM potenciada en T2. La correlación de ambas imágenes muestran la similitud de los detalles anatómicos generales entre ambas imágenes. Columna cervical $(\mathrm{CC})$ desde la primera vértebra cervical hasta la séptima vértebra cervical (C1-C7); columna dorsal (CD), desde la primera vértebra dorsal hasta la duodécima vértebra dorsal (D1-D12); columna lumbar (CL), desde la primera vértebra lumbar hasta la quinta vértebra lumbar (L1-L5); Sacro, (S1-S5). 1 y 2, primera vértebra cervical o atlas (C1) y odontoides; 3 , apófisis espinosa; 4, cuerpo vertebral; 5 , Canal medular y medula espinal. 


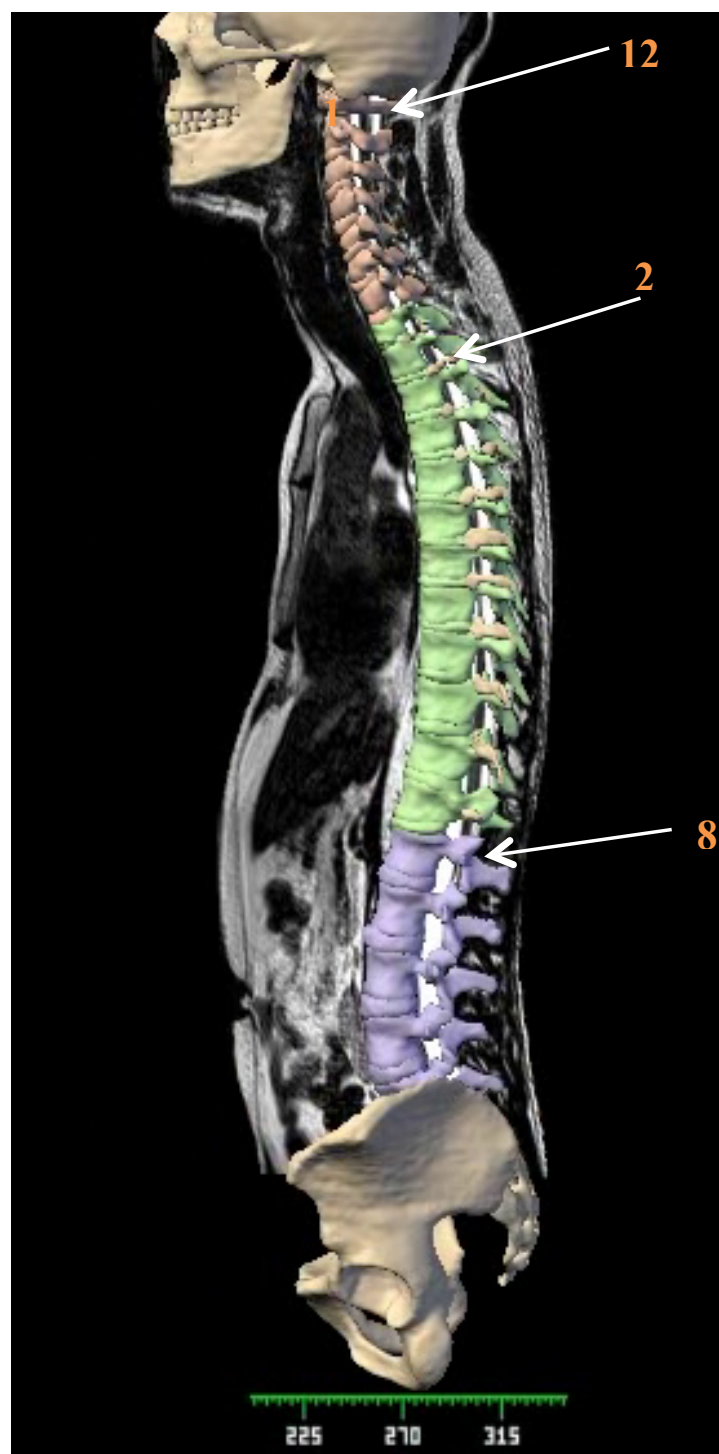

A

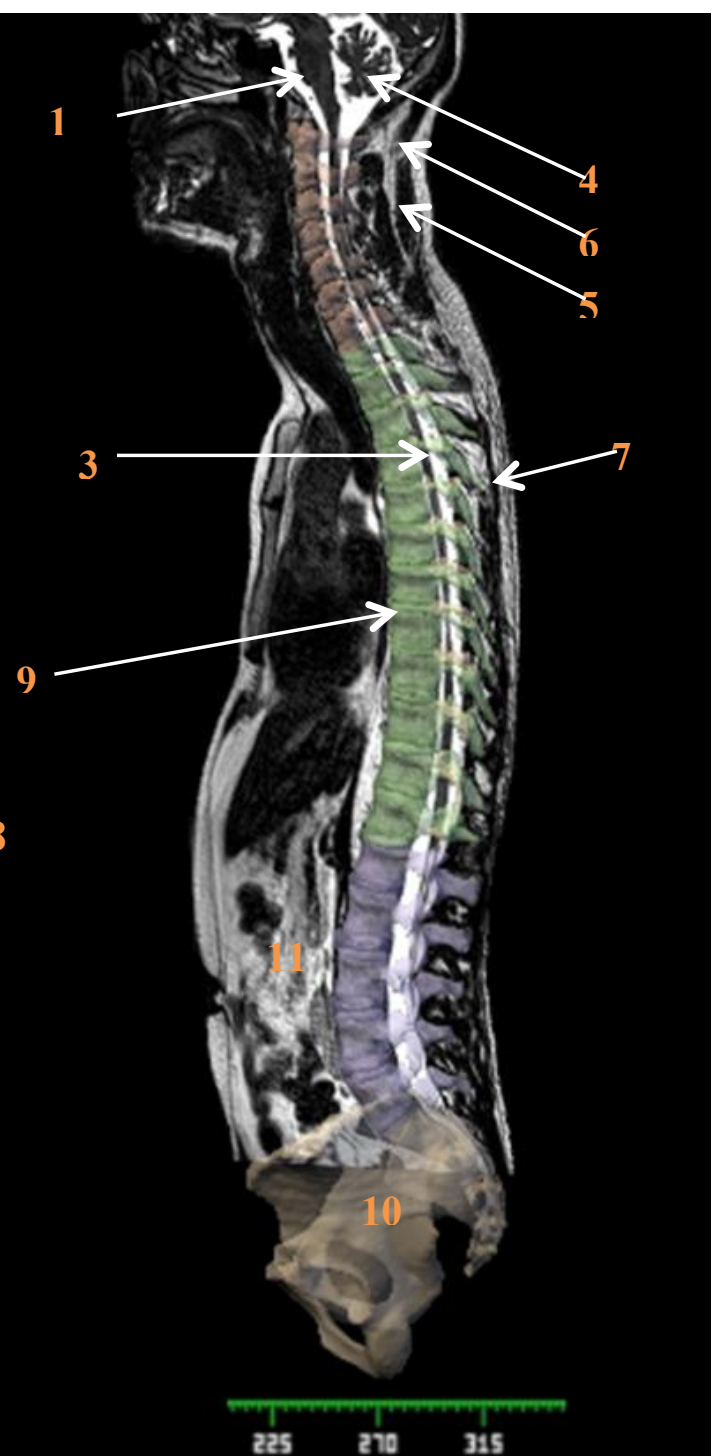

B

Figura 47. A y B. Modelo 3D de la Columna vertebral completa incluyendo cráneo y pelvis, embebidas en cortes medio sagitales del tronco de RM potenciada en T2. Se muestra la relación de la CV modelada con las estructuras y órganos de línea media. En las imágenes se observan los músculos paravertebrales con sus inserciones desde la unión cráneo-cervical, hasta la región lumbo-sacra. Nótese en ambas imágenes que la parte ósea se observa más transparente en la imagen $\mathbf{B}$ (efecto realizado con el visor anatómico funcional), con lo cual también es posible ver la relación del canal medular con las diferentes estructuras. 1, protuberancia; 2 , agujero de conjunción; 3 , médula y canal medular; 4 , cerebelo; 5 , músculo semiespinoso; 6 , ligamento nucal; 7, ligamento supraespinoso; 8, ligamento interespinoso; 9, disco intervertebral. 10, sacro y pelvis; 11, cavidad peritoneal (línea media); 12, unión cráneo-cervical. Con el visor anatómico funcional es posible quitar o transparentar las estructuras óseas con el objetivo de valorar su relación con las partes blandas (en la figura $\mathbf{B}$ se ha retirado el cráneo). 


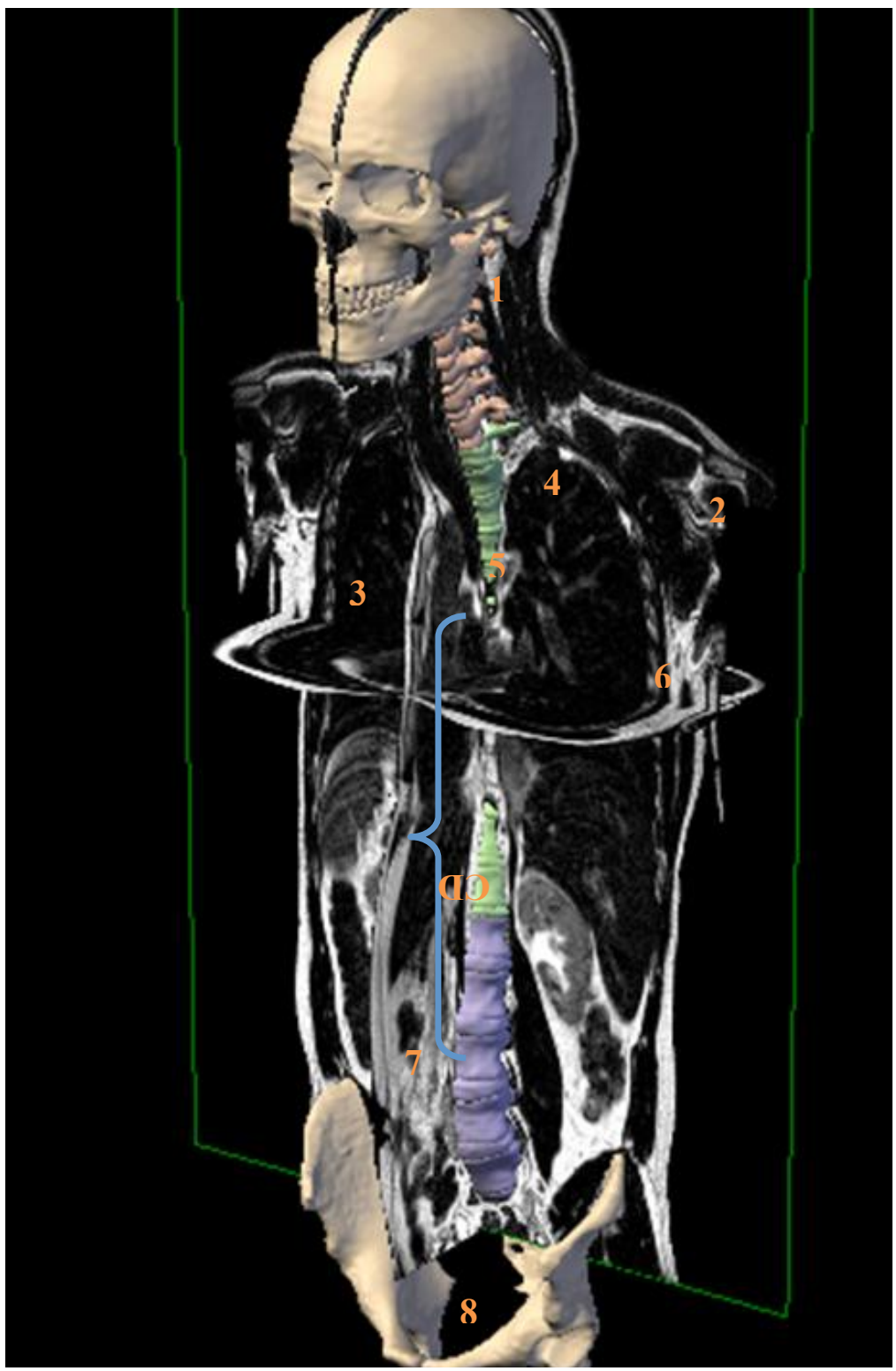

Figura 48. CV completa, cráneo y pelvis, vista anterior oblicua. EL modelo 3D fue embebido en imágenes de RM del tronco (corte coronal), además se agrega corte sagital de línea media y corte axial a nivel de mediastino (D9). 1, ligamento nucal o rafe medio, es la membrana fibrosa que se extiende desde la cresta occipital externa hasta la apófisis espinosa de la séptima vértebra cervical; 2, Hombro y cintura escapular; 3, parenquima pulmonar derecho; 4, apex pulmonar izquierdo; 5 , cuarta vértebra torácica, más abajo se encuentra la bifurcación traqueal o carina traqueal (a nivel de la quinta vertebral torácica), saliendo el bronquio principal derecho a $2 \mathrm{~cm}$, y el bronquio del lóbulo superior izquierdo a $5 \mathrm{~cm} ; 6$, corte coronal de arcos costales; 7 , músculo iliopsoas, constituido por dos porciones: psoas e ilíaco. El psoas, se inserta en las vértebras D12 y las cinco lumbares (D12-L5), así como en la base de las apófisis costiformes correspondientes, y desciende hacia la fosa ilíaca, dónde se une con la porción ilíaca; 8, cavidad pélvica. 


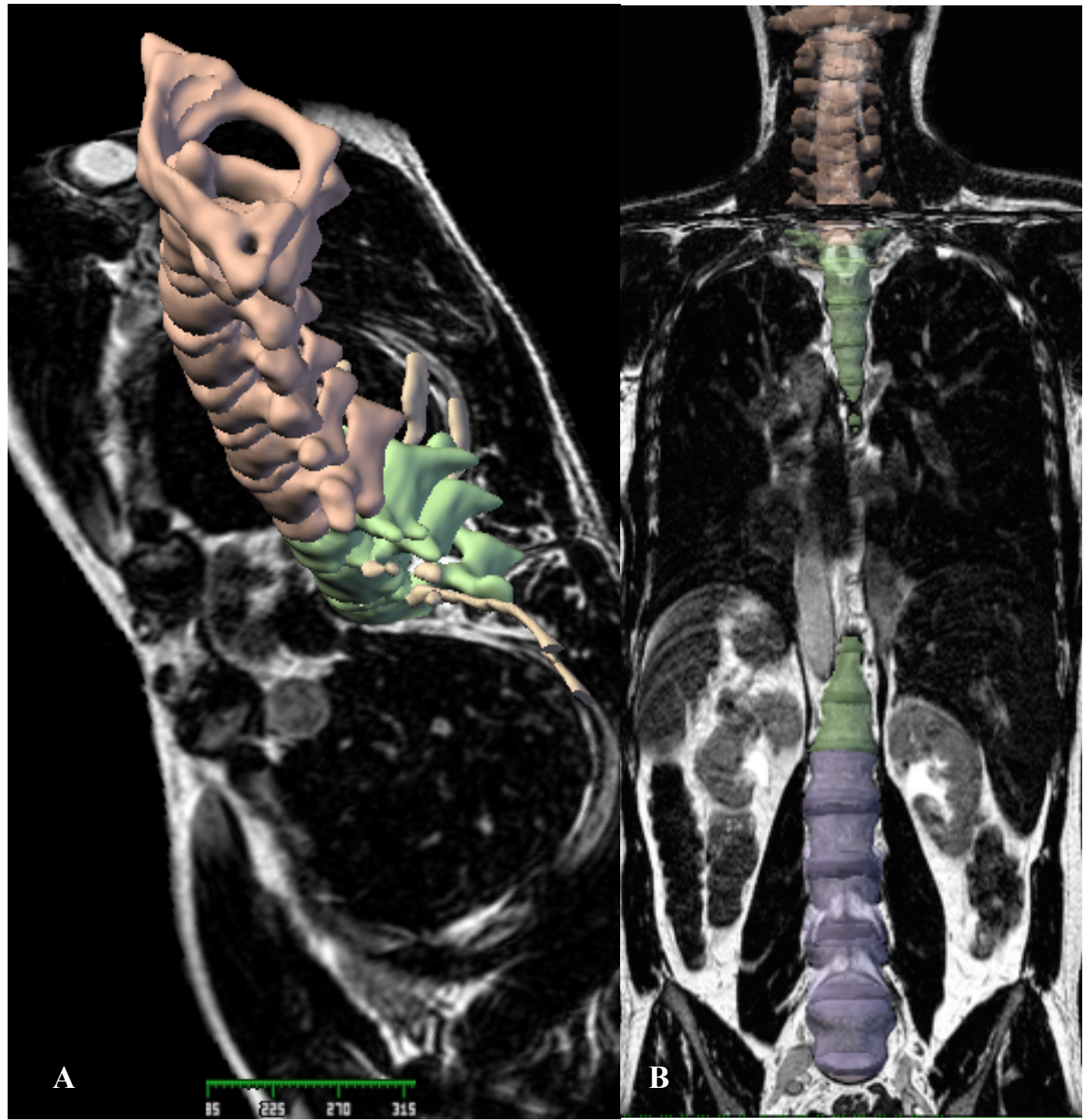

Figura 49. Esta imagen muestra la correcta correlación anatómica y radiológica que existe entre el modelo 3D y los órganos y estructuras del tronco. A: Vista cráneo-caudal oblicua. B: proyección anterior. 


\subsubsection{Región cervical}

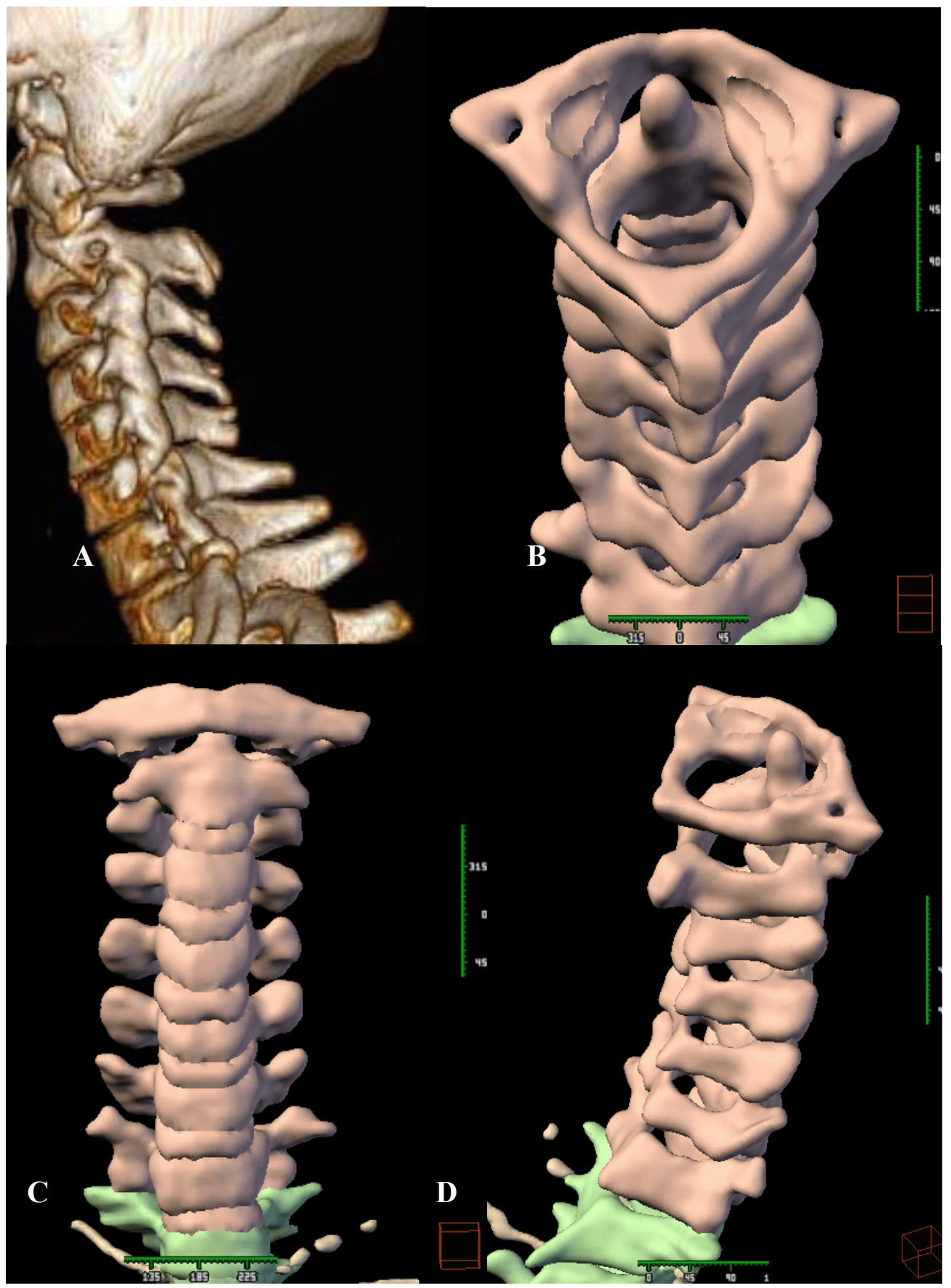

Figura 50. A, B, C y D. Modelo $3 \mathrm{D}$ de la columna cervical en las diferentes posiciones del espacio. A: Vista lateral izquierda de reconstrucción a partir de ventana ósea de TC. B: modelo 3D en proyección posterior con ligera inclinación cráneo-caudal. C: vista anterior. D: vista posterior oblicua. Con este tipo de modelo $3 \mathrm{D}$, se valora la columna cervical desde las diferentes proyecciones espaciales. 
La columna cervical se divide en superior C1-C2 e inferior C3-C7. El raquis superior $\mathrm{C} 1-\mathrm{C} 2$ poseen una morfología diferente al resto de las vértebras. Los movimientos cervicales tienen su máxima rotación en la articulación atlanto-axoidea (C1-C2).

Analizando el raquis por segmentos, el segmento cervical ocupa el primer tercio del raquis. Entre C1-C2 no existe disco. Los discos intervertebrales cervicales son más gruesos por delante que por detrás, siendo los responsables de la curvatura lordótica. Debido a esta geometría, el núcleo pulposo se localiza más ventralmente respecto a las demás curvas del raquis (figs.: 51-56).

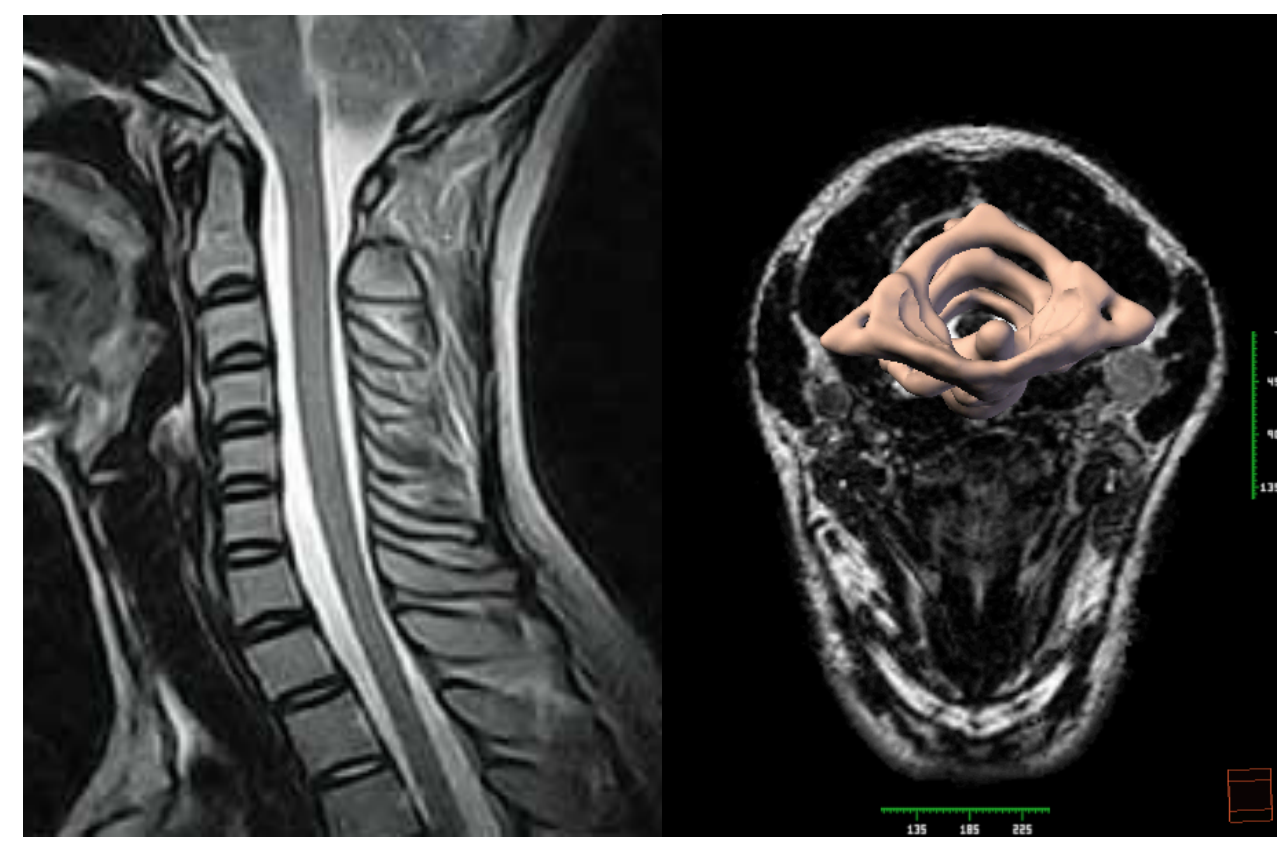

A

B

Figura. 51. A y B. Corte sagital de RM de columna cervical y Modelo 3D en proyección cráneo-caudal mostrando el primer segmento de la columna cervical (segmento C1-C2). A: Corte sagital de RM de columna cervical, potenciado en T2. B: corresponde al mismo modelo 3D de la figura 50 que se ha movido a la proyección cráneo-caudal y embebido en un corte axial de RM para una mejor valoración del atlas y la apófisis odontoides. 

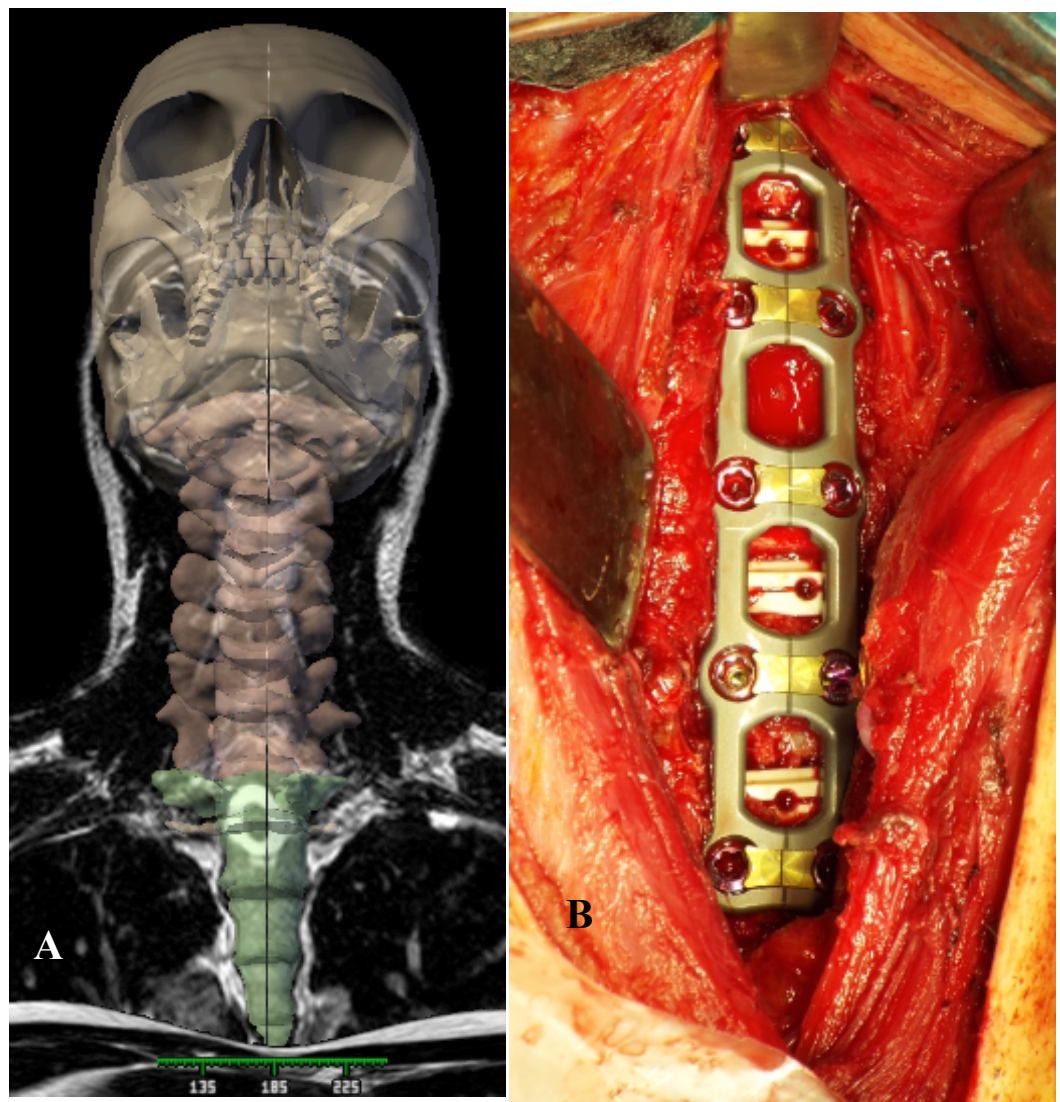

Figura 52. A: Vista anterior de la columna cervical y correlación con abordaje anterior amplio a la columna cervical. A: modelo 3D en proyección anterior embebido en una imagen de RM de partes blandas de la región cervical y tronco superior. B: Abordaje a la columna cervical por vía anterior, muestra artrodesis C3-C4 , C5-C6 y C6-C7 más fijación con placa anterior.

La unión cráneo-cervical o región occipito-cervical (ROC), representa la zona de transición entre la columna vertebral y el cráneo. Está formada por el occipital, las dos primeras vértebras cervicales y las estructuras neurales alojadas en ellas, la ROC constituye una unidad funcional donde se produce la mayor parte de los movimientos de la cabeza. Posee características morfológicas, embriológicas y funcionales propias, diferentes del resto del eje cráneo-espinal, que explican su especial predisposición mórbida. En las figuras 50-51 y 53-56, se muestran detalles anatómicos de la unión cráneo-cervical en las diferentes proyecciones espaciales. 

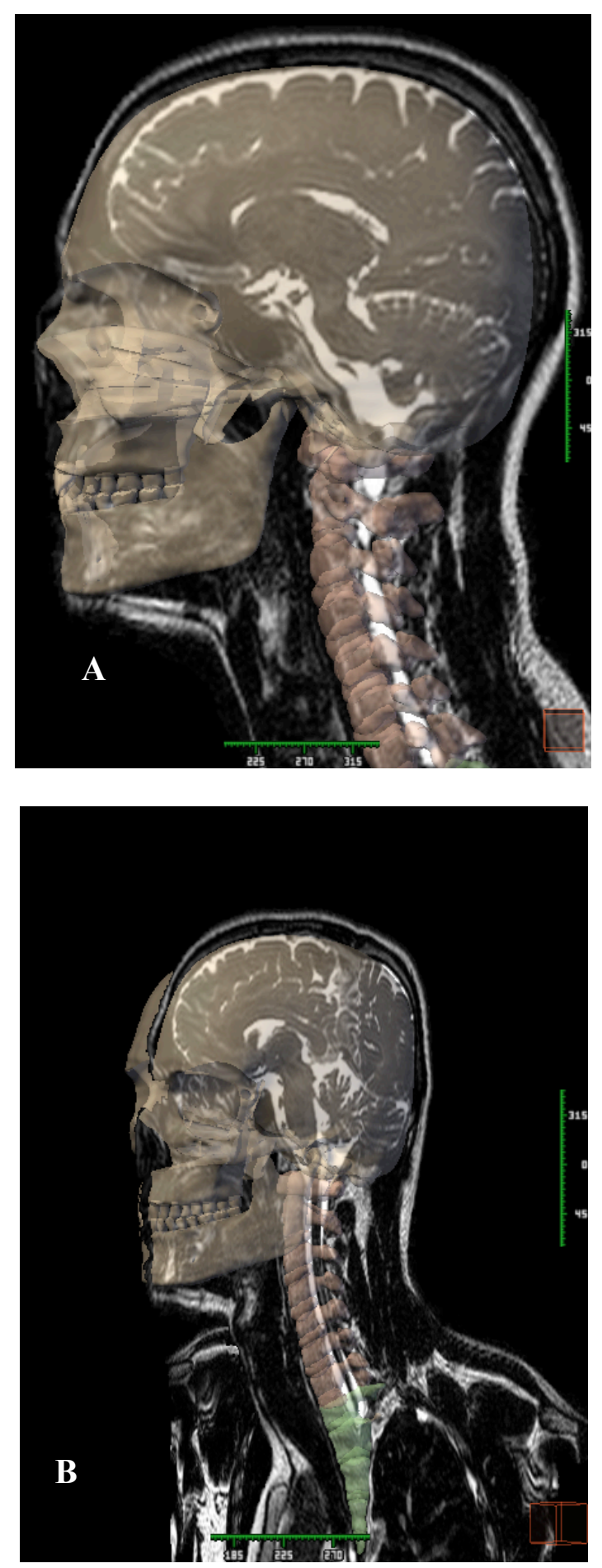

Figura 53. A y B. Reconstrucción $3 \mathrm{D}$ de la Columna cervical y fusión con estudios de RM de cabeza y cuello. 

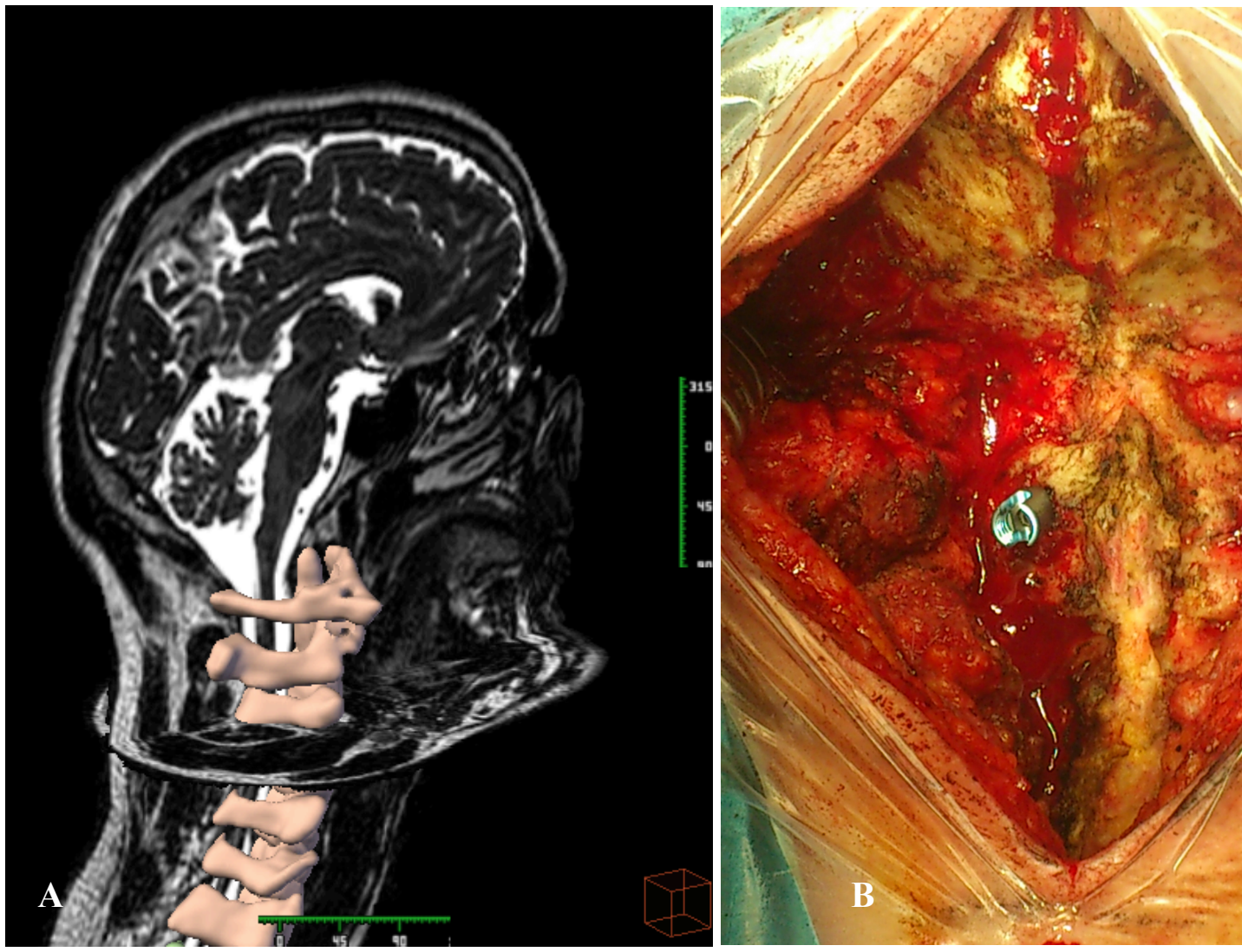

Figura 54. A-B. Modelo 3D que muestra en detalle la unión cráneo cervical. A: proyección posterior oblicua de modelo 3D embebido en RM potenciada en T2 eco spin cerebral y cervical. El objetivo de esta reconstrucción 3D es valorar tanto la unión cráneo-cervical como la fosa craneal posterior que incluyen el hueso occipital, el agujero magno, los dos primeros segmentos vertebrales, sus músculos, articulaciones y ligamentos. Estas estructuras rodean el bulbo raquídeo, la mitad caudal del cerebelo y la porción inicial de la médula espinal, los pares craneales bajos y el espacio subaracnoideo subyacente. B: abordaje a la unión cráneo-cervical por vía posterior, donde se observa la anatomía quirúrgica de la unión cráneo cervical. 

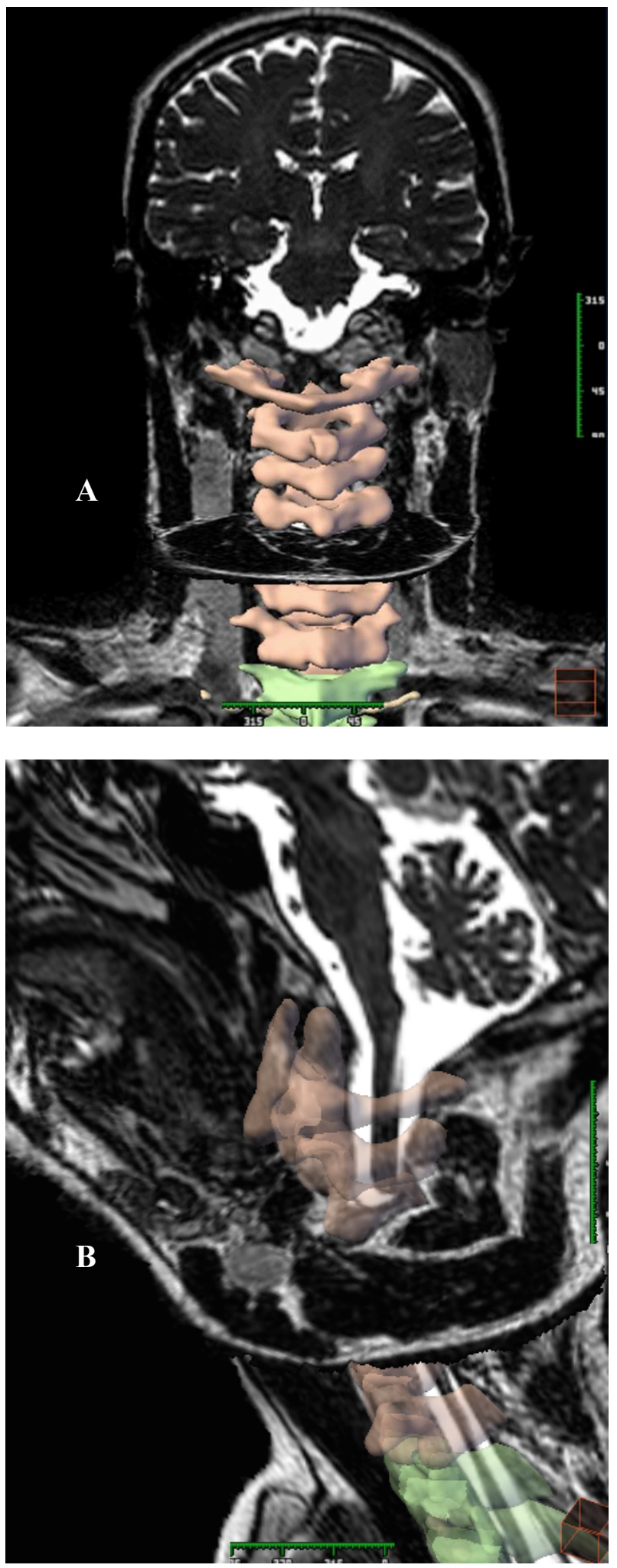

Figura 55. A y B. Modelo 3D y RM en diferentes proyecciones del espacio. A: proyección posterior con cortes de RM coronal y axial a nivel del nivel C4-C5. B: el mismo modelo 3D tras rotar la imagen y colocación de un nuevo corte sagital de RM. 


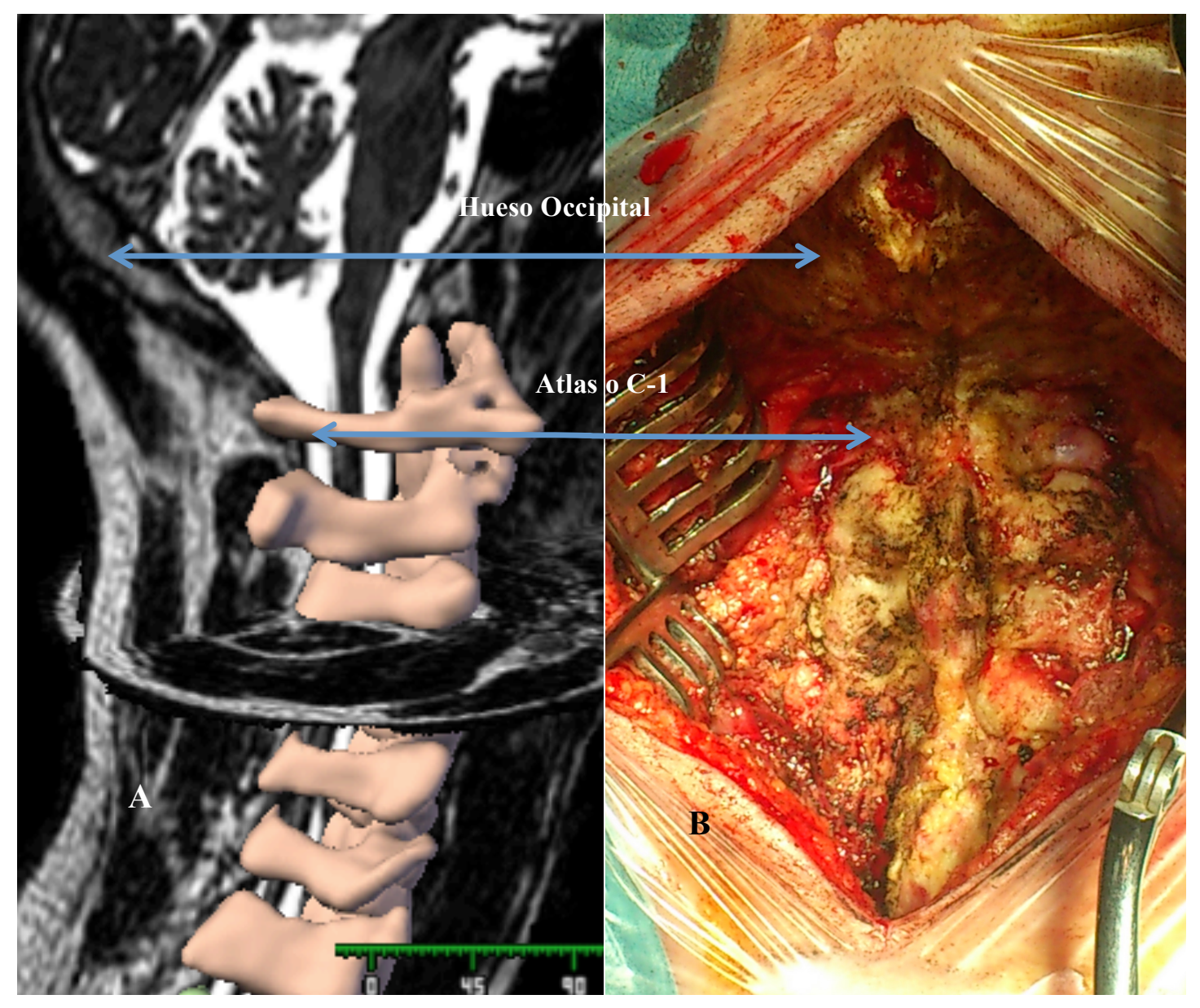

Figura 56. Correlación anatómica de modelo $3 \mathrm{D}$ con abordaje de la unión cráneo-cervical. A: modelo 3D de la columna cervical, embebido en estudio de RM cráneo-cervical. B: abordaje a la unión cráneo-cervical por vía posterior, tras la disección de la musculatura subperiosticamente y exposición de los elementos posteriores.

\subsubsection{Región dorsal}

El segmento torácico está más posterior respecto al eje de gravedad del tórax, se extiende desde D1 a D12 y presenta una curva ligeramente cifótica, producida por la forma vertebral en el plano medio. La altura de los discos dorsales, es idéntica anterior y posteriormente, por lo que la cifosis fisiológica es debida más a la estructura cuneiforme de los cuerpos vertebrales que a la forma de los discos intervertebrales (ver los modelos 3D del segmento dorsal en las figs.: 57-62). 
La participación del raquis dorsal en el mantenimiento de la estática y de la movilidad del eje vertebral es secundaria. Biomecánicamente, el raquis torácico es relativamente más estable que el lumbar por sus estructuras circundantes: costillas y musculatura.

El raquis torácico en postura cifótica obliga a las láminas y a los ligamentos amarillos, a resistir fuerzas de tensión. Las carillas articulares son grandes y forman parte de un amplio arco de apertura anterior, donde una relación axial mínima puede cumplirse. Así, el ángulo de la carilla articular dorsal con relación a la horizontal de la superficie somática aumenta a más de $45^{\circ}$ respecto a la cervical que es un ángulo agudo, lo cual permite una movilidad en flexión y extensión muy limitada por la parrilla costal.

Los diámetros pediculares de las vértebras dorsales son pequeños lo que obliga al uso de tornillos adecuados (cuando el paciente requiere instrumentación transpedicular). En todas las vértebras, los pedículos constituyen la parte más fuerte y hace de puente entre la columna posterior de la articular y el cuerpo vertebral. 


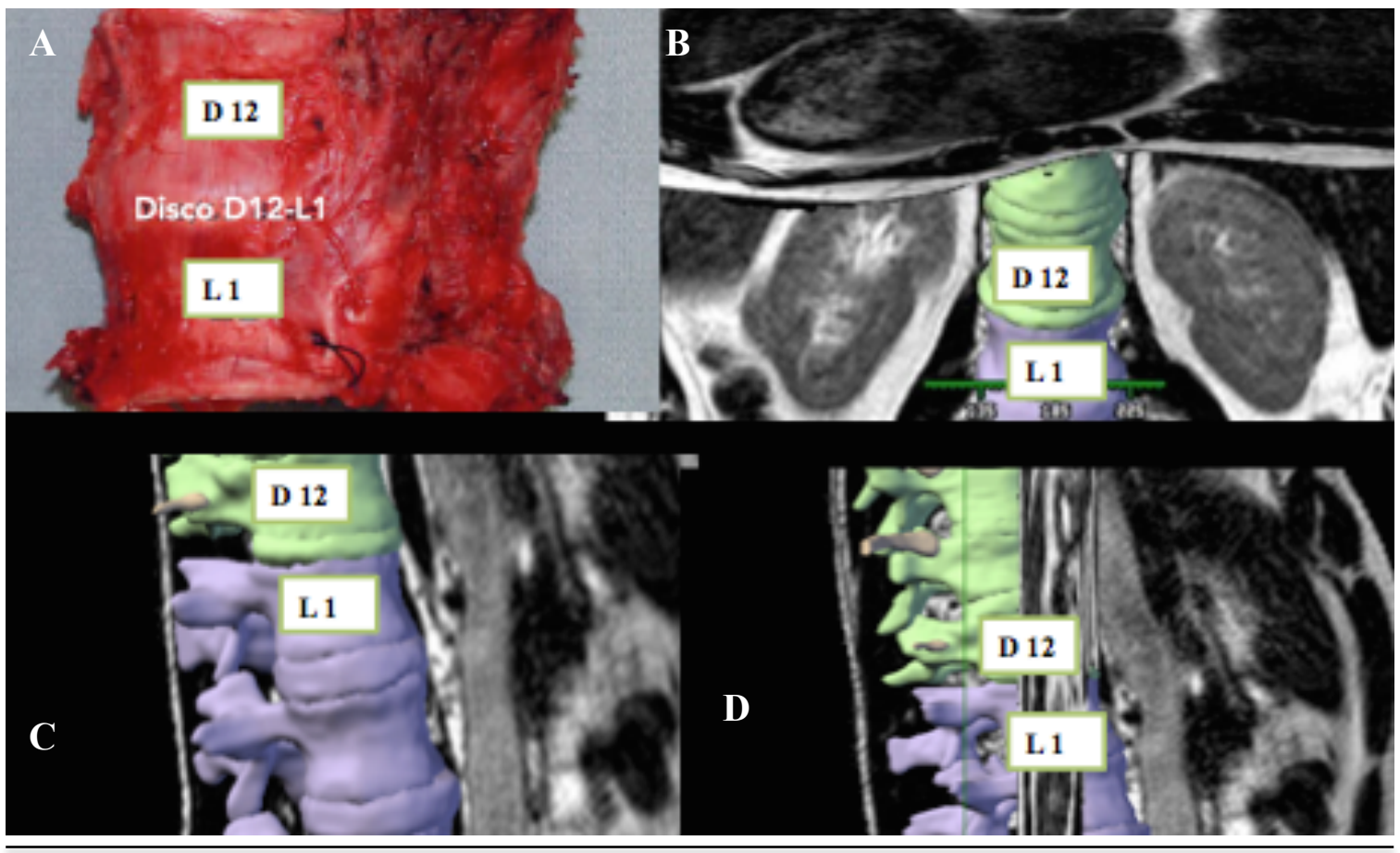

Figura 57. A, B, C y D. Correlación de la charnela dorso-lumbar (vértebras D12-L1) con modelo 3D en diferentes proyecciones espaciales. A: charnela dorso-lumbar (tras vertebrectomía radical de espécimen). B, C y D: modelo 3D de la charnela dorso-lumbar en diferentes posiciones espaciales, el cual se encuentra embebido en secciones de RM de la misma región.

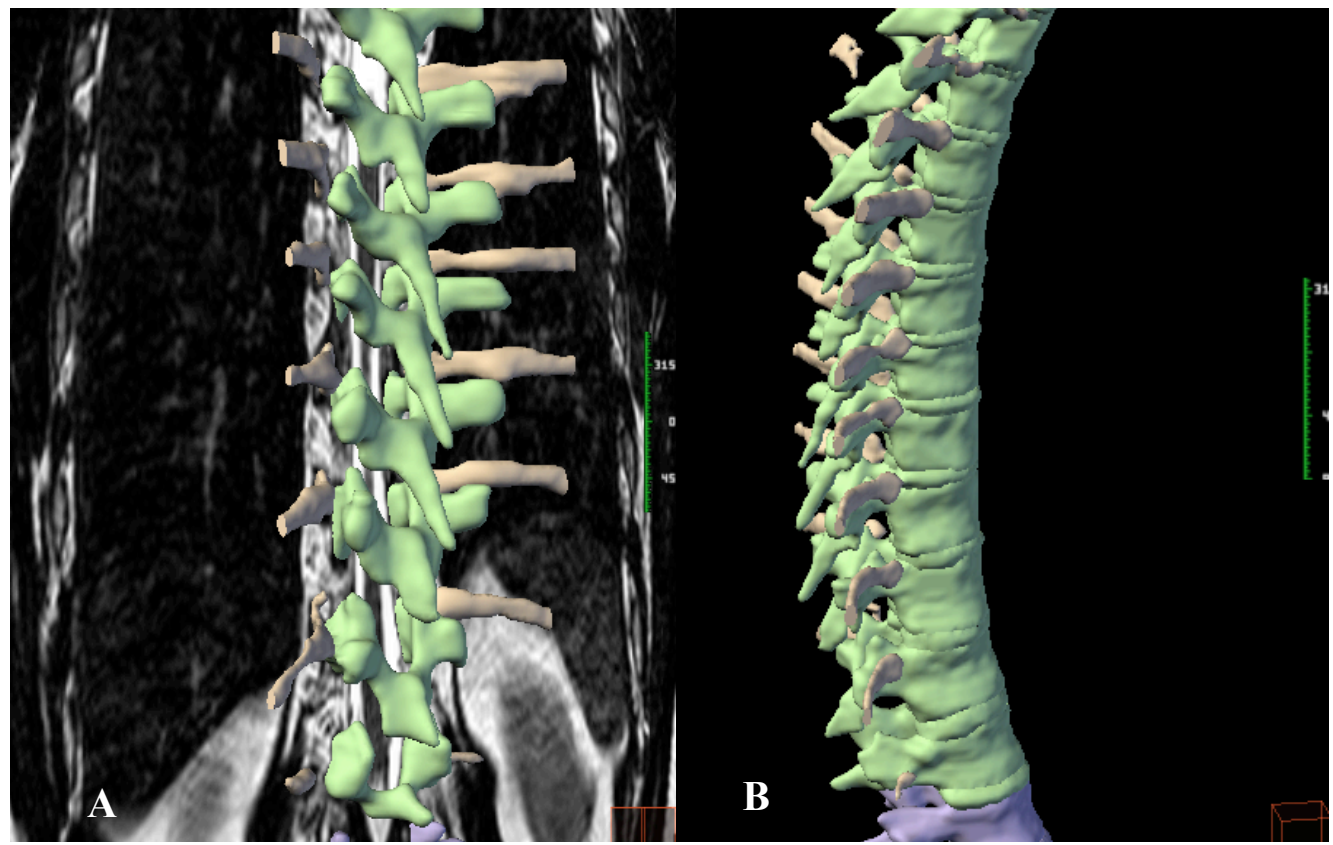

Figura 58. A y B. Modelo 3D de la columna dorsal. A: vista posterior oblicua de la columna dorsal, embebida en sección coronal de RM. B: modelo 3D en posición lateral. 

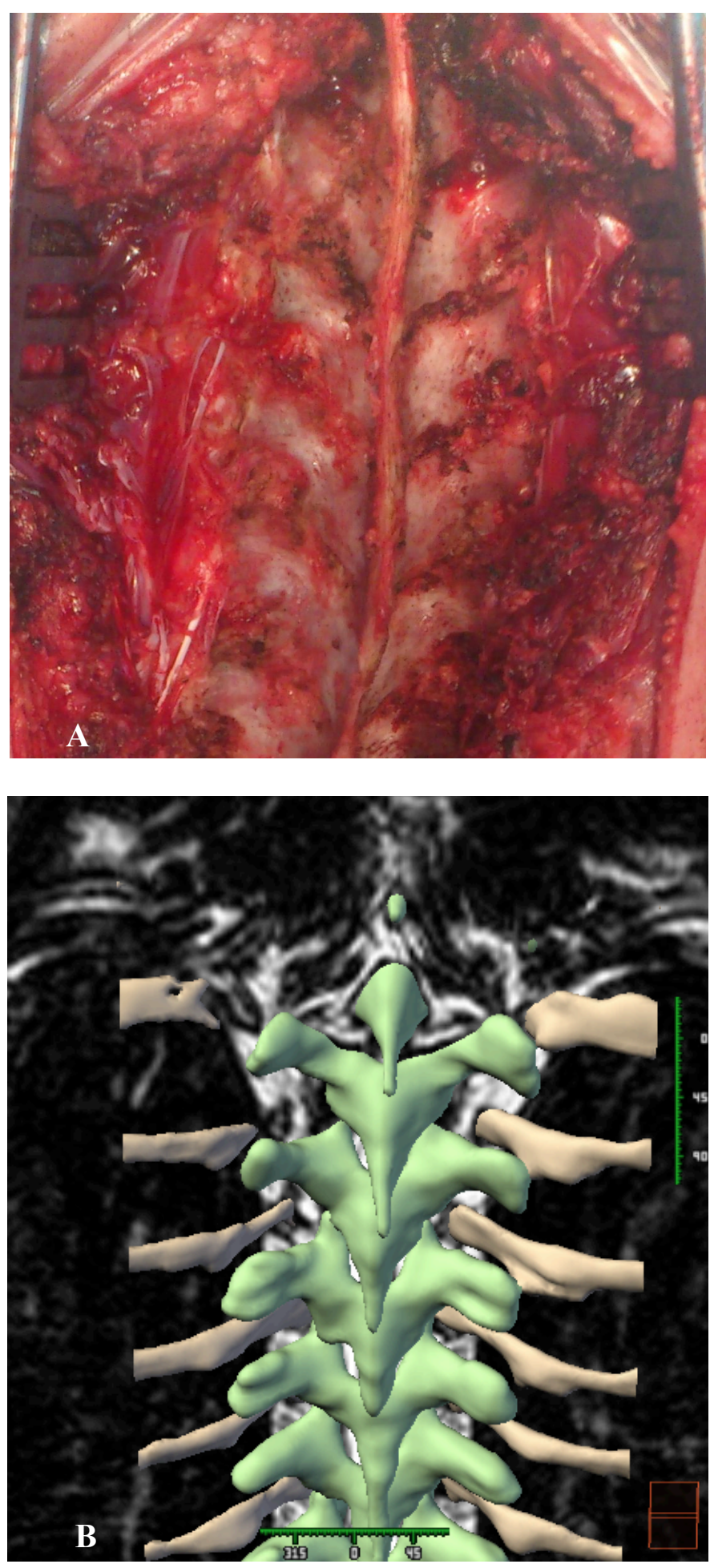

Figura 59. A y B. Correlación de la anatomía quirúrgica de un abordaje por vía posterior a la columna dorsal (A) con los elementos posteriores del modelo 3D de Columna dorsal (B). 


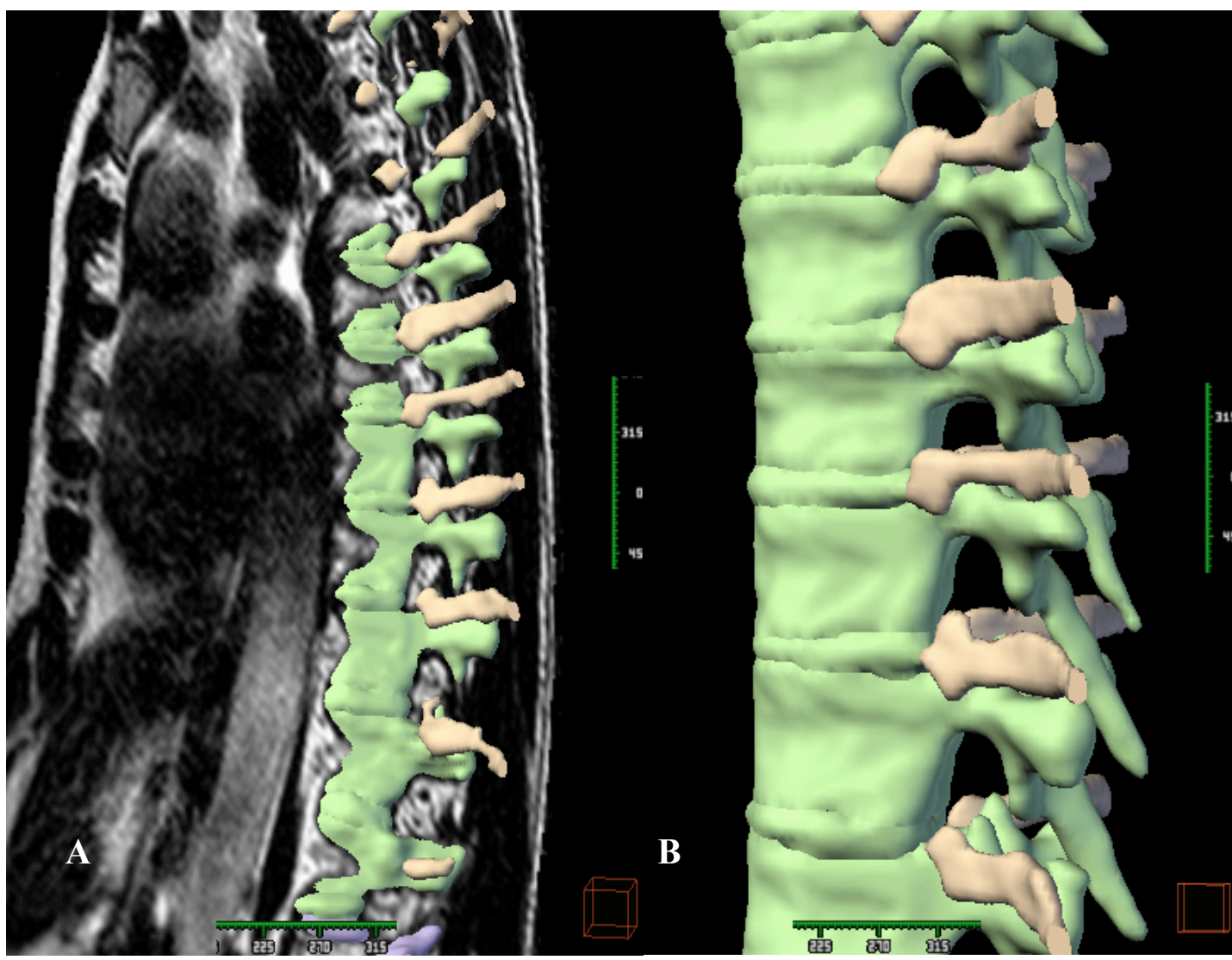

Figura 60. A y B. Modelo 3D de la columna dorsal, vista lateral izquierda. A: correlación del modelo 3D de la columna dorsal con las partes blandas paramedial de la caja torácica. B: El mismo modelo 3D aumentado de tamaño, para valoración de la altura de los cuerpos vertebrales, la altura y alineación de los discos intervertebrales, los pedículos y el diámetro de los agujeros de conjunción. 


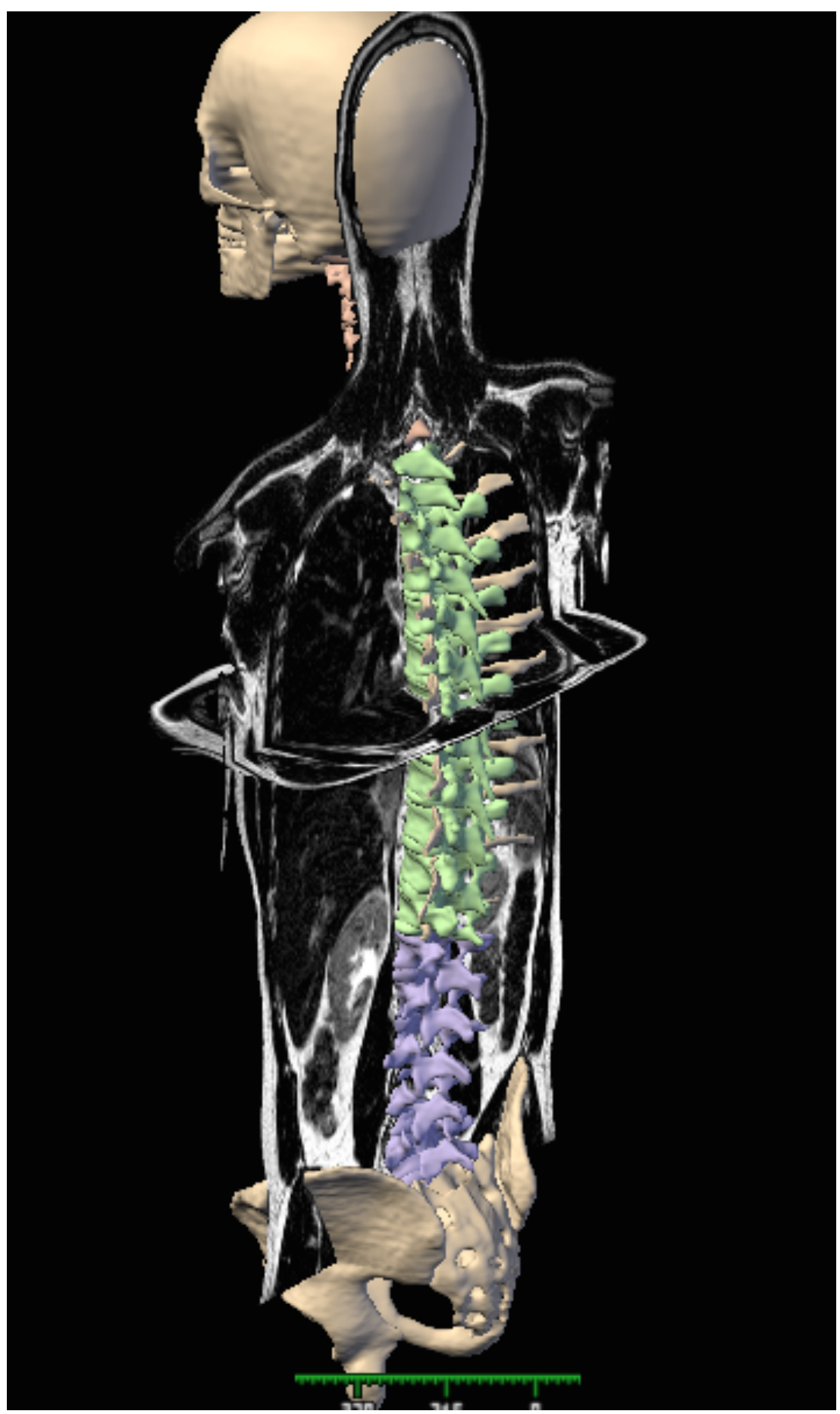

Figura 61. Modelo 3D para una valoración global de la columna dorsal sin perder de vista el objetivo, en esta figura se puede observar una proyección posterior de la columna vertebral, pelvis, cráneo y representación de las partes blandas mediante cortes de RM en las diferentes posiciones del espacio. 


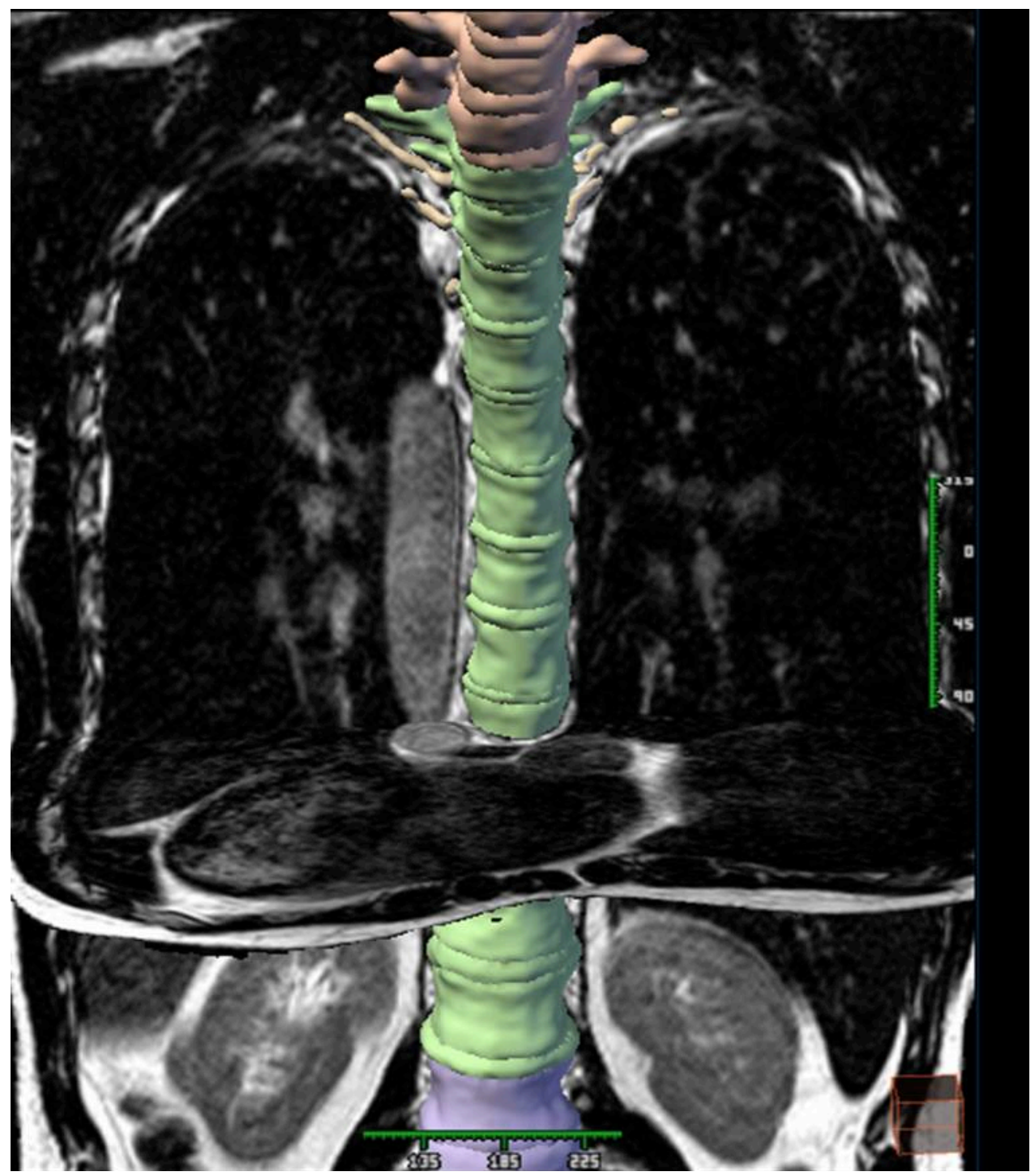

Figura 62. Modelo 3D de la columna dorsal en proyección anterior embebido en cortes coronal y axial de RM. 


\subsubsection{Región lumbo-sacra}

La columna lumbo-sacra, está compuesta por cinco vértebras lumbares de L1 a L5 y cinco vértebras sacras ( $\mathrm{S} 1$ a $\mathrm{S} 5$ ), éstas últimas fusionadas para constituir el hueso sacro. En ésta región los cuerpos vertebrales aumentan de volumen de arriba hacia abajo al igual que las apófisis transversas, donde el factor peso tiene importancia en este desarrollo.

Las vértebras lumbares son las más grandes y más fuertes de la columna vertebral. Los cuerpos de las vértebras lumbares suelen ser más amplios en el plano transversal que largos en el plano anteroposterior. Las tres vértebras lumbares bajas, a menudo en el plano sagital forman dimensiones más altas anteriormente en forma de cuña, contribuyendo así a la lordosis lumbar fisiológica. Los pedículos lumbares tienden a ser relativamente más grande en comparación con los cervicales o torácicos.

El pedículo L5 es ovalado con un diámetro horizontal mayor, lo que produce junto con la angulación de la primera vértebra sacra un agujero de conjunción anatómicamente reducido entre L5-S1 en relación al tamaño de los agujeros de conjunción superiores. La angulación pedicular de las vértebras lumbares en dirección medial aumenta de Ll a L5. Aproximadamente hay $5^{\circ}$ de angulación del pedículo de L5 hacia la línea media, ésta angulación va aumentando 5 grados hasta la quinta vértebra lumbar con $25^{\circ}$ aproximadamente. Las apófisis transversas de la columna lumbar suelen estar bien desarrolladas, corresponden embriológicamente a las costillas rudimentarias.

En las figuras 63 hasta la 68, se muestran modelos 3D de la columna lumbo-sacra, en las diferentes proyecciones espaciales. 


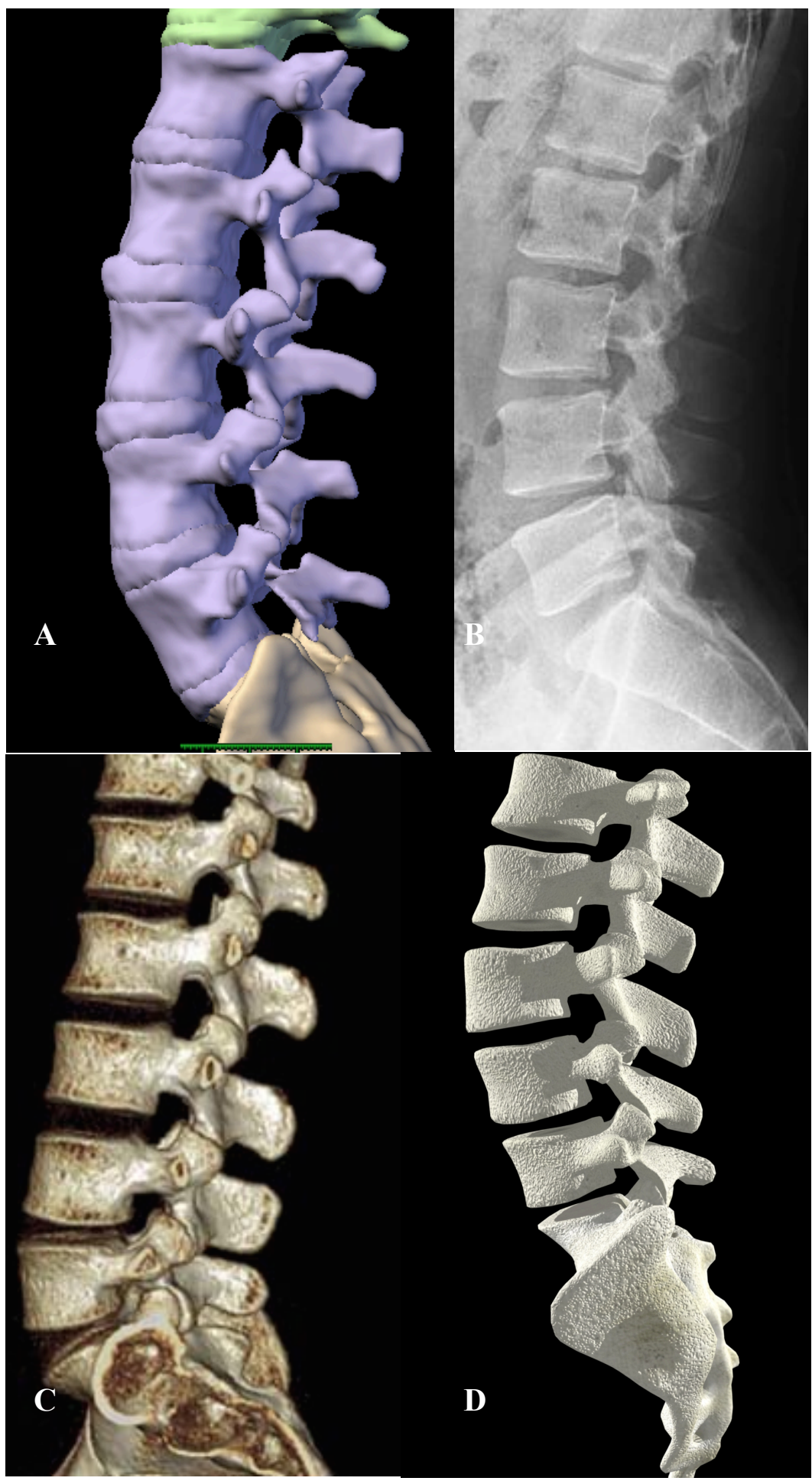

Figura 63. A, B, C Y D. Correlación radiológica de modelo 3D de la columna lumbo-sacra en proyección lateral. A: Vista lateral de modelo 3D de la columna lumbo-sacra. B: radiografía simple lateral de columna lumbo-sacra. C: proyección lateral de tomografía computarizada multicorte. D: Modelo 3D de la columna lumbo-sacra, tras retirar los discos intervertebrales. 


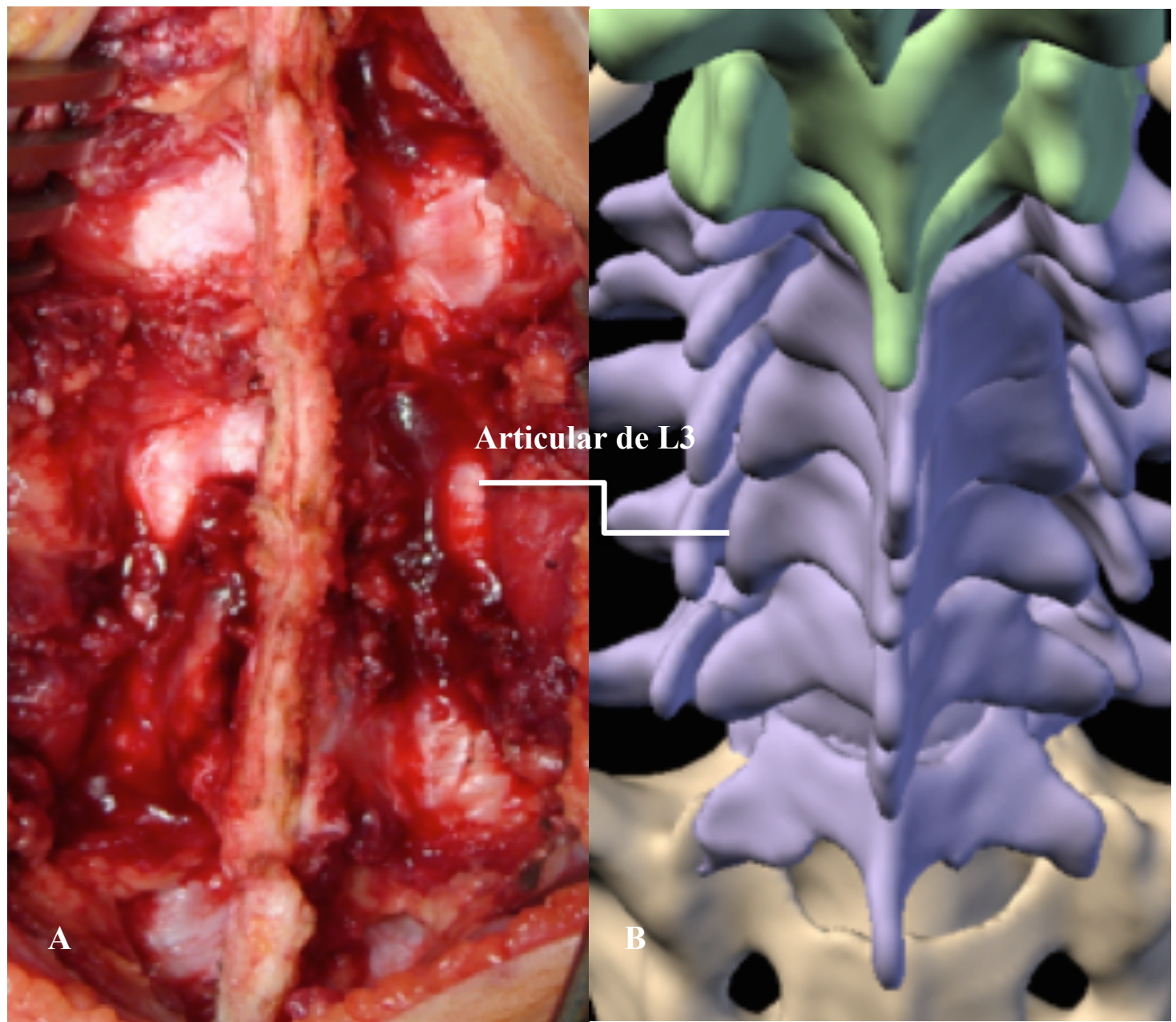

Figura 64. A y B. Correlación de modelo $3 \mathrm{D}$ de la región lumbo-sacra con la imagen de un abordaje lumbar posterior amplio. A: abordaje a la columna lumbar por vía posterior, muestra los niveles L2-L4. B: vista posterior oblicua de modelo 3D lumbo-sacro. 


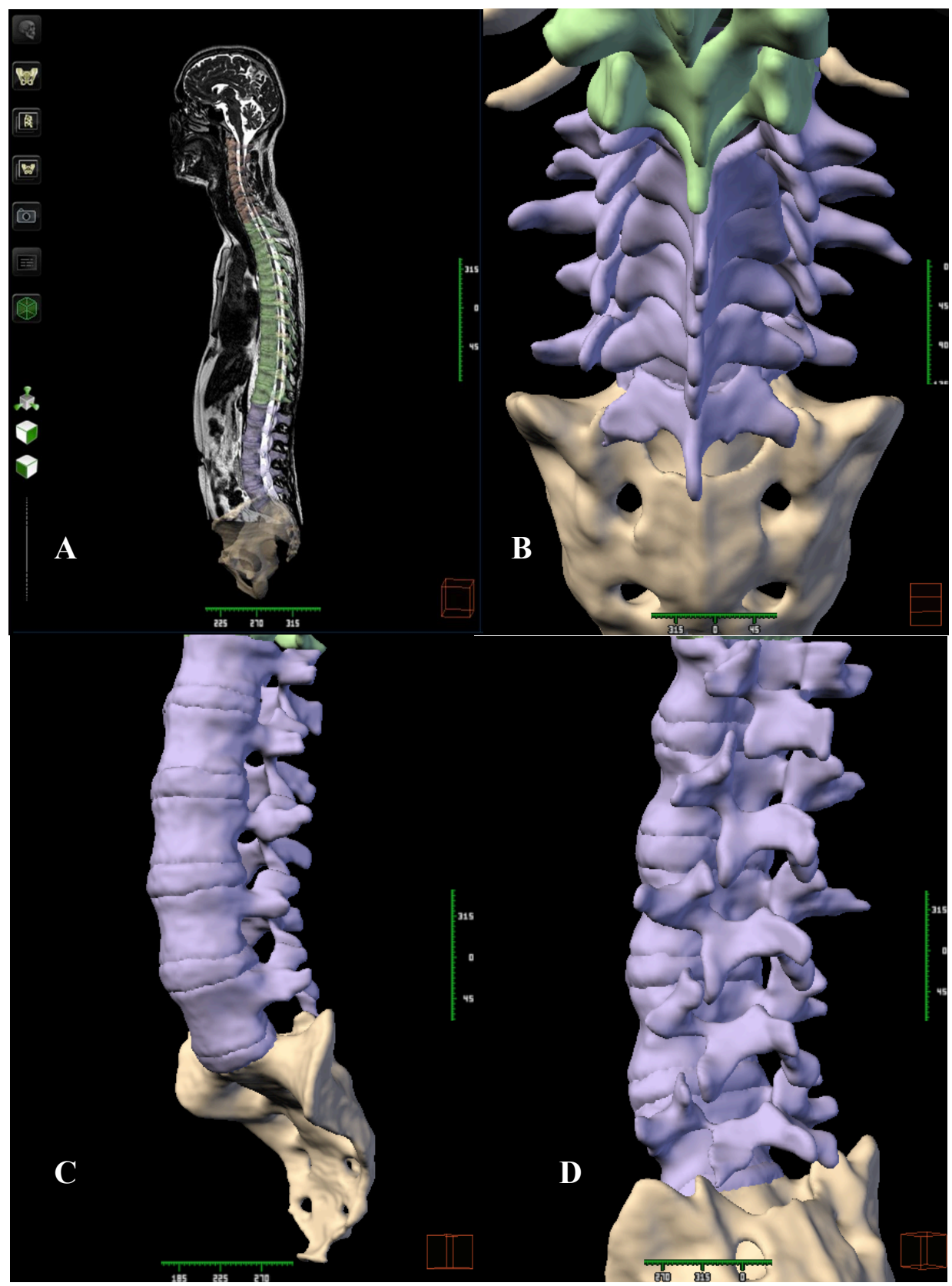

Figura 65. A: Visualización de interface de usuario desde donde es posible manipular el modelo 3D, mediante pequeños íconos dispuestos verticalmente en la parte izquierda del visor. B, C y D: detalles 3D de la columna lumbo-sacra, vista desde diferentes proyecciones espaciales. 


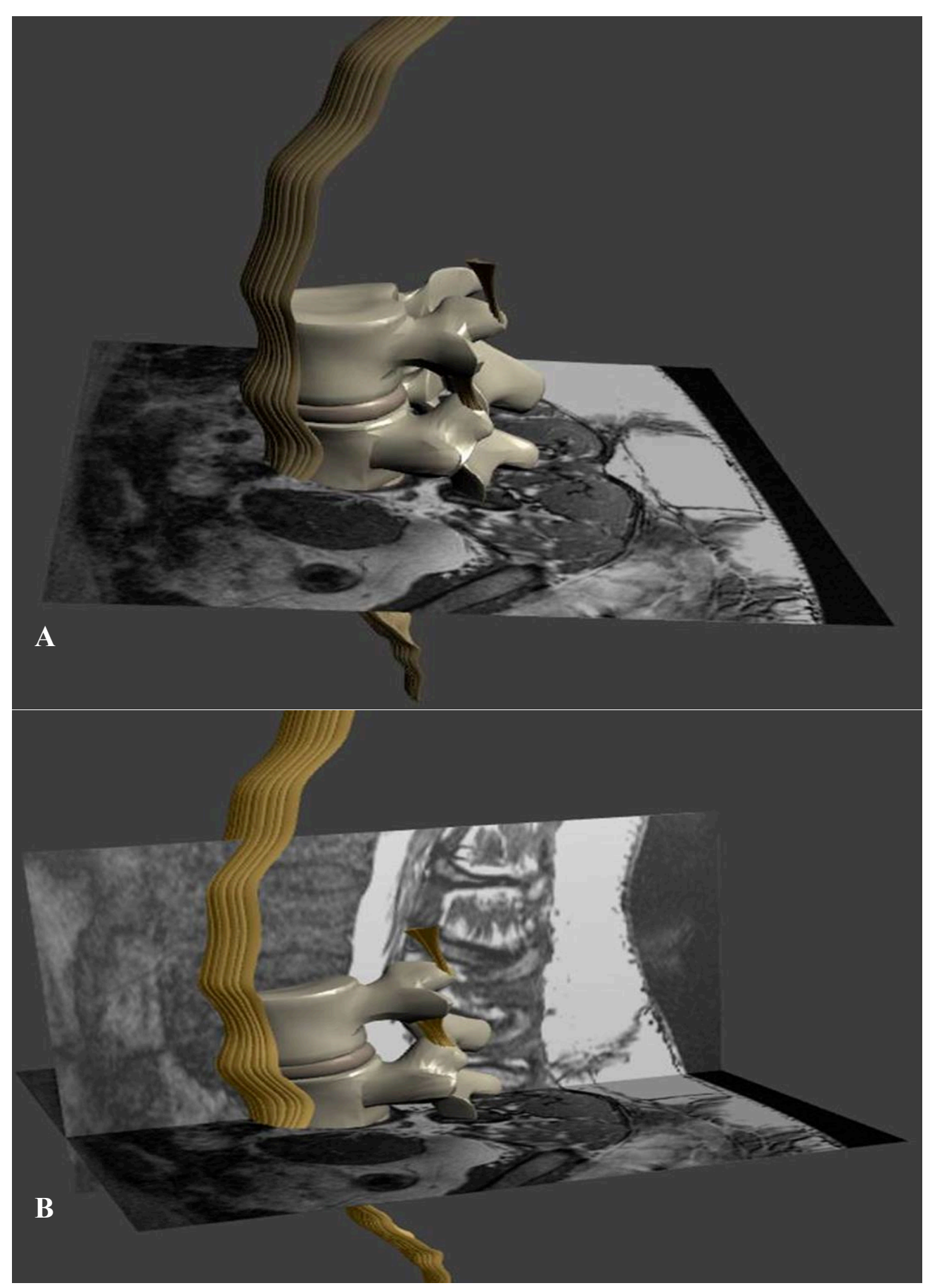

Figura 66. A y B. Modelado de vértebras lumbares, ligamento longitudinal anterior y ligamento capsular facetario. A: representación de la reconstrucción ósea tridimensional, embebida en sección axial de resonancia magnética potenciada en T2, a la altura del disco L3, a la cual se adiciona sección en proyección sagital (B). 

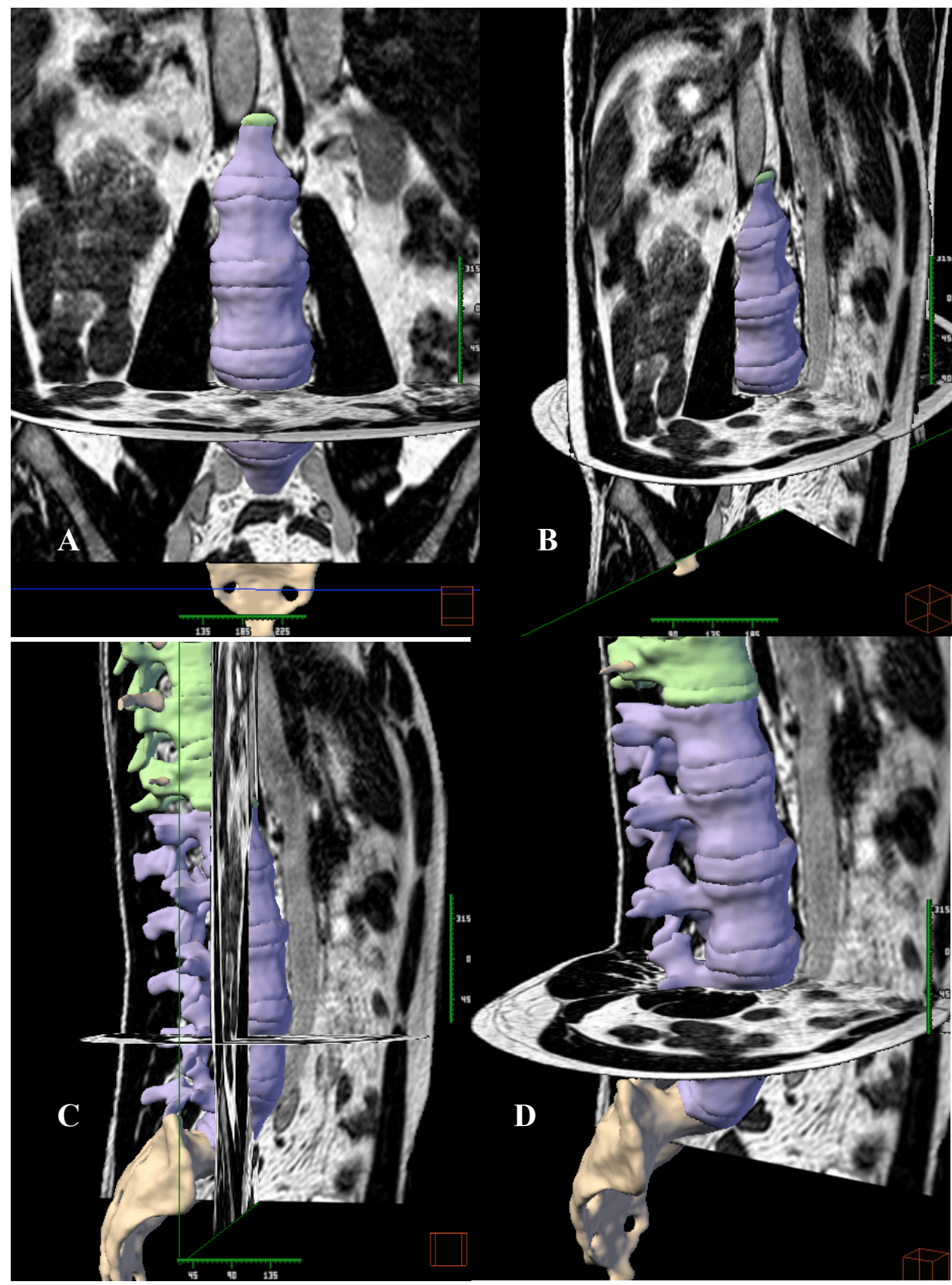

Figura 67. A, B, C y D. Modelo 3D de la columna lumbo-sacra y correlación radiológica en diferentes proyecciones espaciales. Es posible valorar la relación de la columna con las estructuras adyacentes desde el punto de vista radiológico: pared abdominal, planos musculares, grasa extraperitoneal, vísceras, grandes vasos, retroperitoneo, riñones, espacio prerrenal, psoas, vejiga, paquete vásculo-nervioso, y otras estructuras. 


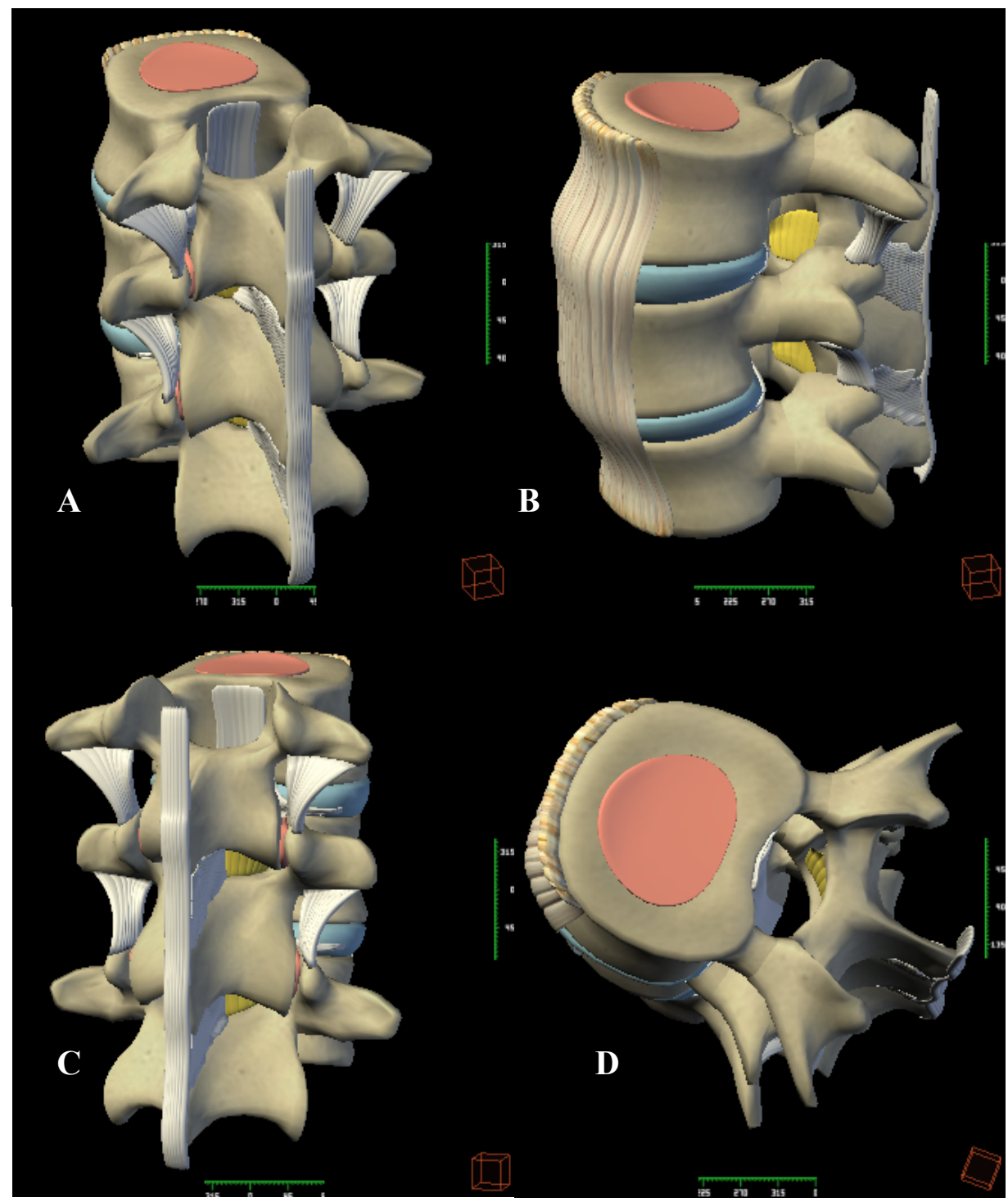

Figura 68. A , B C y D: modelos 3D de vértebras lumbares en diferentes proyecciones espaciales. En las figuras se muestran diferentes estructuras de las vértebras (discos, ligamentos y otras). 


\subsubsection{Resultados de la fase de texturizado}

La fase de texturizado es tan importante como la fase de modelado, sobre todo si lo que se busca es realismo y un buen acabado anatómico. De esta manera, tras realizar el proceso de modelado, la texturización permitió aplicar el color a los modelos buscando siempre la mayor similitud posible a la estructura anatómica real, como se observa en las figura 43 y las figuras 69-80. Por ello, a la hora de confeccionar las texturas en los modelos anatómicos de las vértebras se observó los sombreados que proyectaban sus diferentes partes morfológicas, consiguiendo así texturas que imitan la realidad (figura 69).

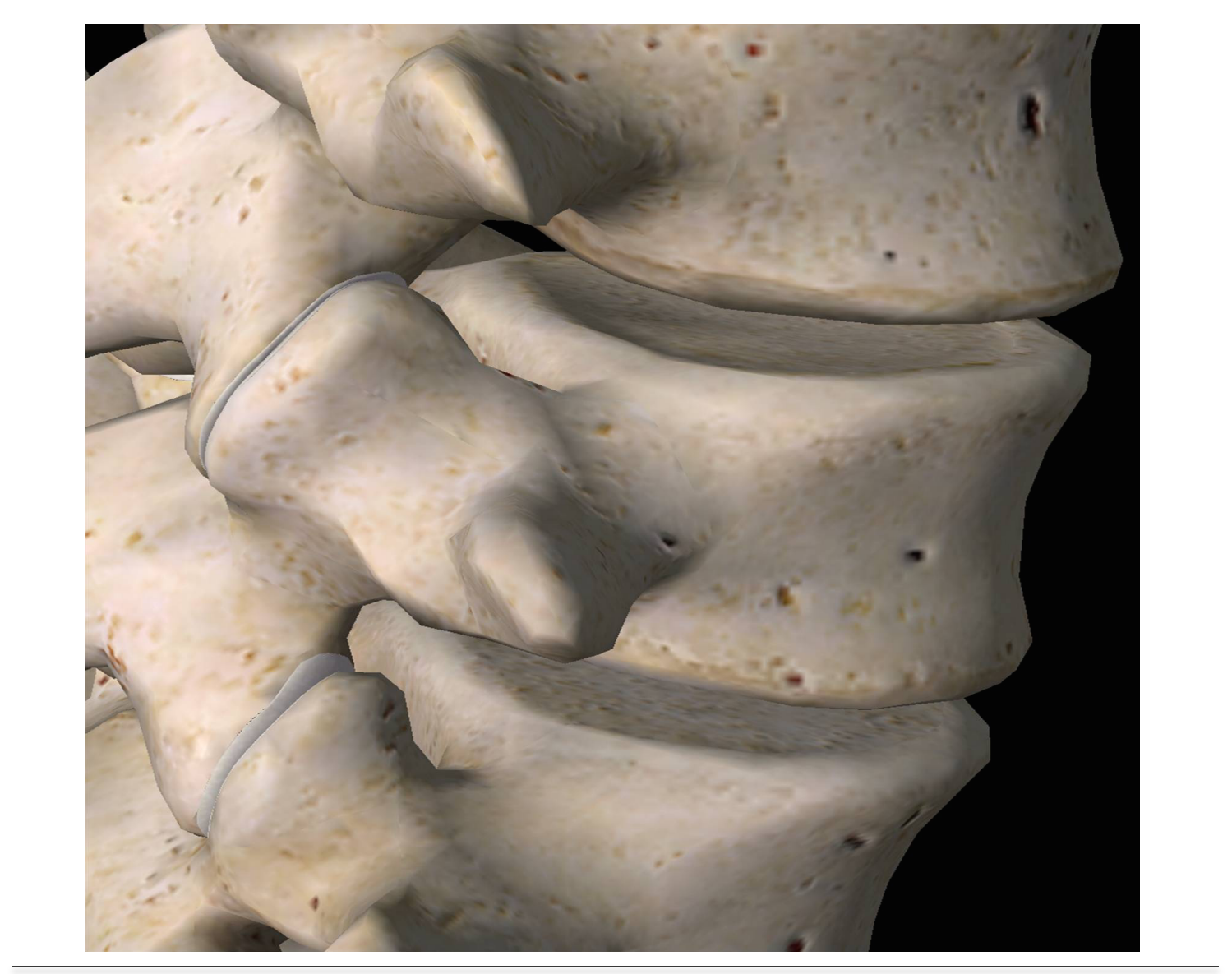

Figura 69. Texturizado de vértebras lumbares, mostrando los cuerpos vertebrales y su unión con los elementos posteriores. 

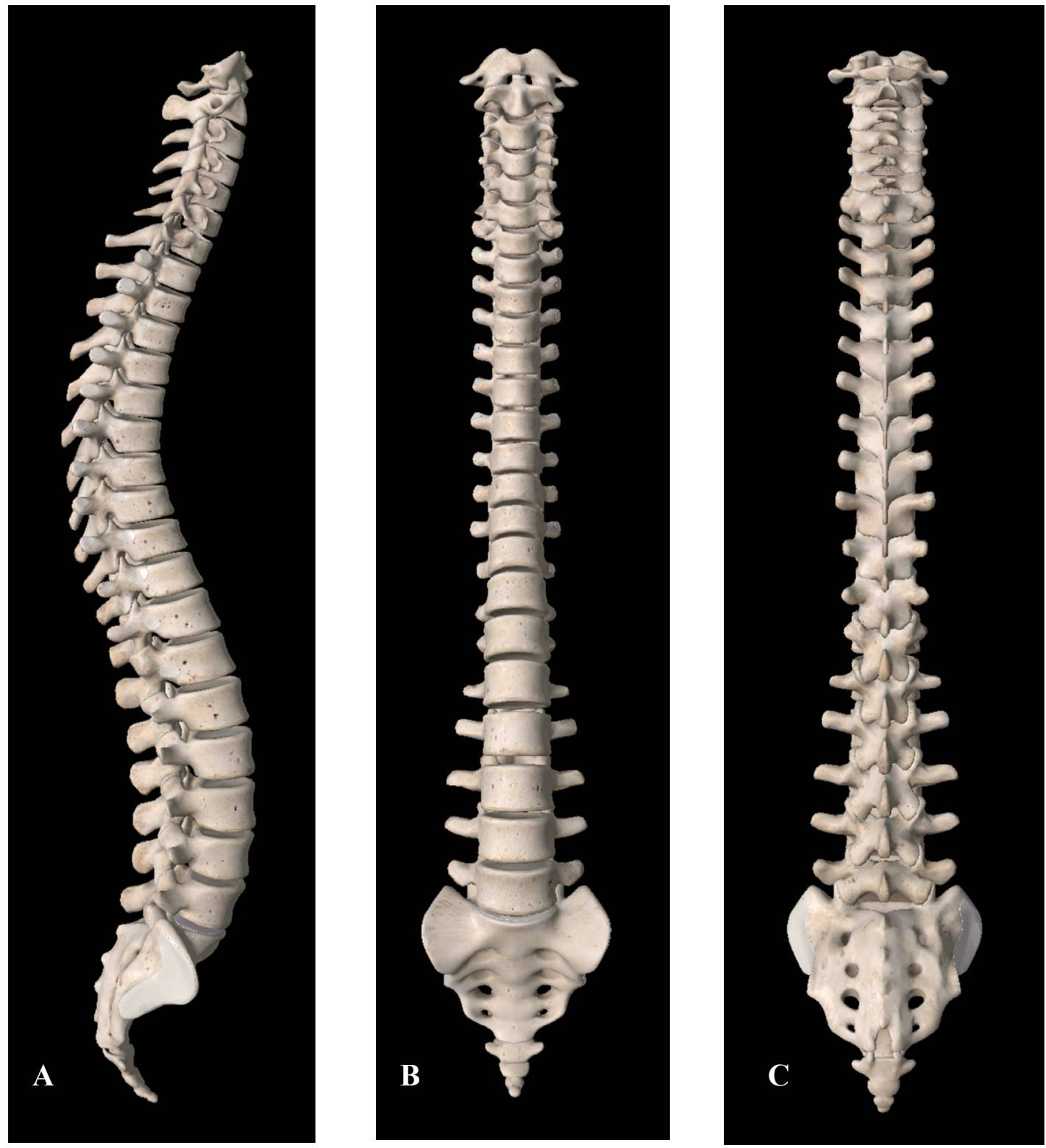

Figura 70. Columna vertebral completa tras la fase de texturizado. A: vista lateral. B: vista anterior. $\mathbf{C}$ : vista posterior. 


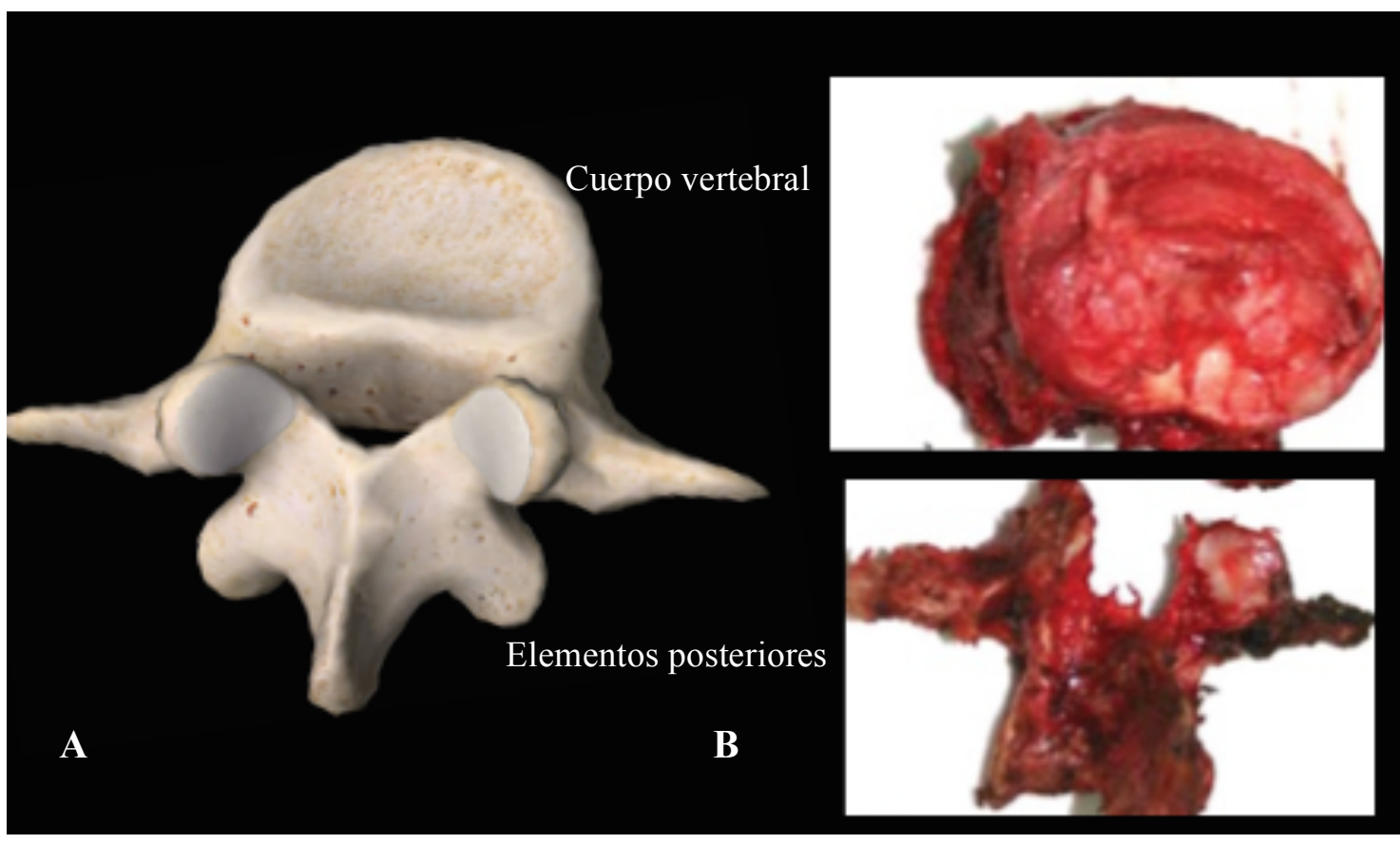

Figura 71. Tercera vértebra lumbar. A: modelo 3D de la tercera vértebra lumbar, en la posición espacial posterior oblicua. B: tercera vértebra lumbar dividida en dos partes: cuerpo y elementos posteriores, tras una vertebrectomía en bloque.

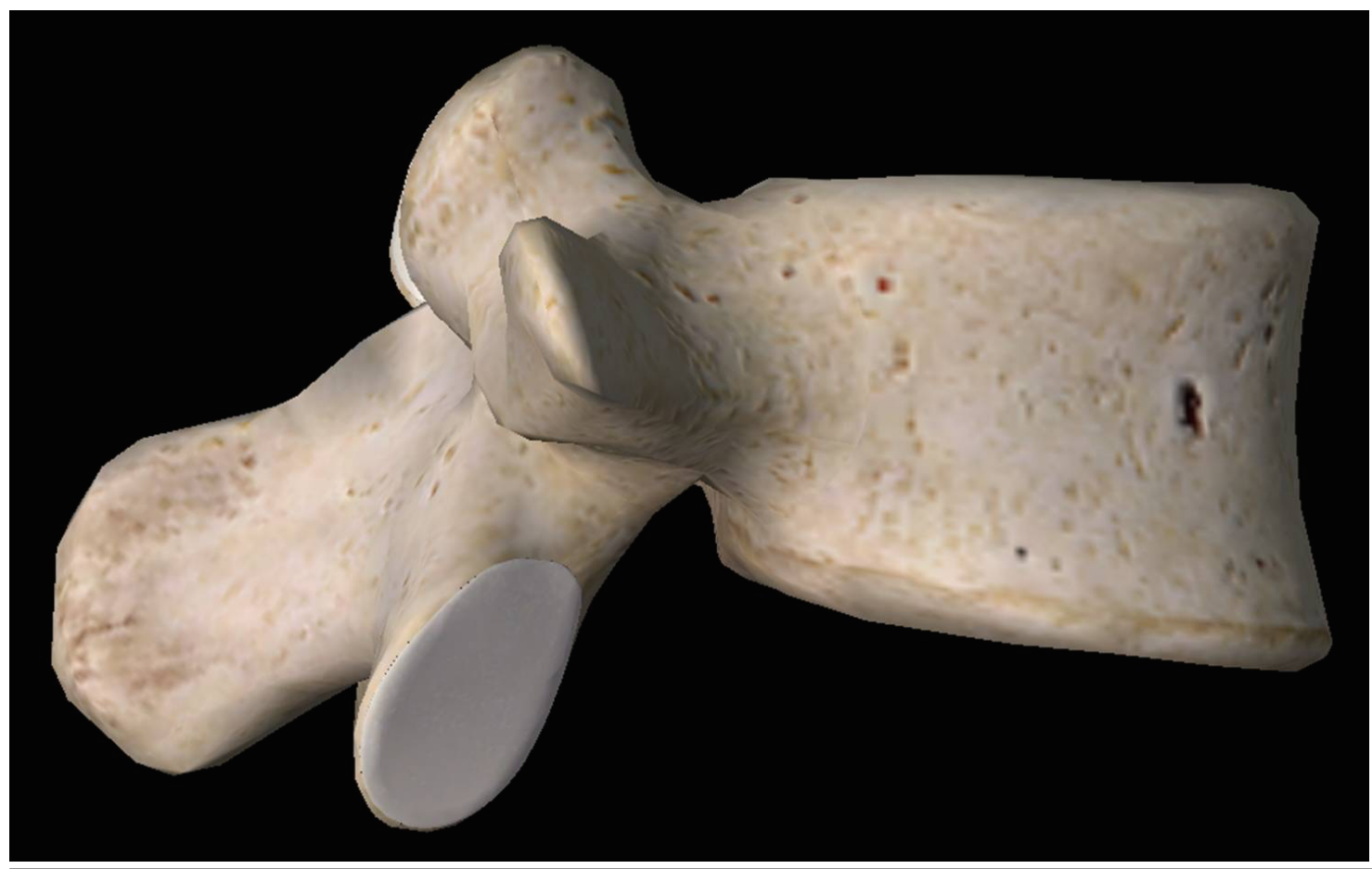

Figura 72. Modelo de la figura anterior (fig. 71) al ser girada a la posición lateral. 


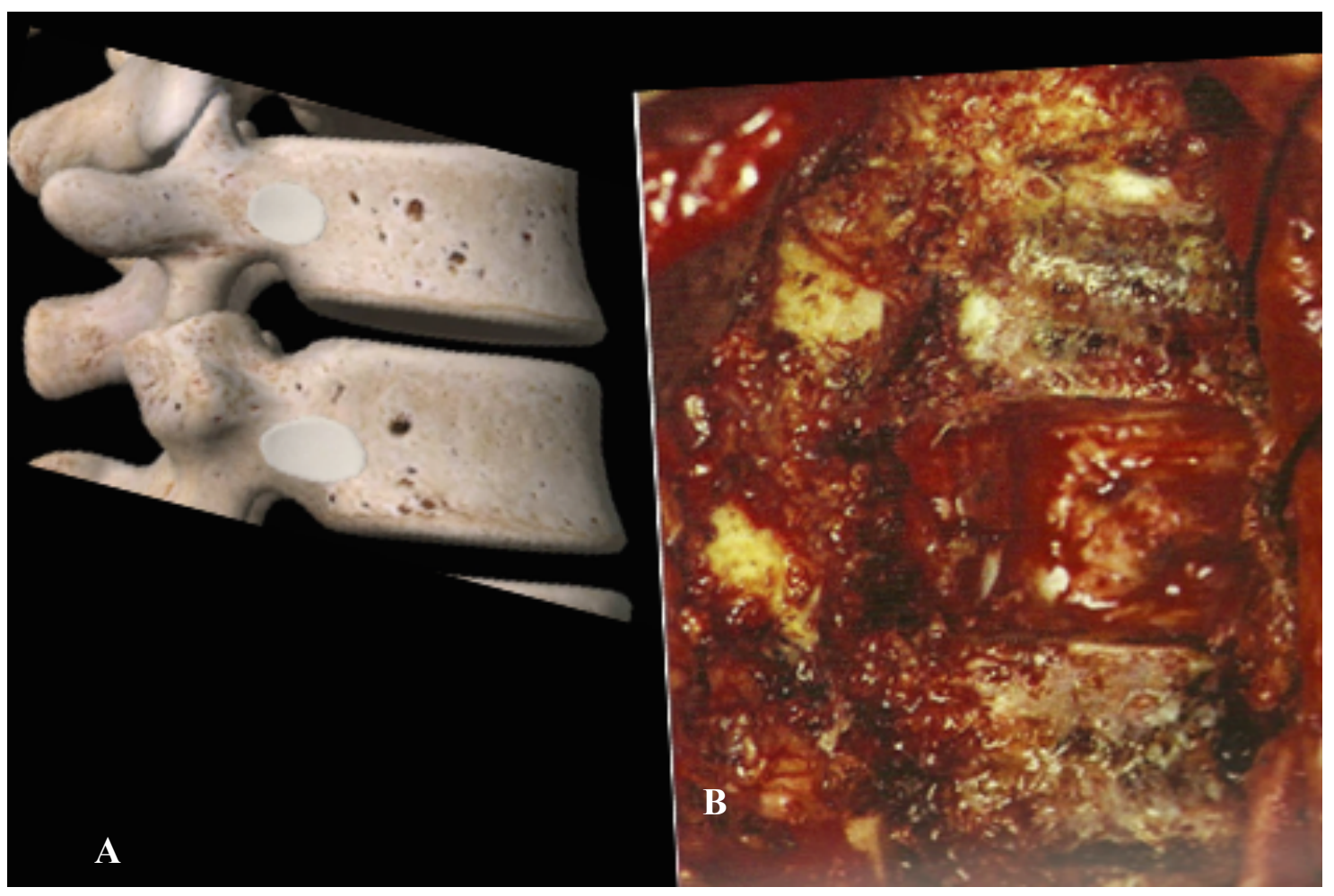

Figura 73. A: modelo 3D en posición lateral de D10 y D11. B: imagen intraoperatoria del defecto tras la realización de una coperpectomía D11.

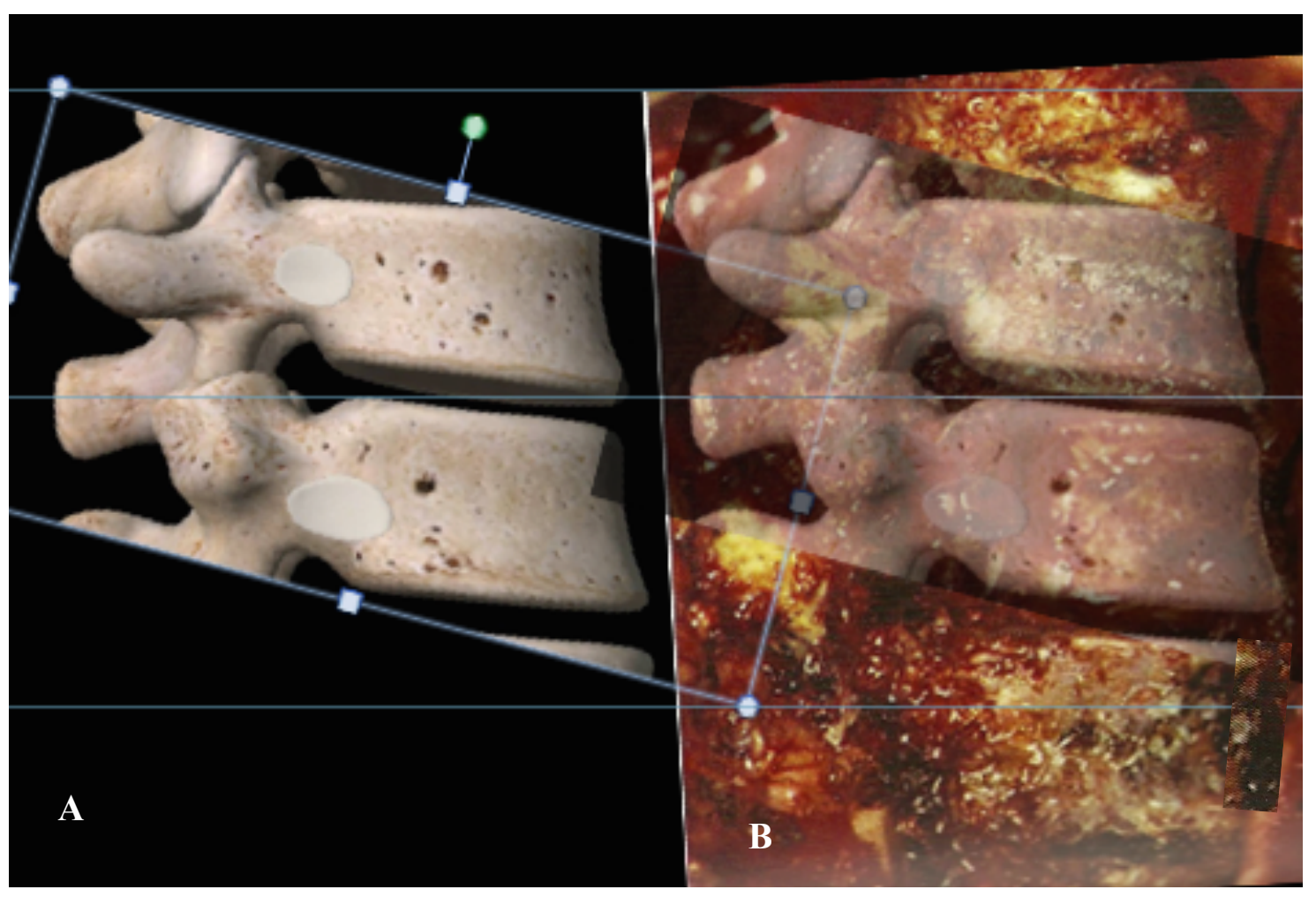

Figura 74. A y B. Superposición de modelo 3D sobre vértebra y defecto óseo de la figura 73, con el objetivo de observar la correlación entre ambas figuras. 


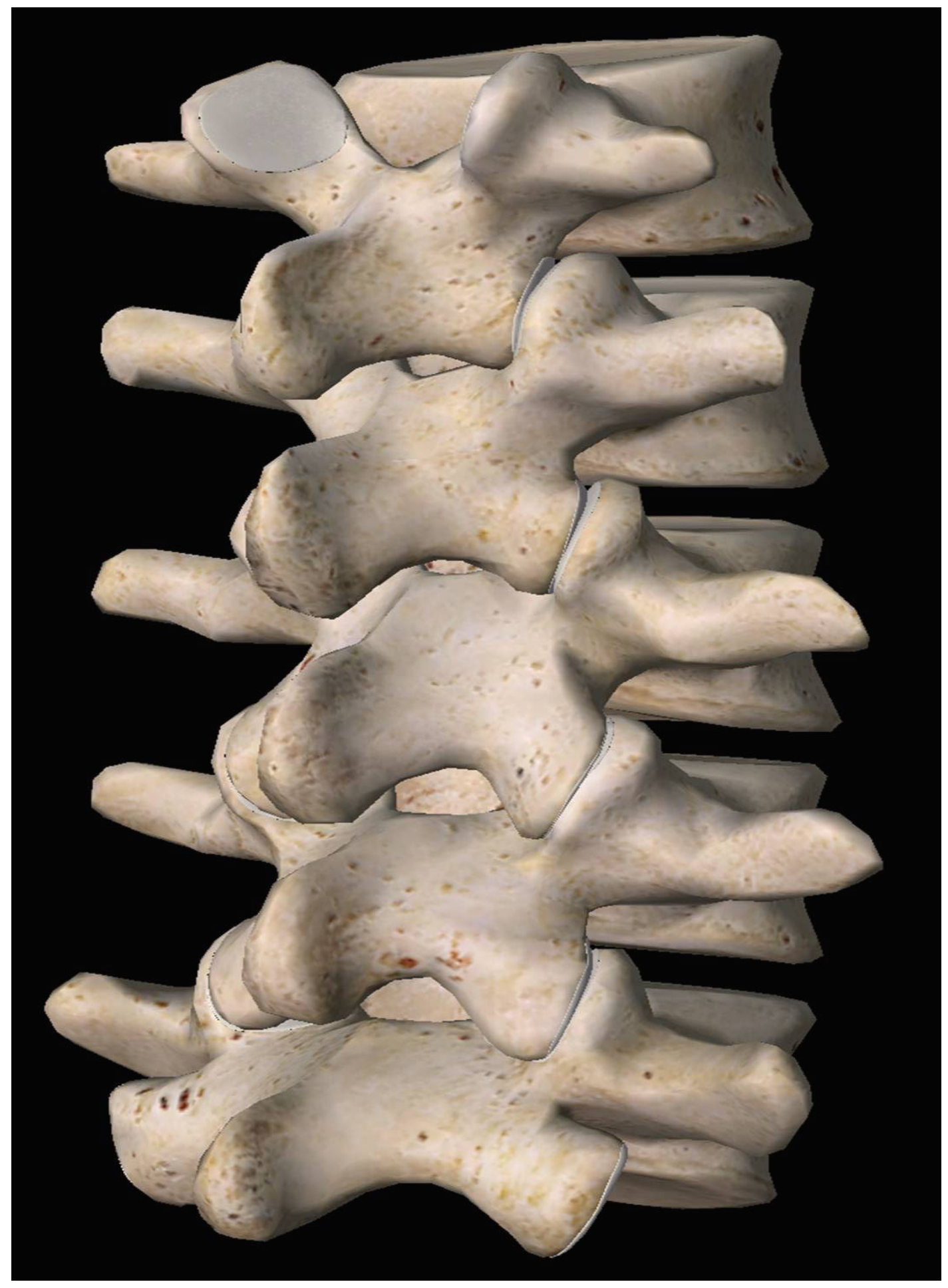

Figura 75. Proyección posterior oblicua de modelo 3D para valorar elementos posteriores. 

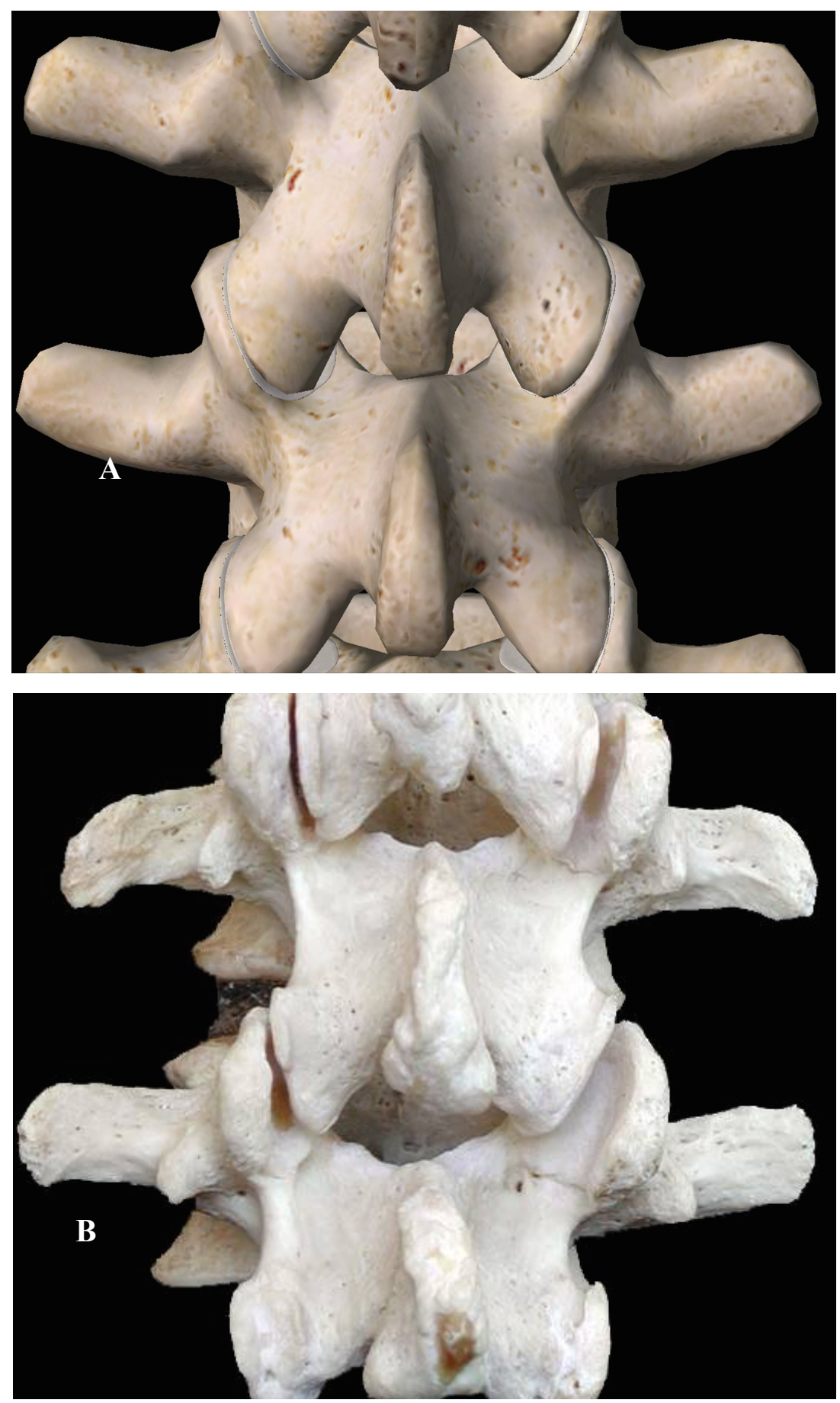

Figura 76. Correlación de modelo $3 \mathrm{D}$ de la columna lumbar con huesos de la misma zona anatómica procedente del Dpto. de Anatomía de la Universidad de Salamanca. A: modelo 3D de vértebras lumbares en proyección posterior. B: Huesos de la columna lumbar en proyección posterior . 

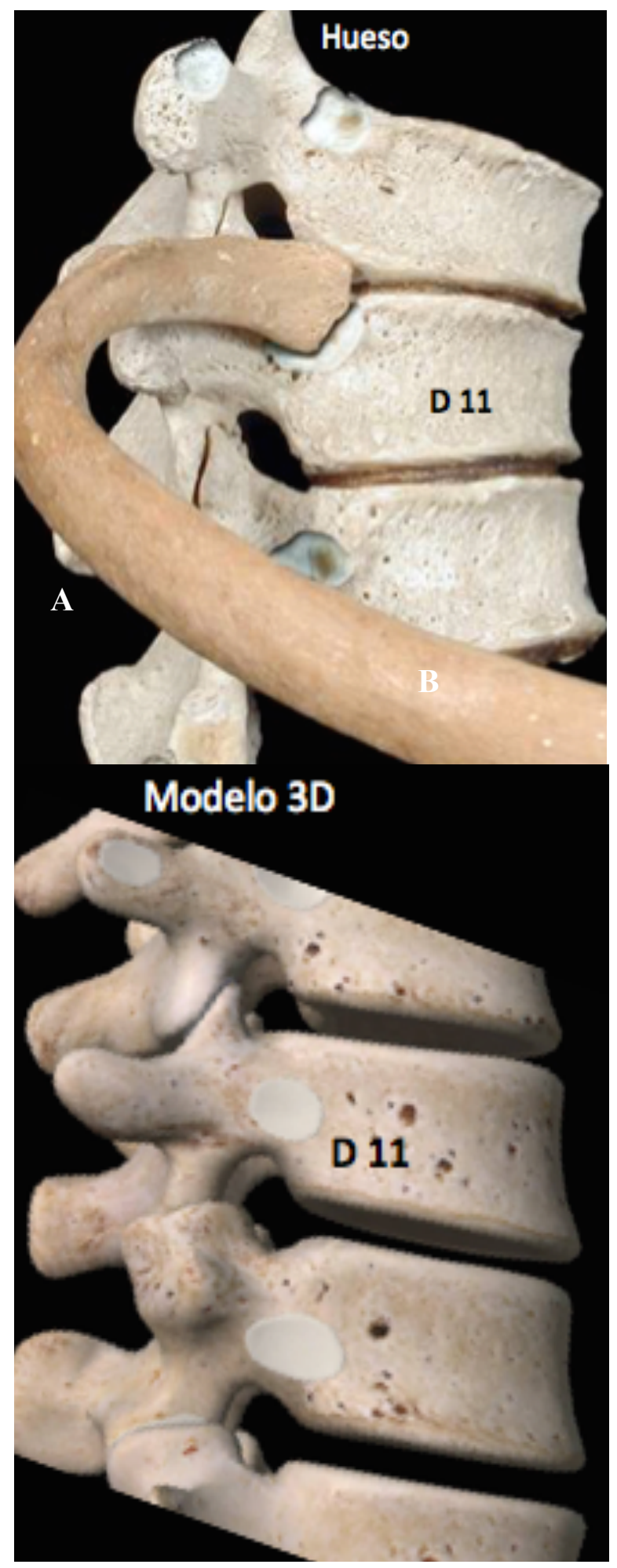

Figura 77. Correlación de modelo 3D con huesos perteneciente al Departamento de Anatomía de la Universidad de Salamanca. A: vista lateral de huesos de las vértebras D10, D11 y D12, costilla superpuesta sobre D11. B: modelo 3D en la misma posición espacial del hueso. 


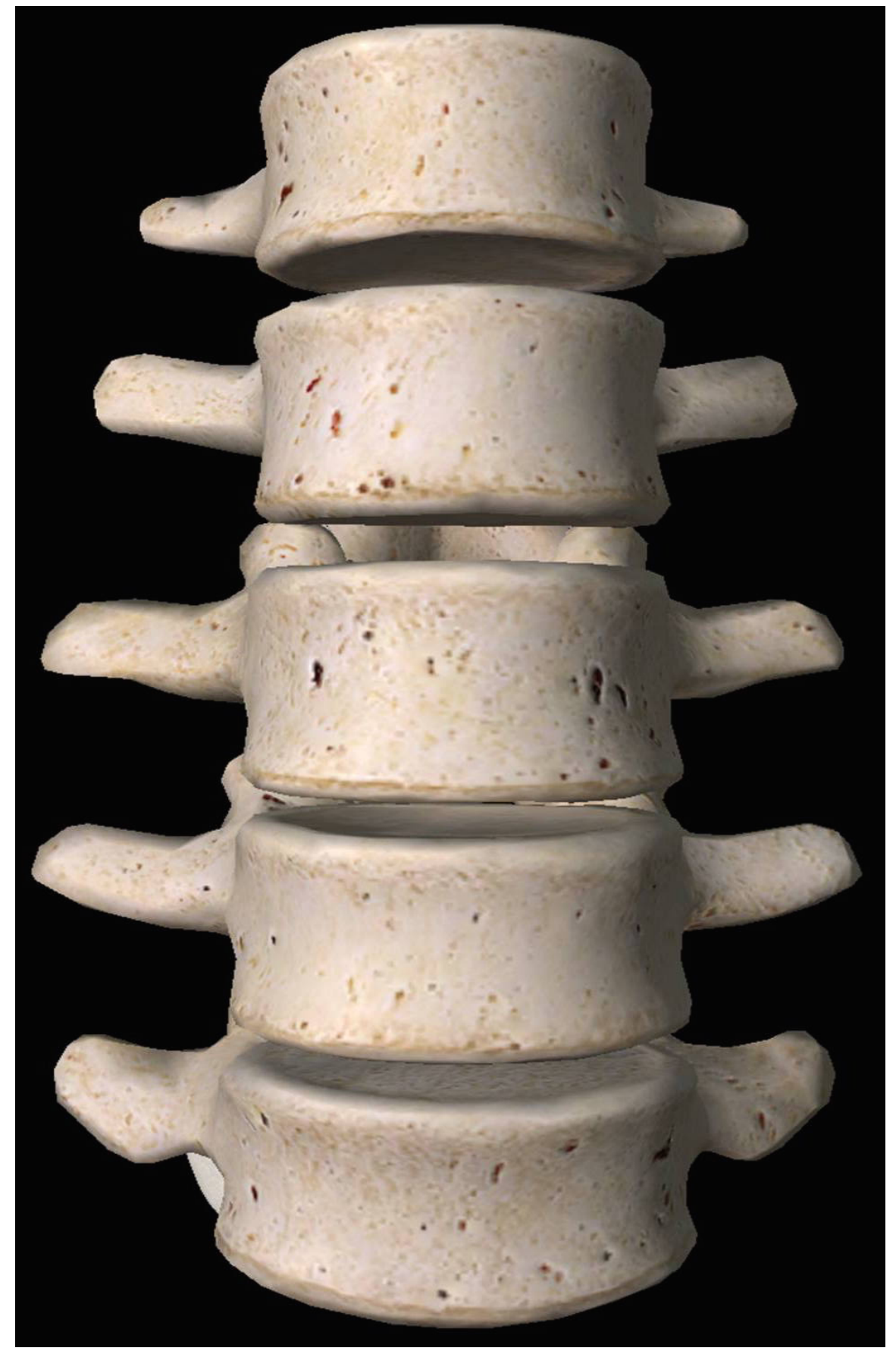

Figura 78. Modelo 3D de la columna lumbar en proyección anterior. 


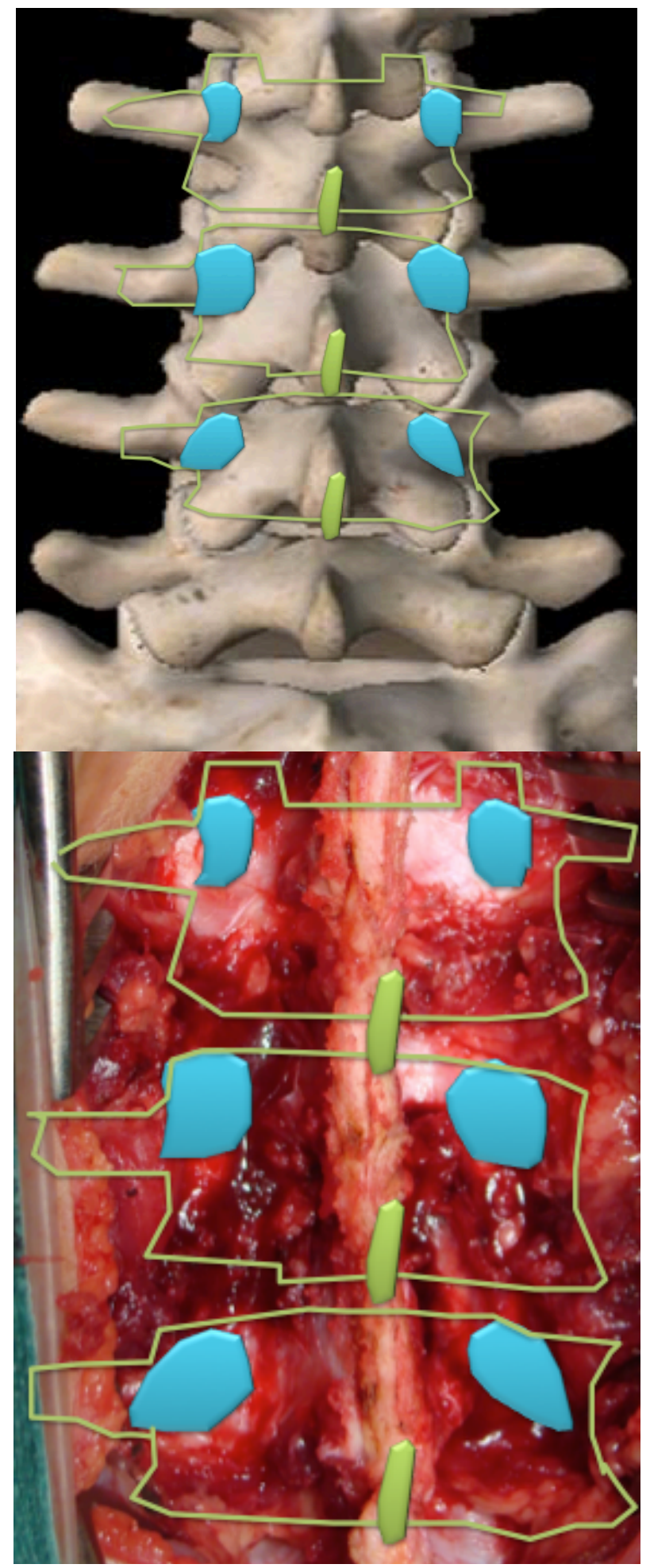

Figura 79. A y B. Correlación de modelo 3D con el abordaje lumbar posterior. A: Modelo 3D de la columna lumbo-sacra con marcas superpuestas de los niveles expuestos en el abordaje lumbar posterior (niveles L2-L3-L4). B: abordaje lumbar posterior, tras superponer las mismas marcas de la figura (A) y amplificar la imagen para una mejor correlación. 


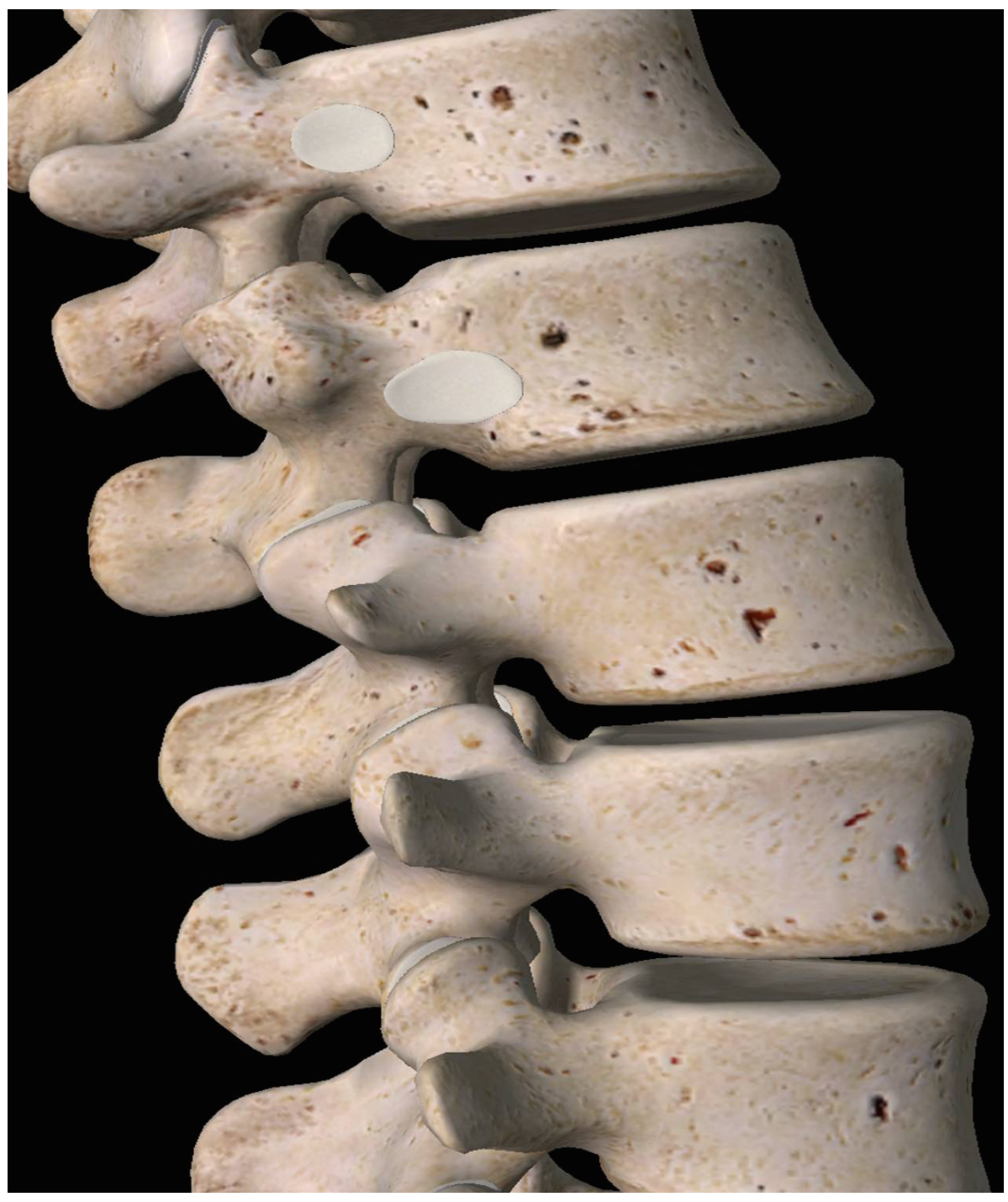

Figura 80. Texturización de las tres primeras vértebras lumbares y charnela dorsolumbar en la posición espacial lateral derecha. 


\subsubsection{Partes blandas: estructuras neurovasculares y músculos}

Además de la reconstrucción tridimensional de los elementos óseos de la columna vertebral, se procedió a la identificación de las diferentes estructuras vásculo-nerviosas y musculatura para vertebral, para su reconstrucción $3 \mathrm{D}$, como se muestra en las figuras 81-85.

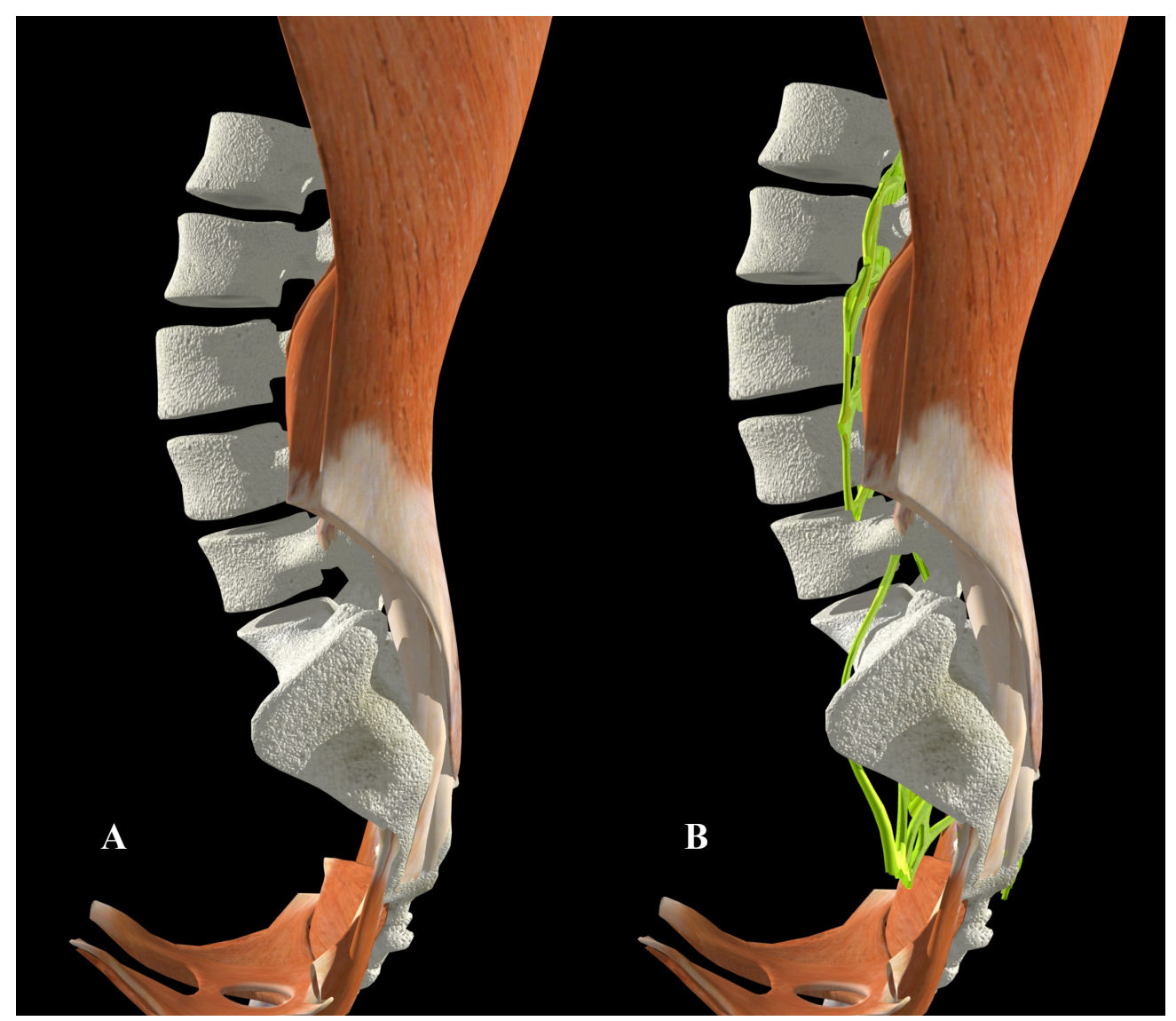

Figura 81. A y B. Representación de la reconstrucción tridimensional de la columna lumbosacra, con identificación en color de estructuras nerviosas (B), además se ha modelado parte de la musculatura que se insertan en la columna lumbo-sacra (A y B). 


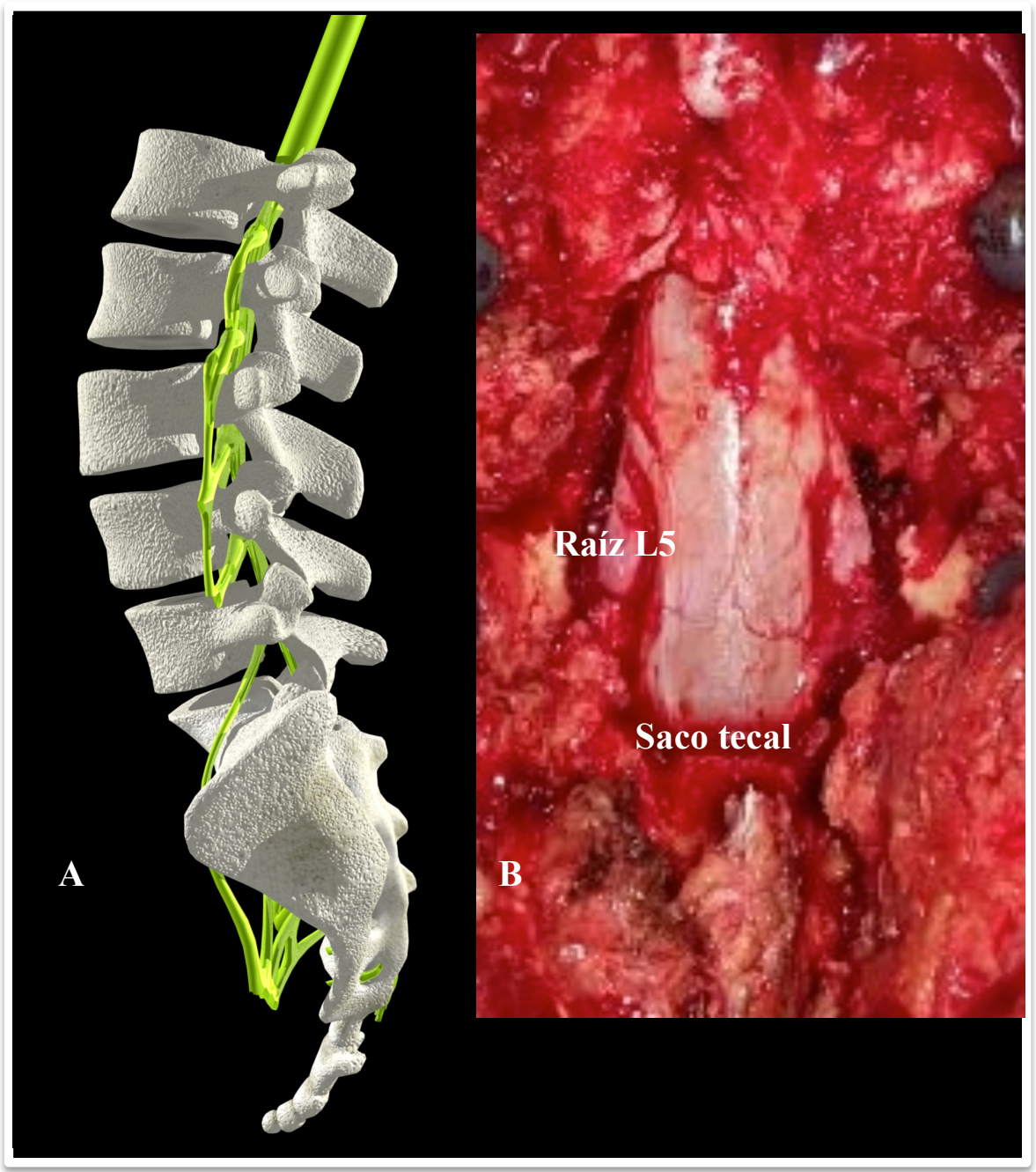

Figura 82. A: Representación tridimensional de nervios raquídeos, en su salida por los agujeros de conjunción, tras haber eliminado de la imagen anterior las estructuras musculares. B: abordaje lumbar posterior para descompresión amplia por estenosis de canal congénita severa. Se observa el saco tecal y las raíces de L5 bilateral. 


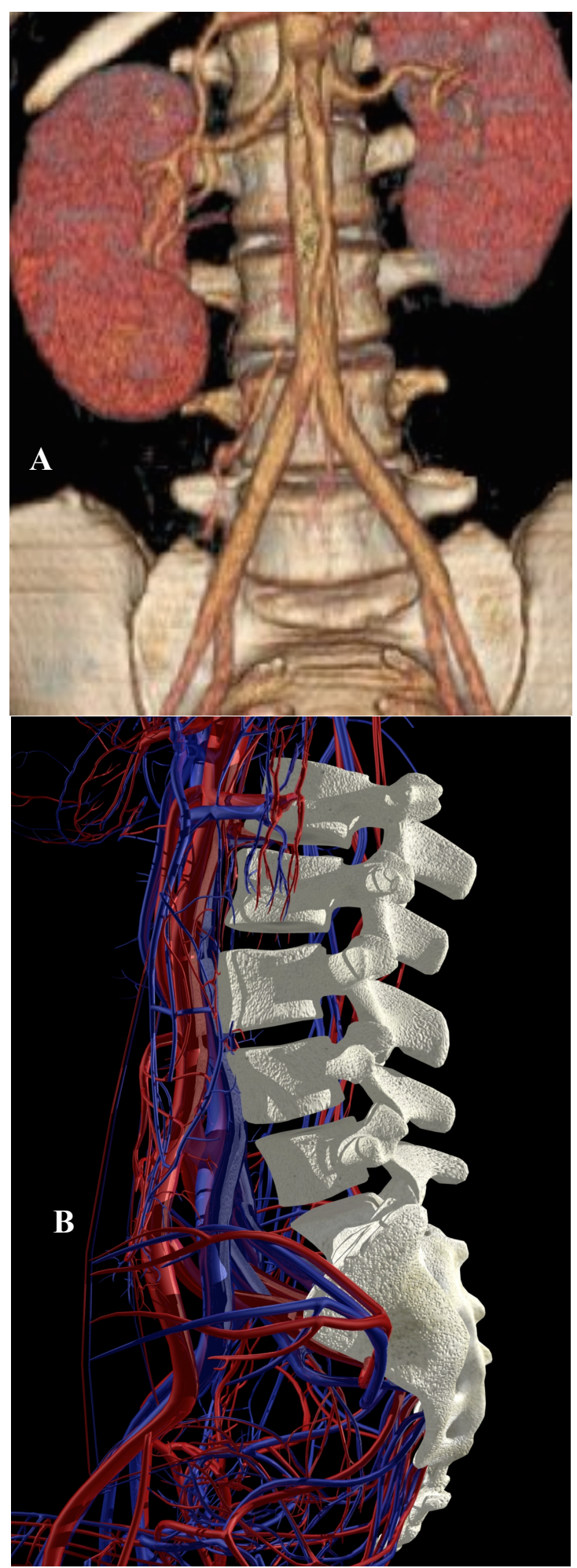

Figura 83. A: Reconstrucción 3D de la columna lumbo-sacra a partir de tomografía computarizada multicorte. B: Modelo 3D de la columna lumbo-sacra, con identificación en color de las diferentes estructuras vasculares. 


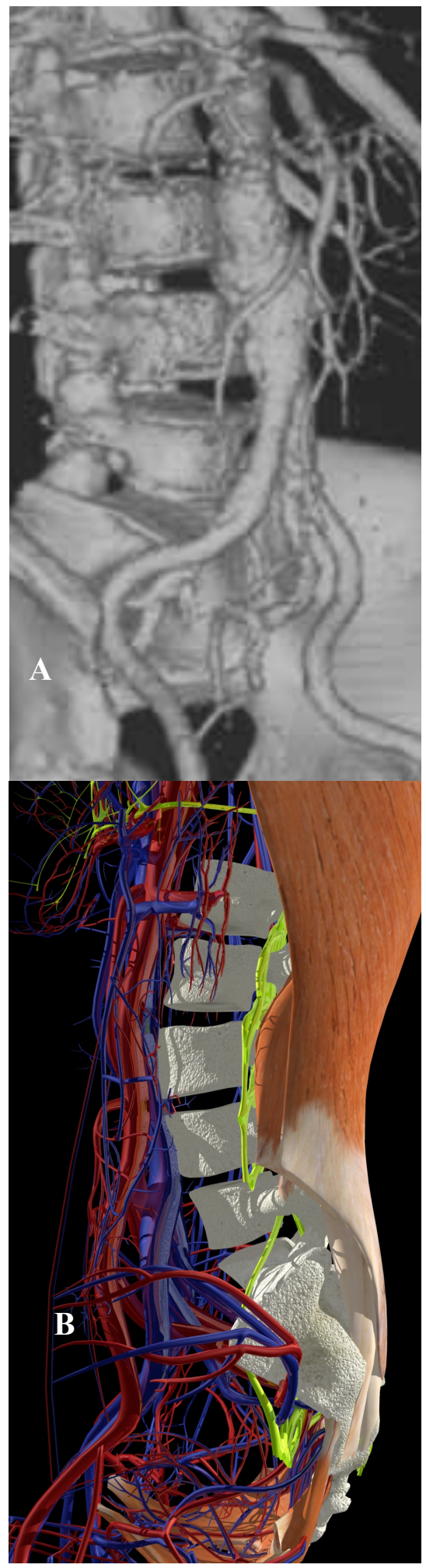

Figura 84. A: Reconstrucción $3 \mathrm{D}$ de la columna lumbo-sacra a partir de tomografía computarizada multicorte. B: modelo 3D de la columna lumbo-sacra mostrando las estructuras vásculo-nerviosas y parte de la musculatura paravertebral. 


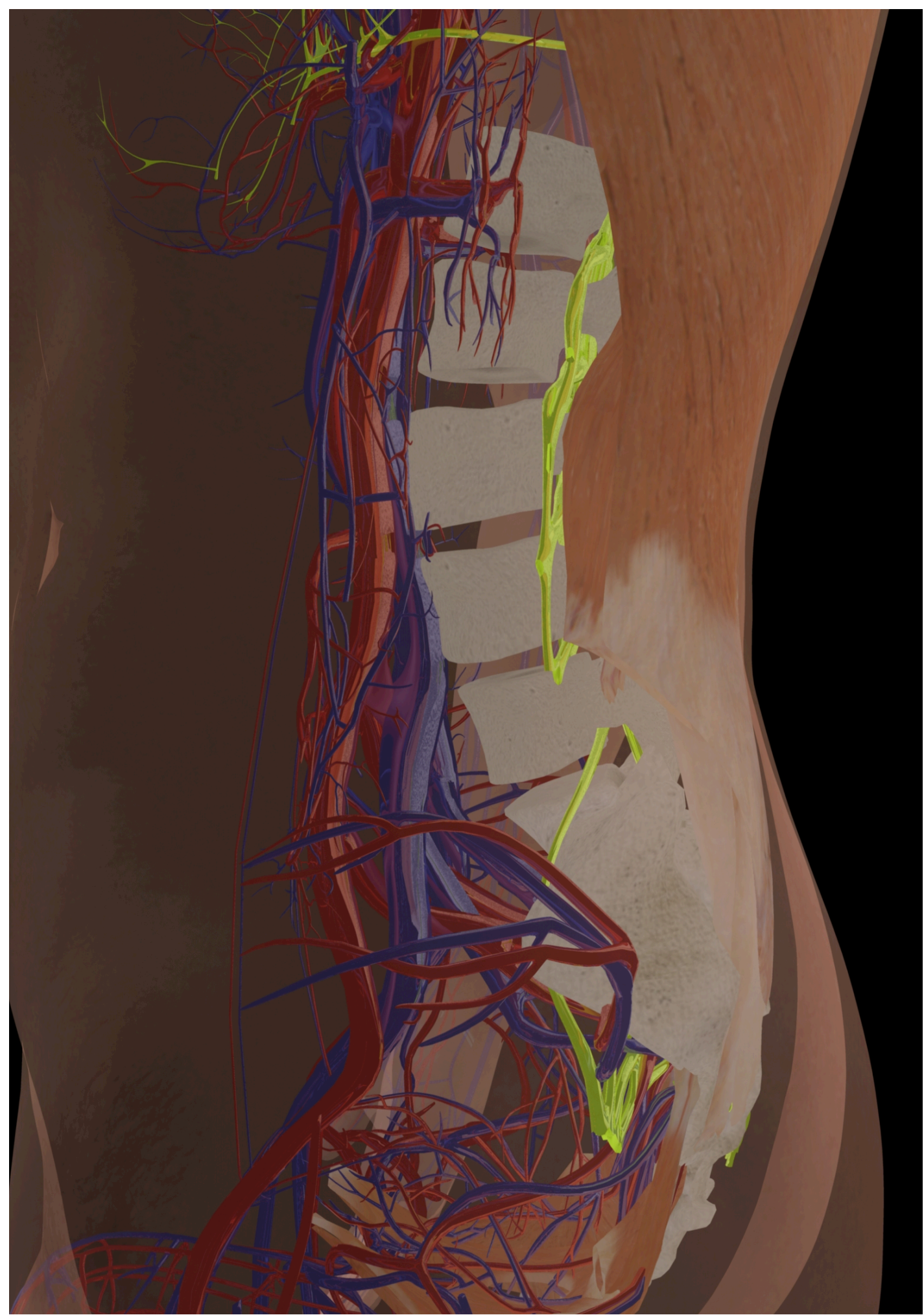

Figura 85. Modelado 3D de la columna lumbo-sacra, estructuras vásculo-nerviosas, musculatura paravertebral y parte de la piel en transparencia. 


\subsubsection{Visor anatómico funcional}

EL visor anatómico cuenta con un diseño intuitivo, para facilitar su uso. Dispone de múltiples ventanas emergentes, donde cada una encierra una función bien definida y consistente, con un sistema adecuado de retroalimentación de las operaciones que se realizan con mensajes en ventanas secundarias (figs 86-88). Al seleccionar cada modelo $3 \mathrm{D}$ se describen los aspectos morfológicos más relevantes.

Los modelos 3D generados son compatibles con la mayoría de ordenadores y programas de visualización de imágenes; con lo cual el objetivo del diseño y desarrollo del visor anatómico es facilitar la manipulación de los modelos 3D generados para este trabajo de Tesis Doctoral.

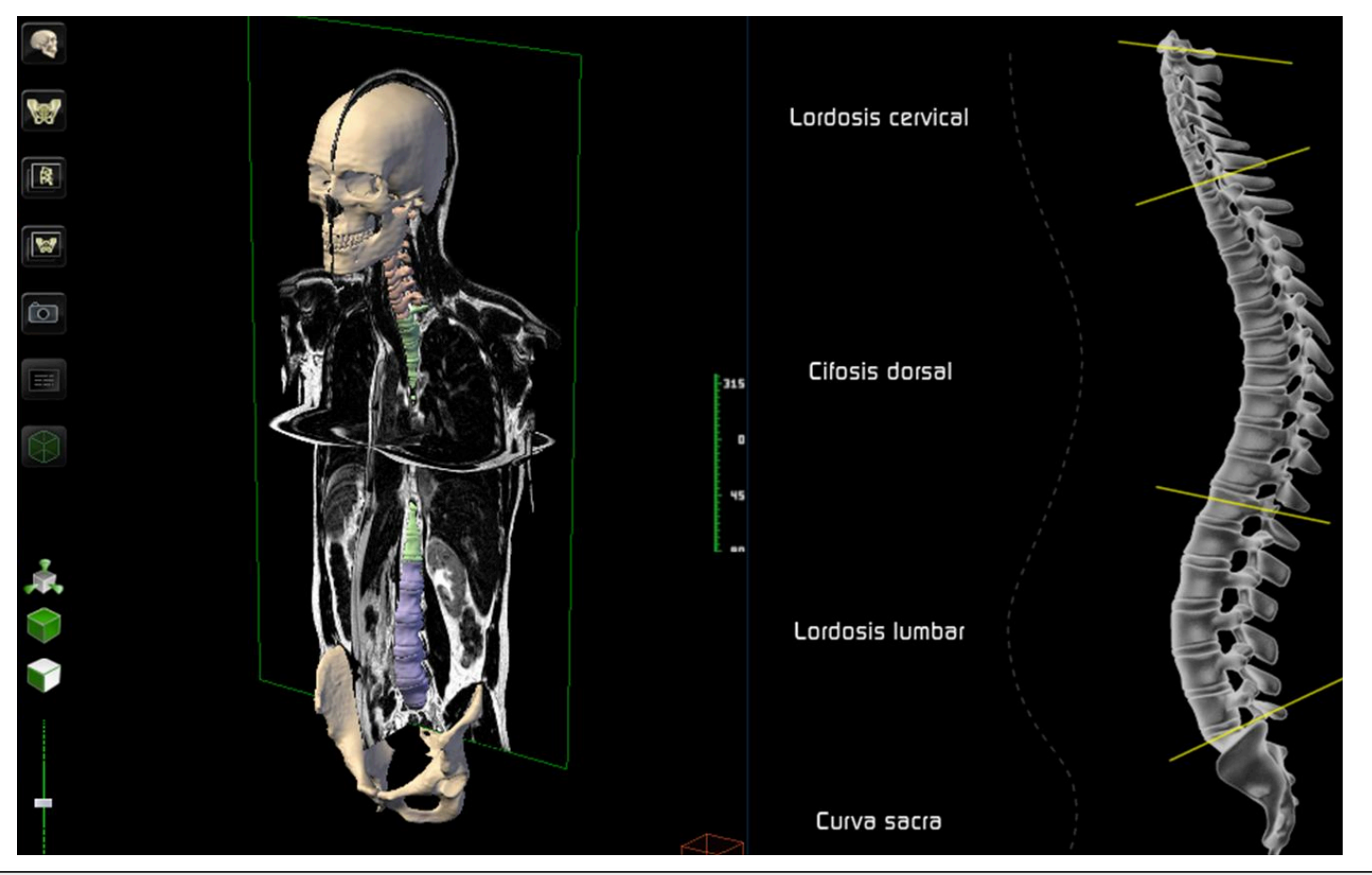

Figura 86. Visualización del interface de usuario estructurado en dos partes: a la izquierda el visor anatómico para la observación de los modelos anatómicos tridimensionales generados a partir de las imágenes en formato DICOM; y a la derecha el visor dinámico de los aspectos funcionales de la columna vertebral. Desde este visor se manipulan los modelos 3D, para ser evaluados desde las diferentes proyecciones espaciales, como veremos más adelante. 


\subsubsection{Características del visor anatómico funcional}

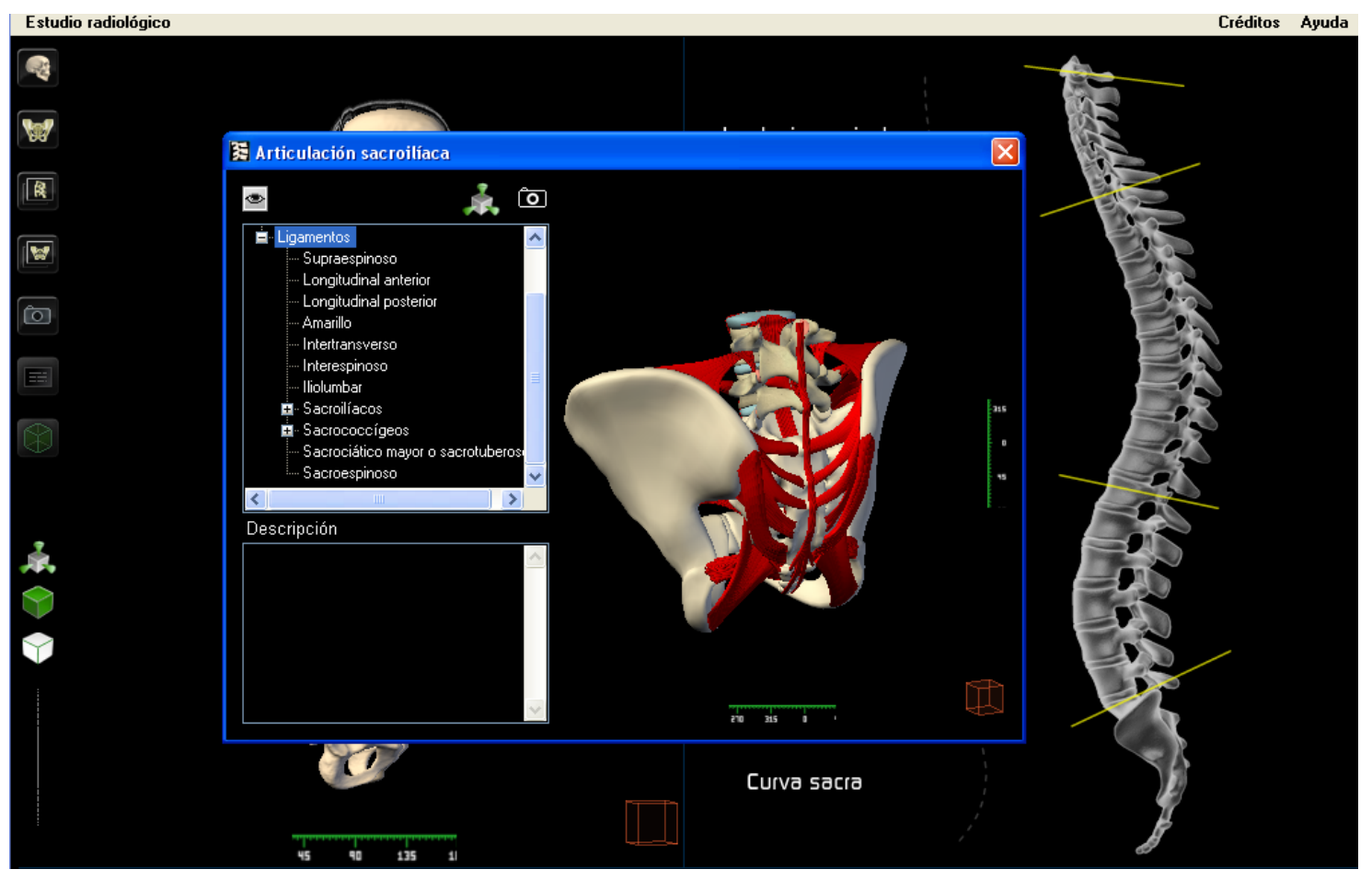

Figura 87. Características del visor anatómico funcional.

El margen izquierdo de la aplicación presenta una barra de herramientas, mediante íconos, con las distintas opciones de interacciones. También presenta opciones para abrir visores en detalle tanto de la columna vertebral, como de la pelvis.

En la parte izquierda se encuentra el visor de modelos $3 \mathrm{D}$ que representa la columna real, con el que se puede interactuar por medio del ratón.

La parte derecha de la aplicación está ocupada por el visor de biomecánica, que se presenta por medio de unas animaciones sobre el modelo ideal (figs.: 87 y 88). 


\subsubsection{Detalle de la barra de herramientas}

En la barra de herramientas de la izquierda se presentan las siguientes opciones, mostradas mediante iconos gráficos:

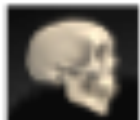

Mostrar u ocultar cráneo: con esta opción, se puede activar o desactivar la visualización del cráneo en el visor.

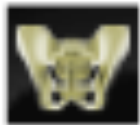

Mostrar u ocultar pelvis: al igual que la opción anterior, se puede activar o desactivar la visualización de la pelvis.

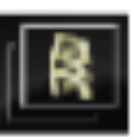

Visor en detalle - Articulación vertebral: abre una nueva ventana donde se puede observar en detalle la articulación de las vértebras, centrándose en sus aspectos de movimiento y articulación.

Visor en detalle - Articulación sacroilíaca: abre una nueva ventana

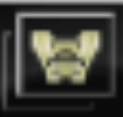
donde se puede observar en detalle los elementos presentes en la articulación de la pelvis.

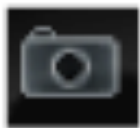

Captura de pantalla: guarda una captura del visor tridimensional de la columna real, en formato bmp.

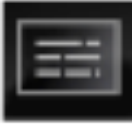

Información en pantalla: muestra u oculta una información técnica sobre el estado de visualización del visor tridimensional, que aparecerá en la esquina inferior izquierda de este.

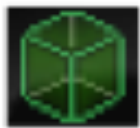

Activar transparencias: hace que los modelos presentes en el visor se presenten de forma sólida o translúcida alternativamente.

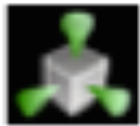

Enfoque de la cámara: pulsando sobre cada una de las flechas que aparecen en el cubo, coloca la cámara enfocando al modelo desde el punto de vista de la flecha pulsada.

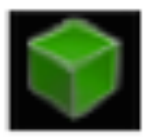

Visibilidad de los planos: al pulsar sobre cada una de las caras del cubo se mostrará u ocultará el plano seccional correspondiente a la orientación de la cara pulsada. Las caras visibles se resaltan en verde, mientras que las ocultas aparecen en blanco.

Plano activo: (Movimiento de planos) permite seleccionar el plano que se desea mover con el deslizador situado por debajo de el. Cada orientación se asocia a un color: rojo para las sagitales, verde para las coronales y azul para las axiales. 


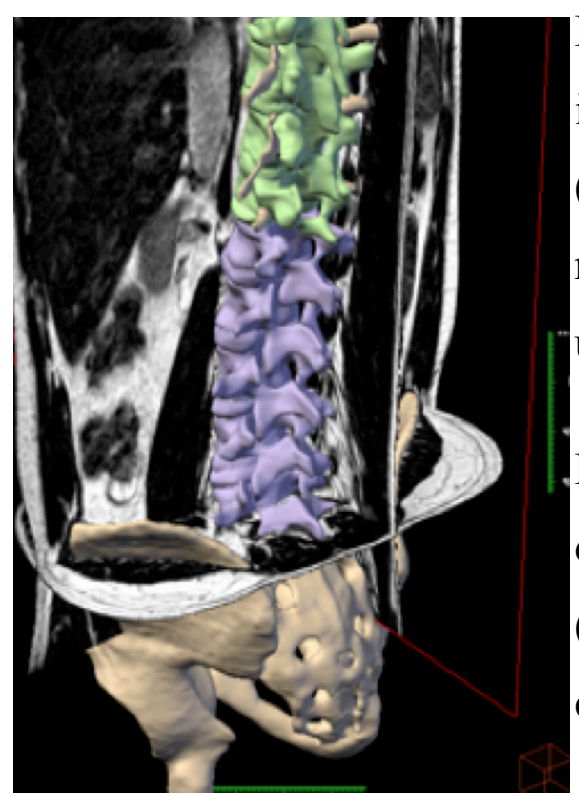

Interacción con el visor anatómico. Todas las interacciones con los elementos de la escena (rotaciones, traslaciones, zoom y selección) se realizan situando el cursor sobre el visor, usando el ratón.

Rotaciones: Para rotar la imagen del visor, se deberá mantener pulsado el botón principal (izquierdo) del ratón mientras se desplaza el cursor sobre la pantalla.

Traslaciones: Para trasladar la imagen del visor en el plano de la pantalla, es preciso mantener pulsados los dos botones del ratón mientras se desplaza el cursor.

Zoom: Para ampliar o reducir el tamaño de la imagen que se muestra en el visor, se deberá mantener presionado el botón secundario del ratón desplazando el cursor hacia arriba (ampliar) o hacia abajo (reducir).

Selección: Haciendo clic en el visor sobre la cada una de las partes de la columna coloreadas se activará en el visor de movimientos una pantalla que da acceso a todas las posibles acciones de dicha parte. También se puede seleccionar la imagen seccional de la resonancia, que se indicará con un recuadro del color correspondiente a su orientación (rojo para las sagitales, verde para las coronales y azul para las axiales). La posición espacial del plano seleccionado se podrá variar pulsando la tecla mayúsculas y desplazando el ratón sin tener ningún botón pulsado. 


\subsubsection{Visor en detalle}

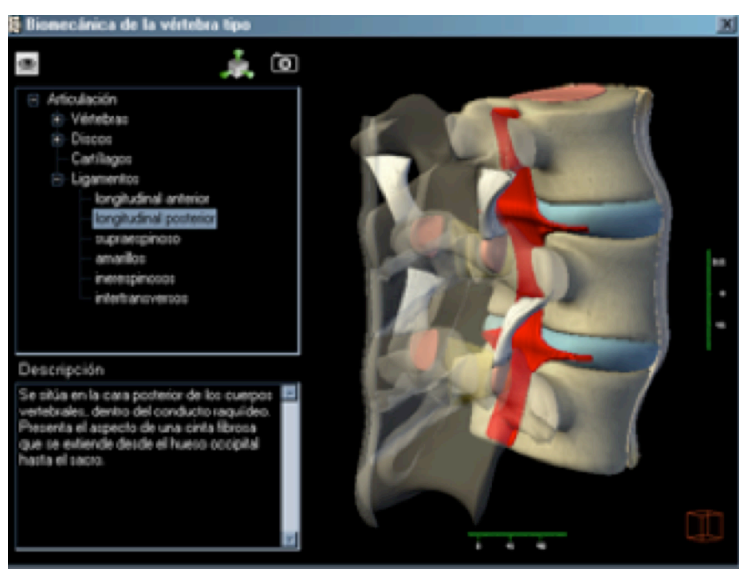

Figura 88. El visor en detalle nos permite ver las particularidades de ciertos modelos específicos, en este caso la biomecánica de la vértebra tipo y la articulación sacroilíaca.

La parte derecha controla las estructuras anatómicas a representar mediante modelos tridimensionales (3D).

En la ventana de árbol podremos seleccionar/deseleccionar los modelos de forma independiente e ir visualizándolos según la selección, abriendo las distintas ramas para ver las estructuras (modelos 3D) disponibles.

El cuadro de selección visible permite activar o desactivar la visibilidad del modelo seleccionado, que aparecerá en color rojo.

El cuadro de texto muestra una breve descripción de la estructura seleccionada.

El botón de enfoque de cámara permite colocar la vista en cada una de las tres posiciones estandar (sagital, coronal y axial) pulsando sobre cada una de las flechitas.

Con la opción de captura se puede guardar una imagen del visor tridimensional en el disco duro, en formato .bmp. Mientras esté activo el visor en detalle, la ventana principal permanecerá deshabilitada, pudiendo regresar a ella al cerrar el visor, ver figura 88 y 89 . 


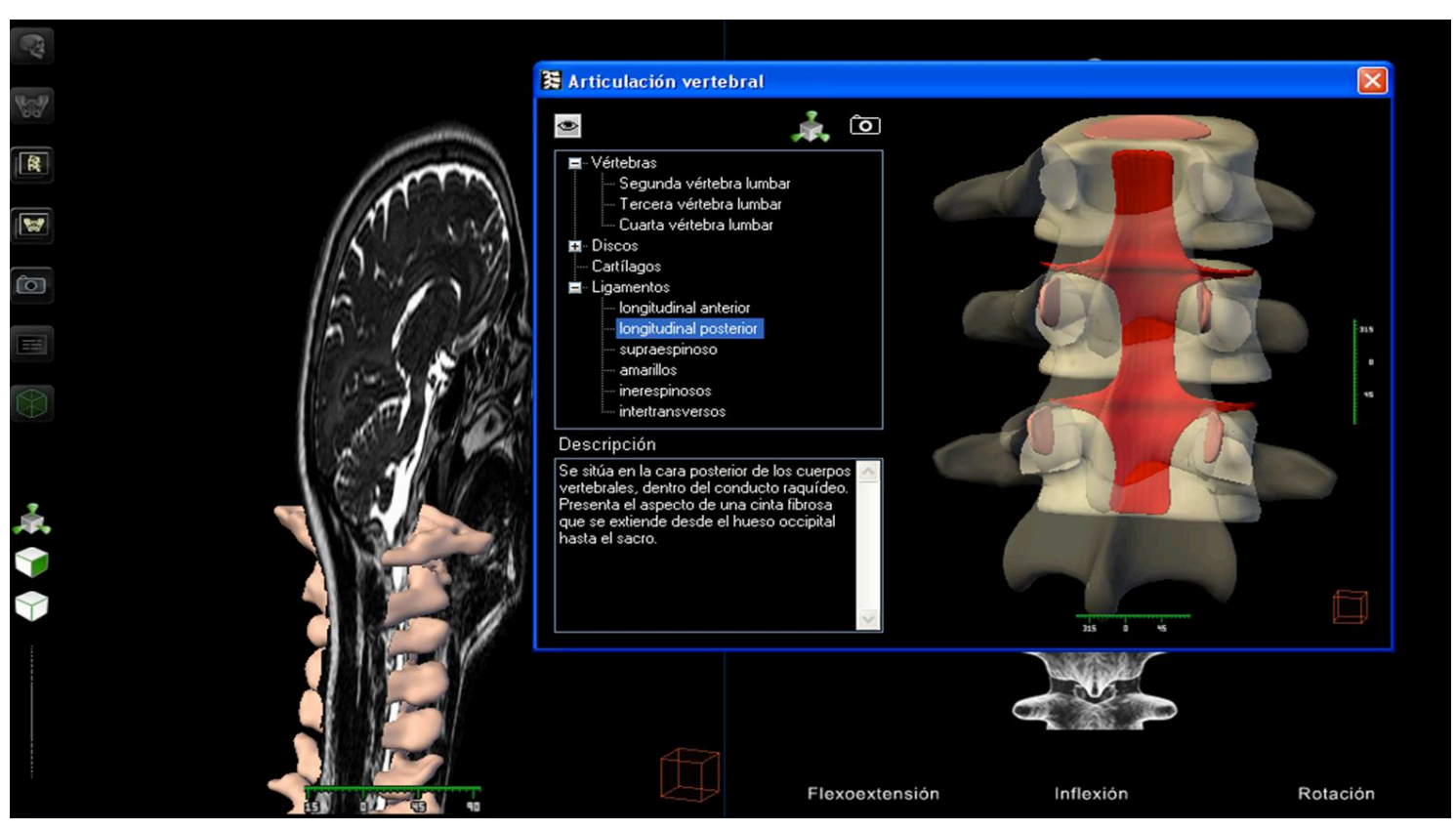

Figura 89. Visor en detalle mostrando ventana secundaria.

\section{Visor de biomecánica}

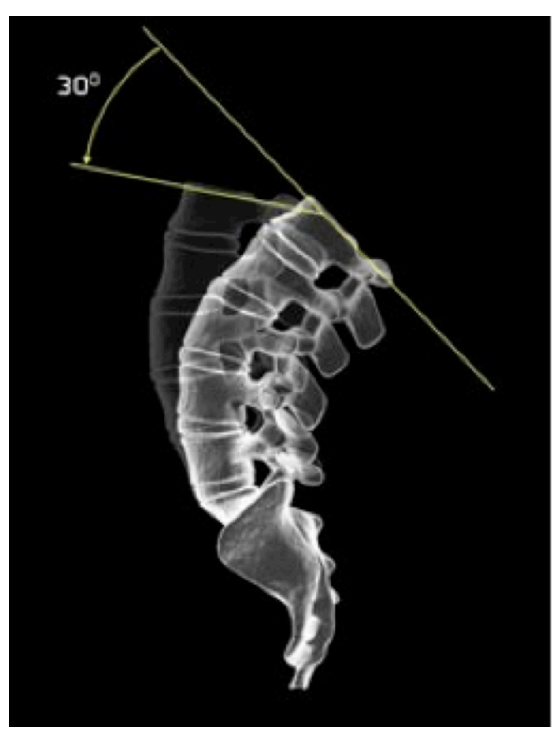

En el visor de biomecánica se muestran las distintas capacidades biomecánicas de la columna vertebral en sus tres secciones: cervical, dorsal y lumbar.

Al pulsar sobre cada una de las secciones coloreadas de la columna real se mostrará en este visor una imagen de la zona seleccionada y los tres posibles movimientos que puede realizar: Flexo-extensión, Inflexión y Rotación.

En cada animación se remarcan los límites de los movimientos. 
V. DISCUSIÓN 
El aumento de la esperanza de vida de la población ha generado un incremento en la demanda de nuevas tecnologías para el desarrollo de técnicas para el diagnóstico y planificación preoperatoria en el campo de la medicina. Todo ello ha dado lugar a más exigencias de formación e investigación y, sobre todo, a un nuevo perfil profesional que conjuga aspectos médicos y tecnológicos dentro de una disciplina reciente, pero con un gran futuro, como son las tecnologías médicas (KLAPAN \& VRANJES, 2008; GAVIDIA et al., 2010).

Las actividades de investigación de la medicina se plantean fundamentalmente en tres áreas: teórica, experimental y actualmente el área de las tecnologías de la información. El elevado costo que supone la experimentación y la imposibilidad de la personalización de la misma, junto al desarrollo acelerado de los ordenadores, en cuanto a potencia, rapidez, versatilidad, visualización gráfica, etc., así como el avance tecnológico en la adquisición de imágenes médicas mediante tomografía computarizada (CT) y resonancia magnética (RM), han motivado un creciente protagonismo de las nuevas tecnologías para la adquisición y visualización de las imágenes médicas. Es en este ámbito donde se encuadra el presente trabajo.

La tecnología del modelado 3D permite conocer los detalles de estructuras que de otro modo no estarían a nuestro alcance, un ejemplo de ello es la estructura del hélice del ADN o la estructura del átomo. En la actualidad la utilización de la tecnología 3D ya ha demostrado ser el camino a seguir, debido a que permitirá, entre otras cosas, maximizar la utilización de recursos tecnológicos con muy buenos resultados. La medicina moderna no sería posible sin los avances en técnicas de imagen y visualización, así gran parte de los tratamientos relacionados con el cáncer y de las intervenciones quirúrgicas dependen de estas tecnologías (MOTOHASHI, 1999; BOSKAMP \& HAHN, 2005; VRTOVEC et al., 2005; LEARDINI et al., 2006; KLAPAN \& VRANJES, 2008; GAVIDIA et al., 2010; REYNOLDS et al., 2011; PARK et al., 2013) 
En el mismo sentido la cirugía asistida por ordenador es un campo tecnológico desarrollado recientemente que intenta crear y dotar de herramientas a los cirujanos para el diagnóstico y la planificación de intervenciones quirúrgicas. Se aplica a un número amplio de especialidades médico-quirúrgicas; si bien donde encuentra mayor utilización es en neurocirugía ya que es la especialidad que demanda mayor precisión en el abordaje quirúrgico (DAMMANN et al., 2001; HASSAN et al., 2009; HAQ et al., 2014; WILHELM et al., 2014).

Según un estudio publicado por Fraunhofer Institute for Telecommunications, el Heinrich Hertz Institute HHI y el Isar University Hospital of Munich (2013), señala que la imagen 3D está cada día más presente en la práctica clínica, en particular gracias a la mejora de esta tecnología. En este estudio los autores resaltan las ventajas de la tecnología 3D en la medicina. Además en este estudio demostraron que los médicos, incluso los más experimentados, podrían beneficiarse de la última generación de dispositivos 3D (KOCKRO et al., 2007; JUERGENS et al., 2008; IORIO et al., 2009; SIERRA et al., 2009; LIU et al., 2010; TANG \& YAMADA, 2010; RAMIREZ, 2011).

La columna vertebral, a pesar de ser una estructura anatómica muy compleja, debido a los huesos que la forman y la estrecha relación que tiene con importantes estructuras neurovasculares, puede ser estudiada adecuadamente con las técnicas de neuroimagen de tomografía computarizada multidetector, o la resonancia magnética. En la mayoría de las lesiones estas pruebas radiológicas anteriormente citadas, son determinantes en la toma de decisiones, además, una imagen de alta calidad, puede evitar repetir pruebas o realizar otros procedimientos innecesarios; ocurre lo contrario cuando en una prueba de neuroimagen no es posible valorar el área de interés, el paciente corre el riesgo de ser sometido a otras pruebas o procedimientos muchas veces agresivos, con el 
objetivo de llegar a un diagnóstico. Con la tecnología 3D este tipo de conducta, en un alto porcentaje, ha sido disminuido, gracias a la alta resolución que puede llegar a tener un estudio de neuroimagen cuando se le aplica tecnología 3D (KLAPAN \& VRANJEŠ, 2008; GAVIDIA). Todo esto, tiene como objetivo final, disminuir la morbimortalidad de los pacientes, ya que estos avances tecnológicos significan menos repetición de estudios, menos pruebas invasivas y un diagnóstico más temprano (VERHELST et al., 1996; DEFRISE, 2001; VRTOVEC et al., 2005; KLAPAN \& VRANJEŠ, 2008; GAVIDIA et al., 2010; KLAPAN et al., 2011).

El diagnóstico es fundamental para una buena planificación preoperatoria. La valoración radiológica precisa definir las lesiones tomando en consideración las estructuras en tres dimensiones, lo cual implica el uso de equipos de tomografía computarizada o de resonancia magnética. Debido a las dimensiones de algunas estructuras, es necesario que el estudio se realice con cortes muy finos entre 2 a $5 \mathrm{~mm}$ entre uno y otro corte, dependiendo del área de interés a estudiar. Cuánto más cortes el estudio es más fiable. Por consiguiente, en cada estudio el número de cortes puede llegar a tener más de 100 a 200 cortes, según el área de interés, sin contar las proyecciones coronales, sagitales y las reconstrucciones tridimensionales. Es muy difícil que la totalidad del estudio llegue a manos del neurocirujano. Por lo general, las imágenes son seleccionadas por el personal de radiología, el cual solo imprime aquéllas en las cuales encuentra alguna alteración. Si bien en la mayoría de los casos estas imágenes suelen ser suficiente para llegar a un diagnóstico, en algunas ocasiones, en el proceso se pierde información que puede resultar decisiva a la hora de tomar una decisión quirúrgica (ROWLAND \& BELL, 1998; BISDAS et al., 2004; PRASTAWA et al, 2004; ROSSET et al., 2004; LANGE, et al., 2004; RATIB \& ROSSET, 2006; LIU et al., 2009; SIERRA et al., 2009; YAMAUCHI et al., 2010; GAVIDIA \& SOUDAH, 2011; HAQ et al., 2014). 
En nuestro trabajo de tesis doctoral aprovechamos las ventajas que ofrecen los equipos de tomografía y resonancia magnética de nueva generación, los cuales permiten grabar la información en medios extraíbles en diversos formatos, de los cuales el formato DICOM es el estándar. De esta manera es posible obtener el estudio radiológico del paciente completo, sacando el máximo provecho al estudio, el cual puede ser visualizado en cualquier ordenador personal con los programas que comentaremos a continuación .

En el mercado, se pueden encontrar diferentes programas informáticos de visualización y planificación digital, especialmente en el área de la Neurocirugía, cirugía maxilofacial, traumatología, y otras especialidades, no obstante para el abordaje a la columna vertebral aun existen dificultades para acceder a estas tecnologías, debido al elevado costo y la complejidad requerida para el aprendizaje de estos sistemas informáticos comerciales, que son utilizados para procesar imágenes DICOM. Hasta hace poco tiempo, este formato solo podía visualizarse y manipularse en las complejas y costosas estaciones de trabajo por personal cualificado, o mediante costosos programas para ordenadores personales (ROSSET et al., 2004; NAGY, 2007; RATIB et al., 2011).

El avance sostenido de la tecnología ha llevado al desarrollo de múltiples visores de código abierto para la visualización de imágenes en formato DICOM, los cuales pueden ser utilizados en ordenadores personales. No obstante, la mayoría presentan la desventaja que solo permiten la visualización y no la manipulación, ni las reconstrucciones volumétricas en 3D (ROSSET et al., 2004; NAGY, 2007). 
Para cumplir con los objetivos marcados en este trabajo de tesis doctoral y conseguir desarrollar modelos 3D de la CV de alta calidad, asequible y compatible con la mayoría de ordenadores, fue necesario superar las barreras económicas, de accesibilidad y de asequibilidad anteriormente expuestas. De esta manera decidimos buscar aplicaciones de código abierto disponibles libremente sin ningún costo (RATIB \& ROSSET, 2006; NAGY, 2007; SIERRA et al., 2009; BOCANEGRA, 2010; RATIB et al., 2011; RORDEN, 2012; FERROLI et al., 2013; ABREU et al., 2014).

Debido a que no existe una aplicación de visualización de imágenes DICOM capaz de desarrollar modelos 3D con las características requeridas para cumplir con los objetivos marcados en nuestro trabajo, dividimos el proceso de creación de modelos 3D en dos partes:

- Primero utilizamos un programa de visualización de imágenes DICOM para seleccionar las imágenes y regiones de interés, en nuestro caso decidimos utilizar el visor de imágenes DICOM MRIcroGL ${ }^{\circledR}$ desarrollado en el año 2012 por Chris Rorden, EEUU. Elegimos MRIcroGL ${ }^{\circ}$, porque es compatible con Windows, Linux y Macintosh, y además de ser una aplicación de código abierto, gratuita, ofrece ventajas sobre otros visores en cuanto a su capacidad para manipular las imágenes.

- Segundo, tras seleccionar las áreas de interés, el siguiente paso fue el desarrollo de los modelos 3D de alta calidad, utilizando programas de modelado 3D. En la literatura existen trabajos publicados, en los cuales utilizan estos programas de modelado 3D para modelar estructuras anatómicas (CHALAZONITIS et al., 2003; PARK et al., 2005; CARVALHO et al., 2007), la diferencia entre estos trabajos y el nuestro, es que en esos trabajos el objetivo no era la planificación preoperatoria, además no llegan a reconstruir extensas 
áreas anatómicas como en nuestro trabajo, donde reconstruimos la columna vertebral completa, incluido el modelado de partes blandas y la superposición de los modelos a los cortes planares de RM o TC del paciente, de esta manera los modelos 3D de nuestro trabajo tiene importancia en la valoración integrar de la columna vertebral y estructuras anatómicas relacionadas.

Así Chalazonitis (2003), describe un método para optimizar las imágenes de las radiografías obtenidas con una cámara digital usando el software Adobe Photoshop. Sin embargo, el objetivo de su estudio no fue sobre la planificación preoperatoria. Por otro lado Park y colaboradores (2005), publicaron en un trabajo el uso de funciones especiales del software Adobe Photoshop para llevar a cabo la segmentación semiautomática de imágenes de RM. Luego utilizaron estas imágenes segmentadas para hacer reconstrucciones tridimensionales de las diferentes estructuras anatómicas, incluyendo la piel, los huesos, tracto digestivo, vías respiratorias y del tracto urinario. Ellos fueron capaces de cumplir con el objetivo de acelerar el proceso de segmentación en la segmentación manual (CHALAZONITIS et al., 2003; PARK et al., 2005).

Otro trabajo publicado por Carvalho et al., (2007), utilizando una aplicación del mismo tipo de software, describe una técnica de radiografía por sustracción digital para evaluar las lesiones dentales periapicales crónicas. Para medir la progresión de estas lesiones se siguió con radiografías seriadas. Tradicionalmente, estas evaluaciones han sido cualitativas. Sin embargo, mediante el uso de la técnica de sustracción digital, los autores fueron capaces de determinar si las lesiones se curaban o se expandían. También utilizaron la aplicación para cuantificar el tamaño de las lesiones óseas en cada periodo de tiempo (CHALAZONITIS et al., 2003; CARVALHO et al., 2007). 
De los programas freeware o de código abierto utilizados más extendidamente, debido a su popularidad y calidad, decidimos utilizar Autodesk Maya, debido a que es una aplicación intuitiva y por las características de modelado que ofrece.

Entre las principales características que describen al programa de modelación en tres dimensiones, Autodesk Maya citamos:

a) Posibilidades de crear y esculpir objetos orgánicos y no orgánicos desde el principio, mediante herramientas de dibujo y transformación.

b) Características de tornado y extracción, que ayudan a la modelación de secciones cóncavas y convexas.

c) Permite la asignación de colores, texturas y materiales que ayudan a acentuar el realismo de un modelo.

d) Posibilita añadir focos de luces locales y globales, tanto internas como externas, colocarlos en cualquier posición y manipularlos para conseguir efectos especiales de iluminación y mayor realismo.

e) Posee un número ilimitado de cámaras, con control de la longitud focal.

f) Permite dibujar trayectos basados en Splines (curvas o formas bidimensionales constituidas por vértices y aristas que podemos modificar, a través de aplicaciones como Torno (Lathe), Extruir (Extrude) y Biselar (Bevel)) también para la realización de animaciones.

De esta manera pudimos conseguir realizar modelos de la CV en 3D con la calidad requerida para cumplir con los objetivos marcados en nuestro trabajo, con la originalidad de que es el primer trabajo en el cual se utilizan estos programas de modelado con el objetivo principal de servir de ayuda a la planificación preoperatoria de la columna vertebral. Además de conseguir desarrollar modelos 3D de alta calidad, también hemos logrado realizar 
reconstrucciones de estructuras anatómicas complejas, como es el caso de estructuras neuro-vasculares adyacentes a la columna vertebral. De esta manera al hacer la valoración preoperatoria es mas fácil tener en cuenta toda la estructura anatómica adyacente a la región de la columna vertebral a intervenir, con lo cual pensamos que es posible reducir el margen de error, lo que se traduce en más capacidad de preservar estructuras adyacentes a la zona quirúrgica.

\subsection{Planificación preoperatoria con modelos 3D}

Desde la década de los ochenta cuando aparecieron los primeros informes sobre diferentes métodos para el análisis de deformidades de la columna vertebral, basándose en el análisis de imágenes radiográficas que aportaban información en 3D de la columna vertebral, se han introducido nuevos conceptos de planificación quirúrgica, lo cual implica explorar nuevas tecnologías al mismo tiempo que se fueron dejando de lado los métodos tradicionales (JEFFRIES et al., 1980; SMET et al., 1984; FERROLI et al., 2013).

Para la planificación preoperatoria se utiliza información volumétrica basada en la intensidad de las imágenes, por lo general obtenidas del TC y/o equipos de RM. Los cirujanos pueden ver estas imágenes utilizando aplicaciones de visualización de imágenes médicas en 2-D. En algunas ocasiones esta tarea puede ser difícil, incluso para los médicos con experiencia, debido a que los procesos patológicos pueden contribuir a la modificación y el aumento de la variabilidad anatómica interindividual, con lo cual la anatomía de la columna vertebral puede estar distorsionada, lo que puede complicar aún más la tarea. Como consecuencia, al momento de planificar una intervención con imágenes en 2D, puede perderse información importante o llegar a conclusiones erróneas que pueden conducir a decisiones de estrategia de tratamiento subóptimo (KIKINIS et al., 1996; LAMADE et al., 2000; DIGIOIA \& SIMON, 2001; BENEDETTI, et al., 2003; HOARAU et al., 2014; XIANG et al., 2014). 
En nuestro trabajo hemos conseguido demostrar que con aplicaciones de código abierto es posible realizar modelos en 3D de alta calidad sin aumentar el costo del estudio del paciente, los cuales pueden aportar datos útiles para la mejor comprensión de las lesiones, con la integración tridimensional de los datos obtenidos en conjunto de las tres proyecciones. Así proponemos seguir el procedimiento de reconstrucción $3 \mathrm{D}$, comenzando con la fase de adquisición de las imágenes o región de interés que defina la lesión patológica a estudiar y su relación espacial con las estructuras normales que deban ser preservadas. El siguiente paso, tras el diagnóstico, es la planificación quirúrgica que defina el tipo de abordaje más seguro y los pasos a seguir durante la intervención y es aquí donde tiene máximo interés la composición 3D de la anatomía del paciente.

Existen publicaciones que demuestran que la planificación preoperatoria con imágenes digitales y reconstrucciones en $3 \mathrm{D}$, es más acertada y más rápida en su ejecución, comparándose con sistemas de planificación con radiografías convencionales. Es por esto que la tendencia en los últimos años, en la mayoría de los grandes hospitales del mundo, es realizar la planificación con herramientas que faciliten las reconstrucciones 3D y radiografías digitales (MOTOHASHI, 1999; LAMADE et al., 2000; RANCO et al., 2010; RAMÍREZ \& COTO, 2011; FERROLI et al., 2013; HANKEN et al., 2014).

Así ECKE (1998) y UNSGAARD (2006) en estudios separados afirman que las imágenes que son procesadas mediante el uso de sistemas gráficos de computación y sistemas especializados, pueden representar mejor la anatomía de un área de interés particular del cuerpo, aumentando las posibilidades de una planificación preoperatoria más exacta. Además aumentan la posibilidad de explorar y visualizar de una manera no invasiva, las relaciones espaciales existentes entre una estructura anatómica y la patología, incluidas calcular el tamaño y el grado de agresión de la patología al tejido sano, con mas precisión. 
KNEZOVI y sus colaboradores (2007) plantean que con la tecnología de modelos 3D, es posible predecir el curso de la intervención quirúrgica, permitiendo al cirujano lograr una ventaja considerable reduciendo el riesgo de complicaciones intraoperatorias. La planificación virtual ofrece una serie de ventajas, que evidentemente sobrepasan las desventajas sobre el elevado costo que supone contar con equipos para la planificación 3D. El procedimiento de planificación y simulación se puede utilizar para la educación de los estudiantes. (WEINBERGER, 1996; ECKE et al., 1998; BISDAS \& VERINK, 2004; KNEZOVIĆ et al., 2007).

La diferencia que existe entre estas publicaciones con nuestro trabajo, es que el cirujano podrá reconstruir las estructuras anatómicas de interés, visualizar el preoperatorio y memorizar las relaciones espaciales entre la lesión y las estructuras vecinas desde diferentes ángulos, facilitando el reconocimiento intraoperatorio, sin la necesidad de costosos equipos, ni estudios adicionales, además podrá realizar la planificación preoperatoria en un ordenador personal.

Para una reconstrucción tridimensional óptima, el cirujano tiene que considerar la estructura original, incluyendo la curvatura, el tamaño y la longitud de la zona a reconstruir de forma individual. Sin embargo, incluso con un plan cuidadoso y completo, el procedimiento quirúrgico real puede presentar problemas inesperados. No obstante autores como DIGIOIA (2001) afirman que los procedimientos bien planificados con modelos $3 \mathrm{D}$, personalizan las intervenciones quirúrgicas y pueden identificar los puntos propensos a fallos durante el proceso de la intervención, con lo cual es posible disminuir los imprevistos que pudieran encontrase en la cirugía (LAMADE et al., 2000; DIGIOIA \& SIMON, 2001; JUERGENS et al., 2008; STADIE et al., 2008; IORIO et al., 2009). 


\subsection{Utilización de modelos 3D para el entrenamiento de vías de abordajes y la docencia.}

Con el advenimiento de la neurocirugía mínimamente invasiva, es necesario elegir el abordaje reduciendo al mínimo el error del procedimiento quirúrgico, al mismo tiempo es imprescindible aumentar la precisión. Es obvio, que esto sólo puede realizarse con un alto grado de orientación espacial de la anatomía. En algunas ocasiones valorar y comprender la anatomía quirúrgica en 3D con las clásicas imágenes en 2D suele ser difícil de conseguir. Según lo propuesto en nuestro trabajo el neurocirujano puede utilizar el estudio radiológico del paciente, para reconstruir su propio modelo anatómico en 3-D personalizado a la anatomía individual del paciente; con lo cual puede resultar mas fácil entender la relación existente entre la $\mathrm{CV}$ con la lesión y órganos vecinos. Así la visualización de las imágenes en 3D basada en la segmentación de las estructuras puede mejorar la comprensión del cirujano sobre la anatomía quirúrgica, incluyendo las distorsiones anatómicas provocadas por la propia patología y la variabilidad anatómica interindividual. De esta manera será más fácil planificar una intervención quirúrgica menos invasiva, sin perder el objetivo quirúrgico (TAYLOR et al., 1995; SATO et al., 1998; ROSSET et al., 2004; JAMALI, 2009; SIERRA et al., 2009; HAQ et al., 2014; XIANG et al., 2014).

Así autores como GARCÍA (2011) y PARK (2014), concluyen que observar un modelo 3D desde las diferentes posiciones del espacio, puede ayudar a la hora de elegir la vía de abordaje, por ejemplo: es el caso de la aproximación quirúrgica de las fracturas transversas tipo «T» del acetábulo en la cirugía traumatológica. De esta manera consideran que la utilización de los modelos $3 \mathrm{D}$ en la cirugía permite una planificación preoperatoria que puede evitar improvisaciones haciendo la cirugía menos invasiva, por otro lado estos 
modelos 3D permiten aplicar esta tecnología para: localizar la lesión, cálculo de vías de abordajes, trayectorias y longitudes de implantes, etc. Es por esto que en la actualidad estos autores coinciden en que es necesario que se implementen sistemas que faciliten el análisis tridimensional, sin necesidad de técnicas invasivas, ni incurrir en costosos estudios adicionales.

Otra aplicación de los modelos 3D, es el desarrollo de simuladores clínicos, en especial quirúrgicos. Hasta hace pocos años, las prácticas que recibían los cirujanos se basaban en el empleo de cadáveres, animales vivos o intervenciones quirúrgicas tuteladas; todo ello conlleva problemas: éticos, escasez de sujetos y posibilidades intervencionistas mínimas en algunas patologías. Con la llegada de la tecnología informática aplicada a la medicina y la generación de modelos 3D surgieron los simuladores quirúrgicos. Sus ventajas son la reducción en costes y en sujetos utilizados, así como el aporte de amplia experiencia para los cirujanos, posibilidad de simular abundantes tipos de patologías y posibles complicaciones, repetir los ensayos quirúrgicos tantas veces como sea necesario, incluso realizar las operaciones virtuales de una forma planificada, en el momento más conveniente para el cirujano (ECKE et al., 1998; GONZALEZ et al., 2000; PARK et al., 2005).

Los sistemas de simulación están compuestos básicamente por una interface de usuario, cuya finalidad es suministrar al cirujano una visualización de la reconstrucción computarizada de los órganos internos de interés, para lo cual se emplean modelos avanzados de geometría compleja para objetos en visualización 3D y modelos deformables para incorporar propiedades físicas a las estructuras 3D generadas por el ordenador junto con técnicas de visualización avanzadas. La implementación de esta tecnología abarca todos los principales campos de la neurocirugía: vascular, funcional, raquis y la cirugía oncológica, contribuyendo al desarrollo de un tipo de cirugía que es individualizada al 
paciente y mínimamente invasiva, no solo por el tamaño del abordaje, si no también debido a las estructuras nobles respetadas.

Por otro lado en diferentes publicaciones científicas, los autores resaltan las ventajas de la utilización de modelos 3D para la enseñanza/aprendizaje, así FERROLI et al., (2013) afirman que el uso de la planificación 3D en medicina, proporciona información útil que puede facilitar la curva de aprendizaje y la orientación espacial en neurocirugía.

Impartir enseñanza debe incluir una mezcla de formatos entre actividades teóricas y actividades prácticas, en el caso especifico del estudio de la anatomía radiológica y quirúrgica de la columna vertebral, deberían incluir métodos modernos de enseñanza, incluyendo el aprendizaje basado en problemas, aprendizaje autodirigido por el estudiante y el aprendizaje asistido por ordenador. Sin embargo, a pesar del desarrollo de la tecnología digital 3D, la implantación de estas tecnologías en los programas de educación médica se utiliza poco. Algunas razones incluyen el coste de los equipos, la dificultad técnica para el manejo de la mayoría de estos equipos modernos y el tiempo personal que requiere desarrollar programas educativos (LAMADE et al., 2000; ROUBIDOUX et al., 2002; DURFEE et al., 2003; RUIZ et al., 2006; CHAPARRO, 2008; BONACASA, 2011; FERROLI et al., 2013).

En las reconstrucciones 3D destacan dos tipos de técnicas empleadas en este trabajo de Tesis Doctoral, cuyos resultados son de gran utilidad en la formación docente de la medicina y en la aplicabilidad al diagnóstico y seguimiento terapéutico, son: 
- La primera de ellas, es la renderización que permite la creación de modelos 3D donde las texturas asignadas a cada objeto pueden ser colores sólidos, lo que resulta útil para identificar y separar estructuras anatómicas.

- La segunda técnica es la reconstrucción volumétrica o "visualización" con la que los colores o texturas asignadas a los objetos se obtienen directamente de los valores de cada uno de los vóxels que forman el objeto 3D. Con esta técnica se obtienen reconstrucciones muy realistas y la posibilidad de ver estructuras situadas en el interior de un corte determinado, a diferencia de la renderización, donde sólo se consigue la superficie del objeto estudiado.

Aunque el objetivo de este trabajo no es describir un nuevo recurso educativo basado en tecnología 3D, podemos citar que además de las ventajas para la planificación preoperatoria, este tipo de modelo puede contribuir a la formación médica sin producir detrimento en el aprendizaje del estudiante. El modelo 3D desarrollado puede ser adaptado al aprendizaje, para fomentar la participación activa del alumno.

Así, podemos decir que las principales ventajas desde el punto de vista docente, son: La posibilidad de aprender en cualquier momento, desde cualquier localización; aproximación individualizada, con un ritmo autodirigido; y la capacidad de entender la patología quirúrgica fácil y rápidamente, al observar la lesión en un contexto en sus tres dimensiones. 
A pesar de que algunos autores resaltan las ventajas de la tecnología 3D para la enseñanza concluyen que se necesitan estudios definitivos que no sólo prueben la superioridad de esta tecnología, sino que además, prueben de forma concluyente que no producen detrimento en la educación (COHEN \& DACANAY, 1992; WATANABE et al.,2005; BEYER \& HADWIGER, 2007; CHAPARRO, 2008).

Aunque entendemos que estos modelos no puede sustituir las clases magistrales, pueden utilizarse como complemento a las clases presenciales, las cuales, debidamente coordinadas con los contenidos virtuales pueden reforzar lo aprendido.

KIRKMAN et al., (2014) en su trabajo sobre la tecnología 3D usada para la simulación de abordajes neuroquirúrgicos, consideran que la tecnología 3D se ha convertido en un segmento muy importante en la formación quirúrgica y planificación de la intervención quirúrgica individual, consideran que esta tecnología, además de ser una aplicación educativa, ofrecen la posibilidad de una planificación preoperatoria en neurocirugía (ROWELL et al., 2007; KIRKMAN et al., 2014).

Por otro lado, algunos trabajos publicados citan algunas de las desventajas de la planificación digital, como son la dependencia del ordenador, el costo del software, la curva de aprendizaje, la falta de disponibilidad fuera del ámbito de la estación de trabajo de radiología y las limitaciones en el diseño de software para cada aplicación. Aunque la desventaja más importante, es que este tipo de tecnología puede incrementar el costo del estudio. Muchos autores reconocen estos inconvenientes, pero concluyen que los beneficios de este tipo de tecnología superan los inconvenientes anteriormente expuestos (DAVISON et al., 2000; GUNDERMAN et al., 2001; SCARSBROOK et al., 2005; ROWELL et al., 2007; ALARAJ et al., 2013; KIRKMAN et al., 2014). 
En nuestro trabajo de tesis doctoral queda demostrado que estas desventajas, del elevado costo y la poca disponibilidad que suponen las aplicaciones comerciales para el neurocirujano, quedan superadas. No obstante la limitación mas importante de nuestro modelo, es que la exactitud y precisión no se han validado clínicamente. A pesar de ello, nuestras observaciones en la comprobación de la anatomía con los estudios originales del paciente, han demostrado una excelente correlación, con una concordancia prácticamente exacta entre el modelo y la anatomía radiología del estudio 2D del paciente.

Otra limitación, se refiere a la necesidad de emplear dos programas informáticos para desarrollar los modelos 3D, con lo cual se aconseja el conocimiento informático a nivel básico, si bien recomendamos un nivel medio con el fin de disminuir la curva de aprendizaje.

En definitiva, desde nuestro punto de vista, los beneficios de la técnica para desarrollar modelos 3D presentada en este trabajo de Tesis Doctoral, superan las limitaciones y han cumplido con el objetivo principal de este estudio consistente en desarrollar una herramienta universalmente disponible para asistir a la planificación neuroquirúrgica de la CV. No obstante es necesario mejoras y estudios que confirmen su utilidad práctica. 


\section{CONCLUSIONES}


Tras desarrollar modelos virtuales de las estructuras anatómicas que componen la columna vertebral, a partir de imágenes DICOM de los equipos de tomografía computarizada multidetector y resonancia magnética, así como su correlación anatomo-radiológica y neuroquirúrgica, hemos llegado a las siguientes conclusiones:

$1^{\mathrm{a}}$. Se han desarrollado modelos $3 \mathrm{D}$ próximos a la realidad, con un gran potencial para personalizar el plan preoperatorio del paciente neuroquirúrgico.

$2^{\mathrm{a}}$. Los modelos 3D desarrollados pueden ser observados desde cualquier ángulo, ayudando a mejorar la orientación espacial y memorizar las relaciones anatómicas entre la lesión y las estructuras vecinas, facilitando el reconocimiento intraoperatorio.

$3^{\mathrm{a}}$. Con los modelos 3D aportamos información anatómica complementaria, útil para reducir el margen de error en los abordajes a la columna vertebral.

$4^{\mathrm{a}}$. Los modelos 3D desarrollados, permiten mejorar la visualización de las estructuras anatómicas de difícil observación en los estudios radiológicos 2D, apoyando el diagnostico.

$5^{\mathrm{a}}$. Este modelo constituye una nueva herramienta para la enseñanza y/o aprendizaje, estableciendo entornos virtuales para observación y estudio repetido sin las limitaciones de tiempo y las tensiones impuestas por una estación de trabajo de visualización de imágenes radiológicas o por la cirugía. 
BIBLIOGRAFÍA 
ABREU, A. L., CHOPRA, S., AZHAR, R. A., BERGER, A. K., MIRANDA, G., DESAI, M. (2014). Robotic radical cystectomy and intracorporeal urinary diversion: The USC technique. Indian Journal of Urology, 30(3), 300-306.

ADAMS, V., (1992). Neck injuries: Atlantoaxial dislocation a pathologic study of 14 traffic fatalities. J Forensic Sci. 37: 565-573

AEBI, M., ZUBER, K., \& MARCHESI, D. (1991). Treatment of cervical spine injuries with anterior plating: Indications, techniques, and results. Spine, 16(3), S38-S45.

AKEYSON, E. W., \& MCCUTCHEON, I. E. (1996). Single-stage posterior vertebrectomy and replacement combined with posterior instrumentation for spinal metastasis. Journal of neurosurgery, 85(2), 211-220.

ALARAJ, A., CHARBEL, F., BIRK, D., \& TOBIN, M. (2013). Role of cranial and spinal virtual and augmented reality simulation using immersive touch modules in neurosurgical training. Neurosurgery, 72, 115-123.

ANDERSON, L.D \& D'ALONZO, R.T (1974). Fractures of the Odontoid Process of the axis. J Bone Joint Surg (Am). 56: 1663-1674.

ANDERSON, P.A. \& MONTESANO, P.X, (1978). Morphology and treatment of occipital condyle fractures. Spine. 13:731-736.

ANDERSSON, G. B. (1999). Epidemiological features of chronic low-back pain. Lancet, 354(9178), 581-5.

APUZZO, M.J., HEIDEN, J.S., WEIS, M.H., ACKERSON, T.T., HARVEY, J.P. $\&$ KURZE, T, (1978). Acute fractures of the odontoid process. An analysis of 45 cases. J Neurosurg. 48: 85-91.

AUROUER, N., OBEID, I., GILlE, O., POINTILlART, V., \& VITAL, J. (2009). Computerized preoperative planning for correction of sagittal deformity of the spine. Surgical and Radiologic Anatomy: SRA, 31(10), 781-792.

AVAZPOUR, I., \& SARIPAN, M. (2009). Segmentation of extrapulmonary tuberculosis infection using modified automatic seeded region growing. Biological Procedures, 11(1), 241-252.

BAILEY, R. W., \& BADGLEY, C. E. (1960). Stabilization of the cervical spine by anterior fusion. The Journal of Bone \& Joint Surgery, 42(4), 565-624. 
BAILlARD, C., HELliER, P., \& BARILLOT, C. (2001). Segmentation of brain 3D MR images using level sets and dense registration. Medical Image Analysis, 5(3), 185-194.

BAJURA, M., FUCHS, H., \& OHBUCHI, R. (1992). Merging virtual objects with the real world: Seeing ultrasound imagery within the patient. $A C M$ SIGGRAPH Computer Graphics, 26, 479-492.

BANASZKIEWICZ, P. A., \& KADER, D. (2014). Classic Papers in Orthopaedics. London: Springer London.

BANKMAN, I. (2008). Handbook of medical image processing and analysis. (Elsevier, Ed.) (Second.). California, EEUU.

BÄTHIS, H., PERLICK, L., \& TINGART, M. (2004). Alignment in total knee arthroplasty: A comparison of computer-assisted surgery with the conventional technique. The Journal of Bone \& Joint Surgery, 86(5), 682687.

BENEDETTI, M., MONTANARI, E., CATANI, F., VICENZI, G., \& LEARDINI, A. (2003). Pre-operative planning and gait analysis of total hip replacement following hip fusion. Computer Methods and Programs in Biomedicine, 70(3), 215-221.

BEUTEL, J., FITZPATRICK, J., \& HORII, S. (2002). Handbook of Medical Imaging, Volume 3. Display and PACS.

BEYER, J., \& HADWIGER, M. (2007). High-quality multimodal volume rendering for preoperative planning of neurosurgical interventions. IEEE Transactions on Visualization and Computer Graphics, 13(8), 1696-1703.

BIDGOOD JR, W. D., HORII, S., PRIOR, F. W., \& VAN SYCKLE, D. (1997). Understanding and using DICOM, the data interchange standard for biomedical imaging. Journal of the America, 4, 199-212.

BISDAS, S., VERINK, M., BURMEISTER, H. PETER, STIEVE, M., \& BECKER, H. (2004). Three-dimensional visualization of the nasal cavity and paranasal sinuses: clinical results of a standardized approach using multislice helical computed tomography. Journal of Computer Assisted Tomography, 28(5), 661-669.

BLADEN, J., ANDERSON, A., BELL, G., RAMEH, B., EVANS, B., \& HEATLEY, D. (1993). Non-radiological technique for three-dimensional imaging of endoscopes. The Lancet, 341(8847), 719-722. 
BOCANEGRA, C. S. (2010). Aplicaciones Open Source en el ámbito de la Salud y Sanidad. RevistaeSalud, 6, 1-21.

BÖHLER, J., \& GAUDERNAK, T. (1980). Anterior plate stabilization for fracture-dislocations of the lower cervical spine. Journal of Trauma-Injury, Infection, and Critical Care, 20(3), 203-205.

BÖHLER, J, (1982). Anterior stabilization for acute fractures and non-union of the dens. J Bone Joint Surg (Am). 64: 8-27.

BONACASA, E. V. (2011). Herramientas y métodos para la formación en radiodiagnóstico. Radiología, 53(3), 202-208.

BORNE, G.M., BEDOU, G.L. \& PINAUDEAU, M, (1984). Treatment of pedicular fractures of the axis: A Clinical study and screw fixation thecnique. J Neurosurg. 60: 88-93

BOSKAMP, T., \& HAHN, H. (2005). Geometrical and structural analysis of vessel systems in $3 D$ medical image datasets. (C. T. Leondes, Ed.). Imaging Systems (pp. 1-60). Germany.

BRAYDA-BRUNO, M., \& CINNELLA, P. (2000). Posterior endoscopic discectomy (and other procedures). European Spine Journal, 9(1), S024S029.

BRAU, S. A. (2002). Mini-open approach to the spine for anterior lumbar interbody fusion: description of the procedure, results and complications. The spine journal, 2(3), 216-223.

MAYER, H. M. (2006). Minimally invasive spine surgery (pp. 3-7). Springer Berlin Heidelberg.

BRENNER, D., \& HALL, E. (2007). Computed tomography an increasing source of radiation exposure. New England Journal of Medicine, 357, 22772284.

CARLSON, B. (2009). Embriología humana y biología del desarrollo. (Elservier, Ed.) Embriología Humana y Biología del Desarrollo (4th ed.) Vol. 57, p. 726). España.

CARVALHO, F., GONÇALVES, M., \& TANOMARU-FILHO, M. (2007). Evaluation of chronic periapical lesions by digital subtraction radiography by using Adobe Photoshop CS: a technical report. Journal of Endodontics, 33(4), 493-497. 
CASPAR W, GEISLER FH, PITZEN T \& JOHNSON TA. Anterior cervical plate stabilization in one-and two-level degenerative disc disease: Overtreatment or benefit. J Spinal Disord. 1998;11:1-11.

CASPAR, W., BARBIER, D. D., \& KLARA, P. M. (1989). Anterior cervical fusion and Caspar plate stabilization for cervical trauma. Neurosurgery, 25(4), 491-502.

CERROlAZA, M., GAVIDIA, G., SOUDAH, E., \& MARTIN, M. (2014). Modeling human tissues: an efficient integrated methodology. Biomedical Engineering, 26(1), 145.

CHALAZONITIS, A., KOUMARIANOS, D., TZOVARA, J. \& CHRONOPOULOS, P. (2003). How to optimize radiological images captured from digital cameras, using the Adobe Photoshop 6.0 program. $J$. of Digital Imaging, 16(2), 216-229.

CHAO, E., LYNCH, J., \& VANDERPLOEG, M. (1993). Simulation and animation of musculoskeletal joint system. Journal of, 115(4B), 562-568.

CHAPARRO, O. T. (2008). Diseño y evaluación de una aplicación multimedia para la enseñanza de radiología a alumnos de Medicina (AMERAM).

CHAUDHRY, B., WANG, J., WU, S., MAGLIONE, M., MOJICA, W., ROTH, Shekelle, P. G. (2006). Systematic review: impact of health information technology on quality, efficiency, and costs of medical care. Annals of Internal Medicine, 144(10), 742-752.

CHIBA, K., OGAWA, Y., ISHII, K., TAKAISHI, H., NAKAMURA, M., MARUIWA, H., \& TOYAMA, Y. (2006). Longterm results of expansive open door laminoplasty for cervical myelopathy average 14 year follow-up study. Spine, 31(26), 2998-3005.

CHUANG, C., \& CHEN, C. (2007). A novel region-based approach for extracting brain tumor in CT images with precision. IFMBE Proceeding, $14,2488-2492$.

CIOFOLO, C., \& FRADKIN, M. (2008). Segmentation of pathologic hearts in long-axis late-enhancement MRI. Computer and Information Science, 5241(1), 186-193.

CLARKE, L., VELTHUIZEN, R., CAMACHO, M., HEINE, J., \& VAIDYANATHAN, M. (1995). MRI segmentation: methods and applications. Magnetic Resonance, 13(3), 343-368. 
CLEMENTS, D. H., \& O'LEARY, P. F. (1990). Anterior cervical discectomy and fusion. Spine, 15(10), 1023-1025.

CLOWARD RB. The anterior approach for removal of ruptured cervical disks. $\mathrm{J}$ Neurosurg. 1958;15:602-617.

COHEN, P., \& DACANAY, L. (1992). Computer-Based Instruction and Health Professions Education A Meta-Analysis of Outcomes. Evaluation \& the Health Professions.

COOPER, P. R., ERRICO, T. J., MARTIN, R., CRAWFORD, B., \& DIBARTOLO, T. (1993). A systematic approach to spinal reconstruction after anterior decompression for neoplastic disease of the thoracic and lumbar spine. Neurosurgery, 32(1), 1-8.

CRAFFOORD C, HIERTONN T, LINDBLOM K \& OLSSON SE,1958. Spinal cord compression caused by a protruded thoracic disc: report of a case treated by anterior fenestration of the disc. Acta Orthop Scand. 28: 103-7.

CROCK, H. V. (1982). Anterior lumbar interbody fusion: indications for its use and notes on surgical technique. Clinical orthopaedics and related research, 165, 157-163.

DAMMANN, F., BODE, A., SCHWADERER, E., SCHAICH, M., HEUSCHMID, M., \& MAASSEN, M. (2001). Computer-aided Surgical Planning for Implantation of Hearing Aids Based on CT Data in a VR Environment 1. Radiographics, 21(1), 183-191.

DAVISON, B., TELLO, R., \& BLICKMAN, J. (2000). World Wide Web program for optimizing and assessing medical student performance during the radiology clerkship. Academic Radiology, 7(4), 269-263.

DEFRISE, M. (2001). A short reader's guide to 3D tomographic reconstruction. Computerized Medical Imaging and Graphics: The Official Journal of the Computerized Medical Imaging Society, 25(2), 113-6.

DEMETRIADES, D., CHARALAMBIDES, K., CHAHWAN, S., HANPETER, D., ALO, K., VERMAHOS, G., ASENSIO, J. (2000). Nonskeletal cervical spine injuries: epidemiology and diagnostic pitfalls. Journal of Trauma, 48(4), 724-727. Retrieved from

D-SMET, A. DE, ASHER, M., \& COOK, L. (1984). Three-dimensional analysis of right thoracic idiopathic scoliosis. Spine, 9 (4). 
DICKMAN, C. A., \& SONNTAG, V. K. (1998). Posterior C1-C2 transarticular screw fixation for atlantoaxial arthrodesis. Neurosurgery, 43(2), 275-280.

DICKMAN, C. A., ROSENTHAL, D. J., \& PERIN, N. I. (Eds.). (1999). Thoracoscopic spine surgery. Thieme.

DICKMAN, C. A., FESSlER, R. G., MACMILLAN, M., \& HAID, R. W. (1992). Transpedicular screw-rod fixation of the lumbar spine: operative technique and outcome in 104 cases. Journal of neurosurgery, 77(6), 860870 .

DIGIOIA, A., \& JARAMAZ, B. (1998). Image guided navigation system to measure intraoperatively acetabular implant alignment. Orthopaedic Practice, 355, 8-22.

DIGIOIA, A., \& SIMON, D. (2001). Computer-assisted surgery planner and intra-operative guidance system. US Patent.

DOLAN, P., EARLEY, M., \& ADAMS, M. (1994). Bending and compressive stresses acting on the lumbar spine during lifting activities. Journal of Biomechanics, 27(10), 1237-1248.

DUERSTOCK, B. S., BAJAJ, C. L., PASCUCCI, V., SCHIKORE, D., LIN, K. N. \& BORGENS, R. B. (2000). Advances in three-dimensional reconstruction of the experimental spinal cord injury. Computerized Medical Imaging and Graphics, 24(6), 389-406.

DUMOUlin, S., HOGE, R., BAKER JR, C., \& HESS, R. (2003). Automatic volumetric segmentation of human visual retinotopic cortex. Neuroimage, $18(3), 576-587$.

DUNCAN, J., \& AYACHE, N. (2000). Medical image analysis: Progress over two decades and the challenges ahead. IEEE Xplore Digital, 22(1), 85-106.

DURFEE, S., JAIN, S., \& SHAFFER, K. (2003). Incorporating electronic media into medical student education: a survey of AMSER members on computer and web use in radiology courses. Academic Radiology, 10(2), 205-210.

ECKE, U., KLIMEK, L., MÜLLER, W., ZIEGLER, R., \& MANN, W. (1998). Virtual reality: preparation and execution of sinus surgery. Copunter Aided Surgery, 3(1), 45-50.

EDELMAN, R., \& WARACH, S. (1993). Magnetic resonance imaging. New England Journal of Medicine, 23(2), 437-459. 
EMERY, S. E., BOLESTA, M. J., BANKS, M. A., \& JONES, P. K. (1994). Robinson Anterior Cervical Fusion: Comparison of the Standard and Modified Techniques. Spine, 19(6), 660-663.

ERNST, R., BODENHAUSEN, G., \& WOKAUN, A. (1991). Principles of nuclear magnetic resonance in one and two dimensions. Medical Physics, $15(4), 648$.

ESCOTT, E., \& RUBINSTEIN, D. (2003). Free DICOM Image Viewing and Processing Software for Your Desktop Computer: What's Available and What It Can Do for You 1. Radiographics, 23(5), 1341-1357.

FANG, H. S., \& ONG, G. B. (1962). Direct anterior approach to the upper cervical spine. The Journal of Bone \& Joint Surgery, 44(8), 1588-1604.

FERNYHOUGH, J. C., SCHIMANDLE, J. J., WEIGEL, M. C., EDWARDS, C. C., \& LEVINE, A. M. (1992). Chronic donor site pain complicating bone graft harvesting from the posterior iliac crest for spinal fusion. Spine, 17(12), 1474-1480.

FERROLI, P., TRINGALI, G., ACERBI, F., SCHIARITI, M., BROGGI, M., AQUINO, D., \& BROGGI, G. (2013). Advanced 3-dimensional planning in neurosurgery. Neurosurgery, 72(january), 54-62.

FESSLER, R. G., STECK, J. C., \& GIOVANINI, M. A. (1998). Anterior cervical corpectomy for cervical spondylotic myelopathy. Neurosurgery, 43(2), 257-265.

FESSLER, M. D., RICHARD, G., \& STURGILL, M. D. (1998). Review: complications of surgery for thoracic disc disease. Surgical neurology, 49(6), 609-618.

FITZPATRICK, J., \& SONKA, M. (2000). Handbook of Medical Imaging: Medical Image Processing and Analysis. (The international society for optical engineering, Ed.) (1st ed., p. 1218). EEUU.

FOLEY, K. T., HOLLY, L. T., \& SCHWENDER, J. D. (2003). Minimally invasive lumbar fusion. Spine, 28(15S), S26-S35.

FRENCH, B. (1982). The embryology of spinal dysraphism. Clinical Neurosurgery, 30, 295-340. 
GARCÍA SÁNCHEZ, A., MOREY MAS, M. Á., RAMOS MURGUIALDAY, M., JANEIRO BARRERA, S., MOLINA BARRAGUER, I., \& IRIARTE ORTABE, J. I. (2011). Reconstrucción de la articulación temporomandibular postraumática con prótesis a medida: Planificación quirúrgica virtual. Revista Española de Cirugía Oral Y Maxilofacial, 33(2), $53-60$.

GAVIDIA, G., \& SOUDAH, E. (2011). Generación de modelos discretos de tejidos del ser humano a través del preprocesamiento y segmentación de imágenes médicas. Revista Internacional de Métodos Numéricos Para Cálculo Y Diseño En Ingeniería, 27(3), 200-226.

GOLDENBERG, R., \& KIMMEL, R. (2005). Techniques in Automatic Cortical Gray Matter Segmentation of Three-Dimensional (3D). Brain Images. In Medical Imaging Systems Technology: Methods in cardiovascular and brain systems (1st ed., p. 281). Hifa.

GONZALEZ, J. M., CERVERA, J., GOMEZ, R., PESUDO, J., GARCÍA, T., \& J, T. (2000). racnoidea y de los aneurismas cerebrales. Neurocirugia, 11, 23-30.

GRAHAM, R. N. J., PERRISS, R. W., \& SCARSBROOK, A. F. (2005). DICOM demystified: a review of digital file formats and their use in radiological practice. Clinical Radiology, 60(11), 1133-40.

GRAUER, D., CEVIDANES, L., \& PROFFIT, W. (2009). Working with DICOM craniofacial images. American Journal of Orthodontics, (136) $3460-470$.

GRIEVE, G. (2005). Clinical anatomy of the lumbar spine and sacrum. Physiotherapy, 83(9), 495.

GUNDERMAN, R., KANG, Y., FRALEY, R., \& WILLIAMSON, K. (2001). Instructional Technology and Radiologic Education 1. Radiology, 221(1).

GÜVEN, O., KUMANO, K., YALÇIN, S., KARAHAN, M., \& TSUJI, S. (1994). A single stage posterior approach and rigid fixation for preventing kyphosis in the treatment of spinal tuberculosis. Spine, 19(9), 1039-1043.

HAACKE, E., \& BROWN, R. (1999). Magnetic resonance imaging. Physical Principles (John Wiley and Sons Ed.) (1st ed.). NY. 
HAEBERLEN, U. (2012). High Resolution NMR in Solids Selective Averaging: Supplement 1 Advances in Magnetic Resonance. (I. Academic Press, Ed.) (1st ed.). NY.

HAID JR, R. W., SUBACH, B. R., MCLAUGHLIN, M. R., RODTS JR, G. E., \& WAHLIG JR, J. B. (2001). C1-C2 transarticular screw fixation for atlantoaxial instability: a 6-year experience. Neurosurgery, 49(1), 65-70.

HAMILTON, W. (1962). Human embryology. British Medical Journal, l(Jan), 5271.

HAMILTON, W., BOYD, J., \& MOSSMAN, H. (1945). Human embryology (prenatal development of form and function). Human Embryology, 97(Pt 2), 295-296.

HAMILL, J., BATES, B. T., KNUTZEN, K. M., \& KIRKPATRICK, G. M. (1989). Relationship between selected static an dynamic lower extremity measures. Clinical Biomechanics, 4(4), 217-225.

HANDLER, J., \& ADAMS, J. (2004). Developing consensus in emergency medicine information technology. Academic Emergency Medicine, 11(11), $1109-1111$.

HANKEN, H., SCHABLOWSKY, C., SMEETS, R., HEILAND, M., SEHNER, S., RIECKE, B., \& AL-DAM, A. (2014). Virtual planning of complex head and neck reconstruction results in satisfactory match between real outcomes and virtual models. Clinical Oral Investigations, 014, 1291-125.

HAQ, R., ARAS, R., BESACHIO, D. A., BORGIE, R. C., \& AUDETTE, M. A. (2014). 3D lumbar spine intervertebral disc segmentation and compression simulation from MRI using shape-aware models. International Journal of Computer Assisted Radiology and Surgery, 1861-6429. d

HARTLEY R., \& ZISSERMAN A. (2000). Multiple View Geometry in Computer Vision. Cambridge University Press.

HASSAN, B., VAN DER STELT, P., \& SANDERINK, G. (2009). Accuracy of three-dimensional measurements obtained from cone beam computed tomography surface-rendered images for cephalometric analysis: influence of patient scanning position. European Journal of Orthodontics, 31(2), 12934. 
HENDERSON, C. M., HENNESSY, R. G., SHUEY JR, H. M., \& SHACKELFORD, G. E. (1983). Posterior-lateral foraminotomy as an exclusive operative technique for cervical radiculopathy: a review of 846 consecutively operated cases. Neurosurgery, 13(5), 504-512.

HELlER, J. G., SASSO, R. C., PAPADOPOUlOS, S. M., ANDERSON, P. A., FESSLER, R. G., HACKER, R. J., ... \& RIEW, D. K. (2009). Comparison of BRYAN cervical disc arthroplasty with anterior cervical decompression and fusion: clinical and radiographic results of a randomized, controlled, clinical trial. Spine, 34(2), 101-107.

HELLER, J. G., EDWARDS, C. C., MURAKAMI, H., \& RODTS, G. E. (2001). Laminoplasty versus laminectomy and fusion for multilevel cervical myelopathy: an independent matched cohort analysis. Spine, 26(12), 13301336.

HERKOWITZ, HARRY N., LAWRENCE T. KURZ, and DAVID P. OVERHOLT. "Surgical management of cervical soft disc herniation: a comparison between the anterior and posterior approach." Spine 15.10 (1990): 1026-1030.

HERKOWITZ, H. N. (1988). A comparison of anterior cervical fusion, cervical laminectomy, and cervical laminoplasty for the surgical management of multiple level spondylotic radiculopathy. Spine, 13(7), 774-780.

HIRABAYASHI, K., TOYAMA, Y., \& CHIBA, K. (1999). Expansive laminoplasty for myelopathy in ossification of the longitudinal ligament. Clinical orthopaedics and related research, 359, 35-48.

HIRABAYASHI K, WATANABE K, WAKANO K, SUZUKI N \& ISHII Y. 1983. Expansive open door laminoplasty for cervical spinal stenotic myelopathy. Spine. 8: 693-699.

HOARAU, R., ZWEIFEL, D., SIMON, C., \& BROOME, M. (2014). The use of 3D planning in facial surgery: Preliminary observations. Rev de Stomatol Chir Maxillo-Faciale Chirurgie Orale.

HOUNSFIELD, G. (1973). Computerized transverse axial scanning (tomography): Description of system. The British Journal of Radiology, 46(552), 1016. 
HOUTEN, J. K., \& COOPER, P. R. (2003). Laminectomy and posterior cervical plating for multilevel cervical spondylotic myelopathy and ossification of the posterior longitudinal ligament: effects on cervical alignment, spinal cord compression, and neurological outcome. Neurosurgery, 52(5), 10811088.

HUKUDA, S., MOCHIZUKI, T., OGATA, M., SHICHIKAWA, K., \& SHIMOMURA, Y. (1985). Operations for cervical spondylotic myelopathy. A comparison of the results of anterior and posterior procedures. Journal of Bone \& Joint Surgery, British Volume, 67(4), 609-615.

HUMPHREYS, S. C., HODGES, S. D., PATWARDHAN, A. G., ECK, J. C., MURPHY, R. B., \& COVINGTON, L. A. (2001). Comparison of posterior and transforaminal approaches to lumbar interbody fusion. Spine, 26(5), 567-571.

IORIO, R., SIEGEL, J., SPECHT, L., TILZEY, J., HARTMAN, A., \& HEALY, W. (2009). A comparison of acetate vs digital templating for preoperative planning of total hip arthroplasty: is digital templating accurate and safe? The Journal of Arthroplasty, 24(2), 175-179.

ISAACS, R. E., PODICHETTY, V. K., SANTIAGO, P., SANDHU, F. A., RINGEL, F., STOFFEL, M., STÜER, C., \& MEYER, B. (2006). Minimally invasive transmuscular pedicle screw fixation of the thoracic and lumbar spine. Neurosurgery, 59(4), ONS-361.

IVICA, K., VRANJES, Z., PRGOMET, D., \& LUKINOVIC, J. (2008). Application of Advanced Virtual Reality and 3D Computer Assisted Technologies in Computer Assisted Surgery and Tele-3D-computer Assisted Surgery in rhinology. Collegium Antropologicum, 32(1), 217-219.

JAIN, A. K. (1989). Fundamentals of digital image processing. (I. Prentice-Hall, Ed.). California, EEUU.

JAMALI, A. A. (2009). Digital templating and preoperative deformity analysis with standard imaging software. Clinical Orthopaedics and Related Research, 467(10), 2695-704.

JANG, S., \& KIM, W. (2004). Defining a new annotation object for DICOM image: a practical approach. Computerized Medical Imaging and Graphics, 28(7), 371-375. 
JEFFRIES, B., TARLTON, M., SMET, A. DE, DWYER, S., \& BROWER, A. C. (1980). Computerized measurement and analysis of scoliosis: a more accurate representation of the shape of the curve. Radiology, 134(2), 381385.

JINKINS, J. (2002). Atlas of neuroradiologic embryology, anatomy, and variants. Academic Radiology, 9(3), 352.

JUERGENS, K., SEIFARTH, H., RANGE, F., WIENBECK, S., WENKER, M., HEINDEL, W., \& FISCHBACH, R. (2008). Automated threshold-based 3D segmentation versus short-axis planimetry for assessment of global left ventricular function with dual-source MDCT. American Journal of Roentgenology, 190(2).

KAHN JR, C. E., CARRINO, J., FLYNN, M. J., \& HORIL, S. (2007). DICOM and radiology: past, present, and future. Ournal of the American College of Radiology, 4(9), 652-657.

KANG, Y., ENGELKE, K., FUCHS, C., \& KALENDER, W. A. (2005). An anatomic coordinate system of the femoral neck for highly reproducible BMD measurements using 3D QCT. Computerized Medical Imaging and Graphics: The Official Journal of the Computerized Medical Imaging Society, 29(7), 533-541.

KAPLAN, K., SPIVAK, J., \& BENDO, J. (2005). Embryology of the spine and associated congenital abnormalities. The Spine Journal, 5(5), 564-576.

KAUS, M., WARFIELD, S., NABAVI, A., BLACK, P., \& JOLESZ, F. (2001). Automated segmentation of MR images of brain tumors 1. Radiology, $218(2), 586-591$.

KAWAI, S., SUNAGO, K., DOI, K., SAIKA, M., \& TAGUCHI, T. (1988). Cervical laminoplasty (Hattori's method): procedure and follow-up results. Spine, 13(11), 1245-1250.

KAWAHARA, N., TOMITA, K., BABA, H., KOBAYASHI, T., FUJITA, T., \& MURAKAMI, H. (2001). Closing-opening wedge osteotomy to correct angular kyphotic deformity by a single posterior approach. Spine, 26(4), 391-402.

KIM, C. W., LEE, Y.-P., TAYLOR, W., OYGAR, A., \& KIM, W. K. (2008). Use of navigation-assisted fluoroscopy to decrease radiation exposure during minimally invasive spine surgery. The Spine Journal: Official Journal of the North American Spine Society, 8(4), 584-90. 
KIKINIS, R., GLEASON, P., MORIARTY, T., MOORE, M., EBEN, A., STIEG, P., \& JOLESZ, F. (1996). Computer-assisted interactive threedimensional planning for neurosurgical procedures. Neurosurgery, 38(4), 640-651.

KIRKMAN, M., AHMED, M., ALBERT, A., WILSON, M., DIPANKAR, N., \& SEVDALIS, N. (2014). The use of simulation in neurosurgical education and training: A systematic review. Journal of Neurosurgery, 121(2), 228246.

KLAPAN, I., \& VRANJEŠ, Ž. (2008). Application of advanced virtual reality and 3D computer assisted technologies in tele-3D-computer assisted surgery in rhinology. Collegium Antropologicum.

KLAPAN, I., RAOS, P., \& GALETA, T. (2011). Application of Advanced Virtual Reality and 3D Computer Assisted Technologies in Computer Assisted Surgery and Tele-3D-computer Assisted Surgery in Rhinology. In Tech Europe.

KNEZOVIĆ, J., KOVAČ, M., \& KLAPAN, I. (2007). Application of novel lossless compression of medical images using prediction and contextual error modeling. Collegium Antropologicum, 31(4), 1143-1150.

KOCKRO, R., SERRA, L., TSENG-TSAI, Y., CHAN, C., YIH, S., GIM, C., NOWINSKI, W. (2000). Planning and simulation of neurosurgery in a virtual reality environment. Neurosurgey, 46(1), 118-137.

KOCKRO, R., STADIE, A., SCHWANDT, E., REISCH, R., CHARALAMPAKI, C., NG, I., PERNECZKY, A. (2007). A collaborative virtual reality environment for neurosurgical planning and training. Neurosurgery, 61(5), 379-391.

KOHNO, K., KUMON, Y., OKA, Y., MATSUI, S., OHUE, S., \& SAKAKI, S. (1997). Evaluation of prognostic factors following expansive laminoplasty for cervical spinal stenotic myelopathy. Surgical neurology, 48(3), 237-245.

KOJIMA, T., WAGA, S., KUBO, Y., KANAMARU, K., SHIMOSAKA, S., \& SHIMIZU, T. (1989). Anterior cervical vertebrectomy and interbody fusion for multi-level spondylosis and ossification of the posterior longitudinal ligament. Neurosurgery, 24(6), 864-872.

KUMAR, S. (2007). Skull stripping and automatic segmentation of brain MRI using seed growth and threshold techniques. 2007 International Conference on Intelligent, 1, 422-426. 
LAMADE, W., GLOMBITZA, G., FISCHER, L., CHIU, P., \& CARDENAS, C. (2000). The impact of 3-dimensional reconstructions on operation planning in liver surgery. JAMA Arch Surgery, 135(11), 1256-1261.

LANGE, T., EULENSTEIN, S., HUNERBEIN, M., LAMECKER, H., \& SCHLAG, P. (2004). Augmenting intraoperative 3D ultrasound with preoperative models for navigation in liver surgery. Medical Image Computing and Computer-Assisted, 3217, 534-541.

LANDINI, L., POSITANO, V., \& SANTARELLI, M. (2008). 3D medical image processing. Medical Radiology, 67-85.

LANZINO, G., SHAFFREY, C. I., JANE, J. A., RENGACHARY, S. S., \& WILKINS, R. H. (1999). Neurosurgical operative atlas. Neurosurgical operative atlas.) (figs 55, 56, y 58).

LEARDINI, A., BELVEDERE, C., ASTOLFI, L., FANTOZZI, S., VICECONTI, M., TADDEI, F., \& ENSINI, M. (2006). A new software tool for 3D motion analyses of the musculo-skeletal system. Clinical Biomechanics, 21(8), 870-879.

LATARJET, M., \& LIARD, A. (2004). Anatomía humana volumen 2. (E. M. Panamericana, Ed.) (4th ed.). Buenos Aires.

LATARJET, M., \& LIARD, A. R. (2004). Anatomía humana, Volume 1. (E. M. Panamericana, Ed.) (4th ed., p. 869). Buenos Aires: Ed. Médica Panamericana.

LEARDINI, A., BELVEDERE, C., ASTOLFI, L., FANTOZZI, S., VICECONTI, M., TADDEI, F., \& ENSINI, M. (2006). A new software tool for 3D motion analyses of the musculo-skeletal system. Clinical Biomechanics, 21(8), 870-879.

LEI, C., SHUO, P., \& YU, Z. (2013). The Application of Improved RG-based Wavefront Simulation Model on 3D Bifurcated Tube Segmentation in CT Images. World Congress on Medical Physics and Biomedical, 39, 12641267.

LIFSHUTZ, J., LIDAR, Z., \& MAIMAN, D. (2004). Evolution of the lateral extracavitary approach to the spine. Neurosurgical focus, 16(1), 1-3.

LIESSI, G., BARBAZZA, R., \& SARTORI, F. (1990). CT and MR imaging of melanocytic schwannomas; report of three cases. European Journal of Radiology, 11(2), 138-142. 
LIEW, A., \& YAN, H. (2005). Computer techniques for the automatic segmentation of 3D MR brain images. In C. Leondes (Ed.), Medical Imaging Systems Technology (1st ed., p. 307). Hong Kong.

LIU, J., HUANG, S., IHAR, V., \& AMBROSIUS, W. (2010). Automatic modelguided segmentation of the human brain ventricular system from CT images. Academic Radiology, 17(6), 718-726.

LIU, J., HUANG, S., \& NOWINSKI, W. (2009). Automatic segmentation of the human brain ventricles from MR images by knowledge-based region growing and trimming. Neuroinformatics, 7(2), 131-146.

LOUIS, R., \& GOLDSTEIN, E. (1983). Surgery of the spine: surgical anatomy and operative approaches. Surgical Neurology, 21(1), 97.

LUND, T., OXLAND, T., JOST, B., \& NOLTE, L. (1998). Interbody cage stabilisation in the lumbar spine biomechanical evaluation of cage design, posterior instrumentation and bone density. Journal of Bone \& Surg, 80(2), $351-359$.

MAO, K., WANG, Y., XIAO, S., LIU, Z., \& ZHANG, Y. (2010). Clinical application of computer-designed polystyrene models in complex severe spinal deformities: a pilot study. European Spine Journal, 19(5), 797-802.

MÁRQUEZ, C. C., \& GARCÍA, A. D. (2014). Visor de imágenes médicas digitales web. Revista Cubana de Informatica Medica, 6 (1).

MATSUNAGA, S., SAKOU, T., \& NAKANISI, K. (1999). Analysis of the cervical spine alignment following laminoplasty and laminectomy. Spinal cord, 37(1), 20-24.

MEDOW, J. E., TROST, G., \& SANDIN, J. (2006). Surgical management of cervical myelopathy: indications and techniques for surgical corpectomy. The Spine Journal, 6(6), S233-S241.

MEROLLI, A., LEALI, P., \& AULISA, L. (1995). Considerations on the clinical relevance of photogrammetric error in 3-D reconstruction of the spine based on routine X-ray films. In I. Press (Ed.), Three Dimensional Analysis of Spinal Deformities (1st ed., pp. 185-190). Amsterdam. 
MCAFEE, P. C., REGAN, J. R., ZDEBLICK, T., ZUCKERMAN, J., PICETTI III, G. D., HEIM, S., ... \& FEDDER, I. L. (1995). The incidence of complications in endoscopic anterior thoracolumbar spinal reconstructive surgery: a prospective multicenter study comprising the first 100 consecutive cases. Spine, 20(14), 1624-1632.

MCAFEE, P. C., REGAN, J. J., GEIS, W. P., \& FEDDER, I. L. (1998). Minimally invasive anterior retroperitoneal approach to the lumbar spine: emphasis on the lateral BAK. Spine, 23(13), 1476-1484.

MCCULLOCH, J. A. (1998). Microdecompression and Uninstrumented Single level Fusion for Spinal Canal Stenosis With Degenerative Spondylolisthesis. Spine, 23(20), 2243-2252.

MCCULLOCH, J. A. (1996). [black small square] Focus Issue on Lumbar Disc Herniation: Macro-and Microdiscectomy. Spine, 21(24S), 45S-56S.

MIKAWA, Y., SHIKATA, J., \& YAMAMURO, T. (1987). Spinal deformity and instability after multilevel cervical laminectomy. Spine, 12(1), 6-11.

MILDENBERGER, P., EICHELBERG, M., \& MARTIN, E. (2002). Introduction to the DICOM standard. European Radiology, 12(4), 920-927.

MILlER, R. M., EBRAHEIM, N. A., XU, R., \& YEASTING, R. A. (1996). Anatomic consideration of transpedicular screw placement in the cervical spine: an analysis of two approaches. Spine, 21(20), 2317-2322.

MODIC, M. T., WEINSTEIN, M. A., PAVLICEK, W., STARNES, D. L., DUCHESNEAU, P. M., BOUMPHREY, F., \& R J HARDY, J. (1983). Nuclear magnetic resonance imaging of the spine. Radiology, 148(3), 425432.

MOORE, K., DALlEY, A., \& AGUR, A. (2007). Anatomía con orientación clínica. In E. M. Panamericana (Ed.), Anatomía con orientación clínica (p. 884). Madrid.

MOORE, K. L., PERSAUD, T. V. N., \& SHIOTA, K. (1996). Atlas de embriología clínica. (E. M. Panamericana, Ed.) (1st ed.). Madrid.

MOORE, K., TORCHIA, M., \& PERSAUD, T. (2007a). The Developing Human: Clinically Oriented Embryology With STUDENT CONSULT Online Access. 
MOORE, K., TORCHIA, M., \& PERSAUD, T. (2007b). The Developing Human: Clinically Oriented Embryology With STUDENT CONSULT Online Access.

MORI, S., CRAIN, B., CHACKO, V., \& ZIJL, P. VAN. (1999). Three dimensional tracking of axonal projections in the brain by magnetic resonance imaging. Annals of Neurology, 265-269.

MORRIS, P. G. (1986). Nuclear magnetic resonance imaging in medicine and biology (1st ed., p. 388). Oxford: Clarendon Press.MOTOHASHI, N. (1999). A 3D computer-aided design system applied to diagnosis and treatment planning in orthodontics and orthognathic surgery. The European Journal of Orthodontics, 21(3), 263-274.

MÜHLENBRUCH, G., DAS, M., HOHL, C., WIDBERGER, J., RINCK, D., \& THOMAS, G. (2006). Global left ventricular function in cardiac CT. Evaluation of an automated 3D region-growing segmentation algorithm. European Radiology, 16(5), 117-1123.

MURAI, Y., TAKAGI, R., IKEDA, Y., YAMAMOTO, Y., \& TERAMOTO, A. (1999). Three-dimensional computerized tomography angiography in patients with hyperacute intracerebral hemorrhage. Journal of Neurosurgery, 91(3), 424-431.

NAGY, P. (2007). Open source in imaging informatics. Journal of Digital Imaging, 20(1), 1-10.

NERI, E., THIRAN, J., \& CARAMELLA, D. (1998). Interactive DICOM image transmission and telediagnosis over the European ATM network. IEEE Xplore Digital, 2(1), 35-38.

NETTER, F. H. (2010). Atlas of Human Anatomy. (S. Elservier, Ed.) (fifth., p. 624). Philadelphia.

NURBOJA, B., KACHRAMANOGLOU, C., \& CHOI, D. (2012). Cervical laminectomy vs laminoplasty: is there a difference in outcome and postoperative pain?. Neurosurgery, 70(4), 965-970.

ONEN, M. R., SIMSEK, M., \& NADERI, S. (2014). Robotic spine surgery: a preliminary report. Turkish Neurosurgery, 24(4), 512-8. 
OXLAND, T. R., HOFFER, Z., NYDEGGER, T., RATHONYI, G. C., \& NOLTE, L. P. (2000). A Comparative Biomechanical Investigation of Anterior Lumbar Interbody Cages: Central and Bilateral Approaches*. The Journal of Bone \& Joint Surgery, 82(3), 383-93.

OZGUR, B. M., ARYAN, H. E., PIMENTA, L., \& TAYLOR, W. R. (2006). Extreme Lateral Interbody Fusion (XLIF): a novel surgical technique for anterior lumbar interbody fusion. The Spine Journal, 6(4), 435-443.

PANJABI MM, ODA T \& CRISCO JJ, 1991. Experimental study of injuries I. Biomechanical analysis of their mechanisms and fracture patterns. Spine. 16(10 supplement): S460-S465.

PANJABI, M., GOEL, V., OXLAND, T., TAKATA, K., DURANCEAU, J., KRAG, M., \& PRICE, M. (1992). Human lumbar vertebrae: quantitative three-dimensional anatomy. Spine, 17(3).

PANJABI, M., O’HOLLERAN, J., CRISCO, I., \& KOTHE, R. (1997). Complexity of the thoracic spine pedicle anatomy. European Spine Journal, 6(1), 19-24.

PANJABI, M., OXLAND, T., TAKATA, K., GOEL, V., DURANCEAU, J., \& KRAG, M. (1993). Articular facets of the human spine quantitative threedimensional anatomy. Spine, 18(10).

PANJABI, M. M., KRAG, M., SUMMERS, D., \& VIDEMAN, T. (1985). Biomechanical time-tolerance of fresh cadaveric human spine specimens. Journal of Orthopaedic Research: Official Publication of the Orthopaedic Research Society, 3(3), 292-300.

PAPADOPOULOS SM, DICKMAN CA \& VOLKER KHS, 1991. Atlantoaxial stabilization in rheumatoid arthritis. J Neurosurg. 74: 1-7.

PARK, H., KWON, M., \& HAN, Y. (2005). Techniques in image segmentation and $3 \mathrm{D}$ visualization in brain MRI and their applications. In C. Leondes (Ed.), Techniques in image segmentation and $3 D$ visualization in brain MRI and their applications (p. 207). Korea.

PARK, S., PARWANI, A. V, ALLER, R. D., BANACH, L., BECICH, M. J., BORKENFELD, S. \& PANTANOWITZ, L. (2013). The history of pathology informatics: A global perspective. Journal of Pathology Informatics, 4, 7. 
PARK, Y., \& HA, J. W. (2007). Comparison of one-level posterior lumbar interbody fusion performed with a minimally invasive approach or a traditional open approach. Spine, 32(5), 537-543.

PEROT PL \& MUNRO DD, (1969). Transthoracic removal of a midline thoracic protrusion causing spinal cord compression. J Neurosurg. 31: 452-8.

PHAM, D., XU, C., \& PRINCE, J. (2000). Current methods in medical image segmentation. Annual Review of Biomedical Engineering, 2, 315-337.

POPE, M. H., \& PANJABI, M. (1985). Biomechanical definitions of spinal instability. Spine, 10(3), 255-6.

PRASTAWA, M., BULLITT, E., HO, S., \& GERIG, G. (2004). A brain tumor segmentation framework based on outlier detection. Medical Image Analysis, 8(3), 275-283.

PUIGDELLÍVOL-SÁNCHEZ, A., PRATS-GALINO, A., REINA, M. A., MACHÉS, F., HERNÁNDEZ, J. M., DE ANDRÉS, J., \& VAN ZUNDERT, A. (2011). Three-dimensional magnetic resonance image of structures enclosed in the spinal canal relevant to anesthetists and estimation of the lumbosacral CSF volume. Acta Anaesthesiologica Belgica, 62(1), 37-45.

RAMIREZ, A. (2011). Modelado y simulacion del tejido musculoesquelético. Validación experimental con el musculo tibial anterior de rata. Universidad de Zaragoza.

RAMÍREZ, E., \& COTO, E. (2011). TRAUMAPLAN: para la planificación preoperatoria en traumatología. Revista Venezolana de Información, 8(2), 61-78.

RANASOHOFF J, SPENCER F., SIEW F \& GADE L JR, (1969). Transthoracic removal of thoracic discs: report of three cases. J Neurosurg. 31: 459-61.

RANCO, N., MALIK, A., GONZÁLEZ-DELLA VALLE, A., \& SALVATI, E. A. (2010). La planificación preoperatoria del reemplazo protésico en las fracturas de cadera del anciano. Revista Española de Cirugía Ortopédica $Y$ Traumatología, 54(2), 136-145. 
RASMUSSEN, A., LINDSETH, F., RYGH, O., BERNTSEN, J., NAGELHUS, T., HERNES, E., UNSGAARD, G. (2007). 3D ultrasound: initial experiences during surgical resections close to eloquent brain areas and future directions in automatic brain shift compensation of preoperative. Acta Neurochirurgica, 149(4), 365-378.

RATIB, O., \& ROSSET, A. (2006). Open-source software in medical imaging: development of OsiriX. International Journal of Computer Assisted Radiology and Surgery, 1(4), 187-196.

RATIB, O., ROSSET, A., \& HEUBERGER, J. (2011). Open Source software and social networks: disruptive alternatives for medical imaging. European Journal of Radiology, 78(2), 259-265.

RATLIFF, J. K., \& COOPER, P. R. (2003). Cervical laminoplasty: a critical review. Journal of Neurosurgery: Spine, 98(3), 230-238.

REINER, B. I., SIEGEL, E. L., \& SIDDIQUI, K. (2003). Evolution of the digital revolution: a radiologist perspective. Journal of Digital Imaging, 16(4).

REYNOLDS, M., REYNOLDS, M., ADEEB, S., \& EL-BIALY, T. (2011). 3-d volumetric evaluation of human mandibular growth. The Open Biomedical Engineering Journal, 5, 83-9.

ROGERS, L. (2001). PACS: Radiology in the digital world. American Journal of Roentgenology, 177(3), 499-499.

ROGOWSKA, J. (2000). Overview and fundamentals of medical image segmentation. In A. Press (Ed.), Handbook of Medical Imaging: Processing and Analysis Management (pp. 69-80). California, EEUU.

ROHEN, J., YOKOCHI, C., \& LÜTJEN-DRECOLL, E. (1996). Atlas de anatomía humana: Elservier. Madrid.

ROSAHL, S. K., GHARABAGHI, A., LIEBIG, T., FESTE, C. D., TATAGIBA, M., \& SAMII, M. (2002). Skin markers for surgical planning for intradural lesions of the thoracic spine. Surgical Neurology, 58(5), 346-348.

ROSENTHAL D \& DICKMAN CA, (1998). Thoracoscopic microsurgical excision of herniated thoracic discs. J Neurosurg. 89:224-235.

RORDEN, B. C. (2012). MRIcroGL manual guide (pp. 1-15). 
ROSSET, A., SPADOLA, L., \& RATIB, O. (2004). OsiriX: an open-source software for navigating in multidimensional DICOM images. Journal of Digital Imaging, 17(3), 205-216.

ROSSET, C., ROSSET, A., \& RATIB, O. (2005). General consumer communication tools for improved image management and communication in medicine. Journal of Digital Imaging, 18(4), 270-279.

ROUBIDOUX, M., CHAPMAN, C., \& PIONTEK, M. (2002). Development and evaluation of an interactive web-based breast imaging game for medical students. Academic Radiology, 8(10), 1169-1178.

ROUVIÈRE, H., \& DELMAS, A. (2005). Anatomía humana: descriptiva, topográfica y funcional. Miembros. (M. Elsevier, Ed.) (11th ed., p. 673). Barcelona.

ROWELL, M., JOHNSON, P., \& FISHMAN, E. (2007). Radiology Education in 2005: World Wide Web Practice Patterns, Perceptions, and Preferences of Radiologists. Radiographics, 27(2).

ROWLAND, R., \& BELL, G. (1998). Non-radiological technique for three dimensional imaging of intestinal endoscopes.-A new improved method of computerised graphical 3-D representation of the endoscope and patient's skeleton. Med. Biol. Eng. Comput, 36, 285-290.RUBIN, D. I. (2007). Epidemiology and risk factors for spine pain. Neurologic Clinics, 25(2), 353-71.

RUETTEN, S., KOMP, M., MERK, H., \& GODOLIAS, G. (2008). Fullendoscopic cervical posterior foraminotomy for the operation of lateral disc herniations using 5.9- $\mathrm{mm}$ endoscopes: a prospective, randomized, controlled study. Spine, 33(9), 940-948.

RUF, M., \& HARMS, J. (2002). Hemivertebra resection by a posterior approach: innovative operative technique and first results. Spine, 27(10), 1116-1123.

RUIZ, J., MINTZER, M., \& LEIPZIG, R. (2006). The impact of e-learning in medical education. Academic Medicine, 81(3), 207-212.

RUNGE, V. (2004). Advances in Magnetic Resonance. Investigative Radiology, 39(12), 713-716.

SADLER, T., \& LANGMAN, J. (2007). Langman embriología médica: con orientación clínica. (J. L. Ferran, Ed.) (10th ed.). Madrid: Médica Panamericana. 
SADLER, T. W. (2011). Langman's Medical Embryology (Sixth., Vol. 6). Baltimore: Lippicontt Williams \& Wilkins.

SATO, Y., NAKAJIMA, S., SHIRAGA, N., ATSUMI, H., \& YOSHIDA, S. (1998). Three-dimensional multi-scale line filter for segmentation and visualization of curvilinear structures in medical images. Medical Image Analysis, 2(2), 143-168.

SARAPH, V., LERCH, C., WALOCHNIK, N., BACH, C. M., KRISMER, M., \& WIMMER, C. (2004). Comparison of conventional versus minimally invasive extraperitoneal approach for anterior lumbar interbody fusion. European Spine Journal, 13(5), 425-431.

SCARSBROOK, A., GRAHAM, R., \& PERRISS, R. (2005). The scope of educational resources for radiologists on the internet. Clinical Radiology, 60(5), 524-530.

SCHOENWOLF, G. (2009). Larsen's human embryology. (Elservier, Ed.) (p. 712). Utah.

SCHWENDER, J. D., HOLLY, L. T., ROUBEN, D. P., \& FOLEY, K. T. (2005). Minimally invasive transforaminal lumbar interbody fusion (TLIF): technical feasibility and initial results. Journal of spinal disorders \& techniques, 18, S1-S6.

SCOVILLE, W. B. (1966). Types of cervical disk lesions and their surgical approaches. Jama, 196(6), 479-481.

SHIMODE, M., KOJIMA, T., \& SOWA, K. (2002). Spinal wedge osteotomy by a single posterior approach for correction of severe and rigid kyphosis or kyphoscoliosis. Spine, 27(20), 2260-2267.

SHIN, E. K., PANJABI, M. M., CHEN, N. C., \& WANG, J. (2000). The anatomic variability of human cervical pedicles: considerations for transpedicular screw fixation in the middle and lower cervical spine. European Spine Journal, 9(1), 61-66.

SHIRASAKI N, OKADA K \& OKA S, 1991. Os odontoideum with poserior atlantoaxial instability. Spine. 16(7): 706-15.

SIERRA, E., CIENFUEGOS, R., \& FERNANDEZ, G. (2009). OsiriX, visor DICOM útil para procesar imágenes tomográficas de fracturas faciales. Cir. Ciruj, 77 (2), 95-99. 
SMET, A. DE, ASHER, M., \& COOK, L. (1984). Three-dimensional analysis of right thoracic idiopathic scoliosis. Spine, 9 (4).

SMITH GW \& ROBINSON RA. Anterolateral cervical disc removal and interbody fusion for cervical disc syndrome.(Abstract) Johns Hopk Hosp Bull. 1955;96:223-224.

SOTO V., GERONA GALDAME, P., GUTIERREZ, M., \& RODRIGUEZ, L. (1996). Desarrollo de un sistema fotogramétrico tridimensional computerizado no invasivo para el análisis de la columna vertebral humana. Sociedad Iberica de Biomecanica Y Biomateriales, 4(7), 87-91.

SPEARS, J., KELLY, K., \& FESSLER, R. G. (2006). Minimally invasive microendoscopy-assisted transforaminal lumbar interbody fusion with instrumentation. Journal of Neurosurgery: Spine, 3(2), 98-105.

SPICER, M., APUZZO, M., \& MICHAEL, L. (2003). Virtual reality surgery: Neurosurgery and the contemporary landscape. Neurosurgery, 52(3), 489498.

STADIE, A., KOCKRO, R., REISCH, R., TROPINE, A., BOOR, S., \& STOETER, P. (2008). Virtual reality system for planning minimally invasive neurosurgery. Journal of Neurosurgery, 108(2), 382-394.

STAUFFER, R. N., \& COVENTRY, M. B. (1972). Anterior interbody lumbar spine fusion analysis of Mayo Clinic series. The Journal of Bone \& Joint Surgery, 54(4), 756-768.

STOKES, I. (1987). Three-dimensional spinal curvature in idiopathic scoliosis. Journal of Orthopaedic Researc. Raven Press, 5, 102-113

STOVER, S. L., \& FINE, P. R. (1987). The epidemiology and economics of spinal cord injury. Paraplegia, 25(3), 225-8.

SWANK, M. L., LOWERY, G. L., BHAT, A. L., \& MCDONOUGH, R. F. (1997). Anterior cervical allograft arthrodesis and instrumentation: multilevel interbody grafting or strut graft reconstruction. European Spine Journal, 6(2), 138-143.

TANG, X., \& YAMADA, H. (2010). Virtual reality-based teleoperation construction robot control system with 3Dvisor device. In Mechatronics and Automation (Ed.), Mechatronics and Automation (pp. 384-388). Xian. 
TAYLOR, R. H., FUNDA, J., ELDRIDGE, B., GOMORY, S., GRUBEN, K., LAROSE, D., ANDERSON, J. (1995). A telerobotic assistant for laparoscopic surgery. IEEE Engineering in Medicine and Biology Magazine, 14(3), 279-288.

THEILER, K. (1988). Vertebral malformations. Advances in Anatomy, Embryology, and Cell Biology, 11(2), 1-99.

THOMAS, J. (1995). The DICOM image formatting standard: what it means for echocardiographers. Journal of the American Society of Echocardiography, 8(3), 319-327.

THOMPSON, C. W., \& FLOYD, R. T. (1996). Manual de kinesiología estructural (2nd ed., p. 240). Barcelona: Elsevier.

THORELL, W., COOPER, J., HELLBUSCH, L., \& LEIBROCK, L. (1998). The long-term clinical outcome of patients undergoing anterior cervical discectomy with and without intervertebral bone graft placement. Neurosurgery, 43(2), 268-273.

TORTORI-DONATI, P., ROSSI, A., \& CAMA, A. (2000). Spinal dysraphism: a review of neuroradiological features with embryological correlations and proposal for a new classification. Neuroradiology, 42(7), 471-491.

UMBAUGH, S. (2005). Computer imaging: digital image analysis and processing (1st ed., p. 688). Taylor \& Francis.

UNSGAARD, G., RYGH, O., SELBEKK, T., KOLSTAD, F., LINDSETH, T., $\&$ NAGELHUS, H. (2006). Intra-operative 3D ultrasound in neurosurgery. Acta Neurochirurgica, 148(3), 235-253.

VERHELST, F., DAVID, P., FERMONT, W., JEGERS, L., \& VERVOORT, A. (1996). Correlation of 3D-computerized tomographic scans and 2D-colour image analysis of Westphalian coal by means of multivariate statistics. International Journal of Coal Geology, 29(1), 1-21.

VERHEY, J., \& NATHAN, N. (2006). Finite-element-method (FEM) model generation of time-resolved 3D echocardiographic geometry data for mitralvalve volumetry. Biomedical Engineering, 5(17).

VICECONTI, M., TADDEI, F., JAN, S. V. S., LEARDINI, A., \& CRISTOFOLINI, L. (2008). Multiscale modelling of the skeleton for the prediction of the risk of fracture. Clinical Biomechanics, 23(7), 845-852. 
VOSSBERG, M. (2008). DICOM image communication in globus-based medical grids. Information Technology in Biomedicine, 12(2), 145-153.

VRTOVEC, T., LIKAR, B., \& PERNUS, F. (2005). Automated curved planar reformation of 3D spine images. Physics in Medicine and Biology, 50(19), 4527-4540.

WADA, E., SUZUKI, S., KANAZAWA, A., MATSUOKA, T., MIYAMOTO, S., \& YONENOBU, K. (2001). Subtotal corpectomy versus laminoplasty for multilevel cervical spondylotic myelopathy: a long-term follow-up study over 10 years. Spine, 26(13), 1443-1447.

WANG, Q., \& SUN, W. (2013). Finite element modeling of mitral valve dynamic deformation using patient-specific multi-slices computed tomography scans. Annals of Biomedical Engineering, 4(1), 142-153.

WANG, Z. L., TEO, J. C. M., CHUI, C. K., ONG, S. H., YAN, C. H., WANG, S. C., \& TEOH, S. H. (2005). Computational biomechanical modelling of the lumbar spine using marching-cubes surface smoothened finite element voxel meshing. Computer Methods and Programs in Biomedicine, 80(1), 25-35.

WANG, J. C., MCDONOUGH, P. W., ENDOW, K. K., \& DELAMARTER, R. B. (2000). Increased fusion rates with cervical plating for two-level anterior cervical discectomy and fusion. Spine, 25(1), 41.

WATANABE, Y., IKEGAMI, R., TAKASU, K., \& MORI, K. (2005). Threedimensional computed tomographic images of pelvic muscle in anorectal malformations. Journal of Pediatric Surgery, 40(12), 1931-4.

WAUGH, J. (2012). Advances in magnetic resonance. (A. Press, Ed.) Advances in magnetic resonance (1st ed., p. 321). New York.

WEBER, B. R., GROB, D., DVORÁK, J., \& MÜNTENER, M. (1997). Posterior surgical approach to the lumbar spine and its effect on the multifidus muscle. Spine, 22(15), 1765-1772.

WEINBERGER, M., \& RISSANEN, J. (1996). Applications of universal context modeling to lossless compression of gray-scale images. Image Processing, IEEE, 5(4), 575-586.

WEINSTEIN, C. (1998). Computerized Scanning Erbiumi: YAG Laser for Skin Resurfacing. Dermatologic Surgery, 24(1), 83-89. 
WEISHAUPT, D., ZANETTI, M., HODLER, J., \& BOOS, N. (1998). MR imaging of the lumbar spine: prevalence of intervertebral disk extrusion and sequestration, nerve root compression, end plate abnormalities, and osteoarthritis of the facet joints in asymptomatic volunteers. Radiology, 209(3), 661-667.

WILHELM, D., REISER, S., KOHN, N., WITTE, M., LEINER, U., MÜHLBACH, L., FEUSSNER, H. (2014). Comprehensive evaluation of latest 2D/3D monitors and comparison to a custom-built 3D mirror-based display in laparoscopic surgery. In A. J. Woods, N. S. Holliman, \& G. E. Favalora (Eds.), IS\&T/SPIE Electronic Imaging (p. 9011). San Francisco: International Society for Optics and Photonics.

WILLIAMSON, B. (1998). The Society for Computer Applications in Radiology. The electronic transformation of radiology. Radiology, 209, 606-608.

XIANG, L., ZHOU, Y., WANG, H., ZHANG, H., SONG, G., ZHAO, Y., LIU, J. (2014). Significance of Preoperative Planning Simulator for Junior Surgeons' Training of Pedicle Screw Insertion. Journal of Spinal Disorders \& Techniques.

YAMAUCHI, T., YAMAZAKI, M., \& OKAWA, A. (2010). Efficacy and reliability of highly functional open source DICOM software (OsiriX) in spine surgery. Journal of Clinical Neuroscience, 17(6), 756-759.

YASUOKA, S., PETERSON, H. A., \& MACCARTY, C. S. (1982). Incidence of spinal column deformity after multilevel laminectomy in children and adults. Journal of neurosurgery, 57(4), 441-445.

YONENOBU, K., KORKUSUZ, F., HOSONO, N., EBARA, S., \& ONO, K. (1990). Lateral rhachotomy for thoracic spinal lesions. Spine, 15(11), 11211125 .

ZDEBLICK, T. A., \& BOHLMAN, H. H. (1989). Cervical kyphosis and myelopathy. Treatment by anterior corpectomy and strut-grafting. The Journal of Bone \& Joint Surgery, 71(2), 170-182.

ZDEBLICK, T. A., ZOU, D., WARDEN, K. E., MCCABE, R., KUNZ, D., \& VANDERBY, R. (1992). Cervical stability after foraminotomy. $J$ Bone Joint Surg Am, 74(1), 22-27. 
ZDEBLICK, T. A., \& DAVID, S. M. (2000). A prospective comparison of surgical approach for anterior L4-L5 fusion: laparoscopic versus mini anterior lumbar interbody fusion. Spine, 25(20), 2682-2687.

ZENG, Y., LAI, O., SHEN, B., YANG, J., ZHOU, Z., KANG, P., ZHOU, X. (2014). Three-dimensional computerized preoperative planning of total hip arthroplasty with high-riding dislocation developmental dysplasia of the hip. Orthopaedic Surgery, 6(2), 95-102. 